NOTE TO USERS

This reproduction is the best copy available.

(B)

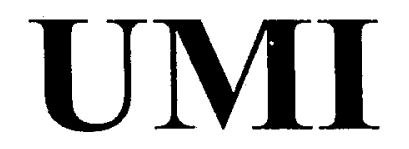

Reproduced with permission of the copyright owner. Further reproduction prohibited without permission. 
Reproduced with permission of the copyright owner. Further reproduction prohibited without permission. 


\title{
HYDRAULIC ANALYSIS OF OIL SPILL CONTROL SYSTEMS IN TRANSFORMER STATIONS
}

by

\author{
Celia Fan \\ B.Eng., Ryerson University, 2002
}

\author{
A thesis \\ presented to Ryerson University \\ in partial fulfillment of the \\ requirement for the degree of \\ Master of Applied Science \\ in the Program of \\ Civil Engineering
}

Toronto, Ontario, Canada, 2004

(C) Celia Fan 2004 
UMI Number: EC52966

\section{INFORMATION TO USERS}

The quality of this reproduction is dependent upon the quality of the copy submitted. Broken or indistinct print, colored or poor quality illustrations and photographs, print bleed-through, substandard margins, and improper alignment can adversely affect reproduction.

In the unlikely event that the author did not send a complete manuscript and there are missing pages, these will be noted. Also, if unauthorized copyright material had to be removed, a note will indicate the deletion.

(B)

\section{UMI}

\section{UMI Microform EC52966}

Copyright 2008 by ProQuest LLC.

All rights reserved. This microform edition is protected against unauthorized copying under Title 17, United States Code.

ProQuest LLC

789 E. Eisenhower Parkway

PO Box 1346

Ann Arbor, MI 48106-1346 


\section{BORROWER'S PAGE}

Ryerson University requires the signatures of all persons using or photocopying this thesis. Please sign below, and give address and data.
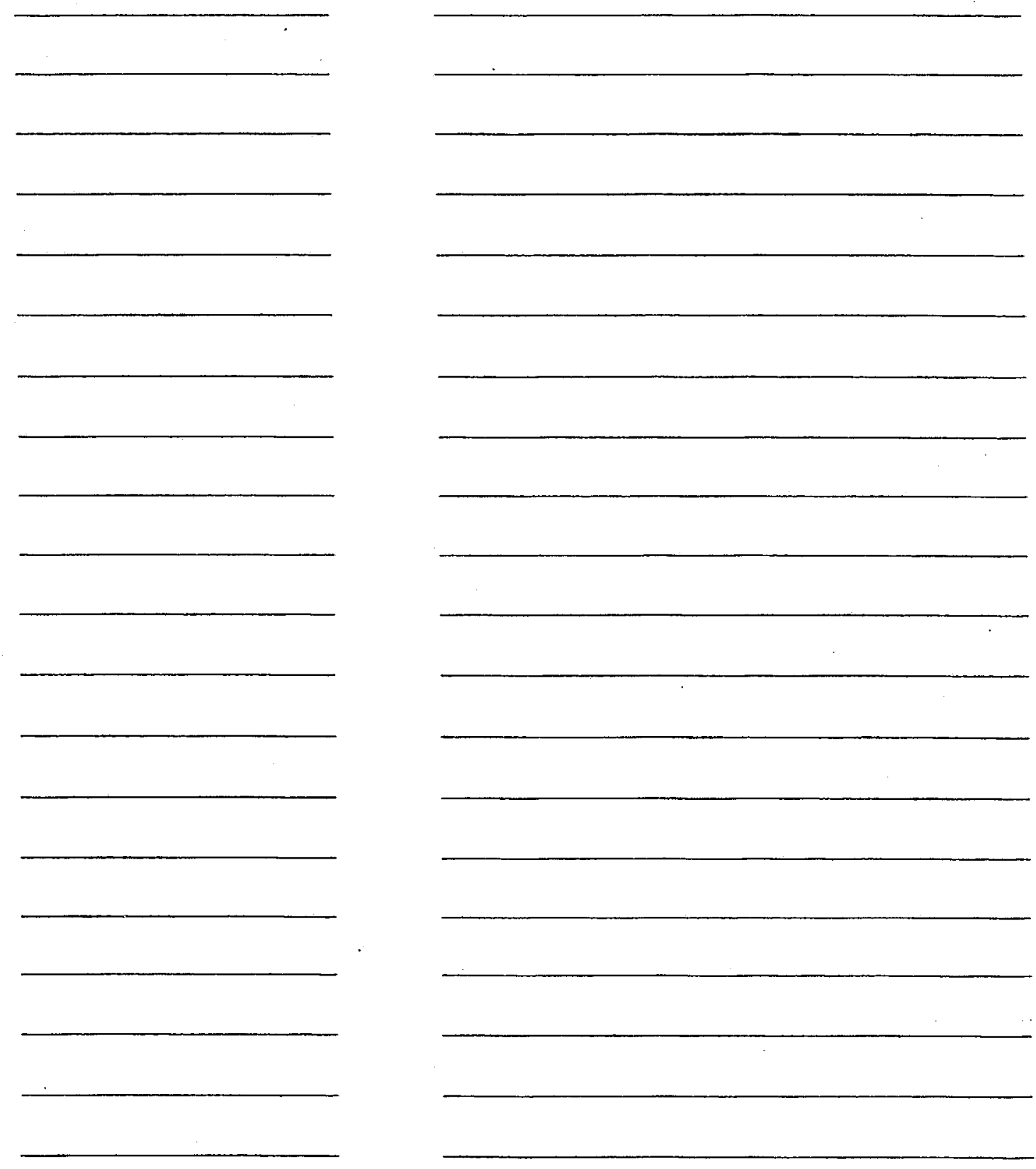

(iii) 


\begin{abstract}
Title: Hydraulic Analysis of Oil Spill Control Systems in Transformer Stations Author: Celia Fan, Master of Applied Science in Civil Engineering, Ryerson University, Canada.

Electrical transformer stations use transformer oil to increase the efficiency of the electrical voltage transfer and to reduce the moisture and air in an electrical transformer. Each year, there is a high probability of spilling the transformer oil accidentally into the environment. Some spill events contain large volume of transformer oil. The objective of this thesis is to investigate oil spill control systems for spilled transformer oil during all operating and weathering conditions at a Hydro One's transformer station near the city of Burlington. This thesis examines the designs of (1) oil trap systems which trap the spilled transformer oil and (2) the oil back-up systems which back up the transformer oil spills to the transformer station. This research focuses primarily on Hydro One's transformer stations and the normal operation conditions in Ontario.
\end{abstract}

(iv) 
Reproduced with permission of the copyright owner. Further reproduction prohibited without permission. 


\section{ACKNOWLEDGEMENTS}

The author would like to thank Dr. James Li of Ryerson University for providing his encouragement, support and expertise throughout this thesis.

Appreciation is extended to Wilkinson Precast Concrete Ltd. for a graduate scholarship and the physical model of the oil trap system supports to this research.

The author would like to thank the funding support by Natural Science and Engineering Research Council.

Thanks are also extended to John Tran, Director of Engineering Services, Wilkinson Precast Concrete Ltd. for the technical advice and assistance to this research; Rob Chandok, Hydro One Inc., for providing the background information of the transformer stations; Dr. Jiri Marsalek of National Water Research Institute and Dr. Alex McCorquodale of University of New Orleans for their advice in conducting the experiments; Dr. Diane Kennedy, Ryerson University, for the technical support of the numerical model; Kevin Sze, Ryerson University, for the assistance on conducting the experiments. 


\section{TABle Of Contents}

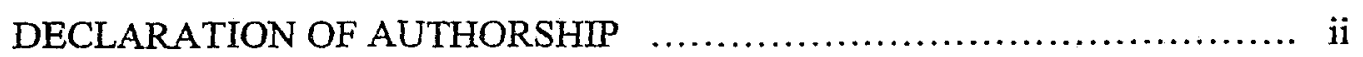

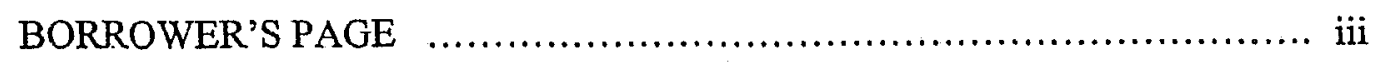

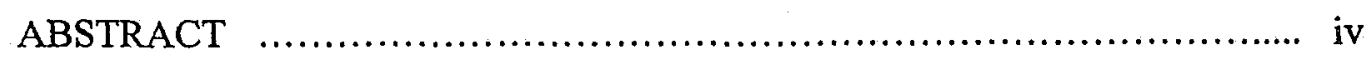

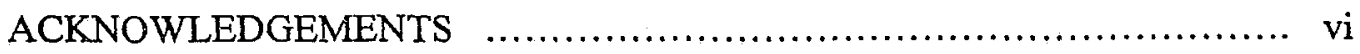

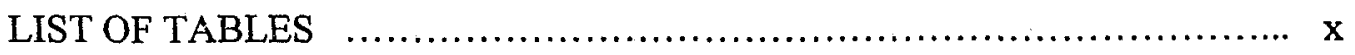

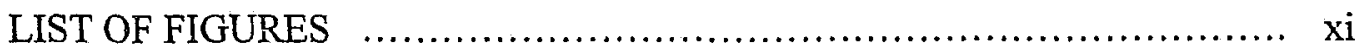

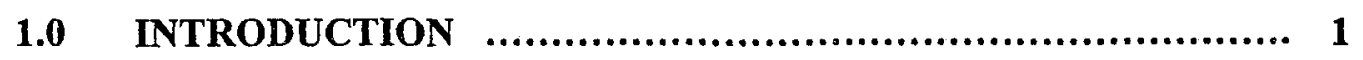

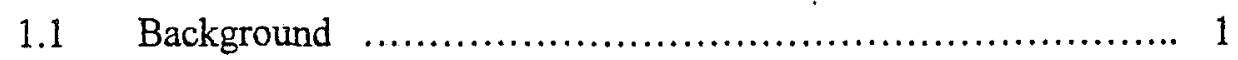

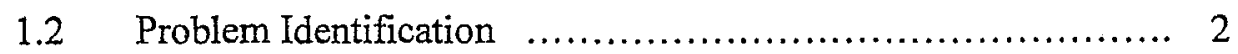

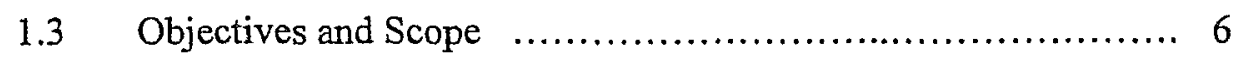

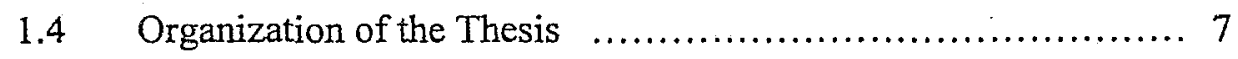

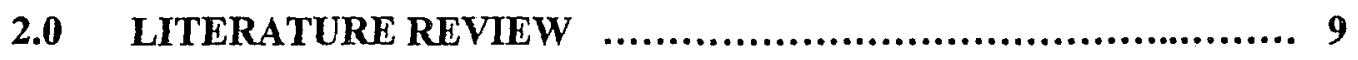

2.1 Electrically-Based Oil Spill Control System $\ldots \ldots \ldots \ldots \ldots \ldots . . . \ldots$

$2.2 \quad$ Hydraulically-Based Oil Trap System $\ldots \ldots \ldots \ldots \ldots \ldots \ldots \ldots \ldots$

2.3 Hydraulically-Based Oil Back-Up System $\ldots \ldots \ldots \ldots \ldots \ldots \ldots \ldots$

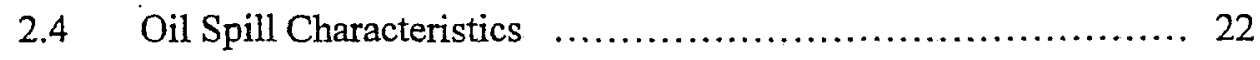

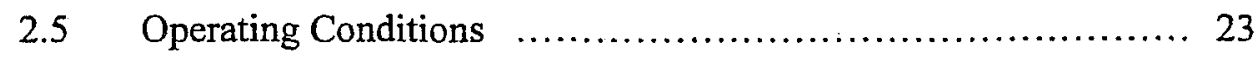

2.6 Basic Theories of Oil-Water Separation $\ldots \ldots \ldots \ldots \ldots \ldots \ldots \ldots . \ldots . \ldots . \ldots 24$ 
2.7 Literature Review on Dynamics of Oil Slicks on Water

Surface

\subsection{PHYSICAL MODEL STUDY OF THE OIL TRAP}

SYSTEM

3.1 Dimensionless Analysis Method of the Oil Trap System …........ 33

3.2 Similitude Analysis Method of the Oil Trap System …........... 40

3.3 Scales of the Physical Model ….................................... 42

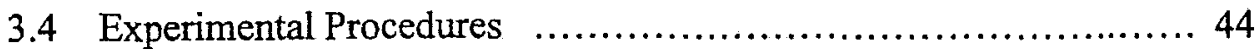

3.5 Observation and Evaluation of the Trapping Oil Experiments $\ldots . . .53$

3.6 Observation and Evaluation of Oil-Water Separation

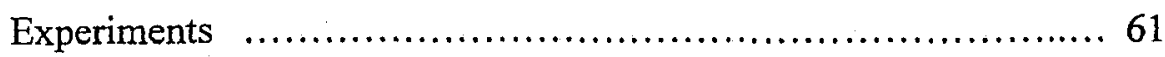

\subsection{NUMERICAL EXPERIMENTS ON THE OIL BACK-UP}

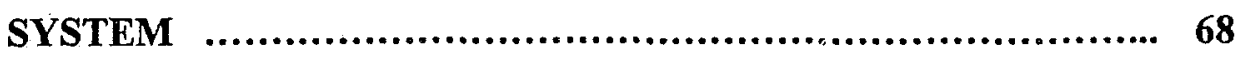

4.1 The Mass Balance Concepts of Transformer Oil and Water for the

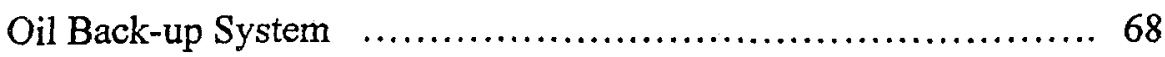

4.1.1 Mass Balance of Transformer Oil at the Catchbasin $\ldots . . .77$

4.1.2 Mass Balance of Transformer Oil at Oil Back-up System …............................................. 79

4.1.3 Mass Balance of Water at Oil Back-up System $\quad$........... 81

4.2 Development of the Mathematical Model …...................... 83

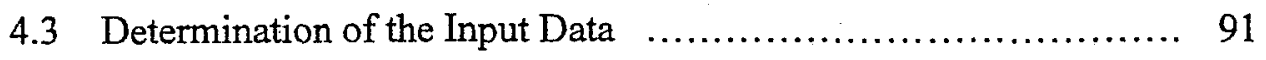

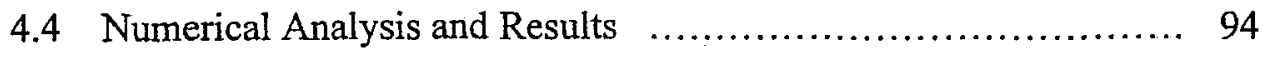


5.0 CONCLUSIONS AND RECOMMENDATIONS

5.1 Conclusions ............................................................... 102

5.2 Recommendations ..................................................... 104

REFERENCE

APPENDIX A DIMENSIONAL ANALYSIS METHOD

APPENDIX B SIMILITUDE ANALYSIS

APPENDIX C DETERMINATION OF MODEL SCALES

APPENDIX D NEWTON-RAPHSON METHOD

APPENDIX E MATLAB FUNCTION FOR SOLVING NON-LINEAR EQUATIONS

APPENDIX $F$ DETERMINATION OF THE FLOW RATE AT EACH DIAL

APPENDIX G DETERMINATION OF THE INFLOW RATE OF THE TRANSFORMER OIL

APPENDIX H MATLAB PROGRAMS FOR THE MATHEMATICAL 


\section{LIST OF TABLES}

Table Title $\quad \underline{\text { Page }}$

3.1 Variables Involved in the Buckingham's Method ............... 35

3.2 Dimensions and Ratios Between the Physical Model and the

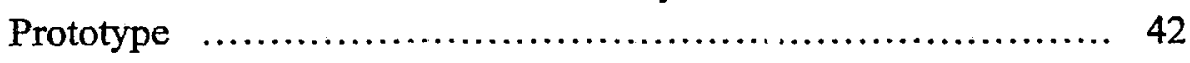

4.1 Parameters Involved in the Oil Back-up System $\ldots . \ldots \ldots \ldots \ldots \ldots . .69$

V.2 Variables Involved in the Oil Back-up System $\ldots \ldots \ldots \ldots \ldots \ldots \ldots \ldots . \ldots 1$

4.3 Experimental Results for the Density of the Transformer Oil ..... 91 


\section{LIST OF FIGURES}

Figure Title Page

1.1 The Transformer Station Near the City of Burlington $\ldots \ldots \ldots \ldots \ldots .4$

1.2 General Storm Water Drainage for a Typical Transformer

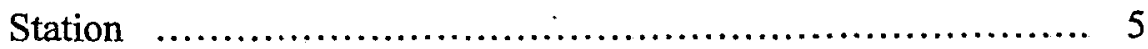

1.3 Hydro One's Transformer Station Drawing Near the City

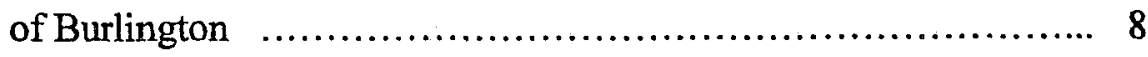

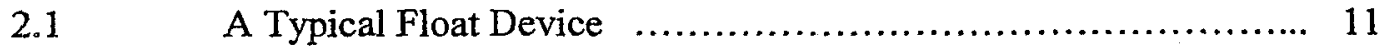

2.2 Top View of a Typical Electrical Oil Spill Control System $\quad \ldots \ldots \ldots .12$

2.3 Side View \#1 of a Typical Electrical Oil Spill Control

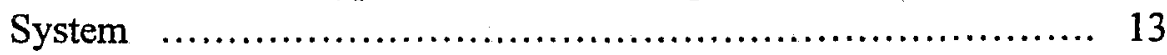

2.4 Side View \#2 of a Typical Electrical Oil Spill Control

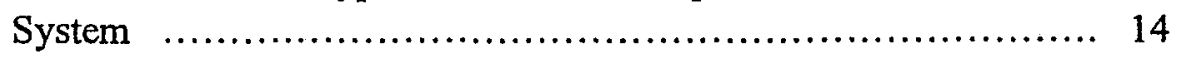

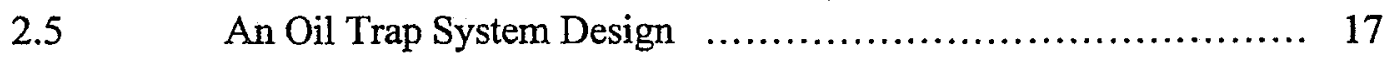

2.6 Preliminary Experiments on the Oil Back-Up System $\quad \ldots \ldots \ldots \ldots \ldots . . .19$

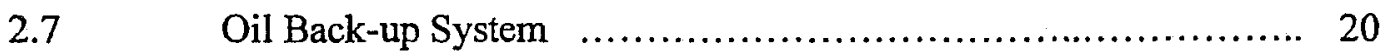

$2.8 \quad$ Transformer Oil Enters into the Oil Back-up System $\ldots \ldots \ldots \ldots \ldots . . \ldots 21$

$2.9 \quad$ Side View of a Typical Oil-Water Separator $\ldots \ldots \ldots \ldots \ldots \ldots \ldots . \ldots \ldots$

2.10 Equilibrium of Forces Acting on a Combined Oil-Water

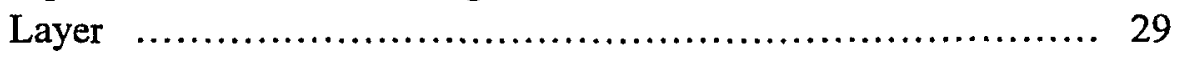

3.1 Variables for the Determination of II-terms in the Oil Trap

System ........................................................... 34

3.2 Precast Concrete Tank Drawing for the Dimensions Design of the Oil Trap System ............................................. 43

F.3 Failure Situation of the Oil Trap System $\ldots \ldots \ldots \ldots \ldots \ldots \ldots \ldots \ldots . . \ldots \ldots$

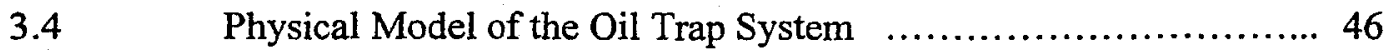




\section{LIST OF FIGURES}

Figure

\section{Title}

Page

Switch of the Pump Used in the Oil Trap System

Experiment 47

Preliminary Setup of the Oil Trap System

Transformer Oil is Added into the Oil Trap System

Experiment

Maximum Capacity of Transformer Oil the Oil Trap System can Trap

Experiment for the Maximum Flow Situation and Maximum

Trapping Capacity at Time $=0$ seconds

Experiment for the Maximum Flow Situation and Maximum

Trapping Capacity at Time $=42$ seconds 54

Velocities for Velocity Upland Method of Estimating $t_{c}$. 58

IDF Curve for the City of Burlington

Small Amount of Transformer Oil Entering into the System

Without Turn on the Pump Experiment

Large Amount of Transformer Oil Entering into the System Without Turn on the Pump Experiment 64

A Closeup for the Large Amount of Transformer Oil Entering into the System Without Turn on the Pump Experiment

Small Amount of Transformer Oil Entering into the System With Pump Turns on Experiment 66 A Closeup for the Small Amount of Transformer Oil Entering into the System With Pump Turns on Experiment 66 Large Amount of Transformer Oil Entering into the System With Pump Turns on Experiment 


\section{LiST OF FIGURES}

Figure $\quad \underline{\text { Title }}$ Page

3.19 A Closeup for the Large Amount of Transformer Oil Entering into the System With Pump Turns on Experiment ............... 67

4.1 Definition of Parameters in the Oil Back-up System $\quad \ldots \ldots \ldots \ldots \ldots . \quad 72$

4.2 Case $1\left(h_{\text {column }} \leq H 3[n]\right)$ of the Oil Back-up System $\ldots \ldots \ldots \ldots . . .73$

4.3 Case $2\left(h_{\text {column }}>H 3[n]\right)$ of the Oil Back-up System $\ldots \ldots \ldots \ldots \ldots . .74$

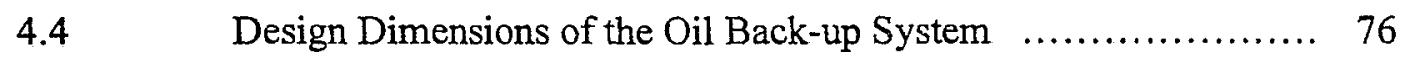

4.5 Typical Grate Located at the Concrete Pad $\ldots \ldots \ldots \ldots \ldots \ldots \ldots . . . . . . . . .93$

4.6 Numerical result of the oil back-up system at $t=0$ seconds $\quad \ldots \ldots . .97$

$4.7 \quad$ Numerical result of the oil back-up system at $t=6$ seconds $\quad \ldots \ldots . . .98$

4.8 Numerical result of the oil back-up system at $t=48$ seconds $\quad \ldots \ldots .99$

4.9 Numerical result of the oil back-up system at $t=146$ seconds $\ldots . . \quad 100$

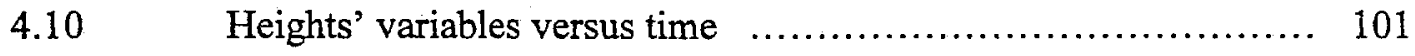




\section{Chapter 1 INTRODUCTION}

\subsection{Background}

Oils are complex compounds composed of carbon and hydrogen. They are known as hydrocarbons and are found under the earth's surface. In most circumstances, oils are fossils of prehistoric vegetation and marine life, where these plants and animals were buried under layers of sediment before decomposition. Over the past millions of years, the pressure and slow bacterial degradation converted these organisms into crude oil (Sit, 1999).

Oils are an essential part in today's society because it is a relatively inexpensive source of energy. This natural resource can be extracted and processed for various uses such as fuel, lubricants and composite materials for industrial uses (Truong, 2002). Since crude oil by-products are being used in a wide variety of ways, there may be a high probability of spilling the oil by-products accidentally into the environment.

Spilled oil can harm the environment in several ways. First, spilled oil has a direct impact on freshwater because the toxicity of the oil can poison the organisms living within the contaminated water. Also, spilled oil can have catastrophic effects on larger animals such as birds being coated with a harmful layer of crude oil by-products. Finally, spilled oil that enters the sanitary sewers can cause deleterious effects, turbidity, filtration difficulty, cbjectionable tastes and odour (Zhen, 1998). 
In 1972, Canadian and American governments signed the Great Lakes Water Quality Agreement in an attempt to control pollutant discharges into the Great Lakes (Zhen, 1998). Hydrocarbons are major pollutant discharges that have drawn both the attention of the public and politicians. With increased public awareness and stringent environmental regulations on oil spills, Hydro One, the largest electrical transmission company in Ontario, has used electrically-based oil spill control systems to control and retain spilled transformer oil at its electrical transformer stations. The advantages and disadvantages of the existing system will be discussed in Section 2.1 in detail. Hydro One is currently developing a hydraulically-based oil spill control system that can replace their existing electrical oil spill control system (Truong, 2002).

\subsection{Problem Identification}

Electrical transformers are generally located at several areas of a power system. Although they may vary in sizes, their functions are to increase the electrical voltage from about 100 to 500 kilovolts for transmission purposes and to decrease the electrical voltage for industrial ( 480 volts) or residential ( 240 or 120 volts) use once the electricity has reached its destinations. Transformer oil is applied to increase the transfer efficiency and to reduce the moisture and air in an electrical transformer. The general characteristics of transformer oil are discussed in Appendix J. 
Each year, there is a high frequency of spilling the transformer oil accidentally into the environment. According to Hydro One Spill Study report provided by Weslake Inc. in 2002, over 860000 litres of spilled transformer oil were reported between 1993 and 1999. Some transformer oil spill events were large in volume. The largest transformer oil spill event volume between 1993 and 1999 was 200,090 litres (Weslake Inc., 2002).

Most of the transformer oil contains PCBs. The Sewer Use Bylow of the city of Toronto states that PCBs for sanitary/combined sewers discharges, and storm sewer discharges must be less than $0.001 \mathrm{mg} / \mathrm{L}$ and $0.0004 \mathrm{mg} / \mathrm{L}$ respectively." Hydro One is currently seeking for a more reliable oil spill control system, other than the electrically-based oil spill control system, to solve the transformer oil spill problems at their transformer stations.

Transformer oil spills are primarily caused by leakage in the system, oil aging and fire or explosion at transformer stations. For a small transformer oil spill, the entire volume will be trapped within the concrete pad underneath the transformer (Figure 1.1). If a rain event occurs after the spill, runoff will carry small amount of spilled transformer oil into the underground oil spill control system. Large spill events will go directly into the oil spill control system. The function of an oil spill control system is to prevent the transformer oil spills from entering the sewer system (Figure 1.2).

\footnotetext{
${ }^{1}$ Reference from website $h t t p: / / w w w . c i t y . t o r o n t o . o n . c a / l e g d o c s / m u n i c o d e / 1184 \_681 . p d f$
} 


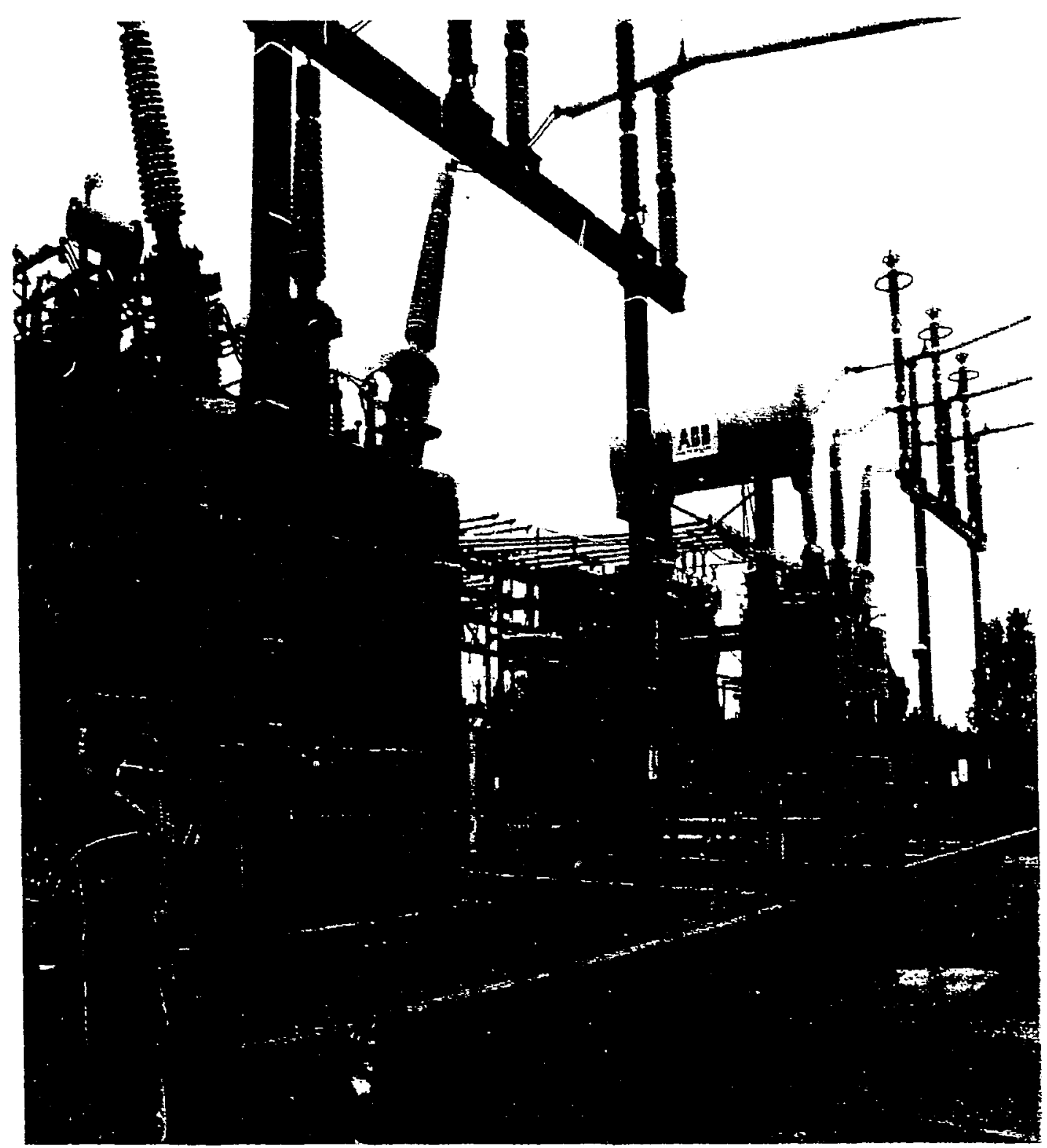

Figure 1.1: The transformer station near the city of Burlington.

Page 4 


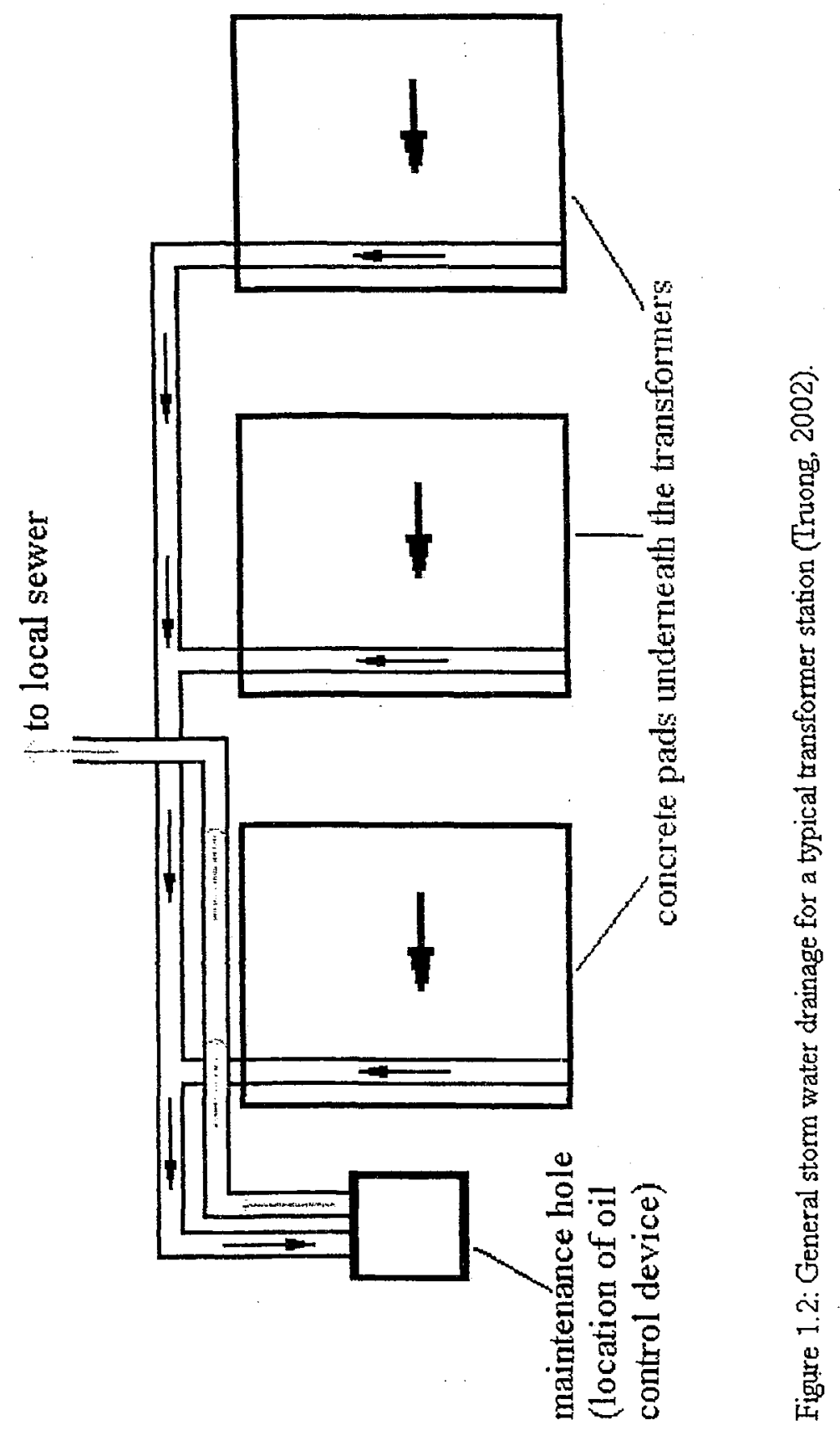

Page 5

Reproduced with permission of the copyright owner. Further reproduction prohibited without permission. 
All oil spill control systems, either electrically- or hydraulically-based, use the concept of different specific gravities between oil and water for oil containment and separation. It is also assumed that the trapped transformer oil globules in the oil spill control system be held for a short period of time until cleanup mechanism is activated. At a nonstaffed transformer station, a sudden surge of spilled transformer oil can be trapped by the oil spill control system. Since the trapped transformer oil may not be cleaned up right away, subsequent rain storms may flush out the trapped oil. Although the design recommendations of American Petroleum Institute (API) for oil-water separators are sufficient for the separation of transformer oil and water, additional design criteria should be developed to prevent the previously trapped transformer oil spills from escaping the separator during a rain storm.

\subsection{Objectives and Scope}

The objective of this thesis is to investigate the hydraulic behaviour of an oil spill control systems under all operating and weathering conditions at a Hydro One's transformer station near the city of Burlington (Figure 1.3). This thesis examines two types of oil spill control systems: (1) oil trap systems which retain spilled transformer oil and (2) oil back-up systems which back up transformer oil spills at the transformer.. For the oil trap systems, dimensionless analyses and physical model studies were conducted. For the oil back-up systems, the mass balance and hydrostatic concept of oil 
and water were applied to develop a mathematical model winich simulates the hydraulic characteristics.

\subsection{Organization of the Thesis}

This thesis is organized in the following manner. Chapter 2 reviews the functions and disadvantages of electrical oil spill control systems, transformer oil characteristics and the operating conditions of the system, and previous research works in oil/water separation. Chapter 3 presents the physical model study for the oil trap system.

Chapter 4 presents the numerical model study of the oil back-up system. Finally, Chapter 5 concludes the research with recommendations. 
transformer station transformer station transformer station

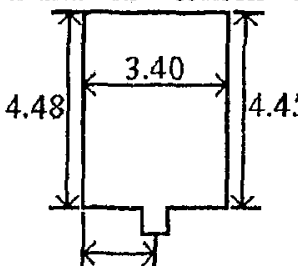

4.45

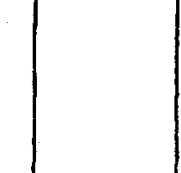

To transformer station

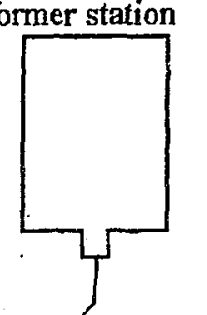

transformer station

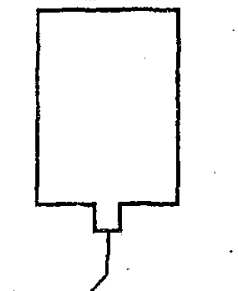

$200 \mathrm{~mm}$ diameter pip

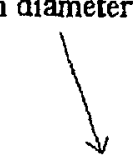

Figure 1.3: Hydro One's transformer station drawing near the city of Burlington 


\section{Chapter 2 LITERATURE REVIEW}

The first part of this chapter is to review the electrically-based and the hydraulically-based oil spill control systems and their limitations. Literatures related to the characteristics of the transformer oil spills at power stations, the different operating conditions of an oil spill control system, the oil-water separation concepts and the dynamics of oil slicks on water surface are then discussed.

\subsection{Electrically-Based Oil Spill Control System}

As indicated in Section 1.1, the electrically-based oil spill control system is currently used by some electrical companies in Ontario, such as Hydro One, to prevent transformer oil spills from entering the sewer system. This system uses several float devices (Figure 2.1) to detect the elevations of water and oil at the maintenance hole. Some float devices will float in the presence of water while other float devices will float in the presence of oil. Figures 2.2 to 2.4 show the locations of float devices (red circles in Figure 2.3) and the sump pump (blue dotted circle in Figures 2.3 and 2.4) at a typical electrically-based oil spill control system. The float devices are connected to switches which control the sump pump. When the float devices reach point B (Figure 2.3), the sump pump will start activating. The function of sump pump is to draw out water from the maintenance hole. When the float devices reach point E (Figure 2.3), the sump pump will be stopped in order to prevent drawing out the spilled transformer oil from the maintenance hole. The major advantage of the electrically-based oil spill control 
system is its relatively cerrpact size, compared to the enormous size of the tank in the hydraulically-based oil trap system or the long pipe columns of the hydraulically-based oil back-up system. In areas where bedrock is closed to the surface elevation, an electrically-based oil spill control system is cost-effective as the rock excavation costs are expensive (Truong, 2002).

The effectiveness of the electrically-based oil spill control system is better than that of the hydraulically-based oil spill control system. If all components of the electricallybased oil spill control system perform perfectly, no transformer oil spills should escape from the system. The effectiveness of hydraulically-based oil spill control systems must rely on the design diameter of oil globules,

Electrically-based oil spill control systems have two major problems. First, when the float devices are surrounded by grits, they may not float properly on the surface. Thus, the inaccurate measurement of different fluid levels may unintentionally allow the transformer oil spills to escape from the system. In order to minimize this problem, electrical companies must spend an enormous amount of money on labours every year to check and maintain the performance of equipment. Secondly, the sump pump in the system is initiated and terminated electronically. If the electricity is out of service due to thunderstorms, fire or other problems, runoff will not be drawn out from the maintenance hole properly. This will cause the transformer oil spills to escape from the system. 


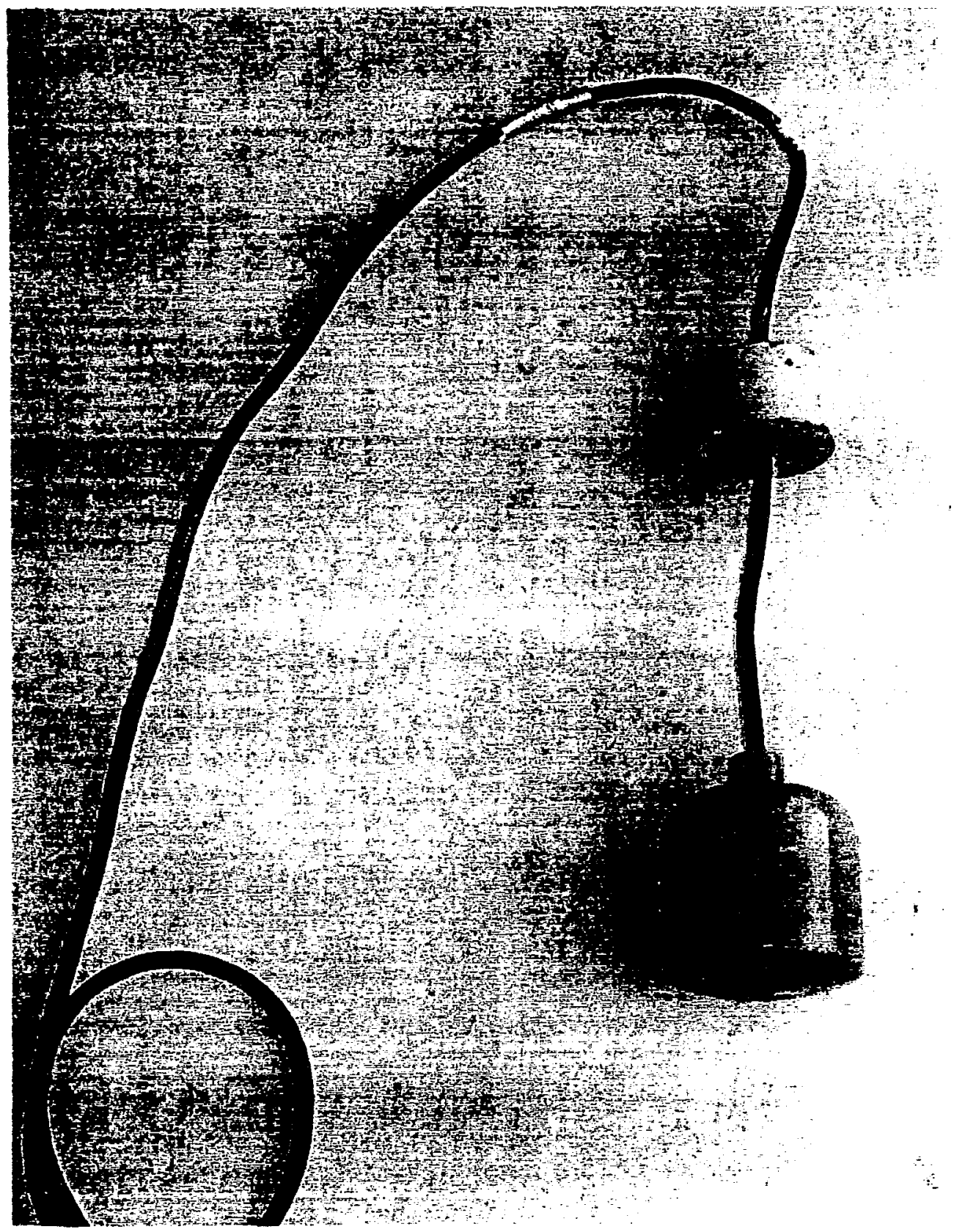

Figure 2.1: A typical float device. 


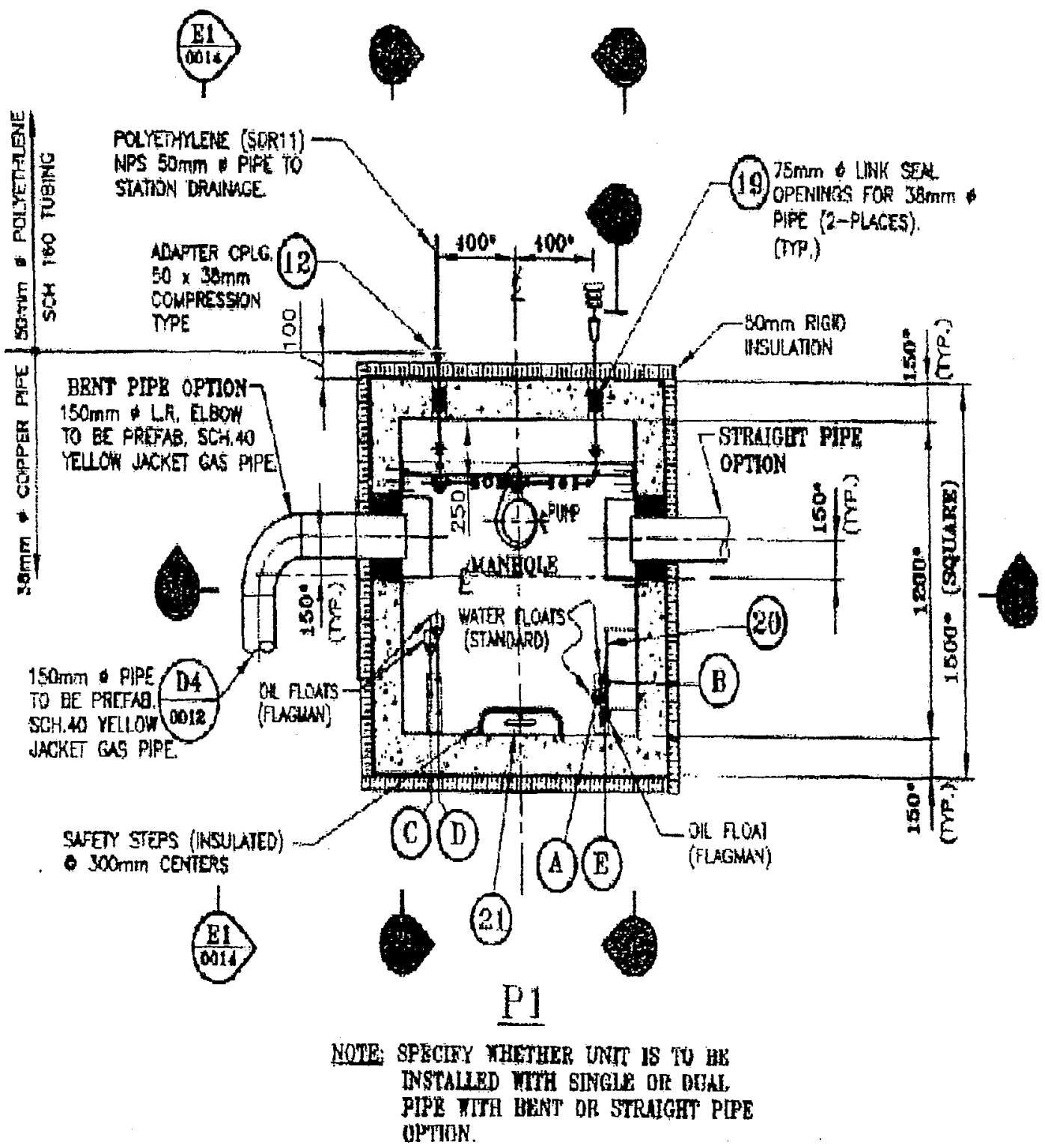

Figure 2.2: Top view of a typical electrical oil spill control system (Troung, 2002). 


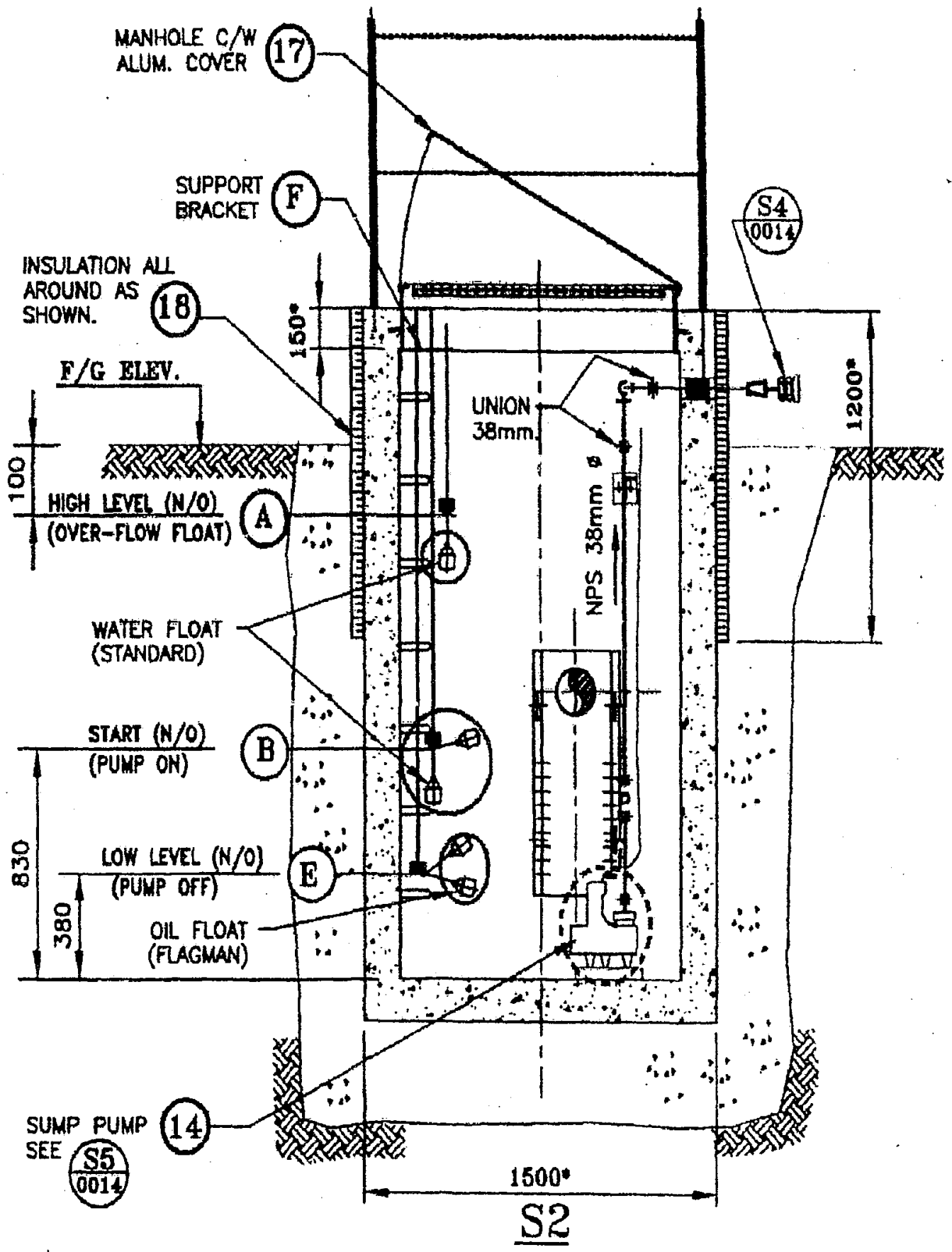

Figure 2.3: Side view \#1 of a typical electrical oil spill control system (Truong, 2002). 


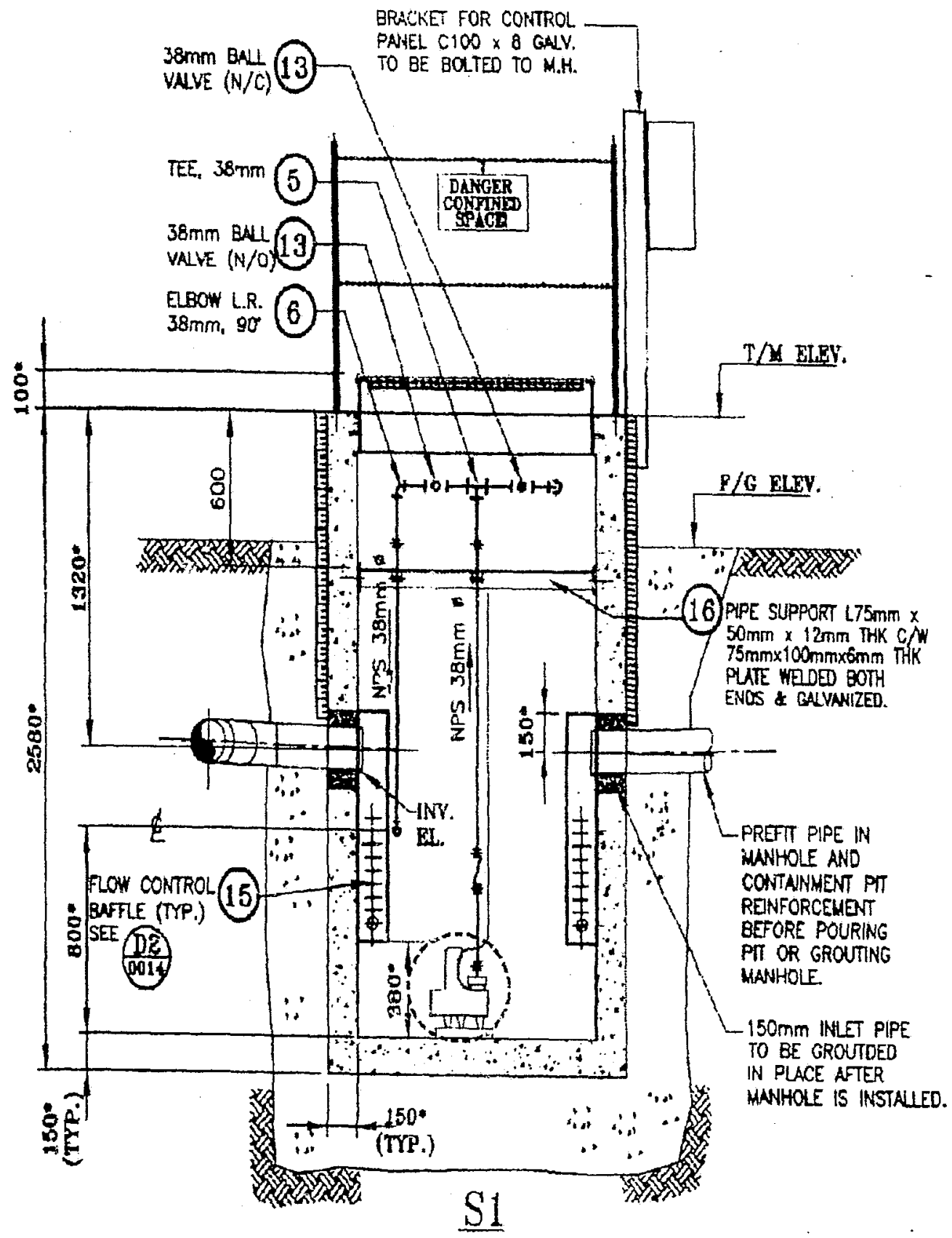

Figure 2.4: Side view \#2 of a typical electrical oil spill control system (Troung, 2002). 


\subsection{Hydraulically-Based Oil Trap Systems}

A hydraulically-based oil trap systems is designed to trap transformer oil spills and prevent the spilled oil from entering the storm sewer system until cleanup mechanism is activated. Thus, an oil trap system must have adequate storage capacity to hold the spilled transformer oil especially for the major oil spill operation condition discussed in Section 2.5. When spilled transformer oil enters into the system, it floats to the water surface due to the density difference between oil and water and is trapped in the system (Figure 2.5). If the inflow is a combination of spilled transformer oil and stormwater, the oil-water separation process will still occur between the two vertical pipes (red dotted lines in Figure 2.5). The purpose of the long inflow and outflow pipes is to trap and prevent the spilled transformer oil from escaping from the system. If a rain occurs after a transformer oil spill, runoff will pass under the oil layer in the oil trap system and exit to local sewers.

The hydraulically-based oil spill back-up system has two advantages when compared to the electrically-based oil spill control system. First, since the hydraulically-based control system does not need any electricity, it will not be prone to electric surges during lightening storms. Thus, the reliability of a hydraulically-based control system is greater than that of an electrical control system. Secondly, the hydraulically-based control system requires less maintenance than that of the electrically-based control system. The required maintenance activities of a hydraulic control system are the removal of the transformer oil spills and grit, cleaning the maintenance hole, and the 
occasional inspection of the two pipe columns and maintenance hole for cracks and clogs to the structure. The electrical oil spill control system requires similar maintenances as the hydraulic control system, but it also requires frequent checks and calibration on its parts, such as the float devices and the sump pumps, due to its proximity to power surges and storm water (Truong, 2002).

The oil trap system is bigger in size than the hydraulically-based oil back-up system discussed in Section 2.3. Thus, the oil trap system should be installed at transformer stations where underground space is available. On the other hand, it may not appropriate to apply the oil trap system in transformer stations near the downtown area where underground utility lines are concentrated. 


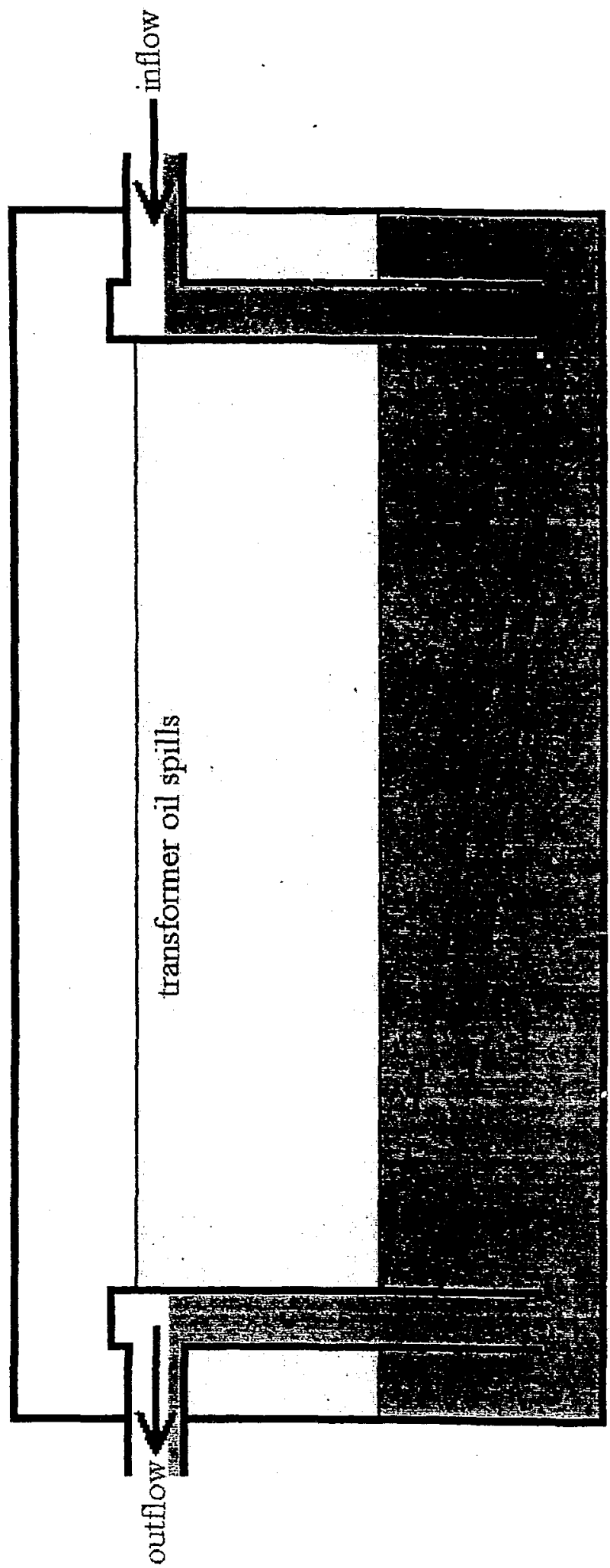

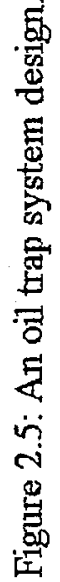

Page 17

Reproduced with permission of the copyright owner. Further reproduction prohibited without permission. 


\subsection{Hydraulically-Based Oil Back-up System}

The hydraulically-based oil back-up system discussed in this section was designed by Wilkinson Concrete Precast Ltd. and investigated by Patrick Truong at Ryerson University in 2002 (Figure 2.6). Figure 2.7 demonstrates the initial condition of the oil back-up system. The separation of water and oil occurs inside two long, vertical pipe columns. After the spilled transformer oil has entered the oil back-up system through the horizontal pipe $h p l$ (Figure 2.8), the transformer oil stays on the water surface and pushes the water downward to the external pipe column. In order to exit the system, the water travels through the external and the internal pipe columns. At the same time, the external pipe column holds the spilled transformer oil back to the concrete pad underneath the transformer.

The base area of the oil back-up system is small. Thus, it should be applied at transformer stations where underground area is limited. The only disadvantage of the hydraulically-based oil spill back-up system is its long, vertical structure. If there is any damage on the bottom part of the pipe columns, the spilled transformer oil may pollute the ground water underneath the transformer station. Truong (2002) conducted only a conceptual experiment on an oil back-up system model (Figure 2.6). This thesis will develop a mathematical model using the Matlab 6.1 program to analyze the hydraulic characteristics of the oil back-up system. 


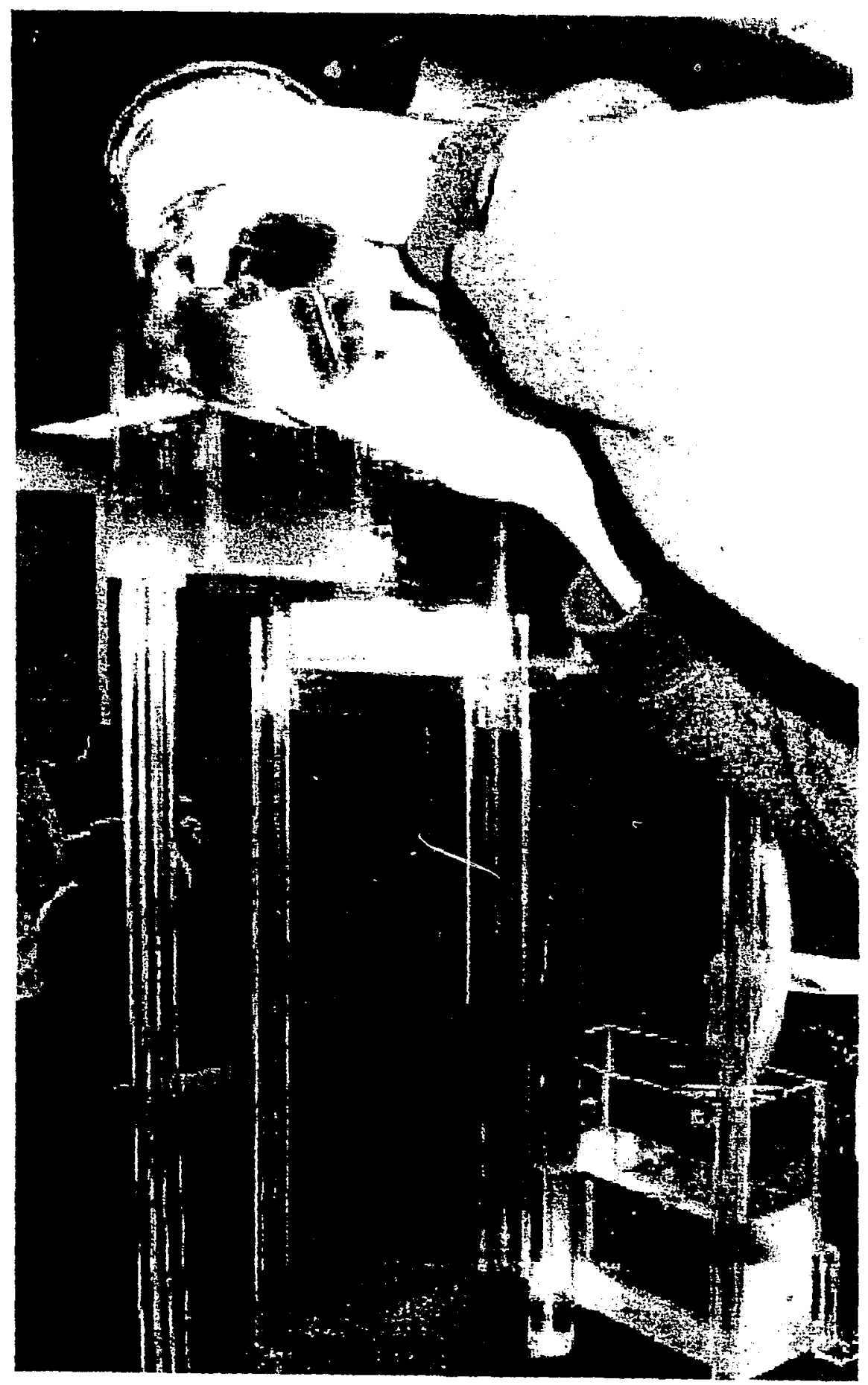

Figure 2.6: Preliminary experiments on the oil back-up system (Truong 2002).

\section{Page 19}

Reproduced with permission of the copyright owner. Further reproduction prohibited without permission. 
concrete pad at transformer station
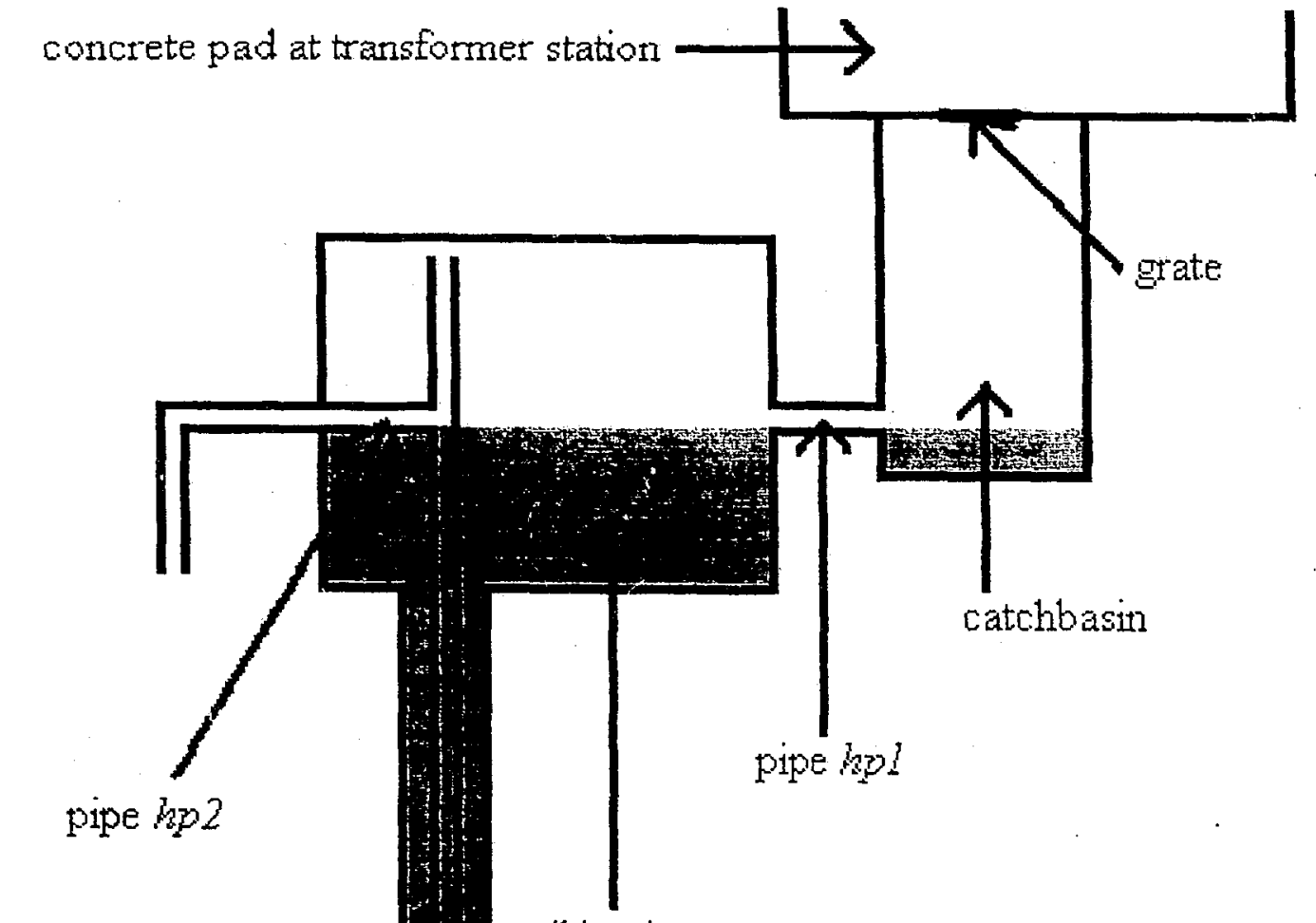

oil back-up system

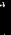

internal pipe column
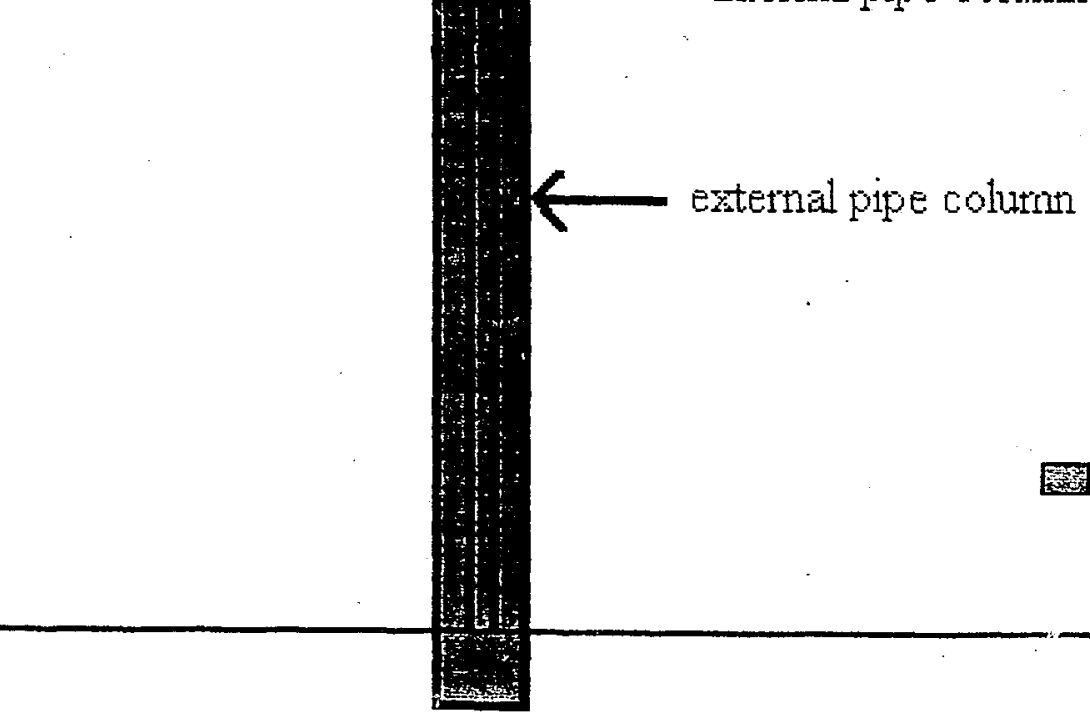

datim

Figure 2.7: Oil back-up system. 


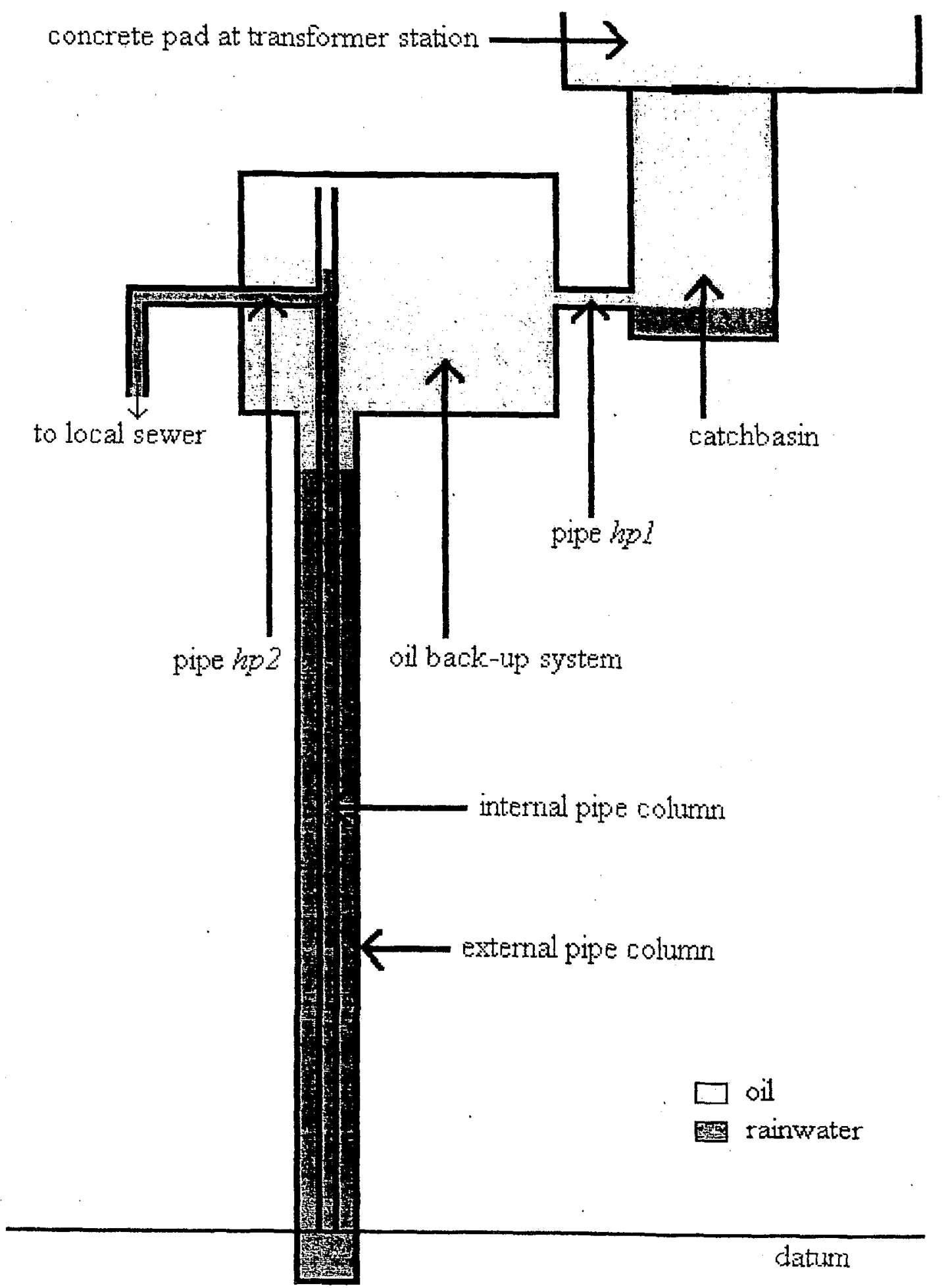

Figure 2.8: Transformer oil enters into the oil back-up system.

\section{Page 21}




\subsection{Oil Spill Characteristics}

Between 1993 and 1999, 2,852,931 litres of materials were reported lost at transformer stations due to spillage, of which over 860,000 litres have been identified as transformer oil (Weslake 2002). Assuming a cost of $\$ 3.00$ per litre of transformer oil, Hydro One loses on average over $\$ 368,000$ per year due to spillage. This is only the material cost. Not included is the manpower and equipment cost associated with clean up, disposal cost of contaminated spilled oil, of contaminated soil material, and monitoring of environmental impacts. Of greater significance is the impact on the surrounding environment and its incalculable cost. These include impacts on the ground water and sources of drinking water, contamination of substrates in spawning area, destruction of micro-invertebrates source of food supply, contamination of aquatic vegetations, and contamination of agricultural lands.

Generally, oil spills may contain oil in three major forms: free oil, emulsified oil and dissolved oil. Free oil has the largest discrete oil globules. The oil globules rise as a result of buoyant forces and form an oil layer on top of the water. Under proper quiescent flow condition, free oil can be removed by gravity separation. This removal is a function of residence time, temperature, stability of the emulsion and the differences in specific gravity between oil and water. Some coarse oily solids with a specific gravity greater than 1.0 will settle to the bottom of the oil control system. Most of the oil and the associated fine solids with a specific gravity less than 1.0 will rise to the water surface. Emulsified oil contains smaller oil globules with a diameter of less 
than 20 microns. Most of these oil globules are between 1 to 10 microns. These globules form a stable suspension in the water as a result of the predominance of interparticle forces over buoyant forces. The presence of particulates also contributes to emulsion formation. Emulsified oil cannot be removed by gravity separation alone; it may be removed by flotation or chemical addition and coalescing. Dissolved oil is the petroleum fraction that forms a true molecular solution with water. Further treatment, such as biological treatment is necessary if removal of dissolved oil is required (API, 1990). The transformer oil spills on transformer stations are mostly in free oil form. Therefore, the conventional oil-water separation concept can still be applied to the design of the oil trap system.

\subsection{Operating Conditions}

All transformer oil spill control systems, either electrically- or hydraulically-based, must meet three general operating conditions: normal, normal oil spill and major oil spill. The normal operating condition assumes that the inflow to the oil spill control system contain rainwater only. Therefore, the function of the oil spill control system is to provide an adequate flow capacity for proper drainage. The normal oil spill operating condition assumes that the inflow to the oil spill control system is a combination of small transformer oil spills and rainwater. Minor transformer oil spills (less than $100 \mathrm{~L}$ ) may come from minor leakages at the transformer station resulting in small quantities. The function of the oil spill control system under minor spill 
conditions is trap the small quantity of spilled transformer oil and pass the rainwater to the sewer system. The major oil spill operating condition assumes that a large sudden surge of oil (larger than $1000 \mathrm{~L}$ ) enters into the oil spill control system. This condition is caused by an explosion and a fire at the transformer station due to lightening or by transformer oil oxidation. Thus, the oil spill control system should have adequate storage capacities to hold the sudden surge of spilled transformer oil. It should prevent any trapped transformer oil from being flushed out from the system by subsequent rain storms until cleanup mechanism is activated (Truong, 2002).

\subsection{Basic Theories of Oil-Water Separation}

Since this research applies the oil-water separation concept to the design of the oil trap system, it is important to understand the basic theories of oil-water separation. Generally, an oil-water separator is a chamber designed to provide laminar flow conditions where globules of free oil can rise to the surface of water and coalesce into a separate oil layer (Figure 2.9). The theory of the oil-water separation is based on the rising rate of the oil globules and its relationship to the surface-loading rate of the separator. The rising rate $\left(V_{S}\right)$ is the vertical velocity at which oil particles move upward to the surface of water due to the differential density between oil and water. The surface-loading rate $\left(V_{H}\right)$ is the flow rate to the separator divided by the surface area of the separator. Ideally, any oil globule with a rising rate greater than or equal to surface-loading rate will reach the surface of water and has to be removed manually. 
The required surface-loading rate for removal of a specified size of oil droplet can be determined from the following equation of the rising rate (API, 1990).

$$
V_{S}=\frac{g\left(\rho_{w}-\rho_{0}\right) a^{2}}{18 \beta}
$$

where $V_{S}=$ vertical velocity of the design oil globule, in $\mathrm{m} / \mathrm{sec}$

$$
\begin{aligned}
& g=\text { acceleration due to gravity, in } \mathrm{m} / \mathrm{sec}^{2}\left(g=9.81 \mathrm{~m} / \mathrm{sec}^{2}\right) \\
& \mu=\text { dynamic viscosity, in } \mathrm{Pa} \cdot \mathrm{sec} \\
& \rho_{w}=\text { density of water at the design temperature, in } \mathrm{kg} / \mathrm{m}^{3} \\
& \rho_{o}=\text { density of oil at the design temperature, in } \mathrm{kg} / \mathrm{m}^{3} \\
& d=\text { diameter of the oil globule to be removed, in metres }
\end{aligned}
$$

The rising velocity of an oil globule is highly dependent on the globule's diameter. Small oil globules rise slower than the larger ones. Normally, oil globules with a diameter greater than or equal to 0.15 millimetres can be removed effectively in any gravity separation device. The performance of oil-water separators varies with changes in the characteristics between oil and water, including flow rate, viscosity, oil-globule size, specific gravity and temperature. The closer the specific gravity between oil and water, the slower the oil globules will rise. Furthermore, oil globules will rise slower at lower temperatures (API, 1990). 


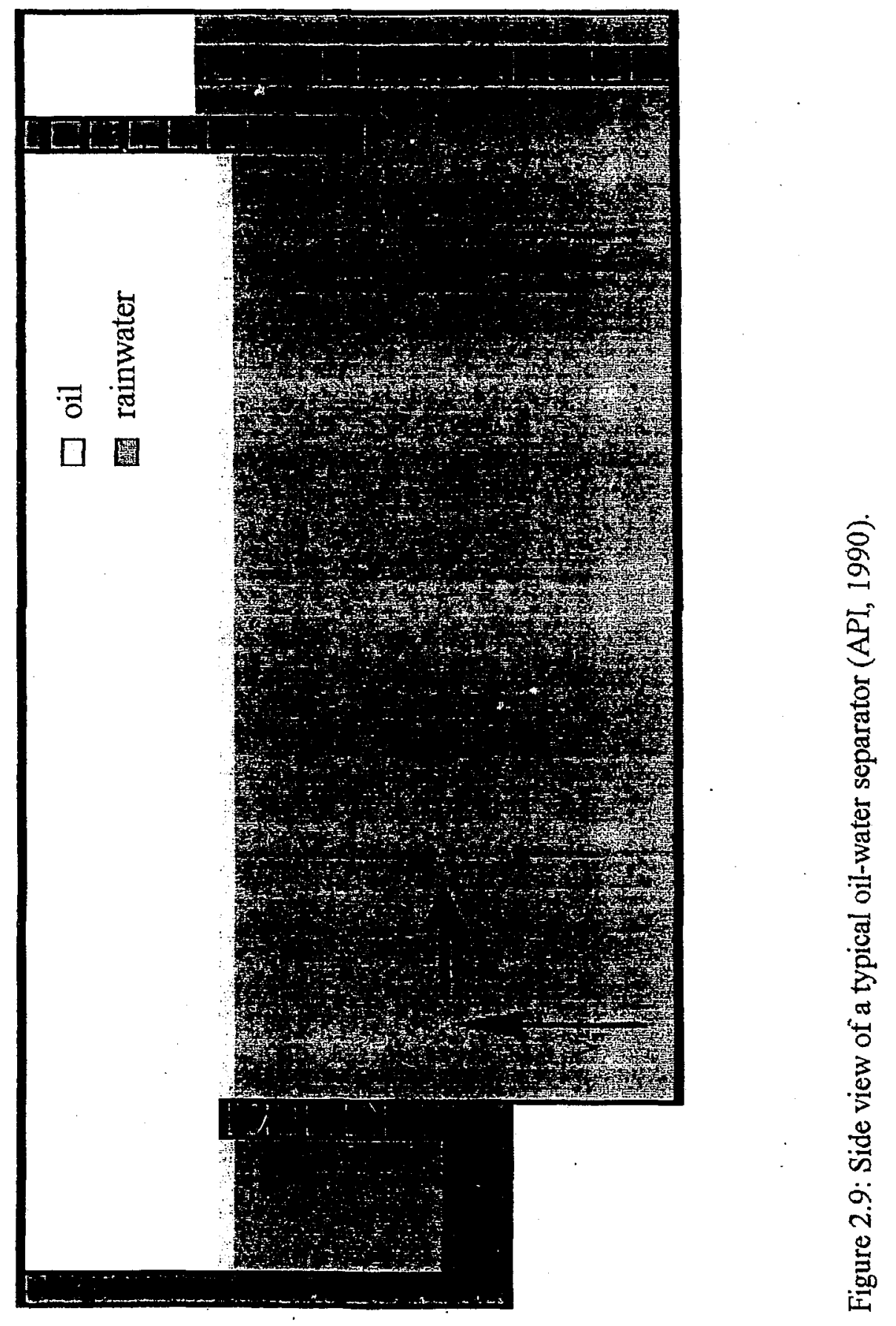

Page 26

Reproduced with permission of the copyright owner. Further reproduction prohibited without permission. 


\subsection{Literature Review on Dynamics of Oil Slicks on Water Surface}

There are only a few published papers, Wilkinson $(1972,1973)$, Wicks (1969), Cross and Hoult (1971), Jones (1972) and Moir and Lau (1975), which dealt with the dynamics of contained oil slicks on the water surface using floating booms. No literature can be found which address oil spill control systems for transformer stations. This section will review these theories which are similar to the oil and water layers situation in the oil trap system.

All the papers discussed below assumed one-dimensional flows which were uniform throughout the depth, except Wilkinson (1973) considered the effects of finite depths of flow. This effect is very important because it causes the change in momentum of the water flowing under the slick which in turn leads to instability of the slick (Moir and Lau, 1975).

Both Wilkinson (1973) and Wicks (1969) recognized that an oil slick on the water surface, such as rivers, can be divided into two regions: the frontal zone and the viscous zone (Figure 2.10). The frontal zone is the upstream region of an oil slick where viscous forces can be neglected in comparison with the dynamic forces. The viscous zone is the downstream of the frontal zone where the viscous shear at the oil-water interface and along the bottom of the river becomes the same order of magnitude as the dynamic forces and can no longer be neglected. The oil and water layers in the oil trap system are similar to the viscous zone discussed by Wilkinson and Wicks (Moir and 
Lau, 1975). The only difference is that the viscous zone is an open system, whereas the oil trap system is a closed system. Thus, more forces components should be involved in the oil trap system.

Wilkinson's theory of the viscous zone is based on three main assumptions: (1) the momentum flux due to circulation in the oil slick is small compared with interfacial shear forces, (2) the flow beneath the oil slick is steady and uniform over the depth and (3) a change in inertia and pressure force must be balanced by boundary shear stresses for equilibrium of the contained oil slick (Wilkinson, 1973). He developed an equation (Equation 2) for the equilibrium of forces acting on a combined oil-water layer at length $\delta x$ (Figure 2.10):

$$
\frac{\partial}{\partial x}\left[\frac{\rho_{w} g(1-\Delta) d^{2}}{2}\right]+\frac{\rho_{w} g \Delta(d-h)^{2}}{2}+\frac{\rho_{w} U_{o}^{2} d_{o}^{2}}{d-h}=-\tau_{b}
$$

where $x$ =downstream coordinate measured from the beginning of the viscous zone

$\rho_{w}=$ density of water

$g=$ gravitational acceleration

$\Delta=\left(1-\rho_{\circ}\right) / \rho_{w}$

$d=$ total thickness of the oil-water layers

$h=$ thickness of the slick in the viscous zone

$U_{0}=$ mean velocity of the flow upstream of the oil slick

$d_{o}=$ flow depth upstream of the oil slick

$\tau_{b}=$ boundary shear stress at the bottom of the channel 


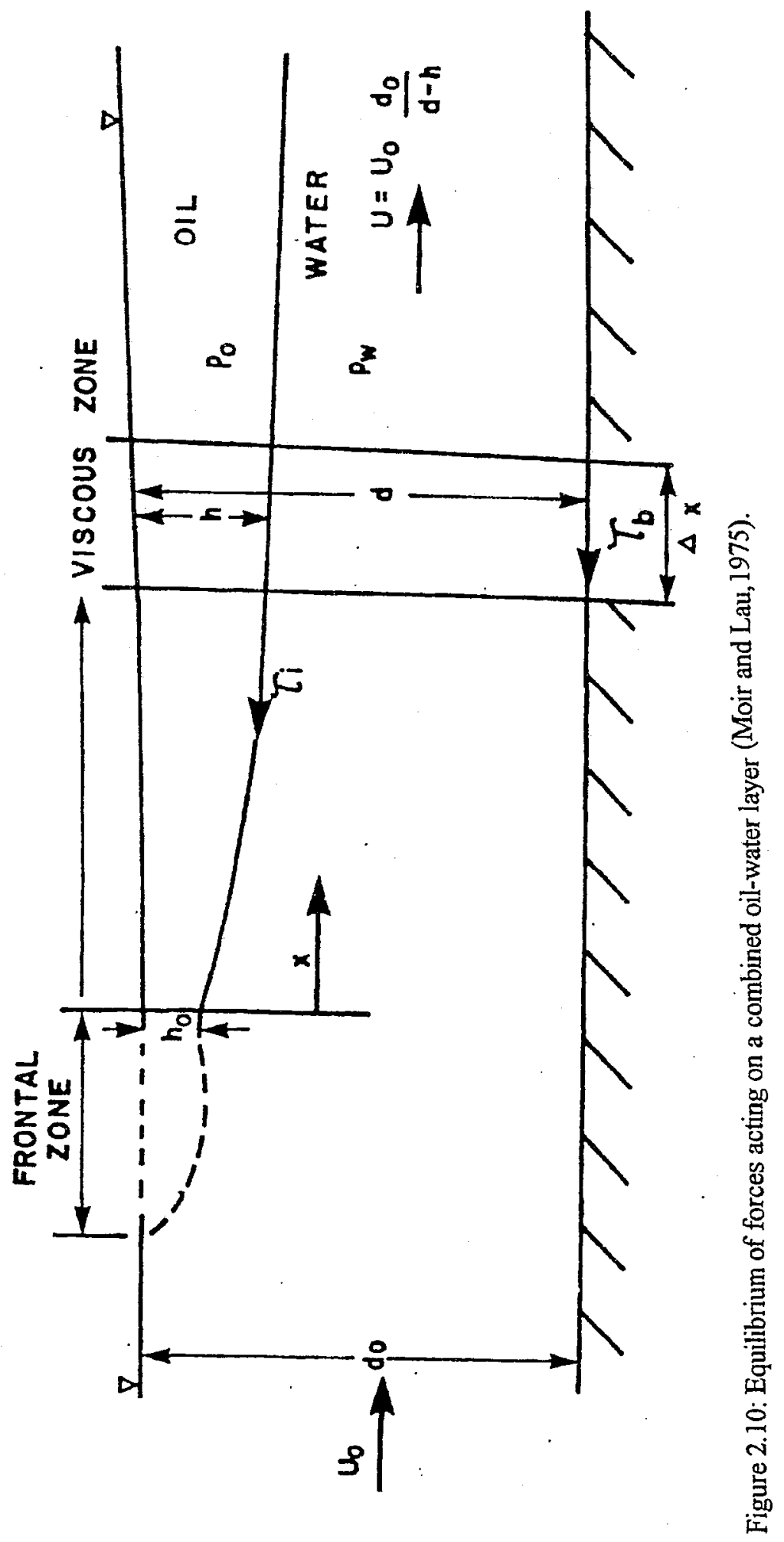

Page 29

Reproduced with permission of the copyright owner. Further reproduction prohibited without permission. 
He also developed another equation (Equation 3) for the forces acting on the oil layer only. This equation demonstrates that equilibrium is achieved by the balance of the pressure forces, the shear at the interface and the weight component of the oil acting along the interface.

$$
\frac{\partial}{\partial x}\left(\frac{\rho_{0} g h^{2}}{2}\right)=\tau_{i}-\rho_{\circ} g h \frac{\partial(d-h)}{\partial x}
$$

where $\tau_{\mathrm{j}}=$ shear stress at the oil-water interface

Equations [2] and [3] can be solved simultaneously for the two unknowns $d$ and $h$, given the upstream velocity $U_{o}$ and depth $d_{o}$, the oil density and values of $\tau_{b}$ and $\tau_{i}$. Wilkinson expressed the shear stress terms as,

$$
\begin{aligned}
& \tau_{i}=\frac{f_{i}}{4} \frac{\rho_{\psi} U^{2}}{2} \\
& \tau_{z}=\frac{f_{b}}{4} \frac{\rho_{\psi} U^{2}}{2}
\end{aligned}
$$

where $f_{i}=$ interfacial friction coefficient

$$
f_{b}=\text { boundary friction coefficient }
$$

Wilkinson showed that for a given set of flow conditions, there was a limiting thickness of the slick which failure would occur. This limiting thickness is independent of the viscous forces. However, the length of the slick and the slick profile are dependent upon the interfacial and boundary shear stresses (Wilkinson, 1973). 
Wicks used the balance of pressure and shear forces to determine the slick profile in the viscous zone. He also introduced the effect of circulation velocity in the oil (Wicks, 1969). However, he used wrong expressions for both the frontal thickness and the oil velocity according to Lau's analysis. Therefore, his calculated slick profiles could not be correct.

Cross and Hoult (1971) do not divide the oil slick into different regions, but treats it as one unit starting from the leading edge and growing with the distance downstream. The authors considered the equilibrium of the oil layer to be maintained by a balance of pressure forces and shear stresses at the interface (Cross and Hoult, 1971). However, the authors left out a term representing the weight component of the slick along the interface. This leads to unreasonable results of this research (Moir and Lau, 1975).

Jones (1972) attempted to explain certain types of boom failures in terms of hydrodynamic instability at the interface. The concept is that as instability develops at an oil-water interface, waves would form and grow. When a wave becomes steep enough, interfacial tension causes the crest of the wave to be broken off into droplets which are then entrained into the flow.

Jones considered the case of a slick of constant thickness $h$ at rest on top of an infinitely deep water layer flowing at velocity $U$. Both layers were considered to be inviscid. An infinitesimal disturbance was then superimposed on the steady flow pattern. Classical methods of stability analysis were used to determine the neutral stability curve. From a 
series of these stability curves, Jones obtained curves of the non-dimensionalized critical velocity $U /(g h)^{1 / 2}$ versus the parameter $\sigma /\left(\rho_{\circ} g h^{2}\right)$. Finally, Jones' analysis showed that thin slicks become uristable at lower velocities than thick slicks.

Part of Wilkinson and Jones' analyses can be applied to the oil trap system. First, since both the oil trap system and Wilkinson's research deal with uniform water flows underneath an oil slick in one-dimensional direction with finite depth, the two shear stresses componeits in Wilkinson's calculation can be used in the oil trap system. Thus, modifications must be done in developing the equilibrium equations for the oil trap system due to its closed system design. Secondly, Jones analysis on the conditions of the occurrence of a Kelvin-Helmholtz type instability at the oil-water interface can be also applied to the oil trap system. It may be too difficult to observe visually if any transformer oil has escaped from the oil trap system due to the small diameter of the outlet pipe and high water flow rate. The formation of waves at the interface can provide some signals of when the failure of the oil trap system will occur. 


\section{Chapter 3 PHYSICAL MODEL STUDY OF THE OIL TRAP SYSTEM}

This chapter describes the physical model study of the oil trap system. It also states the experimental procedures and observations.

\subsection{Dimensionless Analysis Method of the Oil Trap System}

In order to apply the Buckingham's method for the dimensionless analysis of the oil trap system, variables in Table 3.1 are used to derive the $\Pi$-terms. The visual meanings of these variables are shown in Figure 3.1 below. 


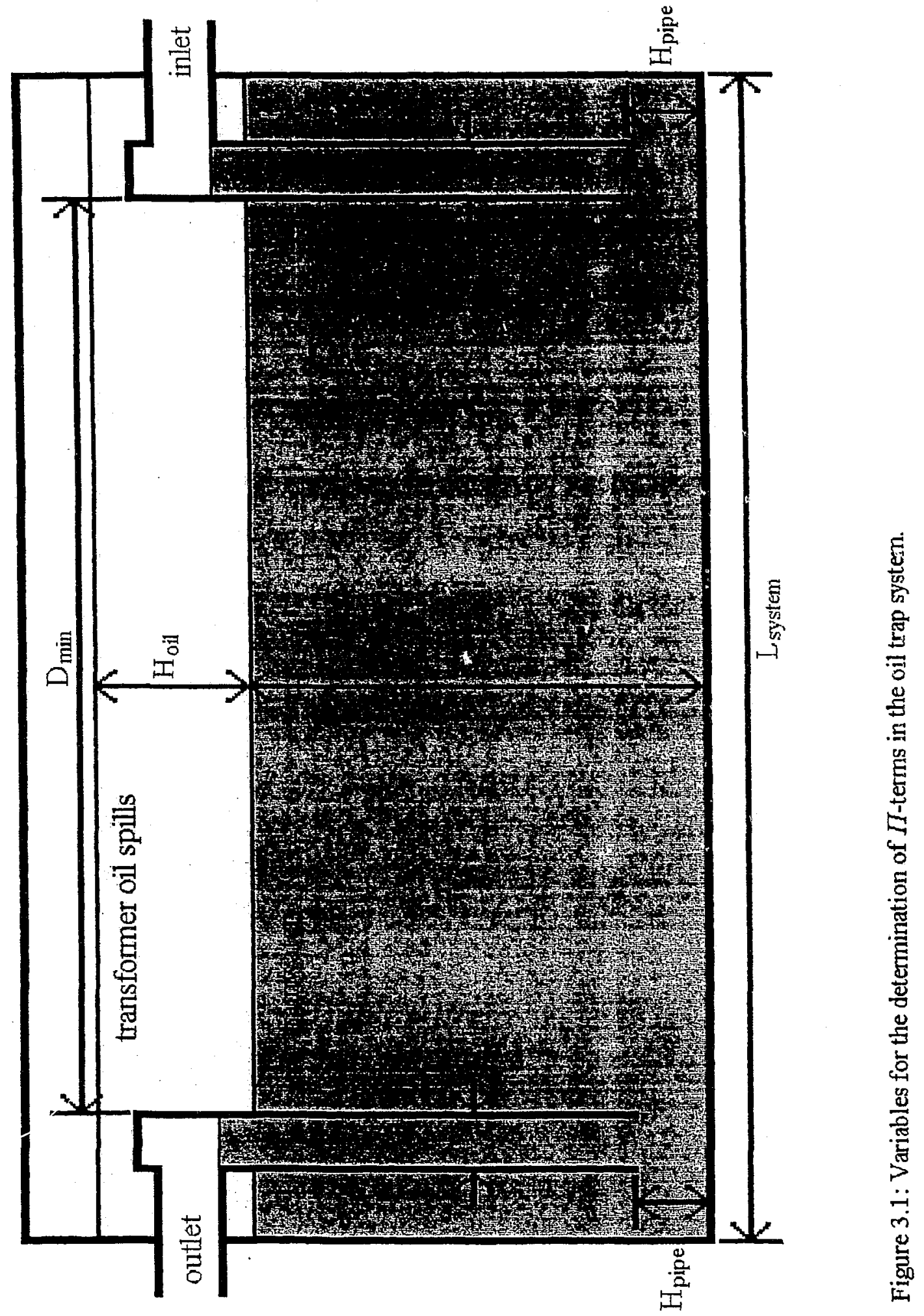

Page 34 
Table 3.1: Variables involved in the Buckingham's method.

\begin{tabular}{|c|c|c|}
\hline Variables & Definition of Variable & Dimension \\
\hline$X$ & volume of oil containment in dimensionless form & $-\cdots$ \\
\hline$B$ & width of the oil trap system & L \\
\hline$d_{\text {pipe }}$ & diameter of the vertical pipe & $\mathrm{L}$ \\
\hline$D_{\min }$ & minimum distance between the vertical pipes & $\mathrm{L}$ \\
\hline$H_{\text {pipe }}$ & $\begin{array}{l}\text { height between the bottom part of the vertical pipe and } \\
\text { the oil trap system }\end{array}$ & $\mathrm{L}$ \\
\hline$H_{\text {water }}$ & head of water at failure situation & $\mathrm{L}$ \\
\hline$H_{\text {oil }}$ & head of oil & $\mathrm{L}$ \\
\hline$\rho_{\text {water }}$ & density of water & $\mathrm{ML}^{-3}$ \\
\hline$\rho_{\text {oil }}$ & density of oil & $\mathrm{ML}^{-3}$ \\
\hline$Q$ & flow of water at failure situation & $\mathrm{L}^{3} \mathrm{~T}^{-1}$ \\
\hline$\mu_{\text {water }}$ & dynamic viscosity of water & $\mathrm{ML}^{-1} \mathrm{~T}^{-1}$ \\
\hline$\mu_{\text {oil }}$ & dynamic viscosity of oil & $\mathrm{ML}^{-1} \mathrm{~T}^{-1}$ \\
\hline$\sigma$ & oil-water interfacial tension & $\mathrm{MT}^{-2}$ \\
\hline$g$ & gravitational acceleration & $\mathrm{LT}^{-2}$ \\
\hline$t$ & time for oil containment stays in the oil trap system & $\mathrm{T}$ \\
\hline
\end{tabular}


Since there are fourteen variables involved in the oil trap system, eleven $\Pi$-terms can be formed. $Q, H_{\text {water }}$ and $\rho_{\text {water }}$ are selected as the three relevant variables for the Buckingham's method. The $\Pi$-terms are derived as follows:

$$
\begin{aligned}
& \Pi_{I}=\left(Q^{a}\right)\left(H_{\text {water }}^{b}\right)\left(\rho_{\text {water }}^{c}\right)\left(B^{d}\right) \\
&([\mathrm{M}][\mathrm{L}][\mathrm{T}])^{0}=\left([\mathrm{L}]^{3 a}[\mathrm{~T}]^{-a}\right)\left([\mathrm{L}]^{b}\right)\left([\mathrm{M}]^{c}[\mathrm{~L}]^{-3 c}\right)\left([\mathrm{L}]^{d}\right) \\
& {[\mathrm{M}]: \quad c=0 } \\
& {[\mathrm{~T}]: \quad \begin{aligned}
-a=0 \\
{[\mathrm{~L}]: \quad 3 a+b-3 c+d=0 } \\
b=-d
\end{aligned} }
\end{aligned}
$$

Therefore, $\quad \Pi_{l}=(B)\left(H_{\text {water }}{ }^{-1}\right)$

$$
\Pi_{2}=\left(Q^{\alpha}\right)\left(H_{\text {water }}^{b}\right)\left({\rho_{\text {water }}}^{c}\right)\left(d_{\text {pipe }}{ }^{d}\right)
$$

Since dimension of $d_{p i p e}$ is similar to dimension of $B$,

$$
\Pi_{2}=\left(d_{\text {pipe }}\right)\left(H_{\text {water }}{ }^{-1}\right)
$$

$\Pi_{3}=\left(Q^{a}\right)\left(H_{\text {water }}^{b}\right)\left(\rho_{\text {water }}{ }^{c}\right)\left(D_{\text {min }}{ }^{d}\right)$

Since dimension of $D_{\min }$ is similar to dimension of $B$,

$$
\Pi_{3}=\left(D_{\text {min }}\right)\left(H_{\text {water }}{ }^{-1}\right)
$$

$\Pi_{4}=\left(Q^{a}\right)\left(H_{\text {water }}^{b}\right)\left(\rho_{\text {water }}{ }^{c}\right)\left(H_{\text {pipe }}{ }^{d}\right)$

Since dimension of $H_{p i p e}$ is similar to dimension of $B$,

$$
\Pi_{4}=\left(H_{\text {pipe }}\right)\left({H_{\text {water }}}^{-l}\right)
$$


$\Pi_{5}=\left(Q^{a}\right)\left(H_{\text {waser }}^{b}\right)\left(\rho_{\text {water }}^{c}\right)\left(H_{\text {oil }}^{d}\right)$

Since dimension of $H_{o i l}$ is similar to dimension of $B$,

$$
\Pi_{5}=\left(H_{o i}\right)\left(d_{p i p e}{ }^{-1}\right)
$$

$$
\begin{aligned}
& I I_{6}=\left(Q^{a}\right)\left(H_{\text {water }}^{b}\right)\left(\rho_{\text {water }}^{c}\right)\left(\rho_{\text {oil }}^{d}\right) \\
& ([\mathrm{M}][\mathrm{L}][\mathrm{T}])^{o}=\left([\mathrm{L}]^{3 a}[\mathrm{~T}]^{-a}\right)\left([\mathrm{L}]^{b}\right)\left([\mathrm{M}]^{c}[\mathrm{~L}]^{-3 c}\right)\left([\mathrm{M}]^{d}[\mathrm{~L}]^{-3 d}\right) \\
& {[\mathrm{M}]: \quad c+d=0} \\
& \quad d=-c \\
& {[\mathrm{~T}]: \quad-a=0} \\
& {[\mathrm{~L}]: \quad 3 a+b-3 c-3 d=0} \\
& \quad b=3 c+3(-c)=0
\end{aligned}
$$

Therefore, $\quad \Pi_{6}=\left(\rho_{\text {water }}\right)\left(\rho_{\text {oil }}{ }^{-1}\right)$

$$
\begin{aligned}
& \Pi_{7}=\left(Q^{a}\right)\left(H_{\text {water }}^{b}\right)\left(\rho_{\text {water }}{ }^{c}\right)\left(\mu_{\text {water }}{ }^{d}\right) \\
& ([\mathrm{M}][\mathrm{L}][\mathrm{T}])^{0}=\left([\mathrm{L}]^{3 a}[\mathrm{~T}]^{-a}\right)\left([\mathrm{L}]^{b}\right)\left([\mathrm{M}]^{c}[\mathrm{~L}]^{-3 c}\right)\left([\mathrm{M}]^{d}[\mathrm{~L}]^{-d}[\mathrm{~T}]^{-d}\right) \\
& {[\mathrm{M}]: \quad c+d=0} \\
& \quad c=-d \\
& {[\mathrm{~T}]: \quad \begin{aligned}
a-d=0 \\
a=-d \\
3 a+b-3 c-d=0 \\
b=-3(-d)+3(-d)+d \\
b=d
\end{aligned}}
\end{aligned}
$$

Therefore, $\quad \Pi_{7}=\left(\mu_{\text {water }}\right)\left(H_{\text {water }}\right)\left(Q^{-1}\right)\left(\rho_{\text {water }}{ }^{-1}\right)$

$$
\Pi_{8}=\left(Q^{\sigma}\right)\left(H_{\text {water }}^{b}\right)\left(\rho_{\text {water }}^{c}\right)\left(\mu_{\text {oil }}^{d}\right)
$$

Since dimension of $\mu_{o i l}$ is similar to dimension of $\mu_{\text {water }}$,

$$
\Pi_{8}=\left(\mu_{\text {oil }}\right)\left(H_{\text {water }}\right)\left(Q^{-1}\right)\left(\rho_{\text {water }}{ }^{-1}\right)
$$

Page 37 


$$
\begin{gathered}
\Pi_{9}=\left(Q^{a}\right)\left(H_{\text {water }}^{b}\right)\left(\rho_{\text {water }}^{c}\right)\left(\sigma^{d}\right) \\
([\mathrm{M}][\mathrm{L}][\mathrm{T}])^{0}=\left([\mathrm{L}]^{3 a}[\mathrm{~T}]^{-a}\right)\left([\mathrm{L}]^{b}\right)\left([\mathrm{M}]^{c}[\mathrm{~L}]^{-3 c}\right)\left([\mathrm{M}]^{d}[\mathrm{~T}]^{-2 d}\right) \\
{[\mathrm{M}]: \quad c+d=0} \\
\quad c=-d \\
{[\mathrm{~T}]: \quad-a-2 d=0} \\
\quad a=-2 d \\
{[\mathrm{~L}]: \quad 3 a+b-3 c=0} \\
b=-3(-2 d)+3(-d) \\
b=3 d
\end{gathered}
$$

Therefore, $\quad \Pi_{g}=\left(Q^{-2}\right)\left(H_{\text {water }}{ }^{3}\right)\left(\rho_{\text {water }}^{-1}\right)(\sigma)$

$$
\begin{gathered}
\Pi_{i 0}=\left(Q^{a}\right)\left(H_{\text {water }}^{b}\right)\left(\rho_{\text {water }}^{c}\right)\left(g^{d}\right) \\
([\mathrm{M}][\mathrm{L}][\mathrm{T}])^{o}=\left([\mathrm{L}]^{3 a}[\mathrm{~T}]^{-a}\right)\left([\mathrm{L}]^{b}\right)\left([\mathrm{M}]^{c}[\mathrm{~L}]^{-3 c}\right)\left([\mathrm{L}]^{d}[\mathrm{~T}]^{-2 d}\right) \\
{[\mathrm{M}]: \quad c=0} \\
{[\mathrm{~T}]: \quad-a-2 d=0} \\
a=-2 d \\
{[\mathrm{~L}]: \quad 3 a+b-3 c+d=0} \\
b=-3(-2 d)-d \\
b=5 d
\end{gathered}
$$

Therefore, $\quad \Pi_{10}=\left(Q^{-2}\right)\left(H_{\text {water }}^{5}\right)(g)$

$$
\begin{aligned}
& \Pi_{I I}=\left(Q^{a}\right)\left(H_{\text {water }}^{b}\right)\left(\rho_{\text {water }}^{c}\right)\left(t^{d}\right) \\
& ([\mathrm{M}][\mathrm{L}][\mathrm{T}])^{o}=\left([\mathrm{L}]^{3 a}[\mathrm{~T}]^{-a}\right)\left([\mathrm{L}]^{b}\right)\left([\mathrm{M}]^{c}[\mathrm{~L}]^{-3 c}\right)\left([\mathrm{T}]^{d}\right) \\
& \text { [M]: } \quad c=0 \\
& \text { [T]: } \quad-a+d=0 \\
& a=d \\
& \text { [L]: } \quad 3 a+b-3 c=0 \\
& b=-3 a=-3 d
\end{aligned}
$$

Therefore, $\quad \Pi_{I I}=(Q)(t)\left(H_{\text {water }}{ }^{-3}\right)$ 
Equation of oil containment, $X$, in dimensionless form can be expressed as:

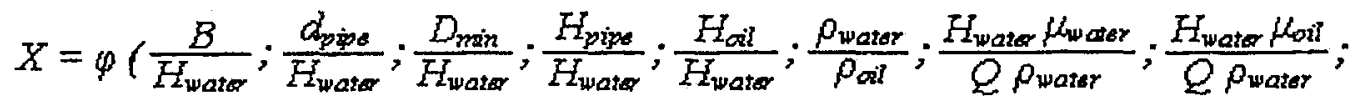

$$
\begin{aligned}
& \left.\frac{H_{\text {wats }}^{3} \sigma}{Q^{2} \rho_{\text {water }}} ; \frac{H_{\text {water }}{ }^{5} g}{Q^{2}} ; \frac{Q t}{H_{\text {water }}}\right)
\end{aligned}
$$

Variable $X$ in Equation [16] is the volume of oil inside the oil trap system in dimensionless form where

$$
X=V_{o i l} /\left(B * H_{o i l} * L_{\text {system }}\right)
$$

Since transformer oil spills will be retained in the system until cleanup mechanism is activated, $\Pi_{11}=(Q)(t)\left(H_{\text {water }}{ }^{-3}\right)$ can be eliminated from Equation [16] as $t \rightarrow \infty$. In other word, $X$ is eventually in steady-state or independent of time. Also, $\Pi_{6}=\left(\rho_{\text {water }}\right)\left(\rho_{o i l}^{-1}\right)$ can be replaced by $I / \Delta$ where $\Delta$ is the relative density difference.

$$
\Delta=\left(\rho_{w a t e r}-\rho_{o i l}\right) / \rho_{w a t e r}
$$

The effect of $\Delta$ is important only when considered in conjunction with the gravity force, Therefore, $\Delta$ can be combined with $\Pi_{10}=\left(Q^{-2}\right)\left(H_{\text {water }}^{5}\right)(g)$ to form $\Pi_{10^{\prime}}=\left(Q^{-2}\right)\left(H_{\text {water }}{ }^{5}\right)(g)(\Delta)$ 


\subsection{Similitude Analysis Method of the Oil Trap System}

Several standard dimensionless products can be found from the $\Pi$-terms in Section 3.1. For instance, if the formula of the Froude number (Table B.1 in Appendix B), Fr, is converted in terms of $Q$ :

$$
\begin{aligned}
F r & =(V)\left(g^{-1 / 2}\right)\left(L^{-1 / 2}\right) \\
& =\left(Q^{*} A^{-2}\right)\left(g^{-1 / 2}\right)\left(L^{-1 / 2}\right) \quad \text { where dimension of } A \text { is same as dimension of } L . \\
& =\left(Q^{*} L^{-2}\right)\left(g^{-1 / 2}\right)\left(L^{-1 / 2}\right) \\
& =(Q)\left(g^{-1 / 2}\right)\left(L^{-5 / 2}\right)
\end{aligned}
$$

Fr must be squared in order to eliminate the rational exponent.

$$
F r^{2}=\left(Q^{2}\right)\left(g^{-1}\right)\left(L^{-5}\right)
$$

Thus, $\Pi_{10}{ }^{\prime}=\left(Q^{-2}\right)\left(H_{\text {water }}{ }^{5}\right)(\mathrm{g})(\Delta)$ is equivalent to the reciprocal of the Froude number shown in Equation [19].

Secondly, if the formula of the Reynolds number (Table B.1 in Appendix B), $R e$, is converted in terms of $Q$ :

$$
\begin{aligned}
\operatorname{Re} & =(V)(L)\left(v^{-1}\right) \\
& =\left(Q^{*} A^{-2}\right)(L)\left[\left(\rho_{\text {water }}\right)\left(\mu_{\text {water }}{ }^{-1}\right)\right] \\
& =(Q)\left(L^{-1}\right)\left(\rho_{\text {water }}\right)\left(\mu_{\text {water }}{ }^{-1}\right)
\end{aligned}
$$

Hence, $\Pi_{7}=\left(\mu_{\text {water }}\right)\left(H_{\text {water }}\right)\left(Q^{-1}\right)\left(\rho_{\text {water }}^{-1}\right)$ is the same as the reciprocal of the Reynolds number in Equation [20]. Also, $\Pi_{8}=\left(\mu_{\text {oil }}\right)\left(H_{\text {water }}\right)\left(Q^{-1}\right)\left(\rho_{\text {water }}{ }^{-1}\right)$ can be divided with the reciprocal of the Reynolds number in Equation [20] to form the ratio $\mu_{\text {oil }} / \mu_{\text {water }}$. 
Finally, if the formula of the Weber number (Table B.1 in Appendix B), We, is converted in terms of $Q$ :

$$
\begin{aligned}
W e & =(V)\left(\rho_{\text {water }}{ }^{1 / 2}\right)\left(L^{l / 2}\right)\left(\sigma^{-l / 2}\right) \\
& =\left(Q^{*} A^{-2}\right)\left(\rho_{\text {water }}{ }^{l / 2}\right)\left(L^{1 / 2}\right)\left(\sigma^{-1 / 2}\right)
\end{aligned}
$$

Both sides are squared for eliminating the rational exponent.

$$
\begin{aligned}
W e^{2} & =\left(Q^{*} A^{-2}\right)^{2}\left(\rho_{\text {water }}\right)(L)\left(\sigma^{-1}\right) \\
& =\left(Q^{2}\right)\left(\rho_{\text {water }}\right)\left(L^{-3}\right)\left(\sigma^{-1}\right)
\end{aligned}
$$

Thus, $\Pi_{9}=\left(Q^{-2}\right)\left(H_{w a t e r}{ }^{3}\right)\left(\rho_{\text {water }}{ }^{-1}\right)(\sigma)$ equals to the reciprocal of the Weber number in Equation [21].

After rearrange the $\Pi$-terms, Equation [16] can be rewritten as:

$$
X=\varphi\left(\frac{B}{H_{\text {water }}} ; \frac{d_{\text {piee }}}{H_{\text {wate }}} ; \frac{D_{\text {min }}}{H_{\text {wate }}} ; \frac{F_{\text {pips }}}{H_{\text {wate }}} ; \frac{H_{\text {ail }}}{H_{\text {water }}} ; \frac{l}{\Delta} ; \frac{l}{R e} ; \frac{H_{\text {oil }}}{H_{\text {wat }}} ; \frac{l}{W e} ; \frac{l}{F r}\right)
$$

The next step is to determine which $I \Pi$-terms in Equation [22] dominate the physical model of the oil trap system. Unfortunately, all the dimensions of the model are fixed due to practical reasons. Therefore, it is impossible to determine any relationships between the first four $\Pi$-terms and the standard dimensionless products in Equation [22]. However, according to the oil-water separation theories discussed in Section 2.6, Froude number will be selected for scaling the model results back to the prototype. 


\subsection{Scales of the Physical Model}

The oil trap system was constructed by Wilkinson Heavy Precast Limited where the base area of the prototype follows the dimensions of the precast concrete tank product (Figure 3.2). Table 3.2 shows the dimensions and the ratios of the physical model and its prototype. The slight difference between the ratios of length and width in Table 3.2 is due to the convenience of the model construction. The percentage error between these two ratios is within $1 \%$.

Table 3.2: Dimensions and ratios between the physical model and the prototype.

\begin{tabular}{|l|c|c|c|c|}
\hline \multirow{2}{*}{} & \multicolumn{2}{|c|}{ Dimension, in mm } & \multicolumn{2}{c|}{ Ratio } \\
\cline { 2 - 5 } & Model & Prototype & Model & Prototype \\
\hline Length & 690 & 8540 & 1 & 12.3768 \\
\hline Width & 260 & 3190 & 1 & 12.2692 \\
\hline Height & 265 & 4100 & 1 & 15.4717 \\
\hline
\end{tabular}


Standard Construction

Concrote: 35 MPA at 28 Days, 5 to $8 \%$ Air Entrainment.

Heinforcing: 20M Bars at $200 \mathrm{~mm}$ centres each way in roof, walls and lloor. Eighl extra $15 \mathrm{M}$ bars around each access opening.

Welght: 196,000 Lbs. $(98,000$ Lbs. Per Half Section) Actual Capacity: 27,832 Litres per Vertical Metre.

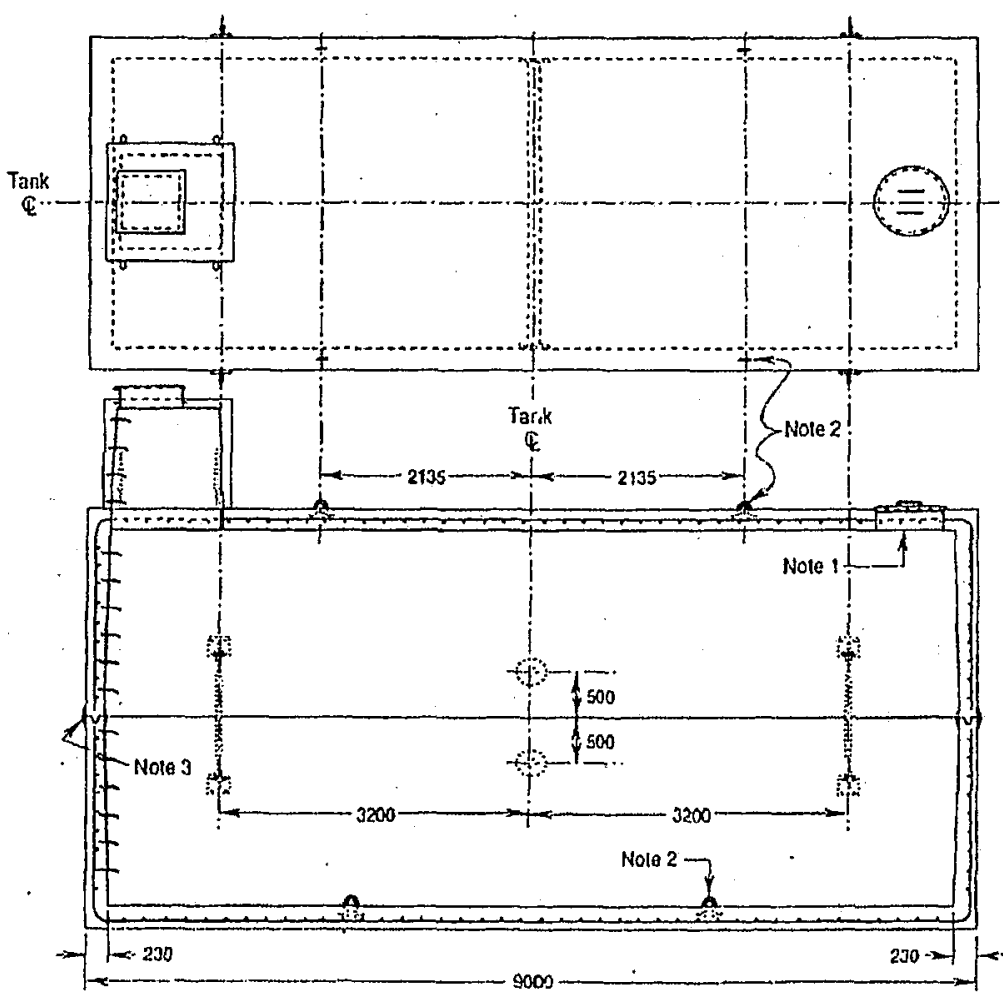

Recommended Burlal Depth - 1.5 Metres over the Top Slab in Firm soil away Irom any aree of vehicular raifo.

\section{Notes:}

1. Slandard Access opening is $685 \mathrm{~mm}$ Dlameter

2. Four Heavy Lith hooks are provid in the Roof and Floor.

Cour (his joint be grouted both will be supplied upon request.

4. $32 \mathrm{~mm}$ Galvanized Steel Brackets and Turnbuckles in 4 Places to prevent separatlon of seat. (Optional)

(Also avallable in Stainless

6recast Conorete AC 400 Access Exiension with Anti-Fiost Heava System and hegrally oast Aluminum Frame and Drip Prool Cover. (Optional)

- Thls tank is availebte with Aluminum Ladder Rungs to the floor in six different locations Consult with the factory as to how this will effect the size and lacation of the access opening.

- This product can be supplied with an Internal Polyethylene or P.V.C. Lining cast as part Orhe tank at the factory.

The Unil shown is a Typical Conliguration. Please call the faclory to discuss your Thil Grade Extensions Galvanized Sloel ar Aluminum Hinged Covers, Flanged Rool Vents and many other Cuslom Appurtenances that can be supplied.

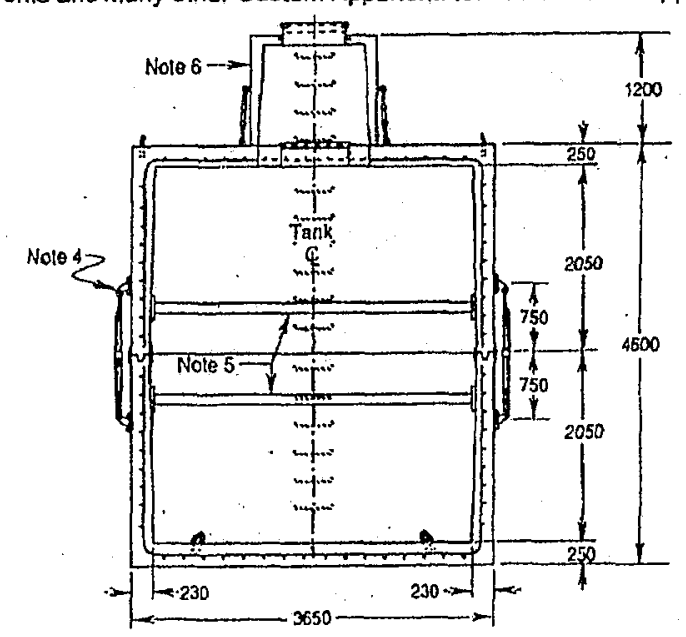

For recommended inslallation procedures reler to Wilknso For recommended inslallation procedures reler lo Whinson

Figure 3.2: Precast concrete tank drawing for the dimensioris design of the oil trap system. 


\subsection{Experimental Procedures}

The objective of the physical model study is to examine whether the oil trap system can trap the transformer oil spills during a rain storm. The physical model of the oil trap system is shown in Figure 3.4. Two smaller tanks, the inlet tank and the outlet tank, are installed before and after the oil trap system in order to create a steady flow entering into the system. In order to achieve this objective, two sets of experiments were conducted. The first set of the experiments is to determine the relationship between the volumes of transformer oil in the system and their failure siturions. The failure situation is defined as the flow rate that causes the formation of waves at the interface of transformer oil and water (Figure 3.3). Since before the transformer oil escapes from the oil trap system, waves should be formed between the interface of oil and water (Moir and Lau. 1975). The purpose of this set of experiments is to determine at what flow rate will transformer oil escape from the system.

The procedures for the first set of the experiment are discussed below. First, the pump used in the experiment must be calibrated before adding the transformer oil into the system. Appendix A shows the determination of the flow rate at each dial of the switch of the pump (Figure 3.5). The pump is located in the outlet tank (Figure 3.4). Once the outlet tank is filled up with water, flow rate of a typical dial at the pump's switch can be measured by dividing the volume of water entering into the inlet tank from the outlet tank through the plastic pipe over time.

Page 44 


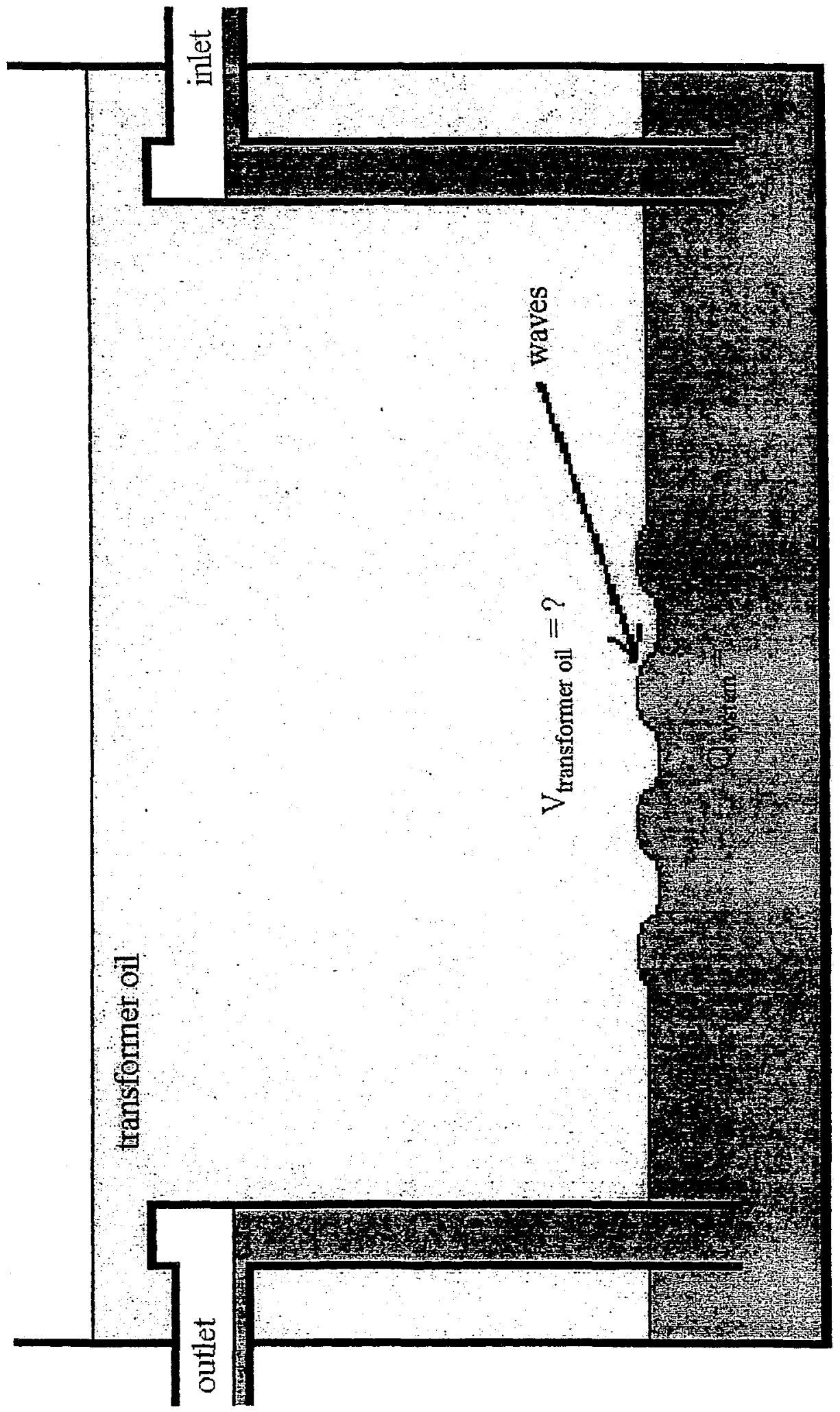

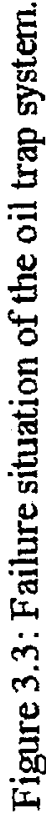

Page 45 


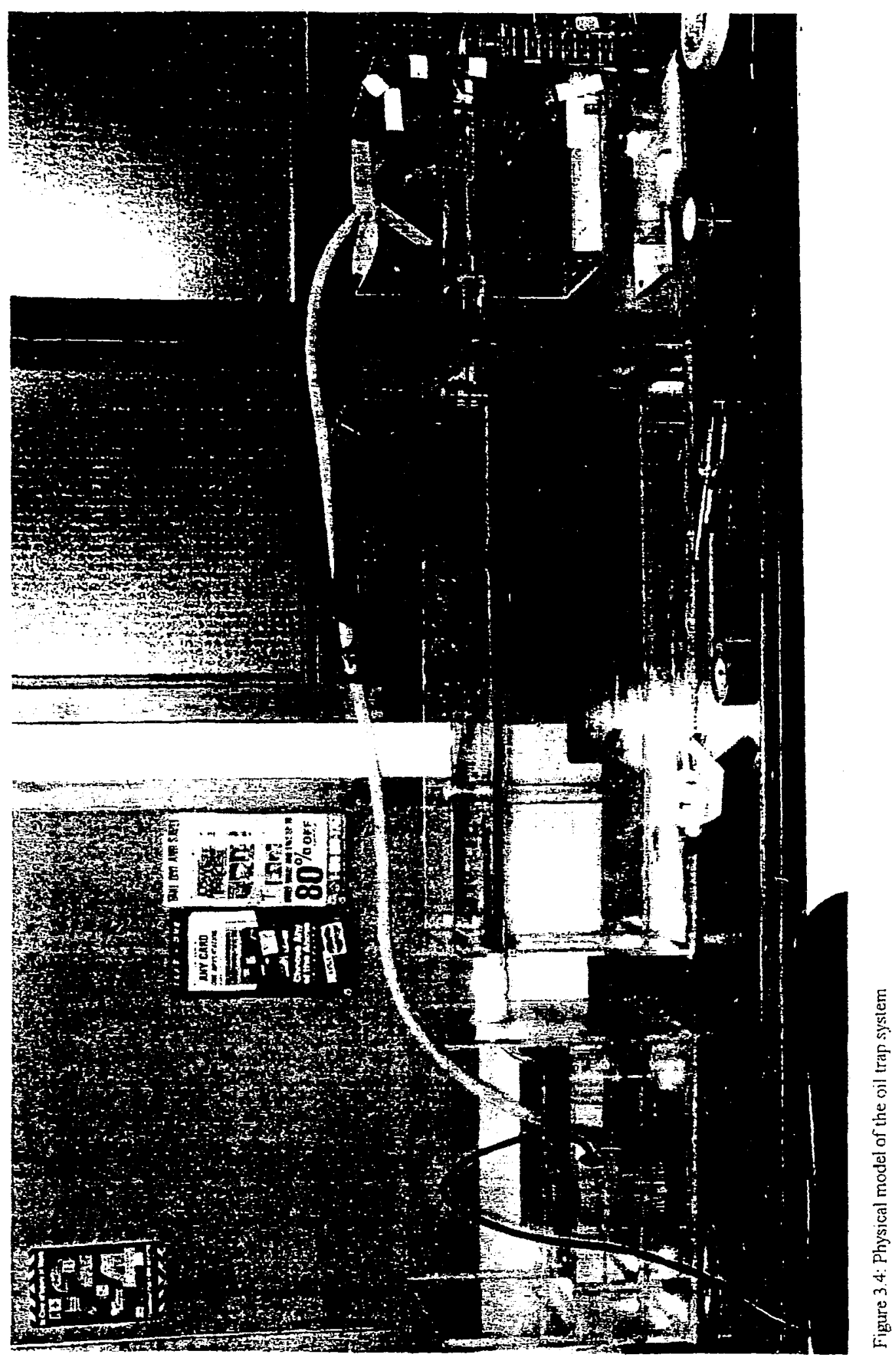

Page 46 


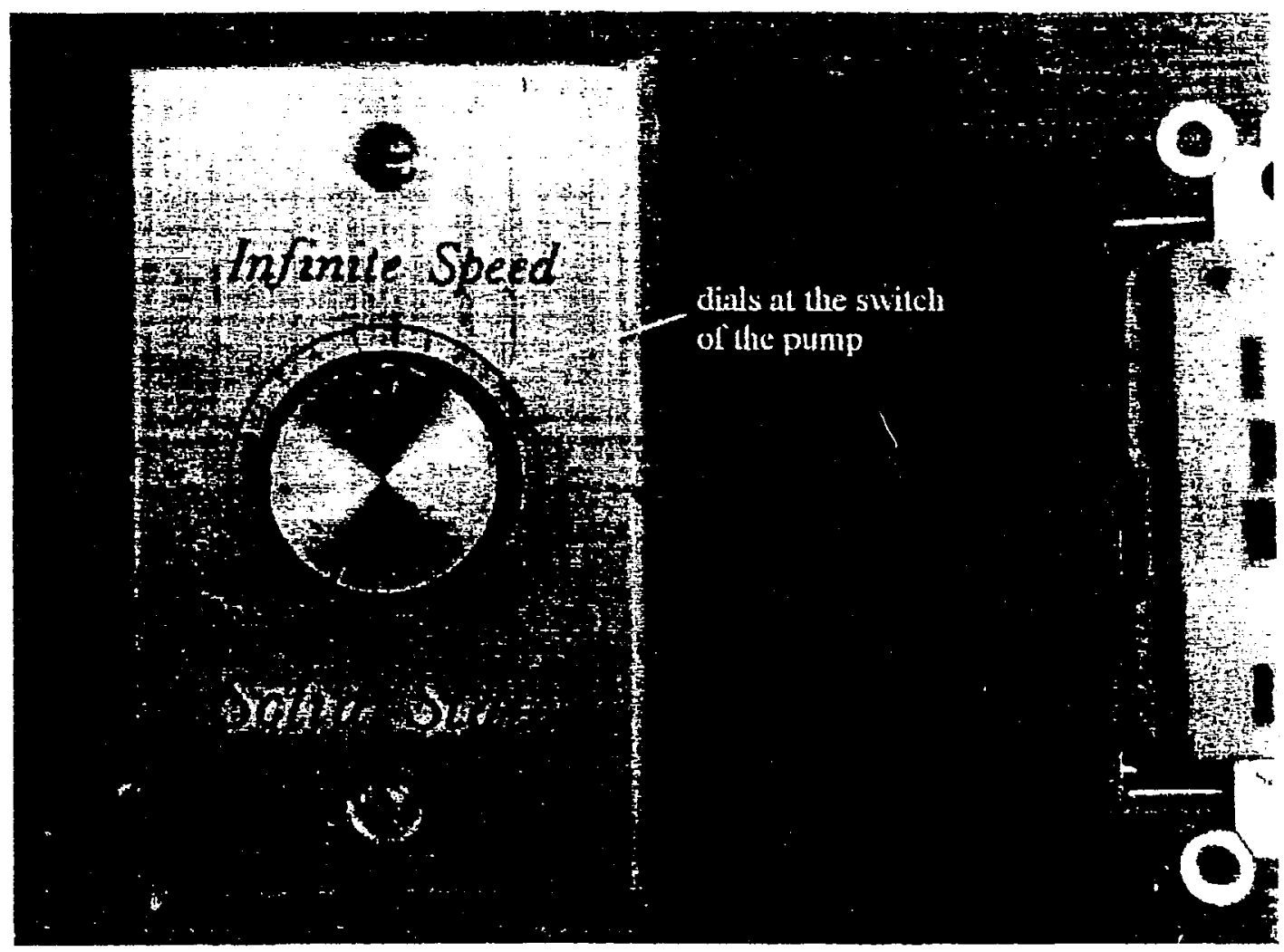

Figure 3.5: Switch of the pump used in the oil trap system experiment. 
After the calibration of the pump, the oil trap system is filled in with water (Figure 3.6). Then, transformer oil is added into the oil trap system slowly in order to avoid any escape of oil through the vertical pipes (Figure 3.7). Once the excessive water in the oil trap system has escaped through the vertical outlet pipe (Figure 3.7), pump will be turned on and switch of the pump will be adjusted until the system reaches two different situations: (1) the water level in the inlet tank is stable and (2) the maximum flow entering into the system. The first situation is the equilibrium state of the system. After observations are taken, more transformer oil will be added into the oil trap system and the above steps (Figure 3.7) are repeated until the amount of transformer oil in the system reaches its maximum capacity (Figure 3.8 ). 


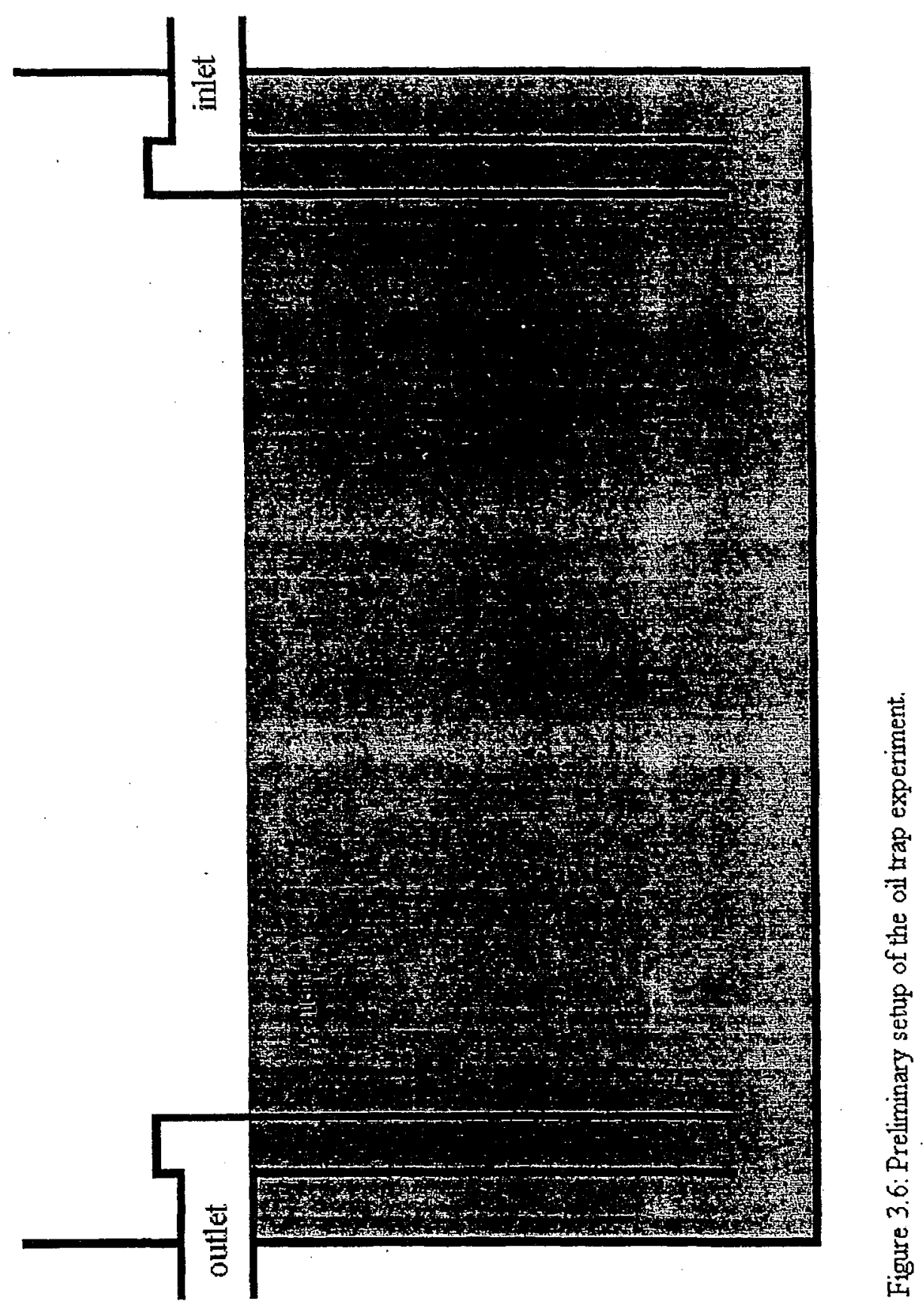

Page 49

Reproduced with permission of the copyright owner. Further reproduction prohibited without permission. 


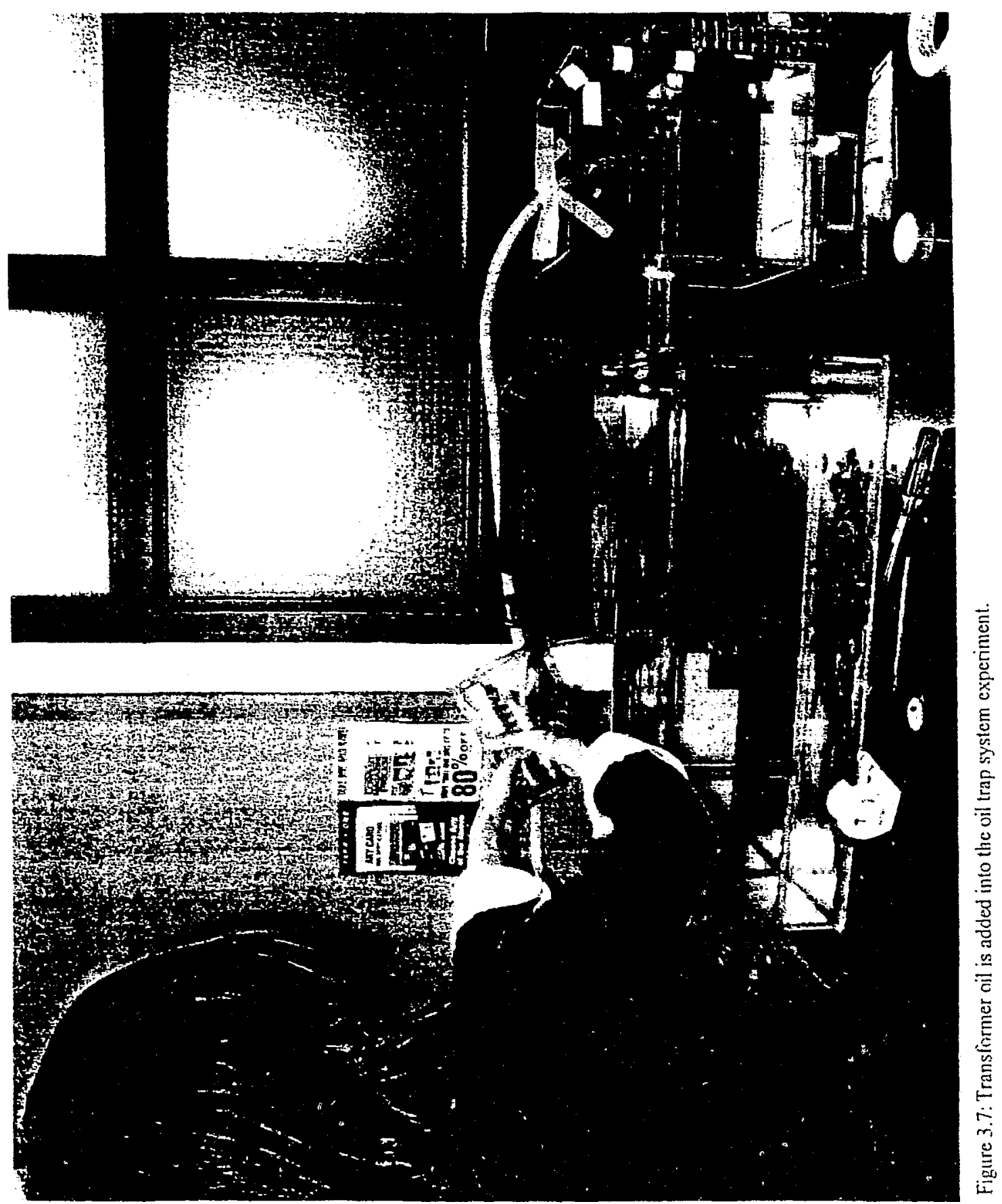

Page 50

Reproduced with permission of the copyright owner. Further reproduction prohibited without permission. 


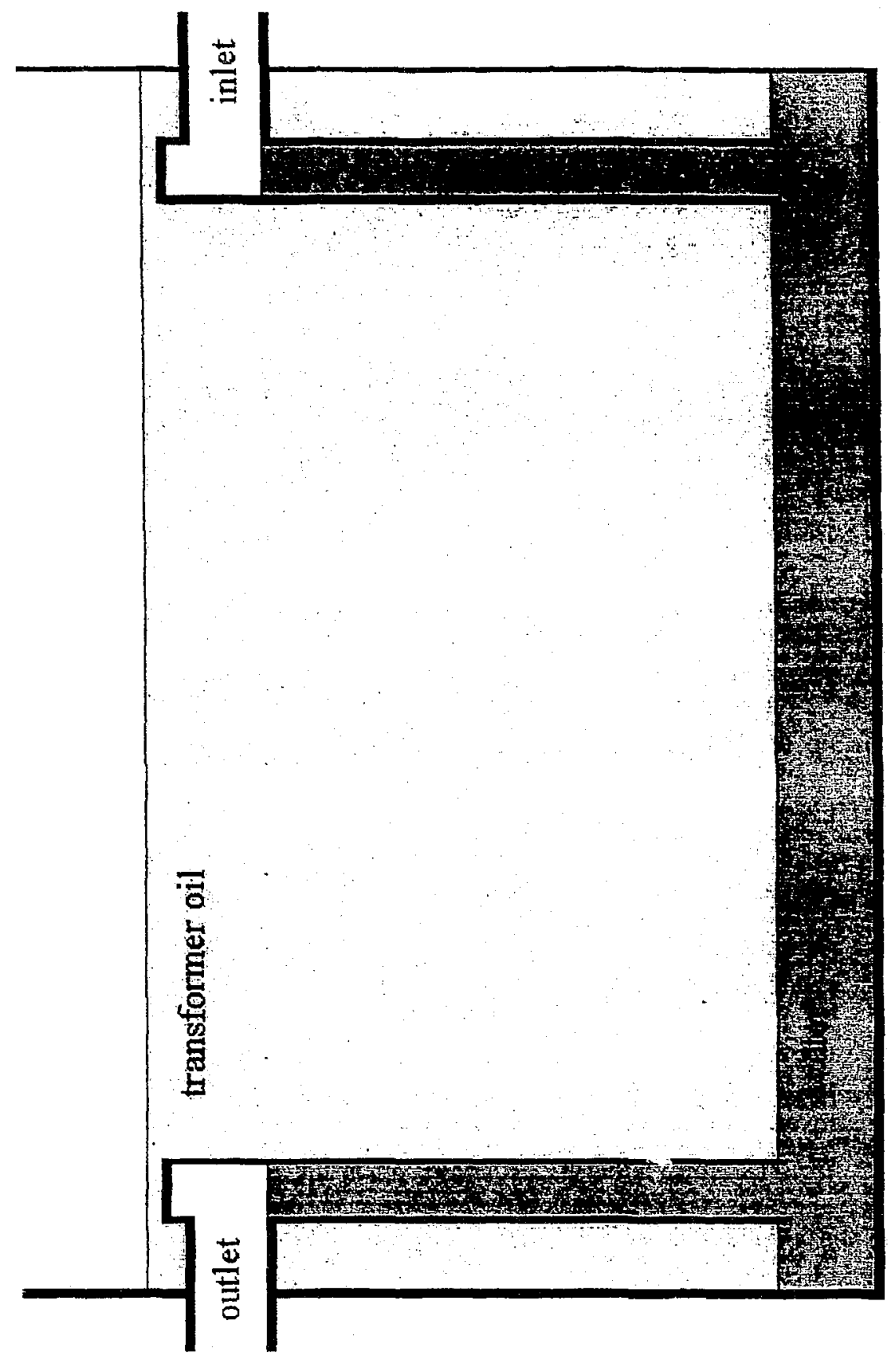

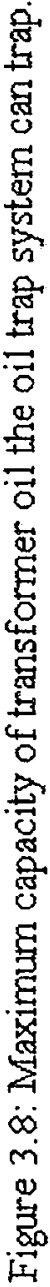

Page 51 
The second set of the experiment is to examine the oil-water separation process within the oil trap system. During a major oil spill, a sudden surge of transformer oil enters into the system. This is different from the inflow characteristics of a typical oil-water separator described in API design manual. Therefore, it is important to observe the oil-water separation process in the oil trap system by conducting a series of experiments. Four experiments are designed to examine the oil-water separation process: (1) small amount of transformer oil entering into the system without turn on the pump, (2) large amount of transformer oil entering into the system without turn on the pump, (3) small amount of transformer oil entering into the system with pump turns on and (4) large amount of transformer oil entering into the system with pump turns on.

It is important to recognize that the physical model was designed specifically for the first set of experiments where the main focus is on the instability of the interface between oil and water. Thus, the second set of experiments only provide some insight to the oil/water separation.

Preliminary setup (Figure 3.6) must be done before adding different amounts of transformer oil in the inlet tank. Transformer oil in the second set of the experiment is added into the inlet tank instead of the oil trap system because observation of oil-water separation process will be taken around the vertical inlet pipe area of the system. The first two experiments, without the operation of the pump, demonstrate the spilled transformer oil entering into the oil trap system without rain storms. The last two 
experiments show the transformer oil spills entering into the system during rain storms period.

\subsection{Observation and Evaluation of the Trapping Oil Experiments}

In the first set of experiments, no waves were formed at the interface of oil and water for the two situations even when the oil trap system reached its maximum trapping capacity (Figures 3.9 and 3.10). This indicates that the system will not fail even though the maximum flow rate has reached. The attached $\mathrm{CD}$ contains video clips of the experiment for the extremie case, the maximum trapping capacity and the maximum flow situation. The total volume of transformer oil for the maximum trapping capacity of the physical model is $36 \mathrm{~L}$ (Figures 3.9 and 3.10). This is equivalent to $84,580 \mathrm{~L}$ in the prototype since

$$
\begin{aligned}
V_{\text {prototype }} & =(36 \mathrm{~L})(12.3768)(12.2692)(15.4717) \\
& \approx 84580 \mathrm{~L}
\end{aligned}
$$

where the last three numbers are the dimension ratios between the model and the prototype (Table 3.2). 


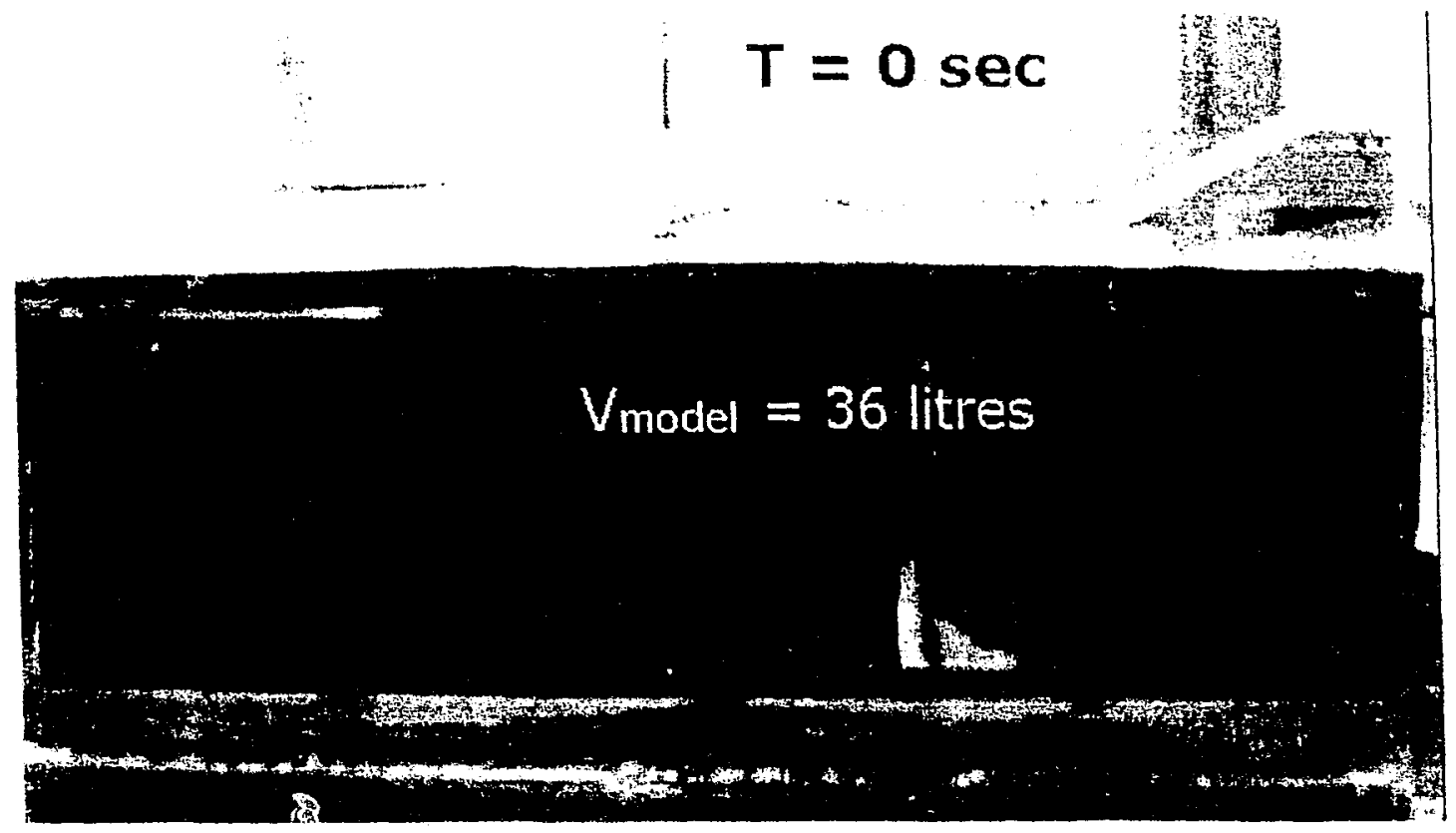

Figure 3.9: Experiment for the maximum flow situation and maximum trapping capacity at time $=0$ seconds.

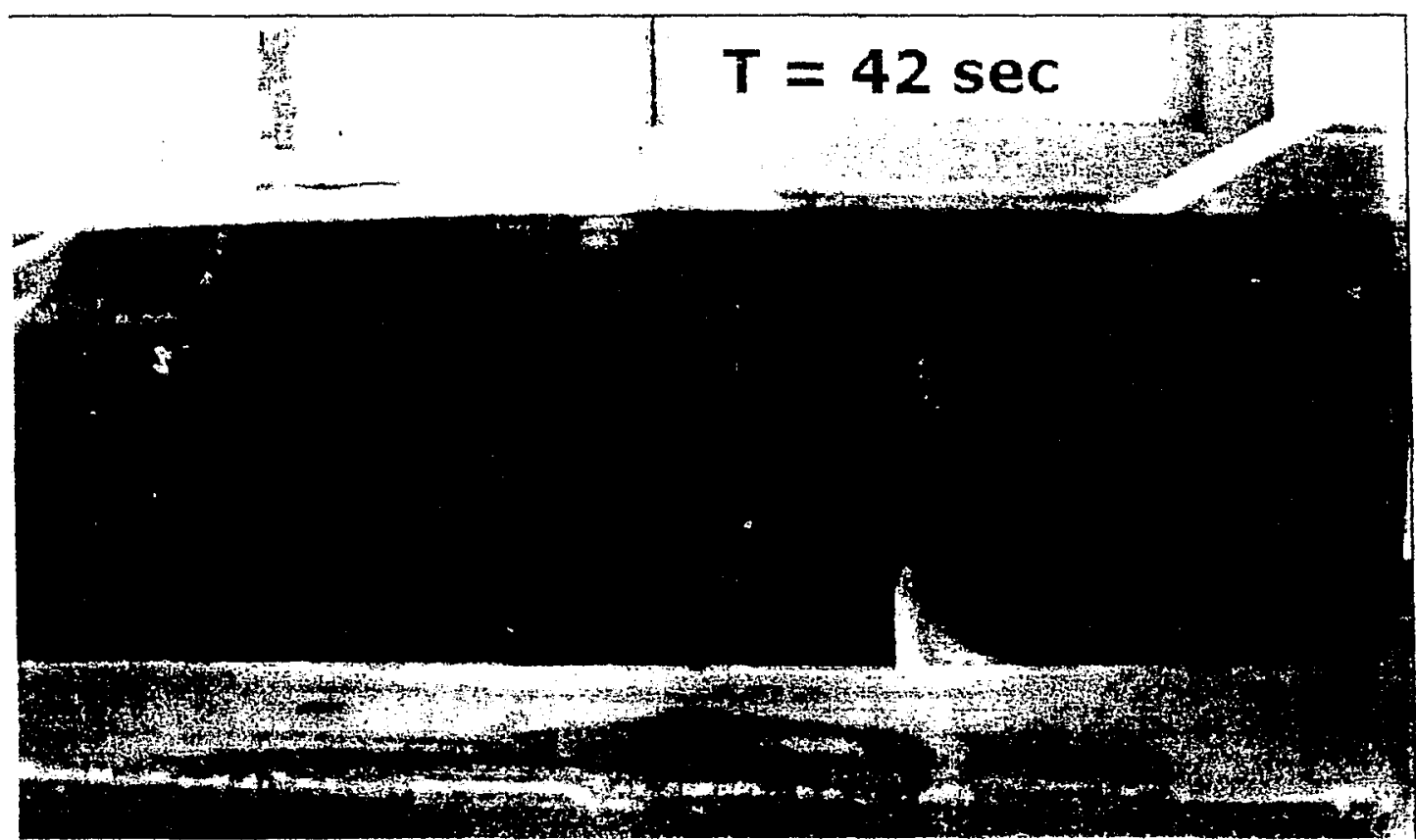

Figure 3.10: Experiment for the maximum flow situation and maximum trapping capacity at time $=42$ seconds. 
The total volume of transformer oil in Hydro One's transformer station near the city of Burlington is $256000 \mathrm{~L}$. Therefore, three oil trap systems will be needed to capture all the transformer oil. However, this extreme case rarely happens. There are six individual transformers (six concrete pads in Figure 1.3) at Hydro One's transformer station near the city of Burlington and is unusual to have all the transformers exploded at the same time.

The following calculation shows the conversion of the maximum flow rate entering into the physical model (Appendix F) to the flow rate in the prototype using the Froude number (Equation [19]) and the length dimensions between the model and the prototype (Table 3.2).

$$
\begin{aligned}
\left(\frac{L^{5} g \Delta}{Q^{2}}\right)_{\text {madel }} & =\left(\frac{L^{5} g \Delta}{Q^{2}}\right)_{\text {protadype }} \\
Q_{\text {protatype }} & =\sqrt{\frac{\left(L_{\text {protatype }}\right)^{3}\left(Q_{\text {model }}\right)^{2}}{\left(L_{\text {madel }}\right)^{5}}} \\
& =\sqrt{\frac{(8540 \mathrm{~mm})^{5}(0.17983 \mathrm{~L} / \mathrm{sec})^{2}}{(600 \mathrm{~mm})^{5}}} \\
& =90.9135 \mathrm{~L} / \mathrm{sec}
\end{aligned}
$$

where $g$ and $\Delta$ are the same for both model and prototype.

The calculation in Equation [25] is exactly the same as in Equation [24] except width dimensions (Table 3.2) is used. 


$$
\begin{aligned}
& \left(\frac{L^{5} g \Delta}{Q^{2}}\right)_{\text {model }}=\left(\frac{L^{5} g \Delta}{Q^{2}}\right)_{\text {procosype }} \\
& Q_{\text {pratape }}=\sqrt{\frac{\left(L_{\text {joctatype }}\right)^{5}\left(Q_{\text {model }}\right)^{2}}{\left(L_{\text {moded }}\right)^{5}}} \\
& =\sqrt{\frac{(3190 \mathrm{~mm})^{5}(0.17983 \mathrm{~L} / \mathrm{sec})^{2}}{(260 \mathrm{~mm})^{5}}} \\
& =94.8 . \mathrm{L} / \mathrm{sec}
\end{aligned}
$$

The flow rate of prototype in Equation [24] is used since it is the worst scenario. This flow rate is compared to the runoff rate of a 100 -year design storm in the city of Burlington. The calculation of the flow rate for a 100-year design storm using the rational method is shown below. First, the total area of Hydro One's transformer station near the city of Burlington (Figure 1.3) is determined as:

$$
\begin{aligned}
A= & (\text { base area of concrete pad })(\text { number of concrete pad at } \\
& \text { transformer station) } \\
= & {[0.5 *(2.2+2.28+4.45) * 3.4] * 6 } \\
= & 91.086 \mathrm{~m}^{2}
\end{aligned}
$$

Since transformer station was built above a concrete pad in order to avoid the grounding effect, the "paved area (sheet flow) and small upland gullies" line in Figure 3.11 was selected. Assuming the slope of the transformer station (the y-axis in Figure 3.11), is $2 \%$, the velocity using the Upland Method, $V_{\text {ypland }}$ is $2.8 \mathrm{ft} / \mathrm{sec}$ (red circle in Figure 3.11). Secondly, the hydraulic flow length, $L_{\text {flow, }}$ of the transformer station is calculated below (pink dotted line in Figure 1.3). 


$$
\begin{aligned}
L_{\text {flow }}= & \text { horizontal traveling distance }+ \text { vertical traveling distance } \\
& + \text { traveling distance at the transformer station } \\
= & (14.33+20.42)+(11+3.24)+\left[(2.2+2.28)^{2}+1.7^{2}\right]^{1 / 2} \\
= & 53.782 \mathrm{~m} \text { or } 176.45 \mathrm{ft}
\end{aligned}
$$

The time of concentration, $t_{c}$, can be determined using the Upland Method (Mays, 2001).

$$
\begin{aligned}
t_{c} & =L_{\text {flow }} /\left(3600 * V_{\text {upland }}\right) \\
& =176.45 /(3600 * 2.8) \\
& =0.01750 \mathrm{hr} \text { or } 1.050 \mathrm{~min}
\end{aligned}
$$

The rainfall intensity can be calculated from $i_{100}$ in Figure 3.12 where

$$
\begin{aligned}
i_{100} & =1114.20 /\left(t_{d}+5\right)^{-0.761} \\
& =1114.20 /(1.011+5)^{-0.761} \\
& =284.57 \mathrm{~mm} / \mathrm{hr} \text { or } 7.904722 \times 10^{-5} \mathrm{~m} / \mathrm{sec}
\end{aligned}
$$

where $t_{d}$ is equivalent to $t_{c}$.

By applying the Rational Method (Lewis and Viessman, 1996),

$$
\begin{aligned}
Q & =C i \mathrm{~A} \\
& =(1.0)\left(7.904722 \times 10^{-5} \mathrm{~m} / \mathrm{sec}\right)\left(91.086 \mathrm{~m}^{2}\right) \\
& =7.2 \times 10^{-3} \mathrm{~m}^{3} / \mathrm{sec} \text { or } 7.2 \mathrm{~L} / \mathrm{sec}
\end{aligned}
$$

where $C$ is the runoff coefficient in dimensionless form. $i$ is equivalent to $i_{100}$ (Equation [29]). $A$ is the total area of the transformer station (Equation [26]). 


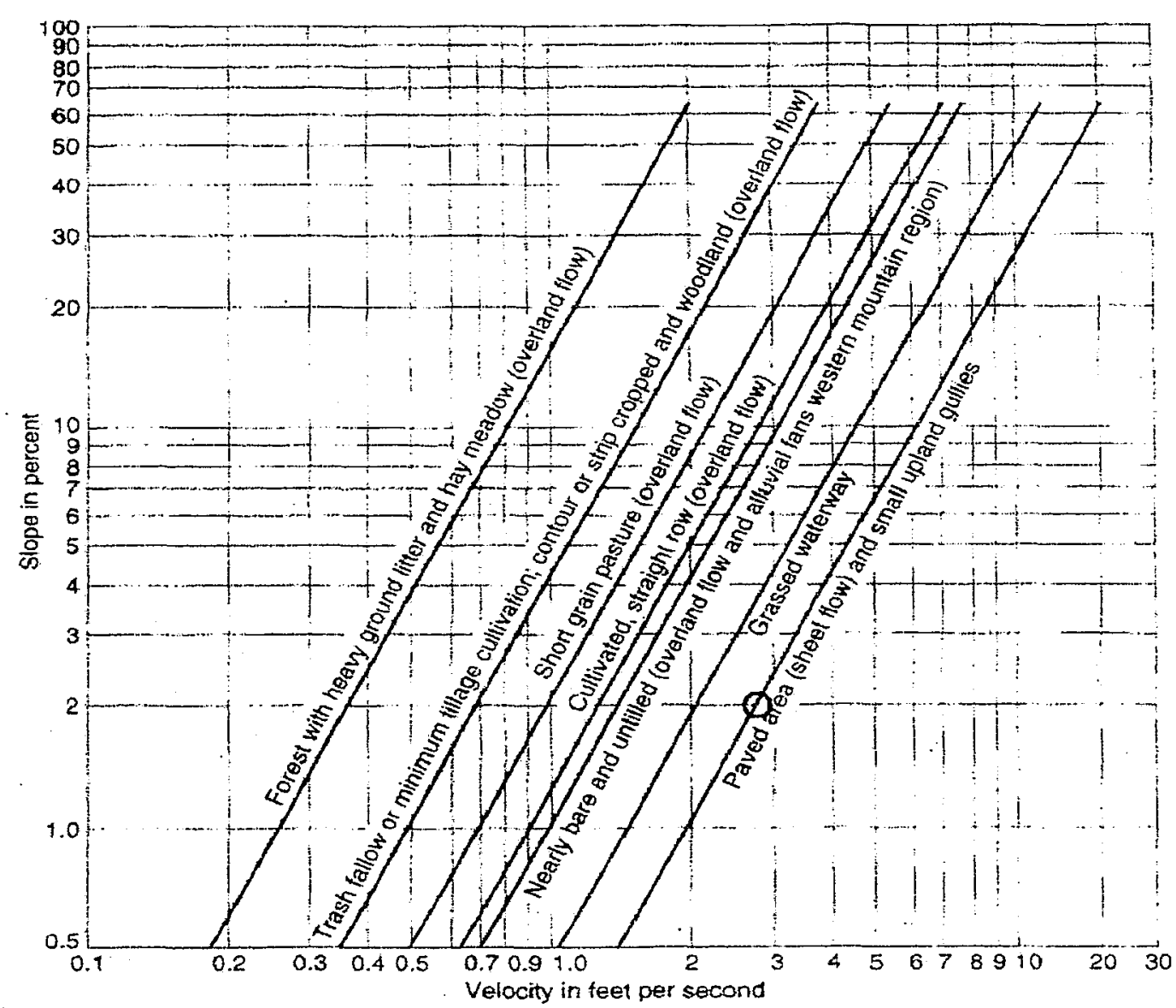

Figure 3.11: Velocities for velocity upland method of estimating $t_{c}$ (U.S. Department of Agriculture Soil Conservation Service, 1986).

Page 58 


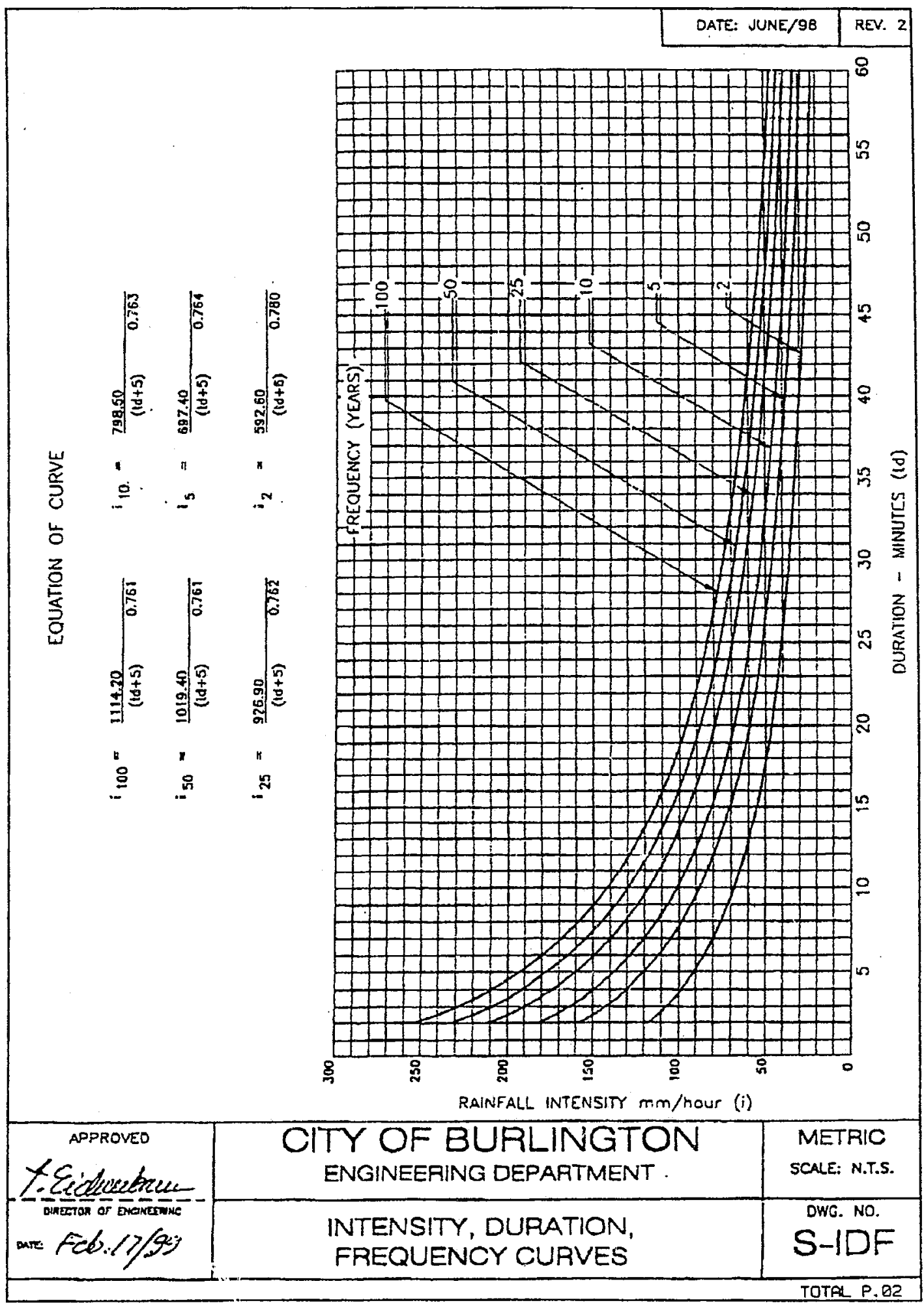

Figure 3.12: IDF curve for the city of Burlington.

Page 59 
The maximum prototype flow (Equation [25]) are much larger than the flow rate for a 100-year design storm (Equation [30]). Since there is no interfacial waves observed in the experiment, the oil trap system should trap the spilled transformer oil successfully for a typical 100-year design storm. However, there are two uncertainties in this experiment. First, the oil layer was pushed up by the water flow rate entering into the system during the experiments of the maximum flow situation (Figure 3.10). This is caused by: (1) the hydraulic grade line difference between the inlet tank and the oil trap system and (2) the design of the physical model as an open system, with opening on the top surface of the oil trap system, instead of a pressurized system. The chance of forming waves at the interface may be increased if a fixed upper bouindary is set up for the oil layer and the oil layer moves upward. Secondly, this experiment has not applied the whole theory of dimensionless analysis. As mentioned in Section 3.2, the $\Pi$-terms in this experiment have not be verified yet. Other $\Pi$-terms may also dominate this experiment. 


\subsection{Observation and Evalution of Oil-Water Separation Experiments}

The following discussion. are based on the four experiments of the oil-water separation.

The video clips of the four experiments can be found in the attached CD.

\section{- First experiment}

When small amount $(500 \mathrm{~mL})$ of transformer oil entered into the system slowly without pump operation (Figure 3.13), small oil globules were formed and rose up along the vertical inlet pipe region due to the density difference between oil and water. The diameters of the oil globules are around 5 to $8 \mathrm{~mm}$ by visual observation and the density of the transformer oil equals to $0.86 \mathrm{~kg} / \mathrm{L}$ (Section 4.3). Oil globules traveled upward around the vertical inlet pipe region because there was no water flow which might force the oil globules to travel horizontally along the oil trap system. Thus, transformer oil did not escape from the system in this experiment. 


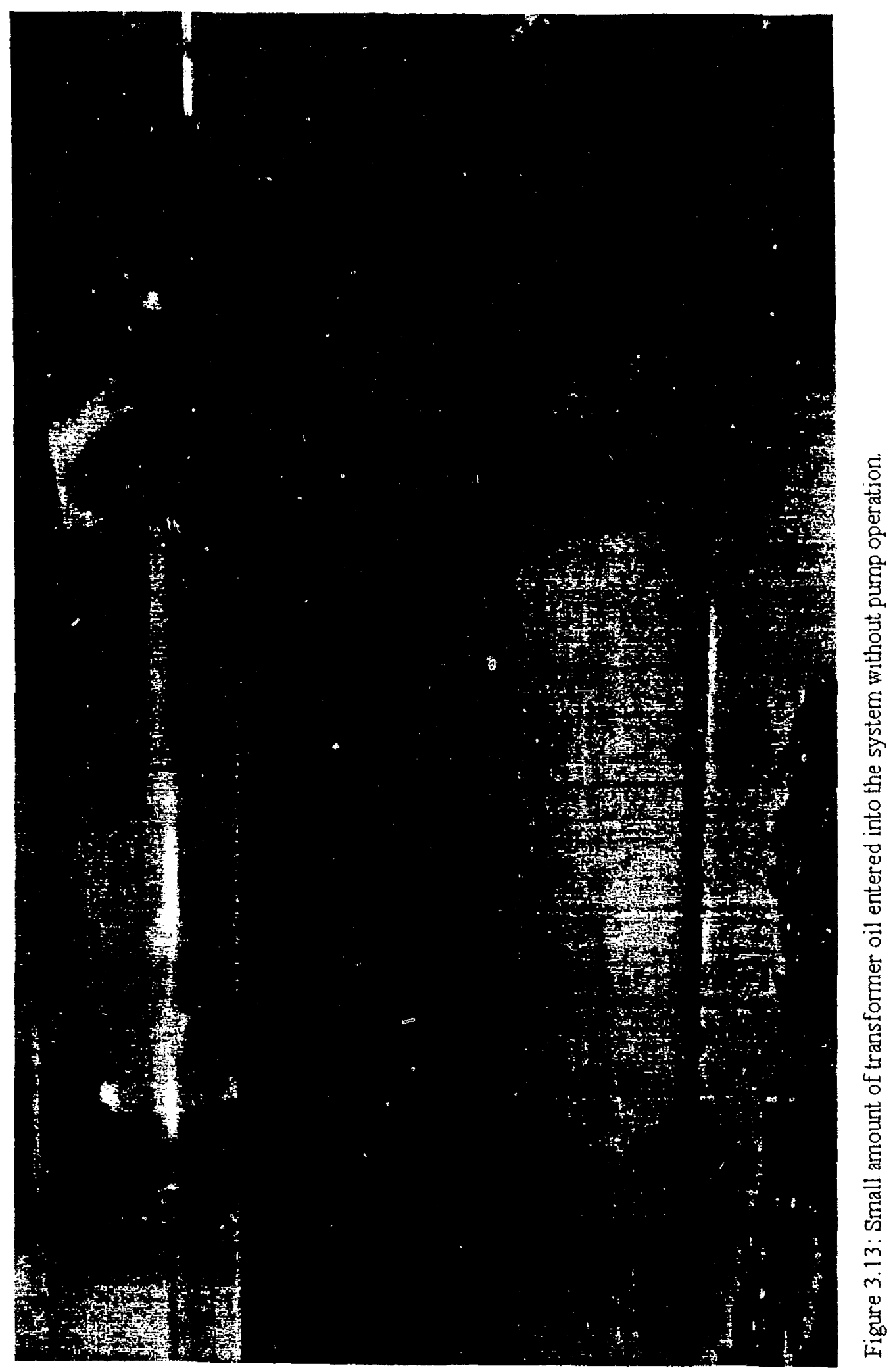

Page 62 


\section{- Second experiment}

When large amount $(15 \mathrm{~L})$ of transformer oil entered into the system rapidly without pump operation (Figures 3.14 and 3.15), the experimental results are exactly the same as the first experiment except the oil globules were much larger in size. Most of the oil globules were in irregular elliptical shape and traveled closely along the surface of the vertical inlet pipe. The average maximum diameters of these irregular elliptical shapes are around $15 \mathrm{~mm}$. The formation of large oil globules in this experiment is due to large amount of transformer oil entering into the oil trap system through the vertical inlet pipe and the coalescence of small oil globules. Since the oil globules are larger in size in this experiment, they rose faster and traveled closer to the vertical inlet pipe. Therefore, the transformer oil in this experiment did not escape from the system. 


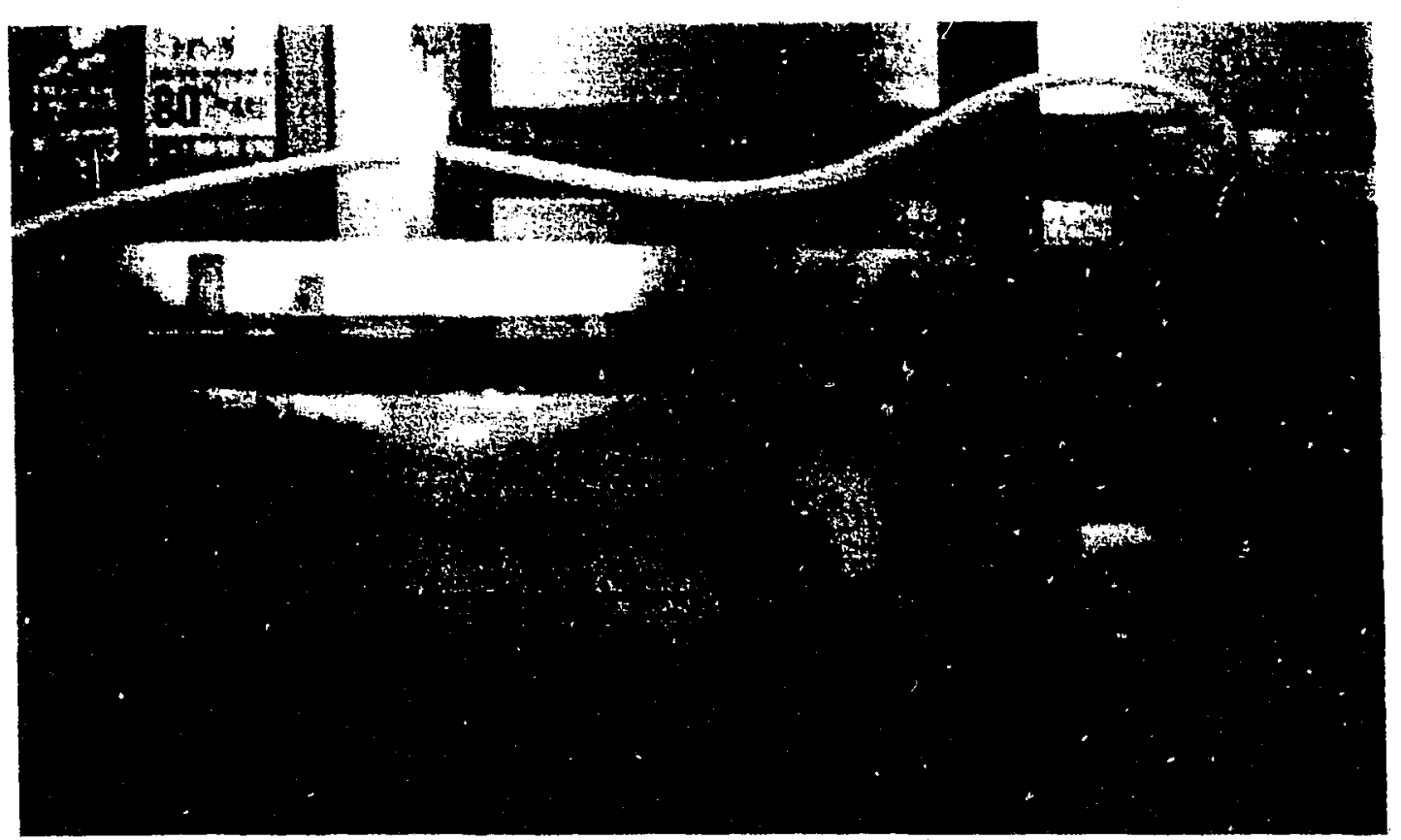

Figure 3.14: Large amount of transformer oil entered into the system without pump operation.

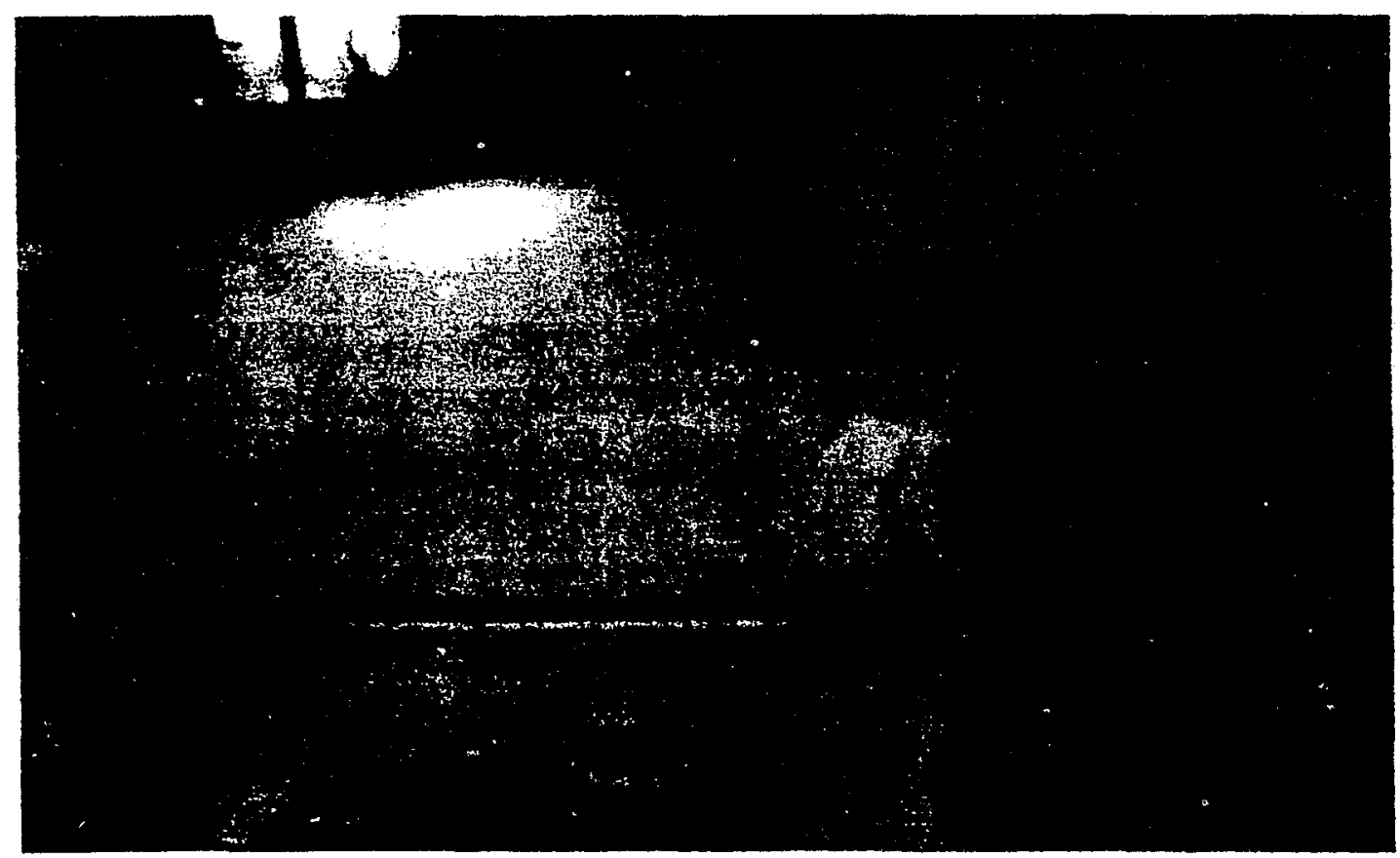

Figure 3.15: A closeup for the large amount of transformer oil entered into the system without pump operation. 


\section{- Third experiment}

When small amount $(500 \mathrm{~mL})$ of transformer oil entered into the system slowly with pump operation (Figures 3.16 and 3.17), oil globules were much smaller in size compared to those in the first two experiments. Most of the oil globules were around 1 $\mathrm{mm}$ in diameter by visual observation. The oil globules spread out to about one-third of the oil trap system length before they rose up. Thus, the transformer oil still did not escape from the system.

\section{- Fourth experiment}

When large amount $(15 \mathrm{~L})$ of transformer oil entered into the system rapidly with pump operation, the shapes of the oil globules were similar to the second experiment. Their sizes were around $10 \mathrm{~mm}$ and were smaller than those in the second experiment. The oil globules traveled along the outside of the inlet pipe instead of the surface of the inlet pipe in the second experimental results. This observation may be caused by the water inflow to the oil trap system which forced the oil globules to move further away from the inlet pipe. Since the oil globules were larger sizes in this experiment, they could not travel as far as the oil globules in the third experiment. Thus, the transformer oil still did not escape from the system. 


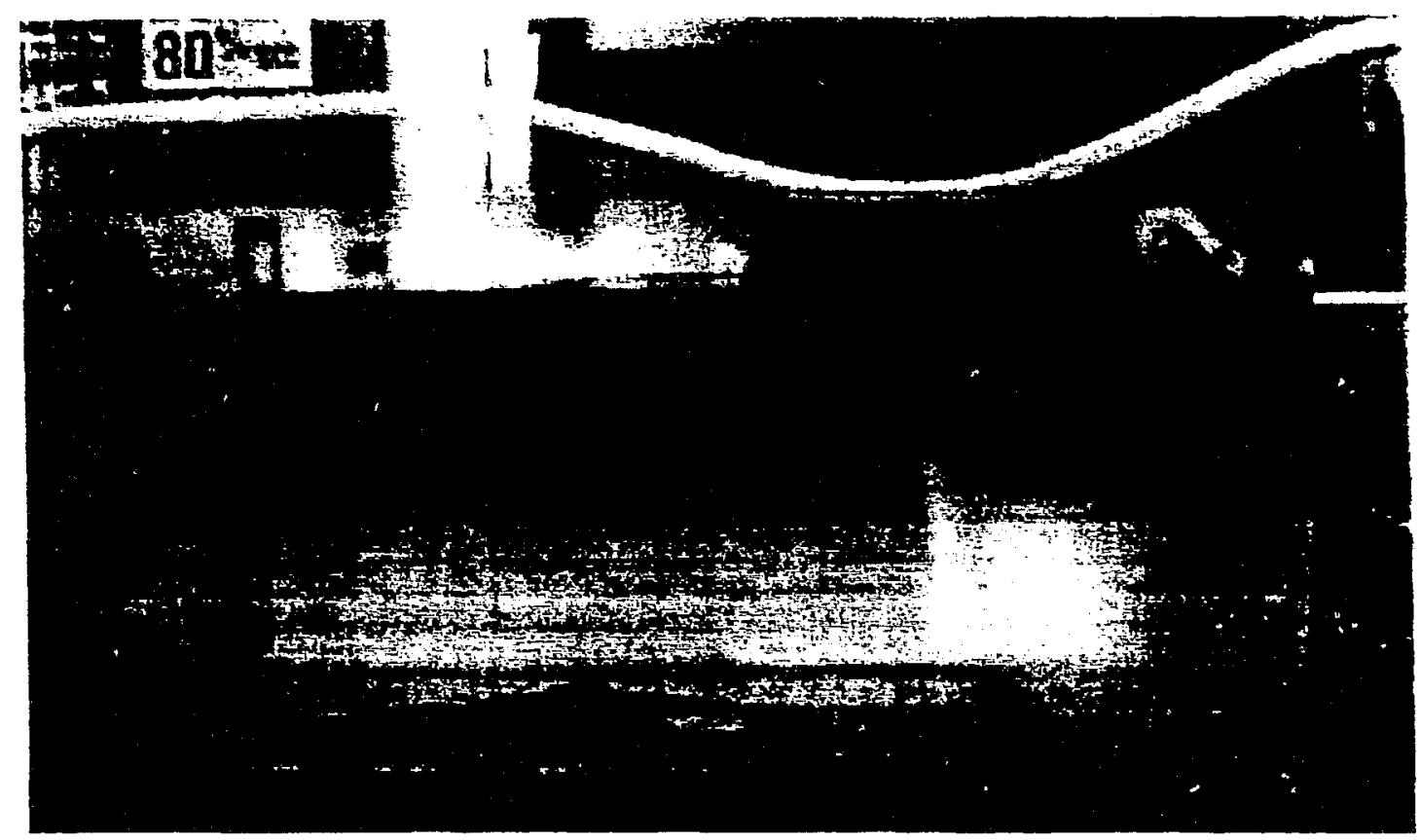

Figure 3.16: Small amount of transformer oil entered into the system with pump operation.

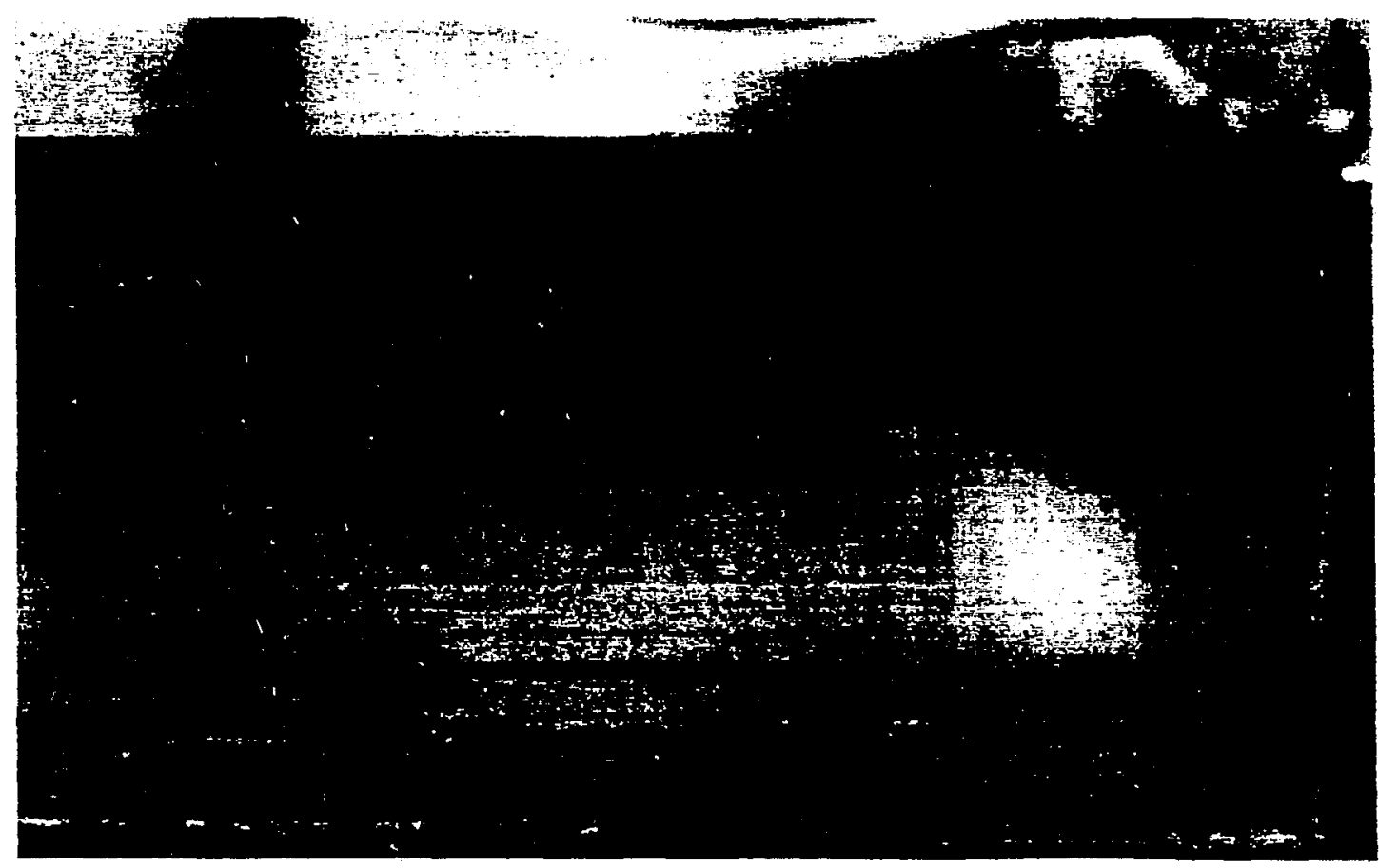

Figure 3.17: A closeup for the small amount of transformer oil entered into the system with pump operation. 


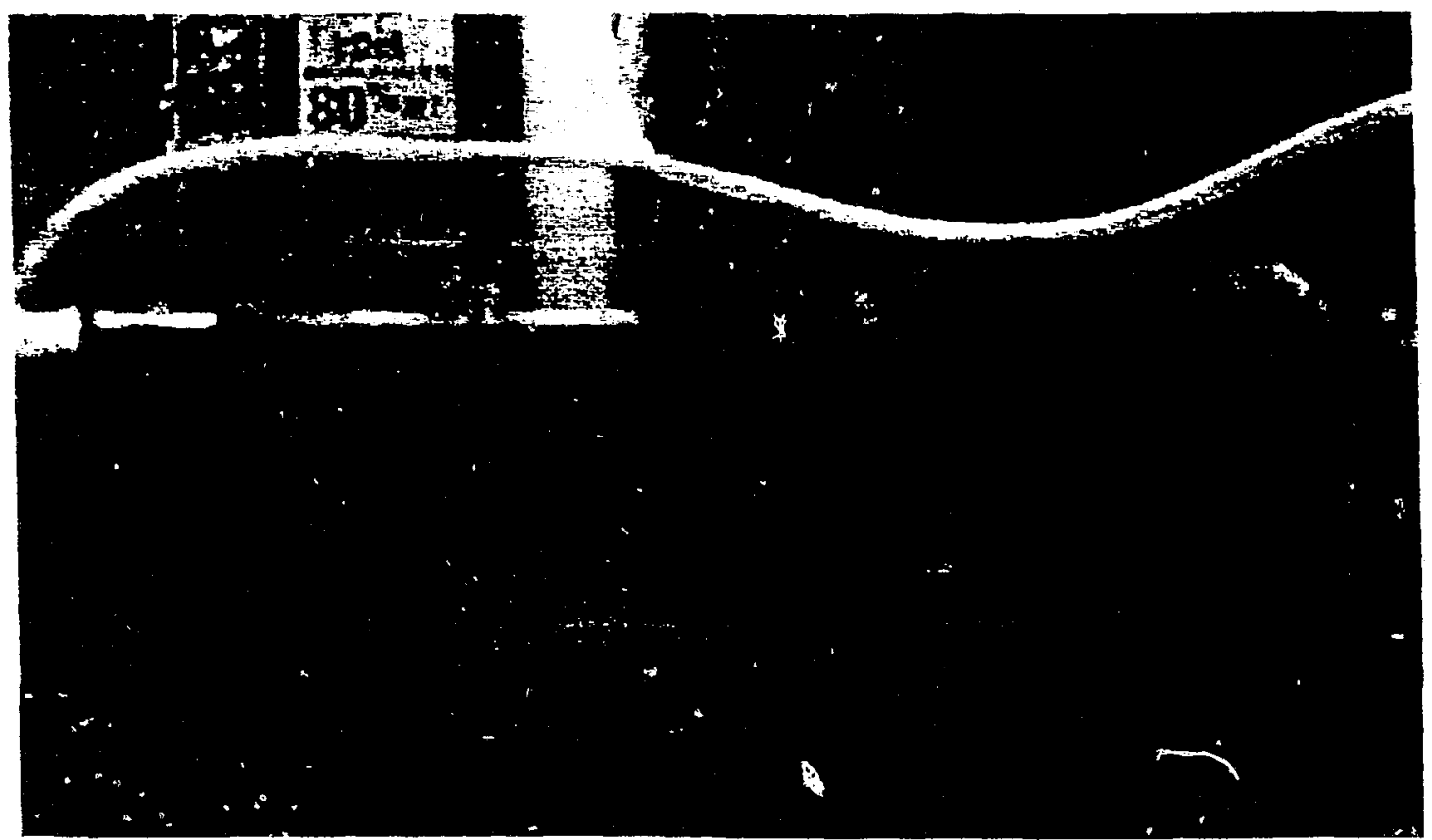

Figure 3.18: Large amount of transformer oil Entered into the system with pump operation.

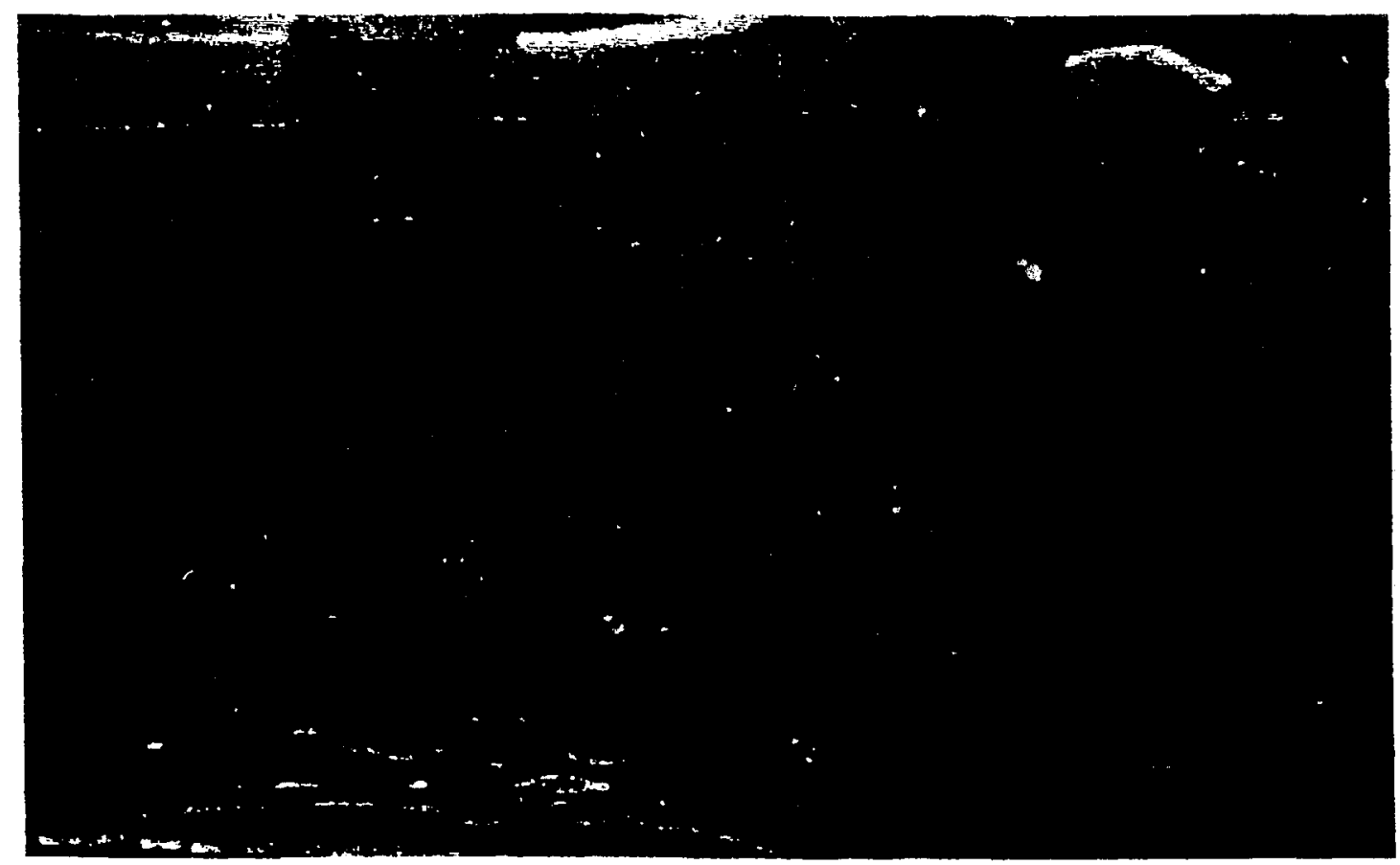

Figure 3.19: Close shot for the large amount of transformer oil entered into the system with pump operation.

Page 67 


\section{Chapter 4 NUMERICAL EXPERIMENTS ON THE OIL BACK-UP SYSTEM}

An oil back-up system could be installed underneath each concrete pad of Hydro One's transformer station in Burlington (Figure 1.3). The first section of this chapter reviews the mass balance concept of oil and water used in the development of a mathematical model using the MATLAB 6.1 program. The subsequent sections present the development of the mathematical model, the determination of the input information, the MATLAB programs and the numerical analysis and results. The purpose of the mathematical model is to determine the heights of the oil and water layers over certain period of time (Figures 4.2 and 4.3). The parameters and variables involved in the oil back-up system model are shown in Tables 4.1 and 4.2 . Figures 4.1 and 4.3 demonstrate the definition of the parameters and variables.

\subsection{The Mass Balance Concepts of Transformer Oil and Water for the Oil Back-up System}

The mass balance concept is applied in two parts, the catchbasin and the oil back-up system, for analyzing the hydraulic conditions during a transformer oil spill. 
Table 4.1: Parameters involved in the oil back-up system.

\begin{tabular}{|c|c|c|}
\hline Parameters & $\begin{array}{l}\text { Corresponding } \\
\text { Parameters Used } \\
\text { in MATLAB }\end{array}$ & Definition of Parameters \\
\hline$A_{h p l}$ & area hp1 & $\begin{array}{l}\text { cross-sectional area of horizontal pipe } h p l \\
\text { between the catchbasin and the oil } \\
\text { back-up system in } m^{2}\end{array}$ \\
\hline$D_{h p l}$ & diameter_hp1 & $\begin{array}{l}\text { diameter of horizontal pipe } h p l \text { between } \\
\text { the catchbasin and the oil back-up system } \\
\text { in metre }\end{array}$ \\
\hline$A_{h p 2}$ & area_hp2 & $\begin{array}{l}\text { cross-sectional area of horizontal pipe } h p 2 \\
\text { inside the oil back-up system in } m^{2}\end{array}$ \\
\hline$D_{h p 2}$ & diameter_hp2 & $\begin{array}{l}\text { diameter of horizontal pipe } h p 2 \text { inside the } \\
\text { oil back-up system in metre }\end{array}$ \\
\hline$L_{h p 2}$ & length_hp2 & $\begin{array}{l}\text { length of horizontal pipe } h p 2 \text { inside the oil } \\
\text { back-up system in metre }\end{array}$ \\
\hline$A_{\text {int }}$ & area_internal_pipe & $\begin{array}{l}\text { cross-sectional area of internal pipe } \\
\text { column in } \mathrm{m}^{2}\end{array}$ \\
\hline$D_{\text {int }}$ & diameter_internal_pipe & diameter of internal pipe column in metre \\
\hline$A_{\text {ext }}$ & area_external_pipe & $\begin{array}{l}\text { cross-sectional area of external pipe } \\
\text { column in } m^{2}\end{array}$ \\
\hline$D_{e x t}$ & diameter_external_pipe & diameter of external pipe column in metre \\
\hline$A_{\text {catchbasin }}$ & area_catchbasin & base area of the catchbasin in $m^{2}$ \\
\hline$A_{\text {system }}$ & area_system & base area of the oil back-up system in $m^{2}$ \\
\hline$h_{\text {column }}$ & h_column & $\begin{array}{l}\text { height between datum and the bottom of } \\
\text { the oil back-up system in metre }\end{array}$ \\
\hline$h$ & h & $\begin{array}{l}\text { height between the bottom of horizontal } \\
\text { pipe inside the oil back-up system and the } \\
\text { bottom of the oil back-up system in metre }\end{array}$ \\
\hline
\end{tabular}


Table 4.1: Parameters involved in the oil back-up system (cont.).

\begin{tabular}{|c|c|c|}
\hline Parameters & $\begin{array}{l}\text { Corresponding } \\
\text { Parameters Used } \\
\text { in MATLAB }\end{array}$ & Definition of Parameters \\
\hline$g$ & gravity & gravitational acceleration, $9.806 \mathrm{~m} / \mathrm{sec}^{2}$ \\
\hline$c$ & c & $\begin{array}{l}\text { roughness coefficient of the construction } \\
\text { material used for the oil back-up system, } \\
c_{\text {concrete }}=0.6\end{array}$ \\
\hline$\Delta t$ & delta_time & $\begin{array}{l}\text { time step used for determination of the } \\
\text { variables in the mathematical model in } \\
\text { seconds }\end{array}$ \\
\hline$\rho_{\text {oil }}$ & density_oil & density of transformer oil. in $\mathrm{kg} / \mathrm{m}^{3}$ \\
\hline$\rho_{\text {water }}$ & density_water & density of water in $\mathrm{kg} / \mathrm{m}^{3}$ \\
\hline$Q_{\text {in }}$ & inflow & $\begin{array}{l}\text { inflow rate of transformer oil to the oil } \\
\text { back-up system from the concrete pad of } \\
\text { the transformer station in } \mathrm{m}^{3} / \mathrm{sec}\end{array}$ \\
\hline$A_{p a d}$ & area_concrete_pad & area of concrete area in $m^{2}$ \\
\hline
\end{tabular}


Table 4.2: Variables involved in the oil back-up system.*

\begin{tabular}{ll} 
Variables & \multicolumn{1}{c}{ Definition of Variables } \\
\hline$H ![n]$ & $\begin{array}{l}\text { height between the datum and the surface of fluid at the } \\
\text { catchbasin at the beginning of a time step }\end{array}$ \\
$H 1[n+1]$ & $\begin{array}{l}\text { height between the datum and the surface of fluid at the } \\
\text { catchbasin at the end of a time step }\end{array}$ \\
$H 2[n]$ & $\begin{array}{l}\text { height of the oil layer in the oil back-up system at the beginning } \\
\text { of a time step }\end{array}$ \\
$H 2[n+1]$ & $\begin{array}{l}\text { height of the oil layer in the oil back-up system at the end of a } \\
\text { time step }\end{array}$ \\
$H 3[n]$ & $\begin{array}{l}\text { height of water layer between the datum and the interface of oil } \\
\text { and water in the oil back-up system at the beginning of a time } \\
\text { step }\end{array}$ \\
$H 3[n+1]$ & $\begin{array}{l}\text { height of water layer between the datum and the interface of oil } \\
\text { and water in the oil back-up system at the end of a time step }\end{array}$ \\
$H 4[n]$ & $\begin{array}{l}\text { height of water in the internal pipe column at the beginning of a } \\
\text { time step }\end{array}$
\end{tabular}

* The units of all the variables in Tables 4.2 are in metres. 


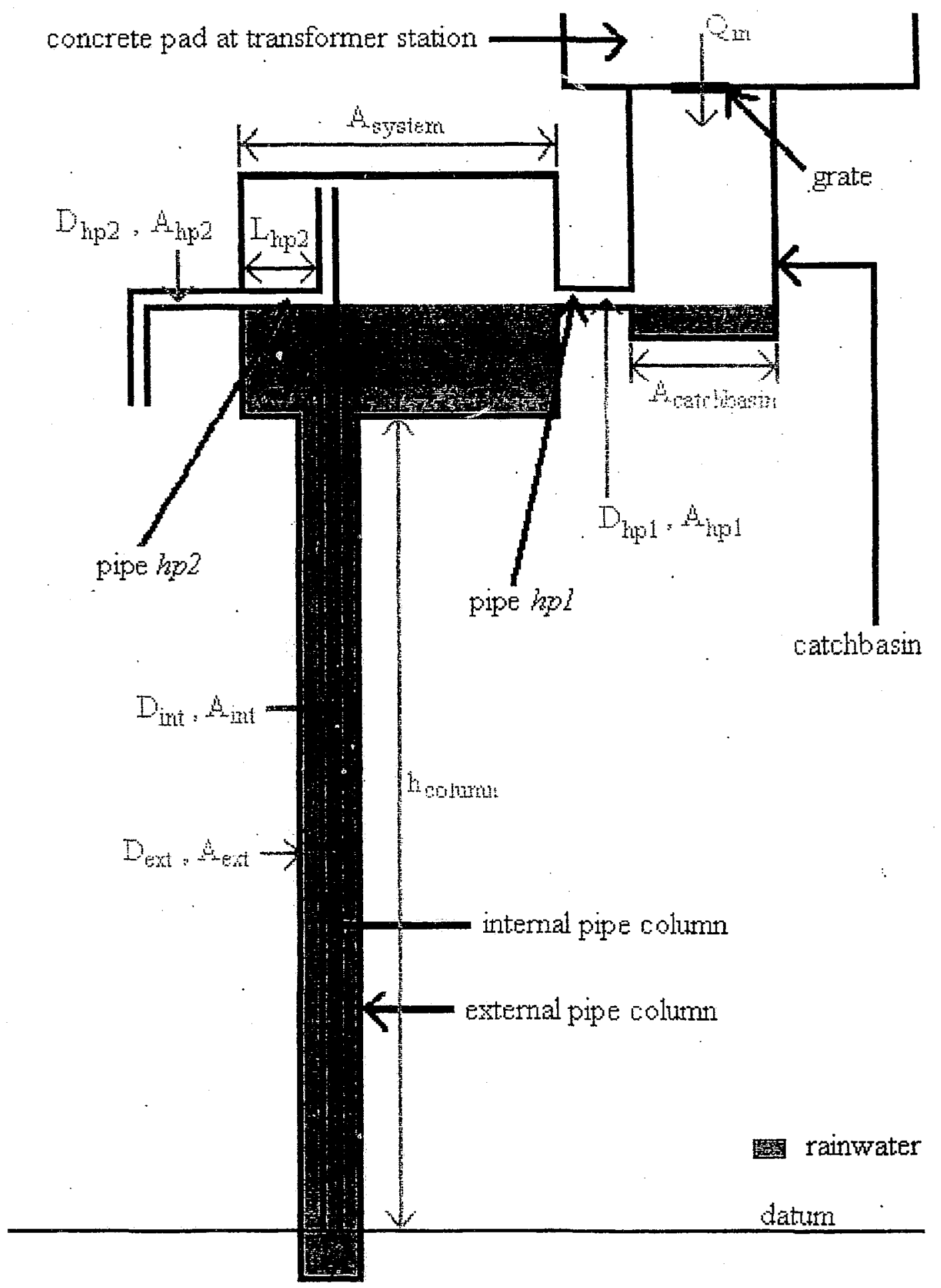

Figure 4.1: Definition of parameters in the oil back-up system.

Page 72 


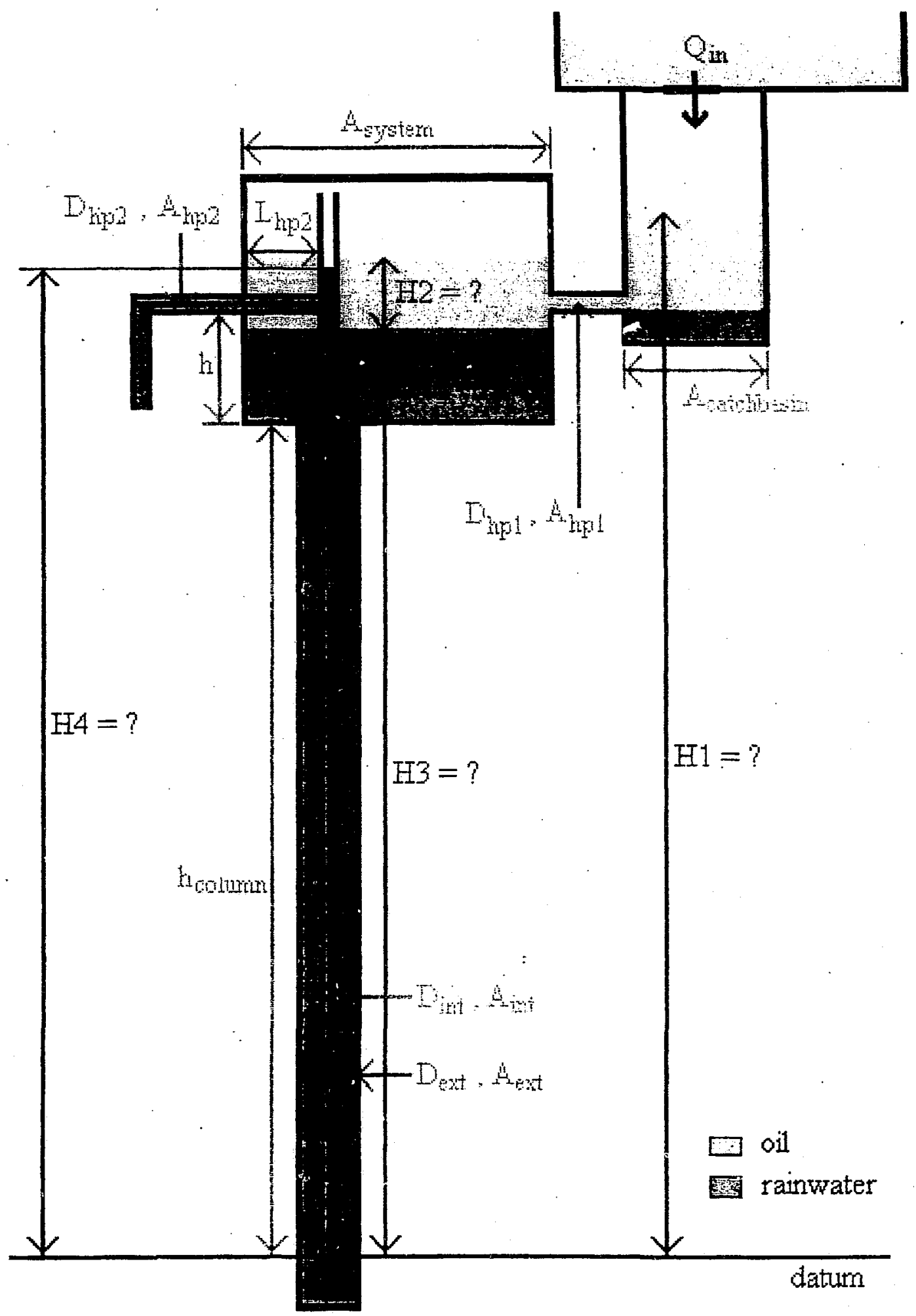

Figure 4.2: Case 1 ( $\left.h_{\text {column }} \leq H 3[n]\right)$ of the oil back-up system.

Page 73 


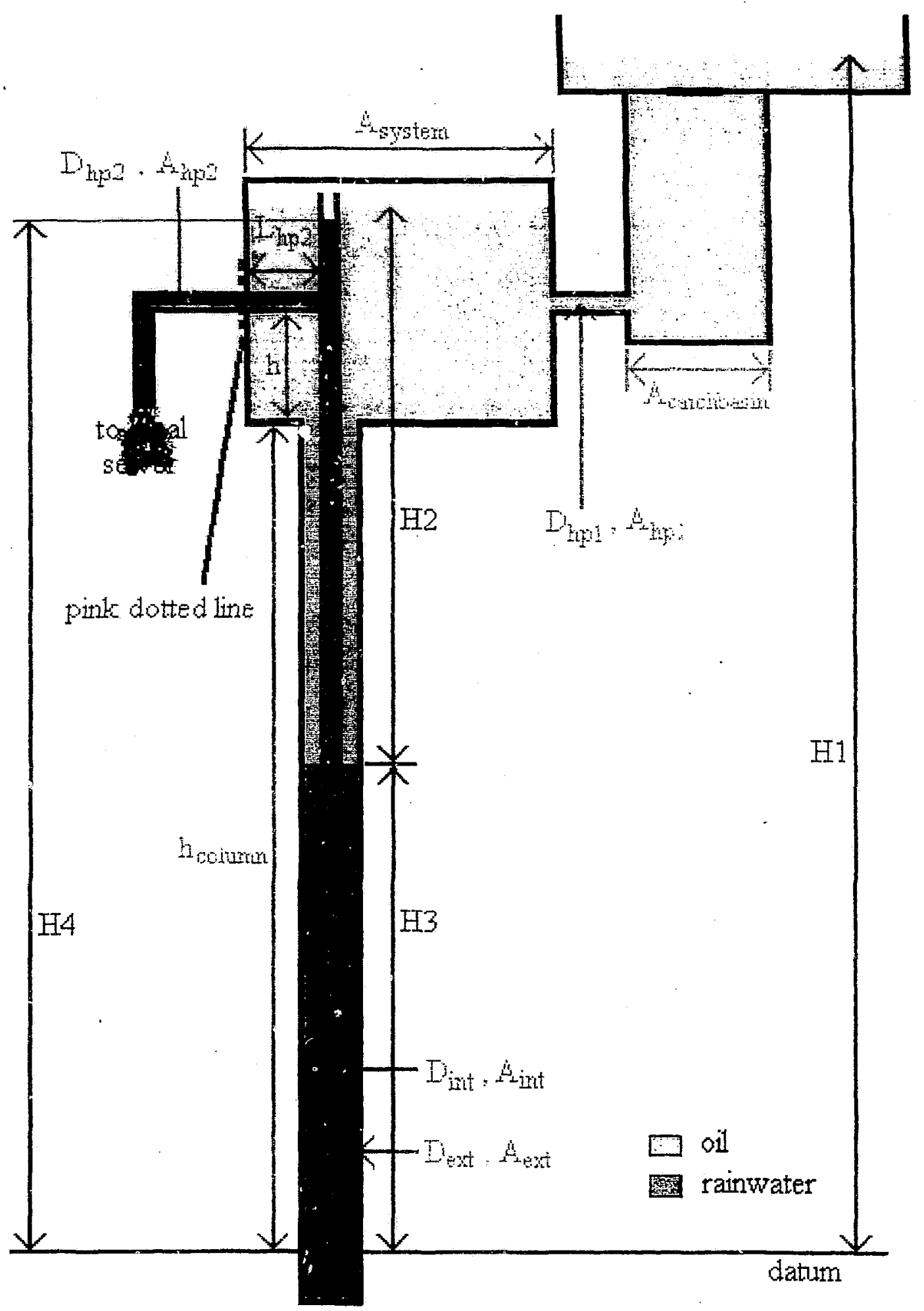

Figure 4.3: Case $2\left(h_{\text {column }}>H 3[n]\right)$ of the Oil Back-up System.

Page 74 
The initial condition of the oil back-up system is shown in Figure 4.1, where the system contains only rainwater. Also, horizontal pipes $h p 1$ and $h p 2$ are at the same elevation. Generally, the spilled transformer oil will first enter into the catchbasin from the concrete pad (variable $Q_{\text {in }}$ in Figure 4.1). Then, it will enter the oil back-up system through the horizontal pipe $h p 1$. The purpose of the oil back-up system is to prevent the spilled transformer oil from reaching the datum (Figures 4.2 and 4.3). The datum is defined as the horizontal elevation at the bottom of the internal pipe column. Once the transformer oil reaches the datum, the oil back-up system will fail and the spilled transformer oil will enter into the local sewer system. Therefore, it is important to find out the changes of heights of oil and water layers at different time intervals in order to determine whether the design dimensions of the oil back-up system (Figure 4.4) can prevent the failure of the system.

The general conservation of mass flow balance equation is shown below.

$$
\begin{array}{r}
\Delta Q_{\text {in }} * \Delta t=\Delta Q_{\text {out }} * \Delta t+\Delta S \\
\Delta S=\left[\Delta Q_{\text {in }}-\Delta Q_{\text {ouf }}\right] \Delta t
\end{array}
$$

where $\Delta Q_{\text {in }}$ is the average inflow entering into the system at one time step in $\mathrm{m}^{3} / \mathrm{s}$; $\Delta Q_{o u}$ is the average outflow exiting from the system at one time step in $\mathrm{m}^{3} / \mathrm{s} ; \Delta S$ is the changes of storage in the system at one time step in $\mathrm{m}^{3}$; and $\Delta t$ is the time step in sec.

The general mass balance equation (Equation [31]) discussed above is applied to: (1) the transformer oil at catchbasin, (2) the transformer oil at the oil back-up system and (3) the water at the oil back-up system. 


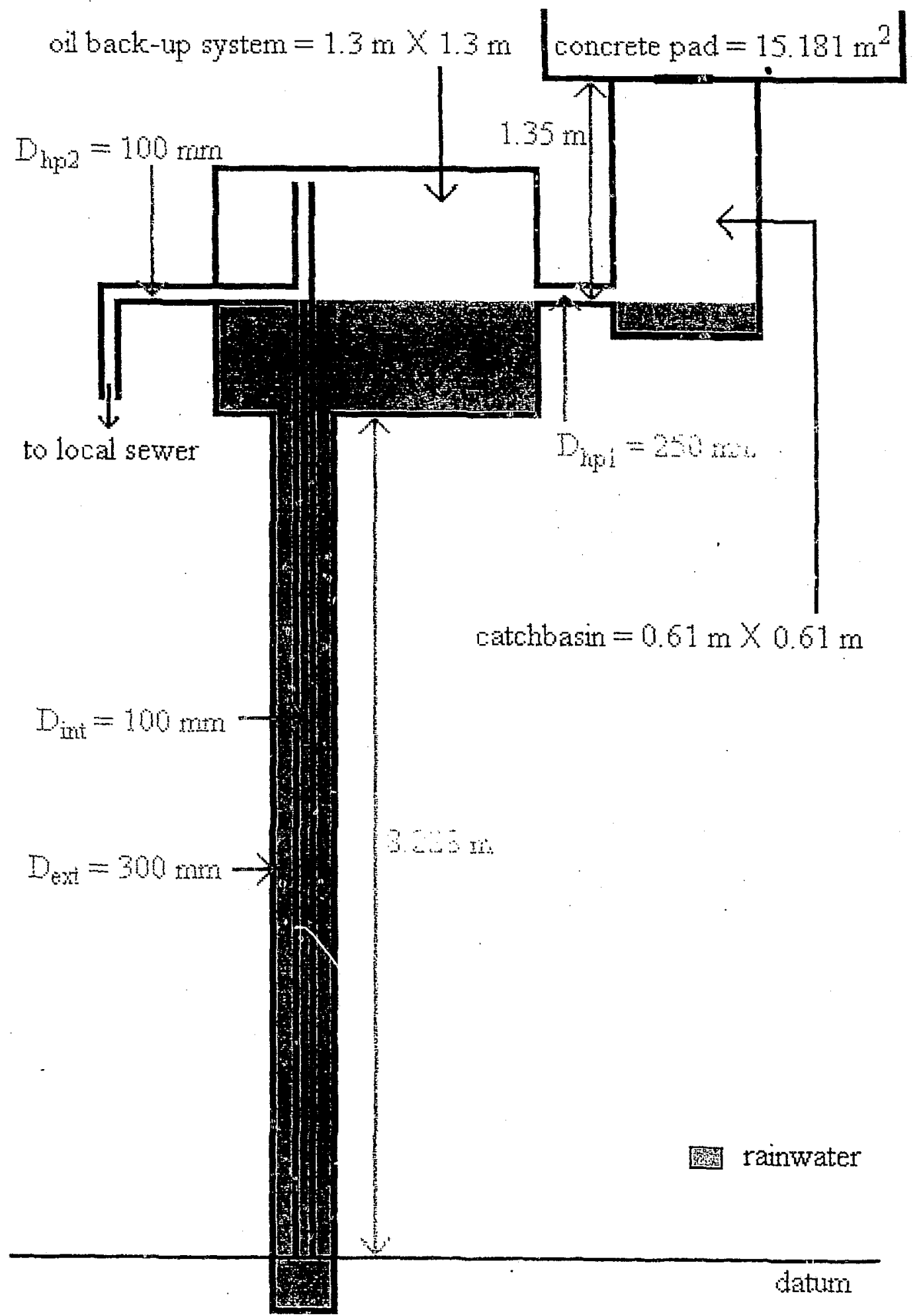

Figure 4.4: Design dimensions of the oil back-up system. 


\subsubsection{Mass Balance of Transformer Oil at the Catchbasin}

For the mass balance of transformer oil at catchbasin, the change of storage of transformer oil, $\Delta S$, at catchbasin is:

$$
\left.\Delta S=A_{\text {catchbasin }}(H][n+1]-H I[n]\right)
$$

where $A_{\text {catchbasin }}$ is the base area of the catchbasin in $m^{2}$ (Table 4.1$) ; H I[n+1]$ is height between the datum and the surface of fluid at the catchbasin at the end of a time step in metres (Table 4.2); and $H I[n]$ is the height between the datum and the surface of fluid at the catchbasin at the beginning of a time step in metres (Table 4.2).

The average inflow of transformer oil enters into the catchibasin from the concrete pad of the transformer station is calculated as:

$$
\Delta Q_{i n}=1 / 2\left(Q_{i n}[n+1]+Q_{i n}[n]\right)
$$

where $Q_{\text {in }}[n]$ is the inflow rate entering into the catchbasin at the beginning of a time step in $\mathrm{m}^{3} / \mathrm{sec} . Q_{\text {in }}[\mathrm{n}+1]$ is the inflow rate entering into the catchbasin at the end of a time step in $\mathrm{m}^{3} / \mathrm{sec}$.

The outflow rate is determined using the orifice equation.

$$
Q=c A \sqrt{2 \rho g H}
$$


where $Q$ is the flow coming out from the pipe in $\mathrm{m}^{3} / \mathrm{sec} ; \mathrm{c}$ is the orifice coefficient of the pipe in dimensionless form; $A$ is the cross-sectional area of the pipe in $m^{2} ; \rho$ is the density of fluid in $\mathrm{kg} / \mathrm{m}^{3} ; \mathrm{g}$ is the gravitational acceleration, which is $9.81 \mathrm{~m} / \mathrm{sec}^{2}$; and $H$ is the head or the oil surface elevation above the centre of the pipe in metres.

Thus, the average outflow rate of transformer oil from the catchbasin to the oil back-up system through the horizontal pipe $h p l$ is:

$$
\begin{aligned}
& \Delta Q_{\text {ous }}=\frac{1}{2}\left(Q_{\text {ous }}[n+1]+Q_{\text {out }}[n]\right) \\
& =\frac{1}{2}\left\{c A_{\text {ppl }} \sqrt{2 \rho_{\text {oil }} g(F[[n+1]-F 2[n+1]-H 3[n+1])}\right. \\
& \left.+c A_{\text {ppl }} \sqrt{2 p_{\text {oil }} g(H 1[n]-H 2[n]-H 3[n])}\right\} \\
& =\frac{c A_{\text {npl }} \sqrt{2 p_{\text {all }} g}}{2}\{\sqrt{H[[n+1]-H 2[n+1]-H 3[n+1]} \\
& +\sqrt{H I[n]-H 2[n]-H 3[n]})
\end{aligned}
$$

where $Q_{\text {our }}[n+1]$ is the outflow rate exiting the catchbasin at the end of a time step in $\mathrm{m}^{3} / \mathrm{s}$; and $Q_{\text {out }}[\mathrm{n}]$ is the outflow rate exiting the catchbasin at the beginning of a time step in $\mathrm{m}^{3} / \mathrm{s}$. Both $Q_{\text {out }}[n+1]$ and $Q_{\text {out }}[n]$ are derived from Equation [34]. The terms, $(H 1[n]-H 2[n]-H 3[n])$ and $(H 1[n+1]-H 2[n+1]-H 3[n+1])$, represent the transformer oil surface elevations in the catchbasin at the beginning and the end of a time step in metres respectively. 
Therefore, the conservation of mass flow balance equation for the transformer oil at the catchbasin is defined as:

$$
\begin{aligned}
& \Delta S=\left[\Delta Q_{\text {in }}-\Delta Q_{\text {ow }}\right] \Delta t \\
& \left.A_{\text {catchiasin }}(H][n+1]-H L[n]\right)=\Delta t\left\{\frac{i}{2}\left(Q_{\text {in }}[n+1]+Q_{\text {in }}[n]\right)\right.
\end{aligned}
$$

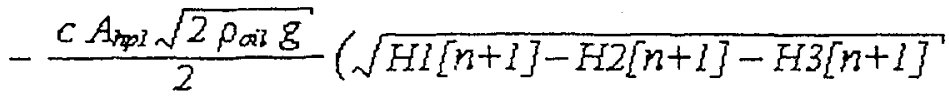

$$
\begin{aligned}
& +\sqrt{H 1[n]-H 2[n]-H 3[n]})\}
\end{aligned}
$$

\subsubsection{Mass Balance of Transformer Oil at Oil Back-up System}

The average outflow rate, $\Delta Q_{\text {out }}$, in this scenario is equal to zero since transformer oil should not escape from the oil back-up system. The average inflow rate, $\Delta Q_{\text {in }}$, equals to the average outflow rate of transformer oil from the catchbasin (Equation [35]) because the catchbasin and the oil back-up system are connected by the horizontal pipe $h p l$. There are two cases for calculating the change of storage at the oil back-up system: $h_{\text {column }} \leq H 3[n]$ and $h_{\text {column }}>H 3[n]$. Figures 4.2 and 4.3 illustrate the details of these two cases. The change of the storage for the Case $1, \Delta S_{(l)}$, is given by:

$$
\Delta S_{(l)}=\left(A_{\text {system }}-A_{\text {int }}\right)(H 2[n+1]-H 2[n])
$$

where $A_{\text {system }}$ is the base area of the oil back-up system in $m^{2} ; A_{\text {int }}$ is the cross-sectional area of internal pipe column in $m^{2} ; H 2[n+1]$ is the height of the oil layer in the oil backup system at the end of a time step in metres; $H 2[n]$ is the height of the oil layer in the oil back-up system at the beginning of a time step in metres (Tables 4.1 and 4.2). 
The change of storage in Case $2, \Delta S_{(2)}$, is given by:

$$
\begin{aligned}
\Delta S_{(2)}= & \left\{\left(\left(A_{\text {system }}-A_{\text {int }}\right)\left(H 2[n+1]+H 3[n+1]-h_{\text {column }}\right)\right.\right. \\
& \left.\left.-\left(A_{h p 2}\right)\left(L_{h p 2}\right)\right)+\left(A_{\text {ext }}-A_{\text {int }}\right)\left(h_{\text {column }}-H 3[n+1]\right)\right\} \\
& -\left\{\left(\left(A_{\text {system }}-A_{\text {int }}\right)\left(H 2[n]+H 3[n]-h_{\text {column }}\right)\right.\right. \\
& \left.\left.-\left(A_{h p 2}\right)\left(L_{h p 2}\right)\right)+\left(A_{\text {ext }}-A_{\text {int }}\right)\left(h_{\text {column }}-H 3[n]\right)\right\}
\end{aligned}
$$

where $h_{\text {colum }}$ is the height between datum and the bottom of the oil back-up system in metres; $A_{h p 2}$ is the cross-sectional area of horizontal pipe $h p 2$ inside the oil back-up system in $\mathrm{m}^{2} ; L_{h p 2}$ is the length of horizontal pipe $h p 2$ inside the oil back-up system in metres; $A_{\text {ext }}$ is the cross-sectional area of external pipe column in $\mathrm{m}^{2} ; H 3[\mathrm{n}]$ is the height of water layer between the datum and the interface of oil and water in the oil back-up system at the beginning of a time step in metres; and $H 3[n+1]$ is the height of water layer between the datum and the interface of oil and water in the oil back-up system at the end of a time step in metres (Tables 4.1 and 4.2).

The conservation of mass flow balance equations for the transformer oil at the oil back-up system for the two cases are given by

$$
\begin{aligned}
& \Delta S_{(1)}=\left[\Delta Q_{\text {in }}-\Delta Q_{\text {out }}\right] \Delta t \\
& \Delta S_{(1)}=\left(\Delta Q_{\text {in }}\right) \Delta t \\
& \left(A_{\text {sysem }}-A_{\text {int }}\right)(H 2[n+1]-H 2[n])= \\
& \Delta t \frac{c A_{\text {rol }} \sqrt{2 p_{\text {oil }} g}}{2}(\sqrt{H 1[n+1]-H 2[n+1]-H 3[n+1]} \\
& +\sqrt{H 1[n]-H 2[n]-H 3[n]})
\end{aligned}
$$




$$
\begin{aligned}
& \Delta S_{(Z)}=\left[\Delta Q_{\text {in }}-\Delta Q_{\text {out }}\right] \Delta t \\
& \Delta S_{(R)}=\left(\Delta Q_{i n}\right) \Delta t \\
& \left\{\left(\left(A_{\text {system }}-A_{\text {irz }}\right)\left(H 2[n+1]+H 3[n+1]-h_{\text {colism }}\right)\right.\right. \\
& \left.\left.-\left(A_{\text {ipp } 2)}\right)\left(L_{\text {kpl } 2}\right)\right)+\left(A_{\text {oxt }}-A_{\text {irt }}\right)\left(h_{\text {colum }}-H 3[n+1]\right)\right\} \\
& -\left\{\left(\left(A_{\text {sustem }}-A_{\text {int }}\right)\left(H 2[n]+H 3[n]-h_{\text {caldom }}\right)\right.\right.
\end{aligned}
$$

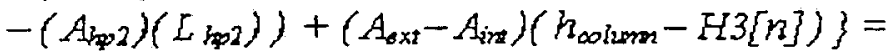

$$
\begin{aligned}
& \Delta t \frac{c A_{\text {ppl }} \sqrt{2 \rho_{\text {ail }} g}}{2}(\sqrt{E I[n+1]-E 2[n+1]-H 3[n+1]} \\
& +\sqrt{H[[n]-F 2[n]-H 3[n]})
\end{aligned}
$$

\subsubsection{Mass Balance of Water at Oil Back-up System}

The mathematical model discussed in this chapter is designed for transformer oil spills without the occurrence of rain storms, where $Q_{i n}$ is defined as the inflow rate of transformer oil to the oil back-up system (Table 4.1). Therefore, the average inflow rate, $\Delta Q_{i n}$, for the mass balance of water at the oil back-up system is equal to zero.

The average outflow rate of water exiting the oil back-up system is measured at horizontal pipe hp2 (pink dotted line in Figure 4.3). Orifice equation (Equation [34]) is used to determine the average outflow rate such that

$$
\begin{aligned}
& \Delta Q_{\text {out }}=\frac{1}{2}\left(Q_{\text {out }}[n+1]+Q_{\text {ous }}[n]\right) \\
& =\frac{l}{2}\left\{c A_{h p 2 \sqrt{2 \rho_{\text {water }} g\left(H 4[n+1]-h_{c o l u m}-h\right)}}\right.
\end{aligned}
$$

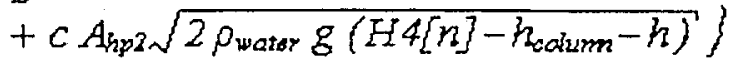

$$
\begin{aligned}
& =\frac{c A_{h p 2} \sqrt{2 \rho_{\text {wast }} g}}{2}\left\{\sqrt{H 4[n+1]-h_{\text {colum }}-h}\right. \\
& \left.+\sqrt{H 4[n]-h_{\text {colum }}-h}\right\}
\end{aligned}
$$

Page 81

Reproduced with permission of the copyright owner. Further reproduction prohibited without permission. 
There are two different equations for the change of storage in this scenario. The first equation (Equation [42]) can be applied for Case 1 in Section 4.1.2.

$$
\begin{aligned}
\Delta S_{(l)}= & \left\{\left(A_{\text {system }}\right)\left(H 3[n+1]-h_{\text {column }}\right)+\left(A_{\text {int }}\right)(H 4[n+1]\right. \\
& \left.-H 3[n+1])+\left(A_{\text {ext }}\right)\left(h_{\text {column }}\right)+\left(A_{\text {hp } 2}\right)\left(L_{\text {hp } 2}\right)\right\} \\
& -\left\{\left(A_{\text {system }}\right)\left(H 3[n]-h_{\text {column }}\right)+\left(A_{\text {int }}\right)(H 4[n]\right. \\
& \left.-H 3[n])+\left(A_{\text {ext }}\right)\left(h_{\text {column }}\right)+\left(A_{\text {hp } 2}\right)\left(L_{\text {hp } 2}\right)\right\}
\end{aligned}
$$

The second equation is used for Case 2 in Section 4.1.2 given by:

$$
\begin{aligned}
\Delta S_{(2)}= & \left\{\left(A_{e x t}\right)(H 3[n+1])+\left(A_{i n 1}\right)(H 4[n+1]-H 3[n+1])\right. \\
& \left.+\left(A_{h p 2}\right)\left(L_{h p 2}\right)\right\}-\left\{\left(A_{e x t}\right)(H 3[n])+\left(A_{i n t}\right)(H 4[n]\right. \\
& \left.-H 3[n])+\left(A_{h p 2}\right)\left(L_{h p 2}\right)\right\}
\end{aligned}
$$

Therefore, the mass balance of water at the oil back-up system is determined as:

$$
\begin{aligned}
& \Delta S_{(i)}=\left[\Delta Q_{\text {in }}-\Delta Q_{\text {out }}\right] \Delta t \\
& \Delta S_{(i)}=\left(-\Delta Q_{\text {oud }}\right) \Delta t \\
& \left\{\left(A_{\text {wstem }}\right)\left(H 3[n+1]-h_{\text {calum }}\right)+\left(A_{2,2}\right)(H 4[n+1]\right. \\
& \left.-I 3[n+1])+\left(A_{\text {oxt }}\right)\left(h_{\text {column }}\right)+\left(A_{h p 2}\right)\left(L_{h p 2}\right)\right\} \\
& -\left\{\left(A_{\text {yystom }}\right)\left(H 3[n]-h_{\text {calum }}\right)+\left(A_{\text {int }}\right)(H 4[n]\right. \\
& \left.-H 3[n])+\left(A_{\text {sxt }}\right)\left(h_{\text {collem }}\right)+\left(A_{\text {hp2 }}\right)\left(L_{\text {hpl }}\right)\right\}= \\
& -\Delta t \frac{C A_{h p 2 \sqrt{2 p_{\text {water }} g}}}{2}\left(\sqrt{F A[n+1]-h_{c d u m}-h}\right. \\
& +\sqrt{[44[n]-h \text { colum }-h}\}
\end{aligned}
$$

Page 82 


$$
\begin{aligned}
& \Delta S_{(2)}=\left[\Delta Q_{\text {in }}-\Delta Q_{\text {out }}\right] \Delta t \\
& \Delta S_{(Q)}=\left(-\Delta Q_{\text {out }}\right) \Delta t
\end{aligned}
$$

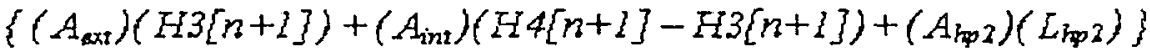

$$
\begin{aligned}
& -\left\{\left(A_{\text {ext }}\right)(H 3[n])+\left(A_{i r t}\right)(K 4[n]-H 3[n])+\left(A_{h p 2}\right)\left(L_{h p 2}\right)\right\}= \\
& -\Delta t \frac{c A_{h p 2} \sqrt{2 \rho_{\text {watsr }} g}}{2}\left\{\sqrt{\left[44[n+1]-h_{\text {colum }}-h\right.}\right. \\
& \left.+\sqrt{F 4[n]-h_{\text {colum }}-h}\right\}
\end{aligned}
$$

\subsection{Development of the Mathematical Model}

The purpose of the mathematical model discussed below is to determine the heights of oil and water layers, $(H 1[n+1], H 2[n+1], H 3[n+1], H 4[n+1])$, at different time intervals. Since there are four unknowns in the mathematical model and only three sets of mass balance equations were developed in the previous section, one more equation is needed in order to solve all the unknowns. The last equation involved in the model is the hydrostatic pressure at the interface of transformer oil and water.

$$
\begin{aligned}
& \left(\rho_{\text {oil }}\right)(H 2[n+1])=\left(\rho_{\text {water }}\right)(H 4[n+1]-H 3[n+1]) \\
& \left(\rho_{\text {oil }}\right)(H 2[n])=\left(\rho_{\text {water }}\right)(H 4[n]-H 3[n])
\end{aligned}
$$

The Newton-Raphson method will be used to solve the four algebraic equations simultaneously. Since most of the unknowns in the mass balance equations are in rational exponent forms, substitution method must be applied to simplify the unknowns before solving the system of algebraic equations. By assuming 


$$
\begin{aligned}
& X 1=\sqrt{H 1-H 2-I 3} \\
& X 2=F 2 \\
& X 3=F 3 \\
& X 4=\sqrt{H 4-h_{\text {coimmn }}-h}
\end{aligned}
$$

$H I$ and $H 4$ can be rewritten as

$$
\begin{aligned}
& H 1=X 1^{2}+X 2+X 3 \\
& H 4=X 4^{2}+h_{\text {column }}+h
\end{aligned}
$$

The mass balance equation for the transformer oil at the catchbasin (Equation [36]) can be modified as:

$$
\begin{aligned}
& \Delta S=\left[\Delta Q_{\text {in }}-\Delta Q_{\text {out }}\right] \Delta t \\
& A_{\text {cotehessin }}\left(X 1^{2}[n+1]+X 2[n+1]+X 3[n+1]-X\right]^{2}[n] \\
& -X 2[n]-X 3[n])=\Delta t\left\{\frac{1}{2}\left(Q_{\text {in }}[n+1]+Q_{\text {in }}[n]\right)\right. \\
& \left.-\frac{c A_{\text {nol }} \sqrt{2 p_{\text {ail }} g}}{2}(X I[n+1]+X 1[n])\right\}
\end{aligned}
$$

Ths calculation for the average inflow rate of transformer oil, ( $\left.\Delta Q_{\text {in }}\right)_{\text {oil }}$, to the catchbasin is demonstrated in Section 4.3 where

$$
\left(\Delta Q_{i n}\right)_{o i l}=1 / 2\left(Q_{i n}[n+1]+Q_{\text {in }}[n]\right)
$$

Page 84 
Further expanding of Equation [51] gives,

$$
\begin{aligned}
& \left.\left(A_{\text {catahbasin }}\right)(X)^{2}[n+1]\right)+\left(A_{\text {cochbasin }}\right)(X 2[n+1])+\left(A_{\text {catchbasin }}\right)(X 3[n+1]) \\
& \left.-\left(A_{\text {caschbasin }}\right)(X]^{2}[n]\right)-\left(A_{\text {caschbarin }}\right)(X 2[n])-\left(A_{\text {catchbosin }}\right)(X 3[n]) \\
& \left.-\Delta t\left(\Delta Q_{\text {in }}\right)_{\text {al }}+\frac{c A_{\text {pqi }} \Delta t \sqrt{2 \beta_{\text {ail }} g}}{2}(X][n+1]\right) \\
& +\frac{c A_{\text {ippi }} \Delta t \sqrt{2 \rho_{\text {ail }} g}}{2}(X I[n])=0 \\
& \left.\left(A_{\text {aachbasin }}\right)(X]^{2}[n+1]\right)+\frac{c A_{\text {ipl }} \Delta t \sqrt{2 \rho_{\text {ai }} g}}{2}(X 1[n+1]) \\
& +\left(A_{\text {cachbasin }}\right)(X 2[n+1])+\left(A_{\text {cauhbasin }}\right)(X 3[n+1])-\left(A_{\text {catchiosin }}\right)\left(X 1^{2}[n]\right) \\
& \left.+\frac{c A_{\text {pol }} \Delta t \sqrt{2 \rho_{\text {oil }} g}}{2}(X][n]\right)-\left(A_{\text {catchbasin }}\right)(X 2[n])-\left(A_{\text {catchbasin }}\right)(X 3[n]) \\
& -\Delta t\left(\Delta Q_{\text {in }}\right)_{\text {ail }}=0
\end{aligned}
$$

The mass balance of transformer oil at the oil back-up system for Case 1 (Equation [39]) can be modified to:

$$
\begin{aligned}
& \Delta S_{(1)}=\left[\Delta Q_{\text {in }}-\Delta Q_{\text {out }}\right] \Delta t \\
& \Delta S_{(1)}=\left(\Delta Q_{\text {in }}\right) \Delta t \\
& \left(A_{\text {system }}-A_{\text {int }}\right)(X 2[n+1])-\left(A_{\text {system }}-A_{\text {irt }}\right)(X 2[n])
\end{aligned}
$$

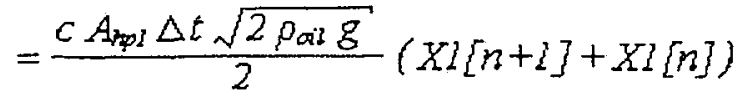

$$
\begin{aligned}
& \frac{c A_{\text {pq } 1} \Delta t \sqrt{2 \rho_{\text {ail }} g}}{2}(X 1[n+1])-\left(A_{\text {wstem }}-A_{\text {int }}\right)(X 2[n+1]) \\
& +\frac{c A_{\text {rppl }} \Delta t \sqrt{2 \rho_{\text {ail }} g}}{2}(X 1[n])+\left(A_{\text {systom }}-A_{i n z}\right)(X 2[n])=0
\end{aligned}
$$


For Case 2, the mass balance of transformer vil at the oil back-up system (Equation 40) can be rewritten as:

$$
\begin{aligned}
& \Delta S_{(2)}=\left[\Delta Q_{\text {in }}-\Delta Q_{\text {ous }}\right] \Delta t \\
& \Delta S_{(2)}=\left(\Delta Q_{\text {in }}\right) \Delta t \\
& \left(A_{\text {system }}-A_{\text {ind }}\right)(X 2[n+1])+\left(A_{\text {system }}-A_{\text {int }}\right)(Y 3[n+1])
\end{aligned}
$$

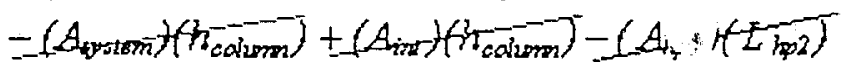

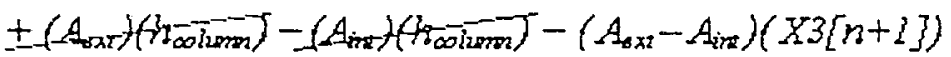

$$
\begin{aligned}
& -\left(A_{3 y t a n}-A_{\text {in }}\right)(X 2[n])-\left(A_{3 w t a n}-A_{\text {in }}\right)(X 3[n])
\end{aligned}
$$

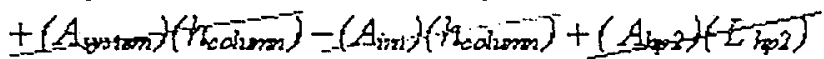

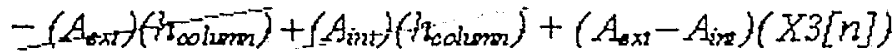

$$
\begin{aligned}
& =\frac{c A_{n p l} \Delta t \sqrt{2 \mu_{a i} g}}{2}(X 2[n+1]+X I[n]) \\
& \left(A_{\text {system }}-A_{\text {ine }}\right)(X 2[n+1])+\left(A_{\text {systom }}\right)(X 3[n+1])=\left(A_{\text {in }}\right)(X 3[n+1]) \\
& -\left(A_{\text {oxt }}\right)(X 3[n+1])+\left(A_{\text {in }}\right)(-733[n+7])-\left(A_{\text {swtem }}-A_{\text {int }}\right)(X 2[n]) \\
& -\left(A_{3 w \text { ten }}\right)(X 3[n]) \pm\left(A_{\text {ind }}\right)(-X 35[n])+\left(A_{8 x}\right)(X 3[n]) \\
& =\left(A_{n+2}\right)(x=[n])=\frac{c A_{\text {nol }} \Delta t \sqrt{2 \rho_{a i} g}}{2}(X 1[n+1]) \\
& \left.+\frac{c A_{\text {ippl }} \Delta t \sqrt{2 \rho_{\text {ail }} g}}{2}(X][n]\right) \\
& \left.\frac{c A_{\text {ppl }} \Delta t \sqrt{2 p_{\text {oil }} g}}{2}(X][n+1]\right)-\left(A_{\text {qustem }}-A_{\text {inz }}\right)(X 2[n+1]) \\
& +\left(A_{\text {sxz }}-A_{\text {system }}\right)(X 3[n+1])+\frac{c A_{\text {ippl }} \Delta t \sqrt{2 \beta_{\text {ail }} g}}{2}(X 1[n]) \\
& +\left(A_{\text {zwian }}-A_{\text {int }}\right)(X 2[n])+\left(A_{\text {zwten }}-A_{8 x:}\right)(X 3[n])=0
\end{aligned}
$$

Page 86 
By substituting Equations [49] and [50] into Equation [44], the modification of Case 1 for the mass balance of water at the oil back-up system scenario becomes:

$$
\begin{aligned}
& \Delta S_{(1)}=\left[\Delta Q_{\text {in }}-\Delta Q_{\text {out }}\right] \Delta t \\
& \Delta S_{(1)}=\left(-\Delta Q_{\text {ors }}\right) \Delta t \\
& \left\{\left(A_{\text {system }}\right)\left(H 3[n+1]-h_{\text {calmon }}\right)+\left(A_{\text {int }}\right)(H 4[n+1]\right. \\
& \left.-[3[n+1\})+\left(A_{s x i}\right)\left(h_{\text {colum }}\right)+\left(A_{h p 2}\right)\left(L_{\text {pqp }}\right)\right\} \\
& -\left\{\left(A_{\text {systom }}\right)\left(F 3[n]-h_{\text {colum }}\right)+\left(A_{\text {int }}\right)(K 4[n]\right. \\
& \left.-H 3[n])+\left(A_{\text {oxt }}\right)\left(h_{\text {collam }}\right)+\left(A_{\text {hp } 2}\right)\left(L_{\text {ipp }}\right)\right\}= \\
& -\Delta t \frac{c A_{h p 2 \sqrt{2} \sqrt{2 \rho_{\text {warer }} g}}^{2}}{2}\left\{\sqrt{\xi 4[n+1]-h_{\text {colum }}-h}\right. \\
& \left.+\sqrt{H 4[n]-h_{\text {colum }}-h}\right\} \\
& \left(A_{\text {system }}\right)(X 3[n+1])-\left(A_{\text {systom }}\right)+\left(A_{\text {cohmon }}\right)+\left(A_{\text {int }}\right)\left(X 4^{2}[n+1]\right)
\end{aligned}
$$

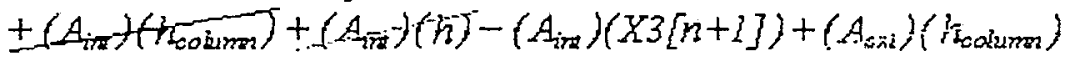

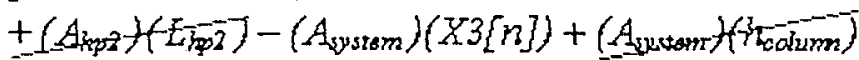

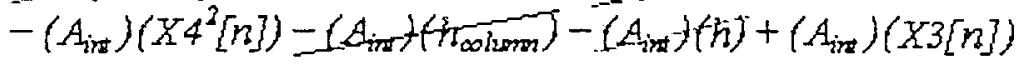

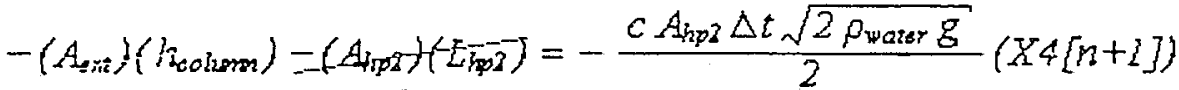

$$
\begin{aligned}
& -\frac{c A_{\text {hp2 }} \Delta t \sqrt{2 \rho_{\text {wats }} g}}{2}(X 4[n]) \\
& \left(A_{\text {systsm }}-A_{\text {irz }}\right)(X 3[n+1])+\left(A_{i r z}\right)\left(X 4^{2}[n+1]\right) \\
& +\frac{c A_{\text {hp } 2} \Delta t \sqrt{2 p_{\text {water }} g}}{2}(X 4[n+1])+\left(A_{\text {irt }}-A_{\text {system }}\right)(X 3[n]) \\
& -\left(A_{\text {int }}\right)\left(X 4^{2}[n]\right)+\frac{c A_{h p 2} \Delta t \sqrt{2 p_{\text {water }} g}}{2}(X 4[n])=0
\end{aligned}
$$

Page 87

Reproduced with permission of the copyright owner. Further reproduction prohibited without permission. 
For Case 2, the mass balance of water at the oil back-up system scenario (Equation [45]) can be modified using the similar procedure in Equation [56] such that:

$$
\begin{aligned}
& \Delta S_{(\lambda)}=\left[\Delta Q_{\text {in }}-\Delta Q_{\text {ous }}\right] \Delta t \\
& \Delta S_{(Q)}=\left(-\Delta Q_{\text {out }}\right) \Delta t \\
& \left\{\left(A_{\text {ext }}\right)(\xi 3[n+1])+\left(A_{\text {int }}\right)(\xi 4[n+1]-\xi 3[n+1])+\left(A_{\text {kp }}\right)\left(L_{k p 2}\right)\right\} \\
& -\left\{\left(A_{\text {sxt }}\right)(K 3[n])+\left(A_{i n t}\right)(H 4[n]-H 3[n])+\left(A_{k p 2}\right)\left(L_{h p 2}\right)\right\}= \\
& -\Delta t \frac{c A_{h p 2 \sqrt{2}} \sqrt{2 \rho_{\text {water }} g}}{2}\left\{\sqrt{H 4[n+1]-h_{\text {colum }}-h}\right. \\
& \left.+\sqrt{\left[44[n]-h_{\text {colum }}-h\right.}\right] \\
& \left(A_{\text {oxi }}\right)(X 3[n+1])+\left(A_{\text {in }}\right)\left(X 4^{2}[n+1]\right) \pm\left(A_{\text {inn }}\right)\left(\beta_{\text {calumn }}^{-}\right) \\
& \pm\left(A_{2 n}\right)(\hbar n)-\left(A_{i n z}\right)(X 3[n+1]) \pm\left(A_{i q 2}\right)\left(\sum_{n, p 2}\right)
\end{aligned}
$$

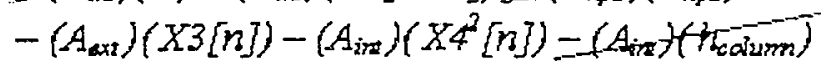

$$
\begin{aligned}
& -\left(A_{\text {inin }}\right)(n)+\left(A_{\text {int }}\right)(X 3[n])=\left(A_{\text {ing }}\right)\left(E_{\text {iqn }}\right)= \\
& -\frac{c A_{h p ?} \Delta t \sqrt{2 \rho_{\text {water }} g}}{2}(X 4[n+1])-\frac{c A_{\text {hp }} \Delta t \sqrt{2 \rho_{\text {water }} g}}{2}(X 4[n]) \\
& \left(A_{\text {ext }}-A_{\text {int }}\right)(X 3[n+1])+\left(A_{\text {int }}\right)\left(X 4^{2}[n+1]\right) \\
& +\frac{c A_{h p 2} \Delta t \sqrt{2 \rho_{\text {woter }} g}}{2}(X 4[n+1])+\left(A_{\text {int }}-A_{\text {ext }}\right)(X 3[n]) \\
& -\left(A_{\text {inn }}\right)\left(X 4^{2}[n]\right)+\frac{C A_{h p 2} \Delta t \sqrt{2 p_{\text {water }} g}}{2}(X 4[n])=0
\end{aligned}
$$

Since one of the hydrostatic pressure equations at the interface of transformer oil and water does not contain any unknowns, only Equation [46] will be used for the nonlinear system. Equation [46] can be rewritten as:

$$
\begin{aligned}
& \left(\rho_{\text {oil }}\right)(X 2[n+1])=\left(\rho_{\text {water }}\right)\left(X 4^{2}[n+1]+h_{\text {column }}+h-X 3[n+1]\right) \\
& \left(\rho_{\text {oil }}\right)(X 2[n+1])+\left(\rho_{\text {water }}\right)(X 3[n+1])-\left(\rho_{\text {water }}\right)\left(X 4^{2}[n+1]\right) \\
& -\left(\rho_{\text {water }}\right)\left(h_{\text {column }}\right)-\left(\rho_{\text {water }}\right)(h)=0
\end{aligned}
$$

Page 88 
Equations [53] to [58] are the fundamental nonlinear system of algebraic equations for the mathematical model. Since there are four sets of nonlinear equations, the Jacobian matrix in Newton-Raphson method will contain sixteen elements. The elements of the Jacobian matrix for Case 1 are demonstrated below. These elements are derived from Equations [53], [54], [56] and [58].

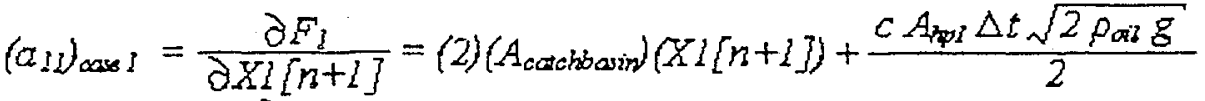

$$
\begin{aligned}
& \left(a_{32}\right)_{\text {cose }}=\frac{\partial F_{1}}{\partial X 2[n+1]}=A_{\text {catchosin }} \\
& \left(a_{i 3)_{\text {case } I}}=\frac{\partial F_{1}}{\partial X 3[n+1]}=A_{c c t c h b a s i n}\right. \\
& \left(a_{d 4) \text { ass } 1}=\frac{\partial \xi_{1}}{\partial X 4[n+1]}=0\right.
\end{aligned}
$$

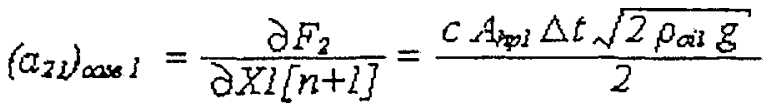

$$
\begin{aligned}
& \left(a_{22}\right)_{\text {cass I }}=\frac{\partial F_{2}}{\partial X 2[n+1]}=A_{\text {irt }}-A_{\text {systom }} \\
& \left(a_{33}\right)_{\cos 1}=\frac{\partial F_{3}}{\partial X 3\{n+1\}}=0 \\
& \left(a_{x 4}\right)_{\text {ass } 1}=\frac{\partial F_{2}}{\partial X 4[n+1]}=0 \\
& \left(a_{3 \nu_{\text {oas }} l}=\frac{\partial F_{3}}{\partial X 1[n+1]}=0\right. \\
& \left(a_{32}\right)_{\text {ase } 1}=\frac{\partial F_{3}}{\partial X 2[n+1]}=0 \\
& \left(a_{39}\right)_{\text {ass } 1}=\frac{\partial F_{3}}{\partial X 3[n+1]}=A_{\text {yssem }}-A_{\text {ins }} \\
& \left(a_{34}\right)_{\text {ass } 1}=\frac{\partial F_{3}}{\partial X 4[n+1]}=(2)\left(A_{\text {int }}\right)(X 4[n+1])+\frac{c A_{\text {hp } 2} \Delta t \sqrt{2 \rho_{\text {watar }} g}}{2} \\
& \left(\alpha_{q 1}\right)_{\text {ass } 1}=\frac{\partial F_{4}}{\partial X[n+1]}=0 \\
& \left(a_{42}\right)_{\text {ans } 1}=\frac{\partial F_{4}}{\partial X 2[n+1]}=\rho_{a i} \\
& \left(a_{43}\right)_{\text {aas } 1}=\frac{\partial F_{4}}{\partial X 3\{n+1]}=\rho_{\text {wator }} \\
& \left(\alpha_{q 4}\right)_{\text {and } 1}=\frac{\partial F_{q}}{\partial X 4[n+1]}=(-2)\left(\rho_{\text {wata }}\right)(X 4[n+1])
\end{aligned}
$$


The elements of Jacobian matrix for Case 2 are shown below.

$$
\begin{aligned}
& \left(a_{1 D}\right)_{\text {cass } 2}=\frac{\partial F_{1}}{\partial X 1[n+1]}=(2)\left(A_{\text {catebbasin }}\right)(K 1[n+1])+\frac{c A_{\text {pol }} \Delta t \sqrt{2 p_{a i} g}}{2} \\
& \left(a_{22}\right)_{\text {cass } 2}=\frac{\partial F_{1}}{\partial \not 2 Z[n+1]}=A_{\text {catchbasin }} \\
& \left(a_{23}\right)_{\text {case } 2}=\frac{\partial F_{1}}{\partial X 3[n+1]}=A_{\text {catchbasin }} \\
& \left(a_{2 q}\right)_{\text {coss } 2}=\frac{\partial F_{1}}{\partial X 4[n+1]}=0 \\
& \left(a_{2 D}\right)_{\text {cass } 2}=\frac{\partial F_{2}}{\partial X \mid[n+1]}=\frac{c A_{\text {ipl } 1} \Delta t \sqrt{2 \rho_{\text {ail }} g}}{2} \\
& \left(a_{22}\right)_{\text {case }}=\frac{\partial F_{2}}{\partial X 2[n+1]}=A_{\text {int }}-A_{\text {wystem }} \\
& \left(a_{23}\right)_{\text {cose } 3}=\frac{\partial F_{2}}{\partial X 3\{n+1\}}=A_{8 x t}-A_{\text {wstem }} \\
& \left(a_{24}\right)_{\text {oass }}=\frac{\partial F_{2}}{\partial X 4[n+1]}=0 \\
& \left(a_{3 j}\right)_{\text {case } 2}=\frac{\partial F_{3}}{\partial X[n+1]}=0 \\
& \left(a_{32}\right)_{\text {cose } 2}=\frac{\partial F_{3}}{\partial X 2[n+1]}=0 \\
& \left(a_{33}\right)_{\text {cass } 3}=\frac{\partial F_{3}}{\partial X 3[n+1]}=A_{\text {ext }}-A_{\text {int }} \\
& \left(a_{34}\right)_{\text {cass } 2}=\frac{\partial F_{3}}{\partial X 4[n+1]}=(2)\left(A_{i n d}\right)(X 4[n+1\})+\frac{c A_{\text {hp } 2} \Delta t \sqrt{2 \rho_{\text {water }} g}}{2} \\
& \left(a_{42}\right)_{\text {coss } 2}=\frac{\partial F_{4}}{\partial X[[n+1]}=0 \\
& \left(a_{42}\right)_{\text {cose } 2}=\frac{\partial F_{4}}{\partial X 2[n+1]}=p_{a i} \\
& \left(a_{q Q}\right)_{\text {cass } 2}=\frac{\partial F_{4}}{\partial X 3[n+1]}=\rho_{\text {wats }} \\
& \left(\alpha_{44}\right)_{\text {case } 2}=\frac{\partial F_{4}}{\partial X+[n+1]}=(-2)\left(\rho_{\text {water }}\right)(X 4[n+1])
\end{aligned}
$$

Page 90 


\subsection{Determination of the Input Data}

The density of transformer oil, $\rho_{\text {oil }}$, and the inflow rate of oil, $Q_{i n}$, are the two input data for the mathematical model. The density of transformer oil can be determined by conducting an experiment described below. First, the mass of an empty $100 \mathrm{~mL}$ graduated cylinder is measured on an electrical balance (row 2 of Table 4.3). Then, $(100 \pm 0.5) \mathrm{mL}$ of transformer oil is filled in the graduated cylinder and its weight is measured again (row 3 of Table 4.3). Finally, the density of oil is calculated by dividing the net weight of transformer oil over its volume (row 4 of Table 4.2;

Table 4.3: Experimental results for the Density of the Transformer Oil.

\begin{tabular}{lcc}
\hline \multicolumn{1}{c}{ Description } & Trial \#1 & Trial \#2 \\
\hline $\begin{array}{l}\text { mass of } 100 \mathrm{~mL} \text { graduated cylinder, in } \\
\text { grams }\end{array}$ & $67.38 \pm 0.01$ & $67.51 \pm 0.01$ \\
$\begin{array}{l}\text { mass of } 100 \mathrm{~mL} \text { transformer oil in the } \\
100 \mathrm{~mL} \text { graduated cylinder, in grams }\end{array}$ & $153.49 \pm 0.01$ & $153.61 \pm 0.01$ \\
$\begin{array}{l}\text { net weight of } 100 \mathrm{~mL} \text { transformer oil, } \\
\text { in grams }\end{array}$ & $86.11 \pm 0.02$ & $86.1 \pm 0.02$ \\
\begin{tabular}{l} 
density of transformer oil, in $\mathrm{kg} / \mathrm{L}$ \\
\hline
\end{tabular} & $0.8611 \pm 0.00451$ & $0.861 \pm 0.00451$ \\
\hline
\end{tabular}

After taking the average of the two trials in Table 4.3, the density of transformer oil used in the mathematical model is $0.86 \mathrm{~kg} / \mathrm{L}$. 
The determination of the inflow rate, $Q_{\text {in }}$, is shown in Appendix G. The concrete pad and containment wall at the transformer station is acted as a big container with $15.18 \mathrm{~m}^{2}$ (Equation [26]) in base area and $1 \mathrm{~m}$ in height. A transformer oil spill must cirst reach the concrete pad before it gets into the catchbasin and the oil back-up system. Any spilled transformer oil that cannot go to the concrete pad is assumed to be spilled out to the ground. This is only happened on the spill events with enormous amount of transforner oil. First, a certain height of spilled transformer oil at the concrete pad at $t=0$ (row 2 column 3 on Appendix $G$ ) is assumed in order to determine the inflow rate. Thus, the total volume of transformer oil remains on the concrete pad (row 2 column 4 on Appendix $G$ ) and the inflow rate (row 2 column 5 on Appendix $G$ ) at that time interval can be determined. The inflow rate is calculated from the orifice equation (Equation [34]) by letting the cross-sectional area be the total area of grate (Figure 4.5) that transformer oil spills exiting from the concrete pad (horizontal red line and vertical $Q_{\text {in }}$ arrow above the concrete pad in Figure 4.2). The calculation of the total area of grate is demonstrated below.

$$
\begin{aligned}
A_{\text {grate }}= & 4 *(\text { area } M)+4 *(\text { area } N)+4 *(\text { area } P)+8 *(\text { area } Q) \\
= & 4[(0.025+0.06)(0.025)(0.5)]+4[(0.13+0.16)(0.025)(0.5) \\
& +4[(0.235+0.275)(0.025)(0.5)]+8(0.35)(0.025) \\
= & 0.11 \mathrm{~m}^{2}
\end{aligned}
$$




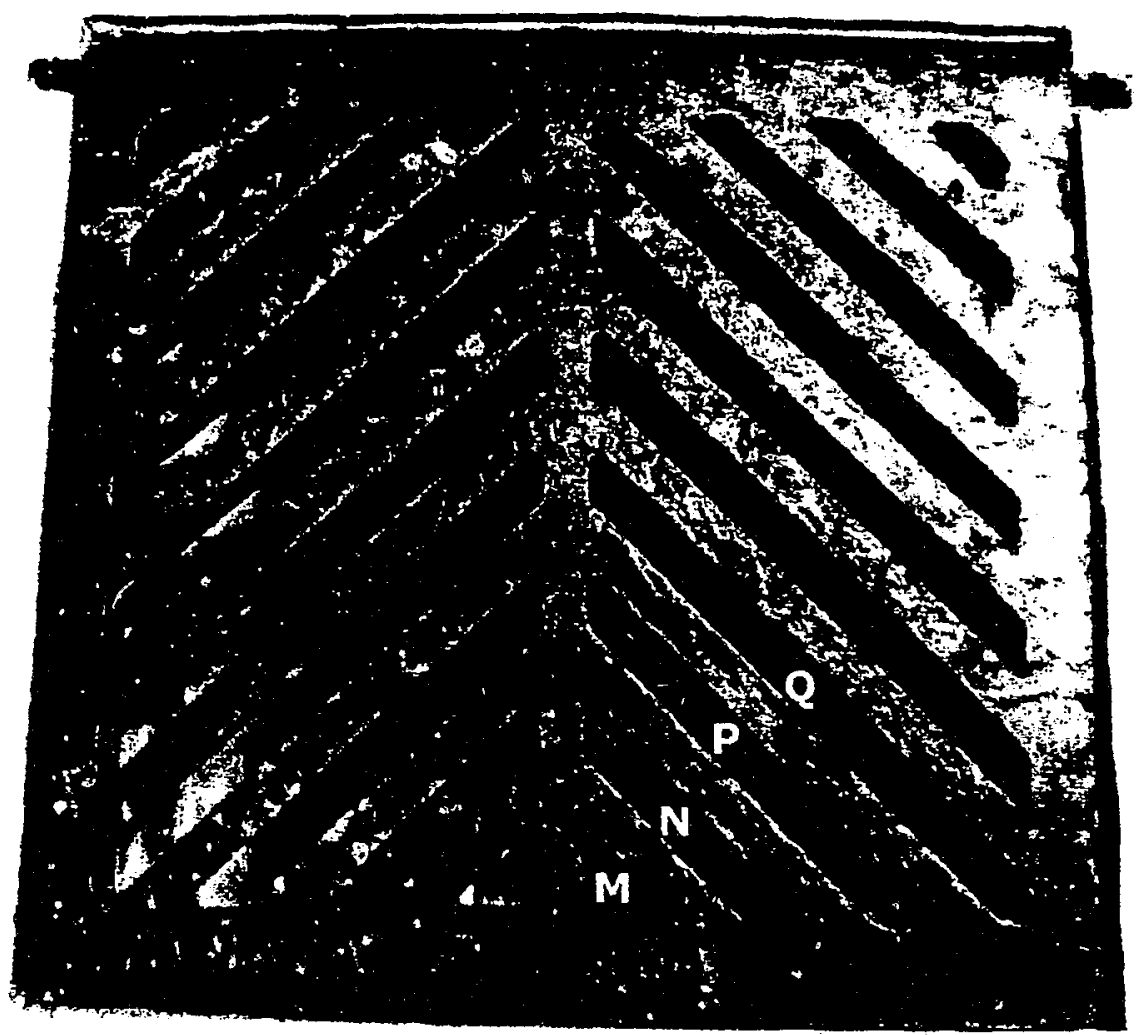

Figure 4.5: Typical Grate Located at the Concrete Pad.

Secondly, the volume of transformer oil goes into the catchbasin within the time step (row 3 column 2 on Appendix G) is calculated by multiplying the inflow rate with the length of the time step. The new height of spilled transformer oil at the concrete pad (row 3 column 3 on Appendix G) is found by dividing the volume of transformer oil remains on the concrete pad at the previous time step with the base area of the concrete pad. The data in columns 4 and 5 always follow the same calculation procedures that were discussed above. Finally, the average inflow rate entering into the catchbasin within the first time step (row 3 column 6 on Appendix $G$ ) is determined by taking the average inflow of the first time interval (column 5 rows 2 and 3 on Appendix G). 
The determination of inflow rate is a function of the surface elevation of the transformer oil layer at catchbasin. A typical catchbasin's sump is $1.8 \mathrm{~m}$ in height. The height between the bottom part of the catchbasin and the bottom part of the outlet pipe is usually $0.45 \mathrm{~m}$. Therefore, the inflow rate equation is used when the surface elevation of the oil layer is within

$$
1.8 m-0.45 m=1.35 m
$$

Once the surface elevation exceeds this height, the head of the transformer oil at the concrete pad will dominate the flow entering the oil back-up system.

Appendix $H$ demonstrates the four MATLAB programs involved for the implementation of the mathematical model of the oil back-up system.

\subsection{Numerical Analysis and Results}

The numerical modeling results can be found in Appendix I. Figures 4.6 to 4.9 illustrate the heights of the layers at different time intervals. Figure 4.10 indicates the variation of water and oil levels over time during a transformation oil spill.

In the numerical experiment of $0.5 \mathrm{~m}$ depth of spilled transformer oil on the concrete pad at $t=0$ seconds (Figure 4.6), HI increases rapidly between 0 to 6 seconds (column 6 rows 2 to 5 in Appendix I) and the transformer oil levels inside the catchbasin and on the concrete pad merge together (Figure 4.7). After $H I$ reaches its highest elevation at 
48 seconds (row 6 column 6 in Appendix G), it decreases slowly and stops at 146 seconds where $H I$ is equal to $10.92 \mathrm{~m}$ (Figure 4.9). The spilled transformer oil is eventually backed up at a depth of $0.12 \mathrm{~m}$ by the oil back-up.

The total height of oil and water lavers $(H 2+H 3)$ at the oil back-up system peaks at 48 seconds (Figure 4.8). The mathematical model of the oil back-up system is designed without defining the height of the tank because the height of the tank can always be determined from the model results. For instance, $(H 2+H 3)$ is around $11 m$ at 48 seconds (Figure 4.8). Therefore, the minimum height requirement for the oil back-up system is $11 \mathrm{~m}$ from datum. Since the height between the datum and the bottom part of the tank is $8.23 \mathrm{~m}$, the minimum height of the tank is $2.77 \mathrm{~m}$. Once $(H 2+H 3)$ reaches its highest elevation, it decreases slowly and stops at the height of $10.92 \mathrm{~m}$ at 146 seconds.

When the variations of $H 2$ and $H 3$ are observed separately, the rate of change in the first half of the numerical experiment, $t=0$ to 100 seconds, are much slower than the second half, $t=100$ to 146 seconds (Figure 4.10). Also, the rate of change of each height is opposite to each other, where $H 2$ (oil layer height) increases and $H 3$ (water layer height) decreases throughout the experiment. These results seem reasonable and satisfy the hydrostatic pressure properties between transformer oil and water (Equation [58]). Thus, the numerical model of oil back-up system perform logically. 
The height of $\mathrm{H3}$ at 146 seconds equals $0.31 \mathrm{~m}$ (Figure 4.9). Since it is greater than zero, the oil back-up system with the design dimensions (Figure 4.4) will not fail for an initial $0.5 \mathrm{~m}$ depth of spilled transformer oil on the concrete pad. Finally, this numerical experiment stops at $t=146$ seconds since the solutions of $H l$ and $H 4$ are in negative. after this time interval (Appendix G). The reason for the negative results after $t=146$ seconds is because the heights of the layers become stable and the numerical scheme become unstable. 
$t=0$ seconds

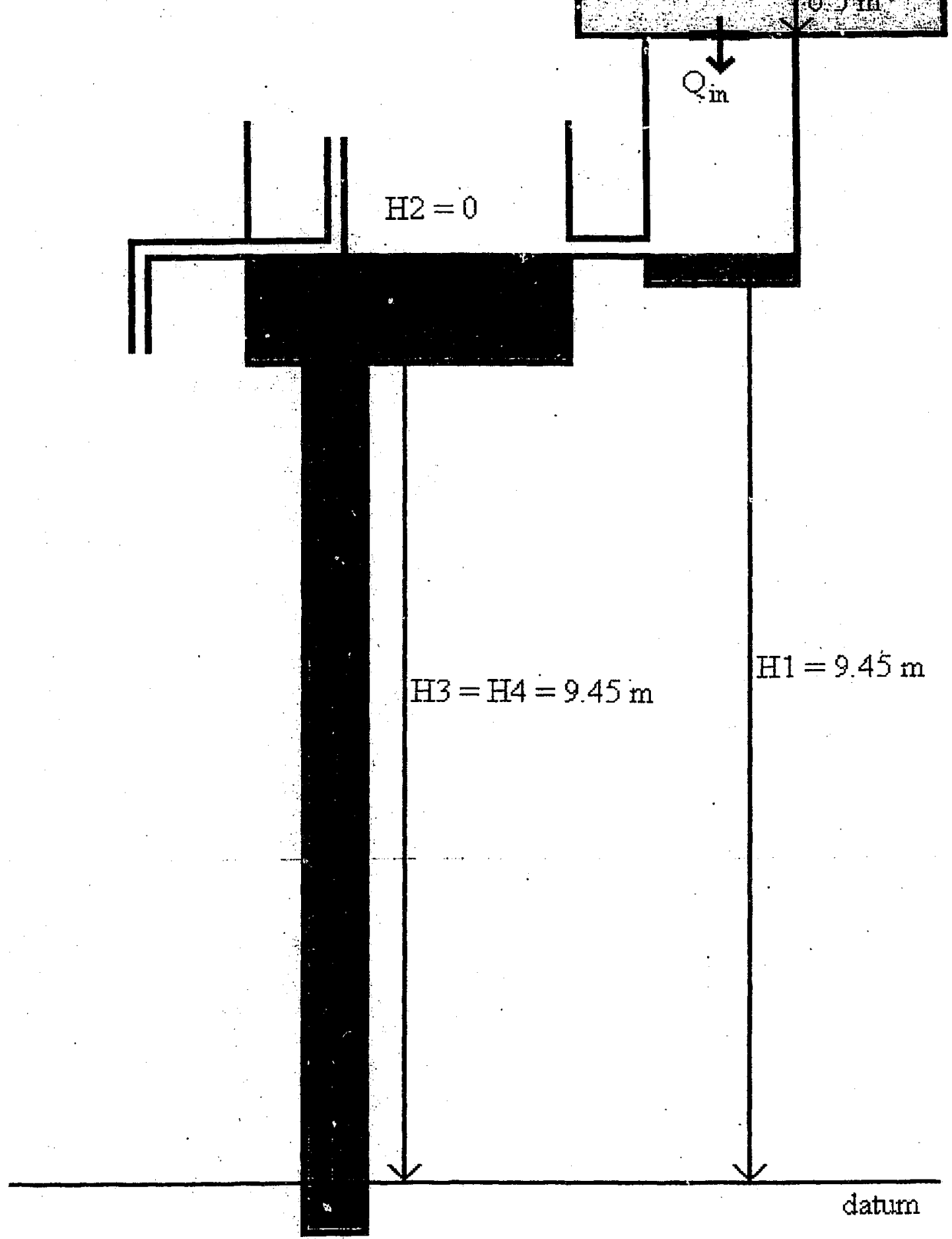

Figure 4.6: Numerical result of the oil back-up system at $t=0$ seconds.

Page 97

Reproduced with permission of the copyright owner. Further reproduction prohibited without permission. 


$$
t=6 \text { seconds }
$$

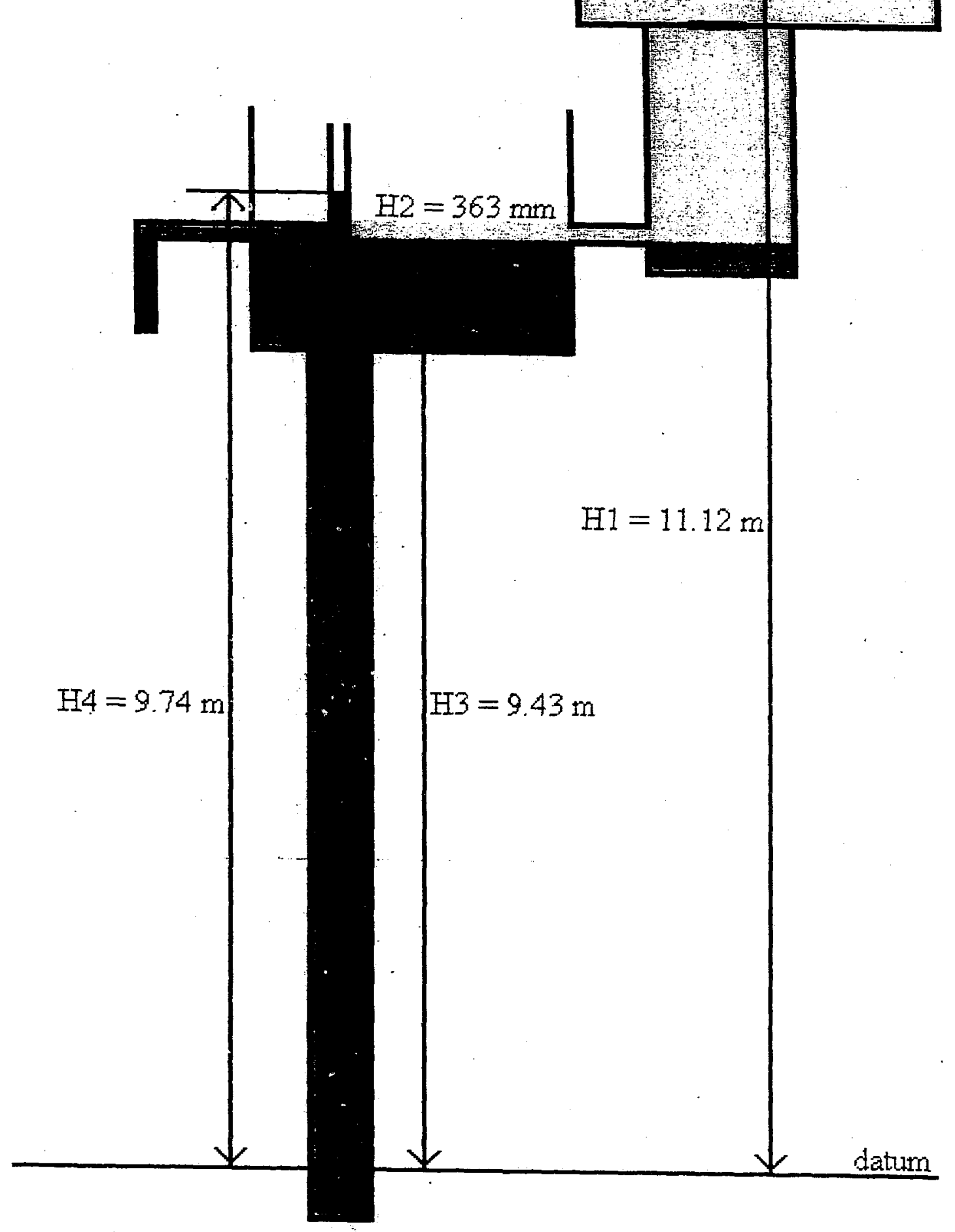

Figure 4.7: Numerical result of the oil back-up system at $t=6$ seconds.

Page 98 


$$
t=48 \text { seconds }
$$

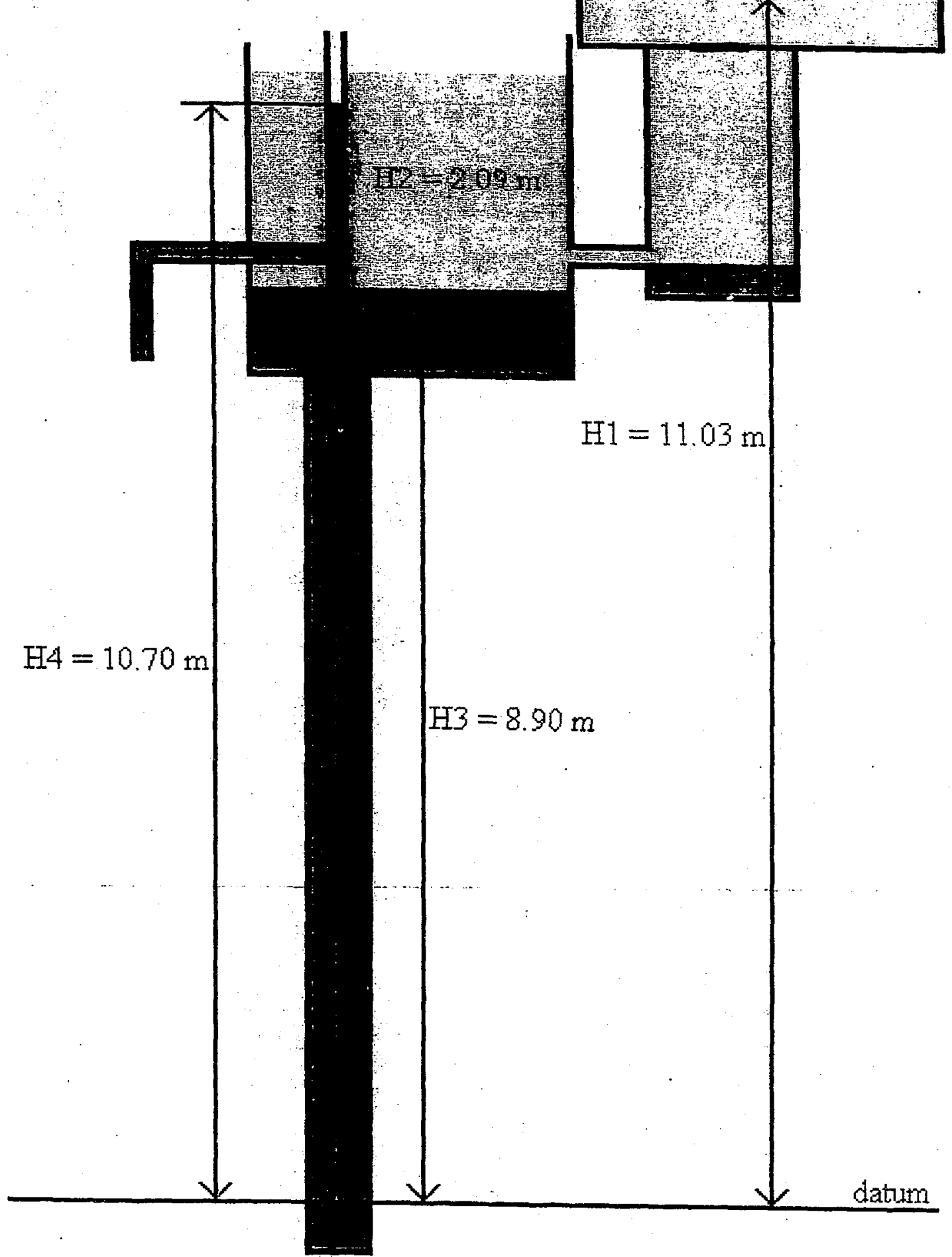

Figure 4.8: Numerical result of the oil back-up system at $t=48$ seconds.

\section{Page 99}




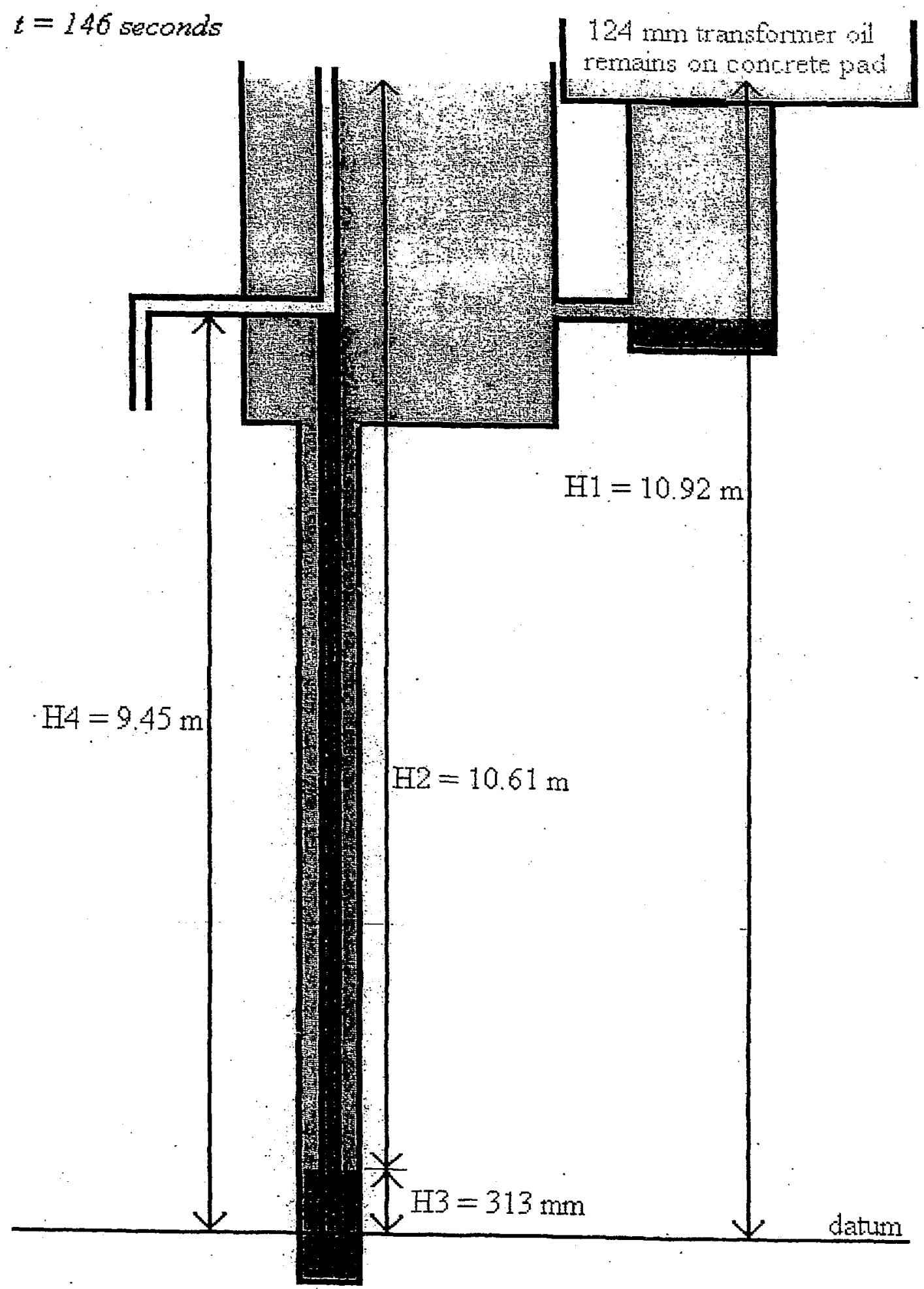

Figure 4.9: Numerical result of the oil back-up system at $t=146$ seconds.

Page 100

Reproduced with permission of the copyright owner. Further reproduction prohibited without permission. 


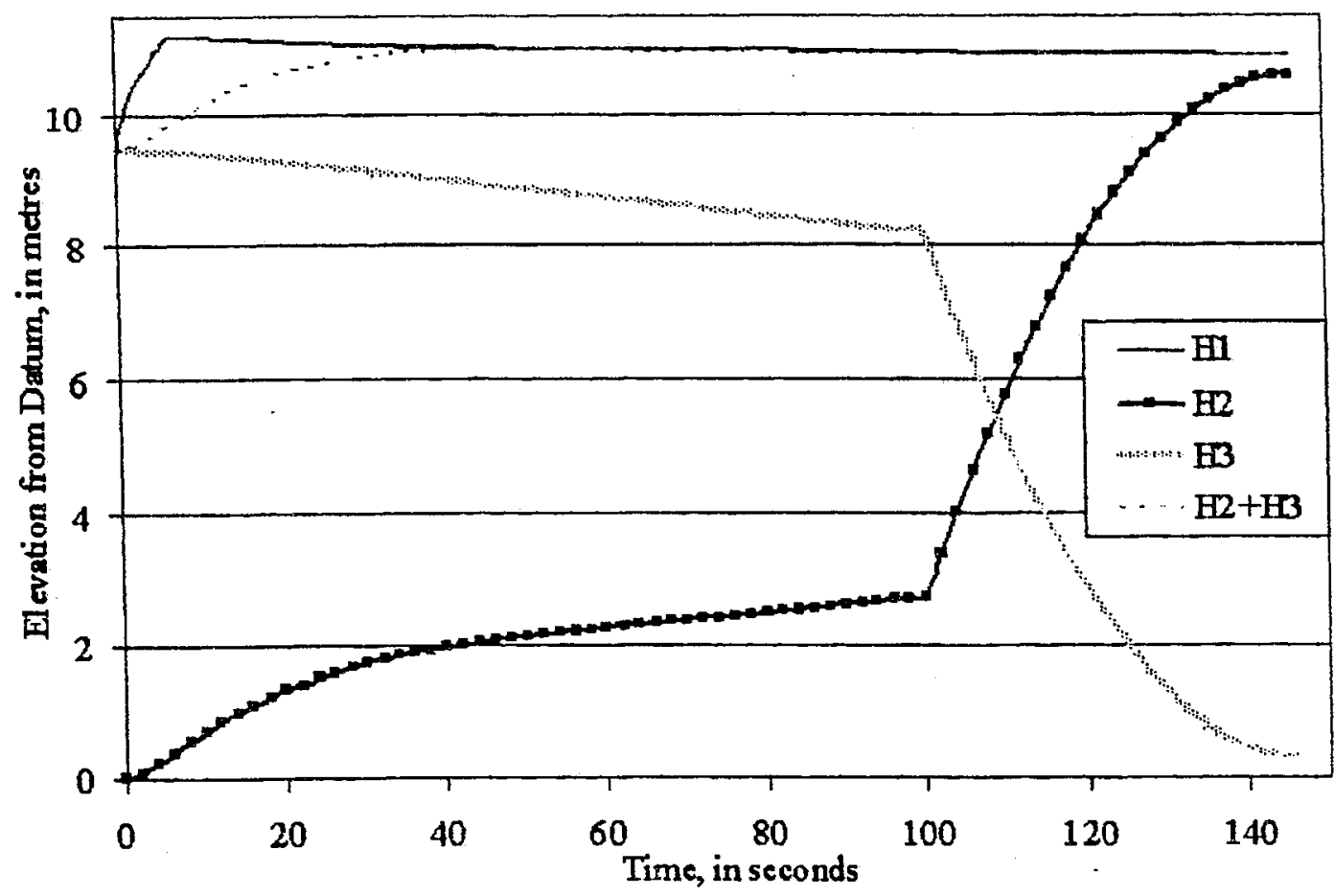

Figure 4.10: Heights' variables versus time.

Page 101 


\section{Chapter 5 CONCLUSIONS AND RECOMMENDATIONS}

\subsection{Conclusions}

Based on the physical and mathematical model analyses, the two hydraulically-based oil spill control systems can prevent spilled transformer oil entering into the local sewers. For the oil trap system, the physical model experiments indicate that the model can trap a quantity of $36 \mathrm{~L}$ transformer oil without being flush out at the maximum water flow of $0.18 \mathrm{~L} / \mathrm{sec}$. These model results are equivalent to approximately $85,000 \mathrm{~L}$ transformer oil in the prototype and a flow greater than the 100 year storm. This amount of transformer oil is about one-third of the total volume of transformer oil used in Hydro One's transformer station near the city of Burlington. Therefore, three oil trap systems will be needed to capture the most severe transformer oil spill. However, it is very unusual to have six individual transformer stations to spill out its total volumes of transformer oil at the same time.

The oil-water separation experiments conducted in the physical model of the oil trap system demonstrate that the spilled transformer oil cannot escape from the system for both dry and wet weather conditions. Without pump operation in the experiments, it represents the occurrence of a dry weather transformer oil spill. The oil-water separation in this situation is mainly dependent on the diameters of oil globules (Equation [1]). The diameter of the oil globule and the rising velocity are in direct proportional to each other. Without pump operation (i.e. dry weather condition), the oil 
globules of large spills rise faster than the oil globules of small spills. With pump operation, it represents the occurrence of a transformer oil spill during a rainstorm. The oil globules of small spills spread out to about one-third of the oil trap system length before they rose up. The oil globules of large spills are much larger than that of the previous case (without pump operation). They also rose along the outside of the inlet pipe area instead of spreading out to the oil trap system.

The mathematical model in Chapter 4 demonstrates that the design dimensions of the oil back-up system shown in Figure 4.4 can back up approximately $7600 \mathrm{~L}$ of spilled transformer oil to the concrete pad of Hydro One's transformer station near the city of Burlington. The final depth of spilled transformer oil on the concrete pad is $0.12 \mathrm{~m}$ (Section 4.4). There is a gap of $0.31 \mathrm{~m}$ (Section 4.4) between the bottom of the internal pipe column and the interface of oil and water. This indicates that the spilled transformer oil will not escape from the system. The height of the oil back-up system is determined to be $11 \mathrm{~m}$ above datum, which is $0.2 \mathrm{~m}$ above the bottom of the concrete pad. Since the height of the concrete pad is about $1 \mathrm{~m}$ and it is constructed $0.5 \mathrm{~m}$ below the ground, the oil back-up system should be constructed $0.3 \mathrm{~m}$ below ground levei. This mathematical model can be used to determine the designed volume of spilled transformer oil for dry weather condition.

Finally, the practical contribution of this research is to provide an estimate of the performance of the two hydraulically-based oil spill control systems to Hydro One in order to solve their existing problems in the transformer station near the city of 
Burlington. The scientific contribution of this research is to develop the mathematical model for the hydraulically-based oil back-up system. This mathematical model can simulate the levels of the transformer oil and water layers within the system at different time step and provide a design tool for this type of devices.

\subsection{Recommendations}

As indicated in Section 3.5, a new physical model must be constructed to minimize the uncertainties in the oil trap system experiments. This new model must be in closed system form in order to prevent the rising up of the transformer oil layer. Thus, a stronger construction material, such as steel, should be chosen instead of plexi-glass. Since steel is non-transparent, a window with sufficient strength to stand the internal pressure forces of a closed system should be built on one side of the physical model for observation purpose. Valve should be also installed on the top of the model in order to insert the transformer oil into the system.

Once the new physical model is ready, experiments for the determination of the failure flow situation versus different volumes of transformer oil within the oil trap system can be conducted. Different amounts of transformer oil should be added into the system through the valve. After inserting each amount of transformer oil, water can be pumped to the system from the vertical inlet pipe until waves are formed at the interface of oil and water. A powerful pump may be needed in order to provide a larger flow rate for the formation of the waves. Furthermore, different sizes of physical models for the oil 
trap system should be constructed for verification of the significance of the $\Pi$-terms derived in Equation [22].

Another set of experiments can be developed in order to determine the relationship between the diameter of the outlet pipe and the width of the oil trap system. The diameter of the outlet pipe is a major factor to cause transformer oil escaping from the system. If the diameter of the outlet pipe is small, the exiting velocity of water in the system will be larger. This may increase the possibility of dragging out the transformer oil from the system. On the other hand, the chance for transformer oil escapes from the system with a small diameter of the outlet pipe is smaller than a large diameter of the outlet pipe. Therefore, experiments must be developed in order to find out the best ratio between the diameter of the outlet pipe and the width of the oil trap system to prevent transformer oil from escaping from the system.

The major oil spill operating condition (Section 2.5) assumes that a large amount of transformer oil spill enters into the system rapidly. Hence, the length of the vertical inlet pipe may create a back-up situation for the spilled transformer oil at this situation. The purpose of the oil trap system is to force spilled transformer oil entering into the system and trap in the system. There is a good chance that the spilled transformation oil be back up if the vertical inlet pipe is long. Thus, experiments should be developed to determine the effect on the creation of a back-up situation with different lengths of the vertical inlet pipe. 
Finally, the results for the oil-water separation experiments of the oil trap system are for observation purpose only. In order to determine whether the distance between the two vertical pipes are suitable for oil-water separation, the rising velocity ratio between the model and the prototype must be maintained (Appendix C). Therefore, a new physical model and a new set of experiments must be developed in order to determine the oilwater separation process within the oil trap system.

For the oil back-up system, it is important to verify the numerical result by conducting a physical model experiment in a future study. Also, this research only did one numerical experiment to demonstrate the operation of the mathematical model and to solve the problem at Hydro One's transformer station in the city of Burlington due to the lack of time. More numerical experiments should be conducted in order to determine the relationship between different amounts of spilled transformer oil at the concrete pad and the base area of the tank in the oil back-up system. Another relationship between different volumes of spilled transformer oil and the height from datum to the bottom of the tank in the oil back-up system (variable $h_{\text {column }}$ ) should be determined in future study as well. These two relationships are the major factors to cause the failure of the system. Once the sensitivity between different amounts of spilled transformer oil and the above two dimensions are developed, the oil back-up system design may be done without running the numerical model.

It is also interesting to find out whether the diameters for the internal and external pipe columns are a major factor to cause the failure of the oil back-up system. The volume 
between the internal and external pipe columns is small. Therefore, the size of the tank in the oil back-up system should dominate the failure of the system. The design of the pipe columns are to slow down the increasing rate of the oil layer due to hydrostatic pressure. More numerical models should be conducted to determine whether the change of the diameters for the internal and external pipe columns affect the final elevation of the interface between oil and water.

Finally, the numerical experiment is designed for the occurrence of a major transformer oil spill under dry weather condition. It does not consider the situation of a transformer oil spill occurring during a rainstorm. Modification for the numerical model is needed for the wet weather condition. Furthermore, when a major transformer oil spill occurs during rainstorm, the rainwater should sink to the catchbasin due to the density difference between oil and water. Since the catchbasin and the concrete pad have limited space, it may cause the transformer oil to spill out to the ground depending on the duration and the intensity of the rainstorm. Thus, more considerations must be included in the modification of the numerical model. 


\section{APPENDIX A}

\section{DIMENSIONAL ANALYSIS METHOD}


Since the experimental studies were conducted on a scaled-down model of the oil trap system, it is important to determine the possible relationships of all the system using the dimensional analysis, such relationships can be used variables to convert the experimental results back to its prototype.

Dimensional analysis is a method of partial analysis which is based on the work of Fourier who developed the principle of dimensional homogeneity (Sharp, 1981). His works stated that any equation is correct only if all terms of the equation have the same dimensions. More specifically, the dimensions of any term can be represented as multiples of mass $[M]$, length $[L]$ and time $[T]$. Therefore the exponents of the mass, length and time dimensions must be the same in each term of the equation. For example, the equation for distance travelled, $d$, by an object moving from rest through a time, $t_{l}$, with acceleration, $a$, and through a time, $t_{2}$, with constant velocity, $v$, is given by:

$$
d=1 / 2 a t_{1}^{2}+v t_{2}
$$

Dimensionally this can be rewritten as

$$
[\mathrm{L}]=1 / 2\left([\mathrm{~L}] /[\mathrm{T}]^{2}\right)\left([\mathrm{T}]^{2}\right)+([\mathrm{L}] /[\mathrm{T}])([\mathrm{T}])
$$

where $1 / 2$ at the first term on the right side is a constant (Sharp, 1981).

Inspection of equation [A.2] shows that the dimension in each term of any equation must be the same. This principle provides immediate insight into the variables which may be relevant in any fluid system. However, one important concept about dimensional analysis is that any correct equation must be dimensionally homogeneous but any 
dimensionally homogeneous equation is not necessarily complete or corrects (Sharp, 1981).

The application of the Fourier's principle has received considerable attention since it was proposed in the early nineteenth century. In particular, Rayleigh and Buckingham developed methods that are widely used today (Sharp, 1981). This research uses the Buckingham's method for the dimensional analysis study of hydraulic oil spill control systems.

\section{BUCKINGHAM'S METHOD}

Buckingham developed the arguments at the previous section into a theorem which related the number of parameters in a correct functional equation to the number of variables needed to specify the phenomenon and to the number of dimensions involved. Generally, he stated that if $m$ variables and $n$ dimensions are involved, a correct partial analysis will result in $(m-n)$ dimensionless parameters. Buckingham called these parameters $\Pi$-terms. Thus, his theorem is usually called the $\Pi$-theorem (Sharp, 1981).

More specifically, with $m$ variables and $n$ dimensions there will be $(m-1)$ exponents to be determined from $n$ simulianeous equations. Therefore, it is possible to solve for $n$ exponents in terms of the remaining $(m-I-n)$ to obtain an equation of the form below. 


$$
A=C \Pi_{l}^{a} \Pi_{2}^{b} \Pi_{3}{ }^{c} \ldots \Pi_{m-1-n}^{k}
$$

where each $\Pi$-term is a dimensionless parameter and $(A / C)$ is another $\Pi$-term. Altogether, there are $(m-n) \Pi$-terms.

Buckingham also suggested a method of approach in which each $\Pi$-term is derived independently from the others. The procedure is to select three relevant variables involving all dimensions present and to combine each other variable in turn with these three relevant variables to form a dimensionless parameter. A practical example will be discussed below to demonstrate Buckingham's method (Sharp, 1981).

Consider the flow of fluid, $Q$, over a variety of vee-notches, $B$ and $H$, with the dynamic viscosity of the fluid, $\mu$, and the density, $\rho$.

$$
Q=\varphi(g, H, B, \mu, \rho)
$$

From the above starting equation, six variables $(m=6)$ and three dimensions $(n=3)$ are presented. So, three $\Pi$-terms ( $m-n=6-3=3$ ) are necessary in a complete functional equation. Taking $\mu, \rho$ and $g$ as the three relevant variables, since they contain all dimensions ( $[M],[L],[T]$ ) involved in the problem (Equation [A.4]) and cannot form $\Pi$-term themselves. The $\Pi$-terms are obtained by combining $H, B$ and $Q$ with the three relevant variables one at a time so that each combination is dimensionless. Thus,

$$
\Pi_{l}=\mu^{a} \rho^{b} g^{c} H^{d}
$$

where $a, b, c$ and $d$ are constants. Writing equation [A.5] in dimensional form: 


$$
([M][L][T])^{0}=\left(\frac{[M]}{[L][T]}\right)^{a}\left(\frac{[M C]}{[L]^{3}}\right)^{b}\left(\frac{[L]}{[T]^{2}}\right)^{C}[L]^{d}
$$

where $[M]: a+b=0$

$[L]:-a-3 b+c+d=0$

$[T]: \quad a+2 c=0$

Solving for $a, b$ and $d$ in terms of $c$ so that equation [A.6] can be rewritten as:

$$
\Pi_{1}=\mu^{-2 c} \rho^{2 x} g^{x} H^{3 x}=\left(\frac{g \rho^{2} H^{3}}{\mu^{2}}\right)^{c}
$$

The value of $c$ is unimportant because the power of a dimensionless number is irrelevant when included in a functional equation. The two $\Pi$-terms may be formed in the same manner above (Sharp, 1981).

$$
\begin{aligned}
& \Pi_{2}=\mu^{a} \rho^{0} g^{c} B^{d}=\mu^{-2 c} \rho^{2 c} g^{c} B^{3 c}=\left(\frac{g \rho^{2} B^{3}}{\mu^{3}}\right)^{c} \\
& \Pi_{3}=\mu^{a} \rho^{b} g^{c} Q^{d}=\mu^{-5 c} \rho^{s c} g^{c} Q^{3 c}=\left(\frac{g \rho^{5} Q^{g}}{\mu^{5}}\right)^{c}
\end{aligned}
$$

Thus, the solution for this example is:

$$
\frac{g \rho^{5} Q^{3}}{\mu^{5}}=\varphi\left(\frac{g \rho^{2} H^{9}}{\mu^{2}}, \frac{g \rho^{2} B^{9}}{\mu^{2}}\right)
$$




\section{APPENDIX B}

\section{SIMILITUDE ANALYSIS}


Similitude and dimensional analyses are both methods of partial analysis. Each provides an incomplete answer. Generally, the final result of both methods is a dimensionless, functional equation suitable for planning experimental studies or designing hydraulic models. However, dimensional analysis is directed towards experimentation, the model laws being obtained by inspection of the dimensionless equation. Similitude analysis concentrates primarily on developing model laws from which a dimensionless, functional equation may be derived (Sharp, 1981).

The three general types of similarity are geometric, kinematic and dynamic. Geometric similarity requires the shape of the model to be the same as the prototype. This is probably the most obvious requirement for a model. It is achieved by making sure that each length of the prototype is reduced by a constant factor called the scale. Kinematic similarity requires that the shape of the streamlines at any particular time is the same in both model and prototype. In order to achieve the same boundaries of the fluid system, the boundaries in the model and prototype must be similar. Therefore, geometric similarity is a prerequisite of kinematic similarity. The basic requirement for dynamic similarity is that the ratio of any two forces acting in the model must be equal to the corresponding force ratio in the prototype. Furthermore, the forces acting on a fluid system includes: (1) forces external to the fluid, such as gravity forces or forces resulting from pressure differences; (2) forces related to the physical properties of the fluid, such as viscous or surface tension forces; (3) resultant forces, such as drag force on a submerged object or the force of the fluid on a hydraulic structure and (4) hypothetical inertia force, such as inertia forces experienced by accelerative fluid systems (Kline, 
1965). Table B.1 contains the standard dimensionless products relevant to fluid mechanics.

The application of the above similarity theory to the derivation of functional equations is known as similitude analysis. There are two basic approaches for similitude analysis. The first method uses the Buckingham $\Pi$-theorem to predict the necessary number of dimensionless parameters. These $\Pi$-terms are then developed using similarity theory. The second method is generally less applicable but valuable in certain specific circumstances. In cases where the dependent variable is a force, it is possible to write a dimensionally homogeneous equation in which every term has dimensions of force. This thesis will use the first method for similitude analysis (Sharp, 1981). 
Table B.1: Standard Dimensionless Products Relevant to Fluid Mechanics (Sharp, 1981).

\begin{tabular}{|c|c|c|}
\hline Name & Format & Comment \\
\hline Froude number & $V /(g L)^{1 / 2}$ & $\begin{array}{l}\text { May also be defined as the square of this } \\
\text { quantity. } \\
\text { Relevant to gravity forces. }\end{array}$ \\
\hline Reynolds number & $V L / v$ & Relevant to viscous force action. \\
\hline Weber number & $V(\rho L / \sigma)^{1 / 2}$ & $\begin{array}{l}\text { May also be defined as the square of this } \\
\text { quantity. } \\
\text { Refers to the action of surface tension forces. }\end{array}$ \\
\hline Euler number & $\Delta P /\left(\rho \nu^{2}\right)$ & $\begin{array}{l}\text { Also expressed as } V /(2 \Delta P / \rho)^{I / 2} \text {. } \\
\text { Important when pressure forces exist. } \\
\Delta P=\text { pressure difference. }\end{array}$ \\
\hline Cauchy number & $\left(\rho V^{2}\right) / K$ & $\begin{array}{l}\text { Relevant to system where compressibility is } \\
\text { important. } K=\text { bulk modulus of fluid. }\end{array}$ \\
\hline Mach number & $V / C$ & $\begin{array}{l}\text { Refers to compressibility effects, high-speed } \\
\text { flow. } \\
C=\text { local velocity of sound wave in fluid. }\end{array}$ \\
\hline $\begin{array}{l}\text { Richardson } \\
\text { number }\end{array}$ & $\left(g \rho^{\prime}\right) /\left[\rho\left(V^{\prime}\right)^{2}\right]$ & $\begin{array}{l}\text { Relevant in cases where fluids mix or interact. } \\
\rho^{\prime} \text { and } V^{\prime} \text { represent vertical density and velocity } \\
\text { gradients, i.e. } \partial \rho / \partial H \text { and } \partial V / \partial H \text {. }\end{array}$ \\
\hline $\begin{array}{l}\text { Froude-Reynolds } \\
\text { number }\end{array}$ & $\left(g^{1 / 2} H^{3 / 2}\right) / v$ & Combined gravity and viscous effects. \\
\hline Thoina number & $\left(P_{1}-P_{v}\right) /\left(P_{2}-P_{l}\right)$ & $\begin{array}{l}\text { A form of cavitation parameter. } P_{1} \text { and } P_{2} \text { are } \\
\text { absolute pressures on the low- and high- } \\
\text { pressure sides of a hydraulic machine. } P_{v} \text { is the } \\
\text { vapour pressure of the liquid. }\end{array}$ \\
\hline
\end{tabular}




\section{APPENDIX C}

\section{DETERMINATION OF MODEL SCALES}


The fundamental scale for any hydraulic model is the geometric scale. That is, the ratio of some length in the model to the corresponding length in the prototype. Choice of a suitable geometric scale depends on the type of fluid system to be studied and on the space available to build the model. However, once the scale of the model has been fixed, the requirements for dynamic similarity may be used to determine other model scales. These are needed in order to operate the model so that it will be dynamically similar to the prototype. Thus, measurements made in the model can be then used to determine prototype values (Pankhurst, 1964).

Although scaling criteria vary depending on the particular model laws to be followed, the procedure used to generate these scales does not change. Therefore, it is sufficient to demonstrate this procedure using the following model law, gravitational forces, which is the most appropriate to hydraulic models.

When gravity forces are important it has been shown that the Froude number (Table B.1), in some form or another, must be the same in model and prototype. For instance,

$$
\left[\frac{V}{(g L)^{1 / 2}}\right]_{m}=\left[\frac{V}{(g L)^{I / 2}}\right]_{p}
$$

where subscripts $m$ and $p$ refer to model and prototype.

Assuming that gravitational acceleration, $g$, is constant over the surface of the earth, rearrangement of Equation [C.1] gives the following velocity scale. 


$$
\frac{V_{m}}{V_{p}}=\left(\frac{L_{m}}{L_{p}}\right)^{1 / 2}
$$

The ratio $L_{m} / L_{p}$ on equation [C.2] is the geometric scale. This is often a source of unnecessary confusion because the geometric scale may be quoted as $L_{m} / L_{p}$ or as $L_{p} / L_{m}$. However, a model would be referred to as, for example, a 1/20 scale model in which the scale is obviously $L_{m} / L_{p}$.

Equation [C.2] may be employed in two different ways. First, it can be used to determine the vclocity at which the model should be run to ensure that it will accurately simulate prototype velocities. For instance,

$$
V_{m}=V_{p}\left(\frac{L_{m}}{L_{p}}\right)^{1 / 2}
$$

Alternatively, it may be used to predict prototype velocities from measured model velocities:

$$
V_{p}=V_{m}\left(\frac{L_{p}}{L_{m}}\right)^{1 / 2}
$$

Other scales may be derived by transforming the Froudian requirement into different forms. For example, discharge, $Q$, is proportional to the product of velocity and area so that

$$
\nabla \propto Q / L^{2}
$$


Substituting equation [C.5] into equation [C.2] gives

$$
\frac{Q_{m}}{Q_{p}}=\left(\frac{L_{m}}{L_{p}}\right)^{S / 2}
$$

This is the discharge scale, commonly employed to determine the discharge at which the model should be run to simulate a known prototype discharge (Sharp, 1981). 


\section{APPENDIX D}

NEWTON-RAPHSON METHOD

Reproduced with permission of the copyright owner. Further reproduction prohibited without permission. 
Oil back-up system discussed in Chapter 4 involves simultaneous nonlinear equations with several variables. The Newton-Raphson method will be applied in order to solve these nonlinear equations. This method is derived from the Newton-Raphson method for solving equation of one variable. Its concept is discussed below.

\section{NEWTON'S METHOD FOR SOLVING EQUATION WITH ONE VARIABLE}

The Newton-Raphson method is calculus based and is one of the most popular rootsolving methods for equations in the form of

$$
f(x)=0
$$

In this method, information about a function $f(x)$ and its first derivative $f^{\prime}(x)$ are used to improve estimates of a root of Equation [D.1] above. Let $x_{o}$ be an initial estimate or guess of the root. A change of $h$ will be determined such that $f\left(x_{0}+h\right)$ is zero.

The Taylor series expansion for a function about a point $x_{0}$ is the infinite series.

$$
f\left(x_{0}+h\right)=f\left(x_{0}\right)+h \frac{d f\left(x_{0}\right)}{d x}+\frac{h^{2}}{2 !} \frac{d^{2} f\left(x_{0}\right)}{d x^{2}}+\cdots+\frac{h^{n}}{n !} \frac{d^{n} f\left(x_{0}\right)}{d x^{n}}+\cdots
$$

where $n$ ! is the factorial product given by

$$
n !=\left\{\begin{array}{l}
(n)(n-1)(n-2) \ldots(2)(1) ; \quad n>0 \\
1 ; n=0
\end{array}\right.
$$


If it is assumed that the function $f(x)$ can be approximated locally by a straight line so that the second and higher derivatives of the Taylor series expansion (Equation [D.2]) are taken to be zero, the equation can be truncated immediately after the first derivative term. The local straight line approximation is then equivalent to the tangent line at $x_{o}$. The value of $h$ for which $f\left(x_{0}+h\right)$ is zero can be approximated by

$$
h=-\frac{f\left(x_{0}\right)}{f^{\prime}\left(x_{0}\right)} \quad \text { where } f^{\prime}\left(x_{0}\right)=\frac{d f\left(x_{0}\right)}{d x}
$$

The improved estimate, $X_{i m p r o v e d}$, of the root is therefore given by

$$
X_{\text {improved }}=x_{0}-\frac{f\left(x_{0}\right)}{f^{\prime}\left(x_{0}\right)}
$$

After $X_{\text {improved }}$ is found from Equation [D.5], it is replaced by $x_{o}$ and Equation [D.5] is applied again. This iterative process continues until convergence is achieved as indicated by the condition $\left|f\left(x_{0}\right)\right| \leq \varepsilon$, where $\varepsilon$ is some small quantity for the stopping conditions (Fausett, 1999).

The reason of why the Newton-Raphson method so popular is that although the determination of the derivative may be tedious for complicated equations, the implementation of the method is simple and convergence is fairly rapid. Nevertheless, the method may fail for a variety of reasons. One obvious difficulty occurs when $f\left(x_{a}\right)$ in the denominator of Equation [D.5] is zero. This situation may occur at the start of the procedure because of an unfortunate choice for the starting value $x_{0}$. The corrective 
action is to reset $x_{0}$ to a different value whenever $\left|f\left(x_{0}\right)\right|$ exceeds $A\left|f^{\prime}\left(x_{0}\right)\right|$, where $A$ is some large value based on the overflow characteristics of the computer (Akai, 1994).

Oscillations of $X_{\text {improved }}$ values may indicate that there is no real root of an equation as shown in Figure D.1. They may also occur when there is a root as shown in Figure D.2. For the case in Figure D.2, round-off errors will break the cycle; but then divergence is just as likely to occur as convergence. Divergence is shown for a function with two real roots in Figure D.3. For the functions in Figures D.2 and D.3, appropriate care in choosing the starting value $x_{0}$ is necessary to guarantee convergence (Akai, 1994). 


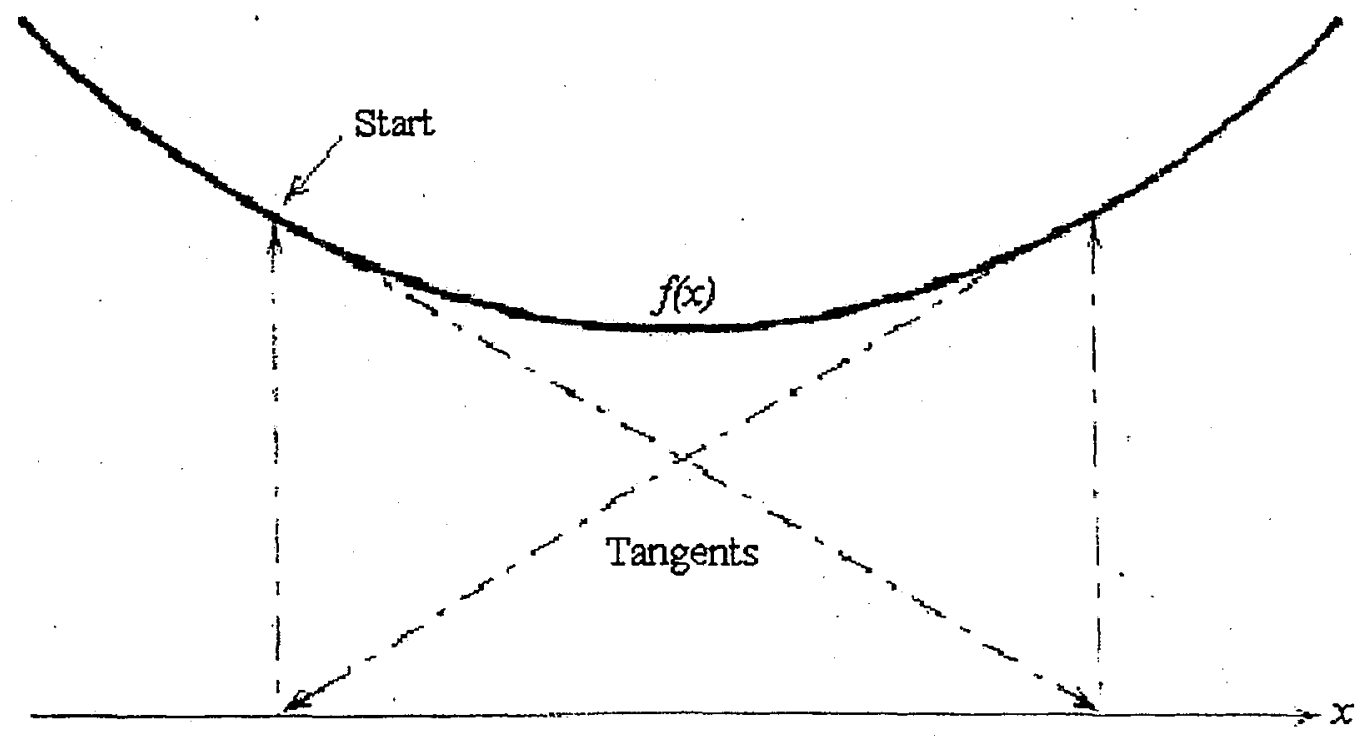

Figure D.1: Oscillations for a function with no real root (Akai, 1994).

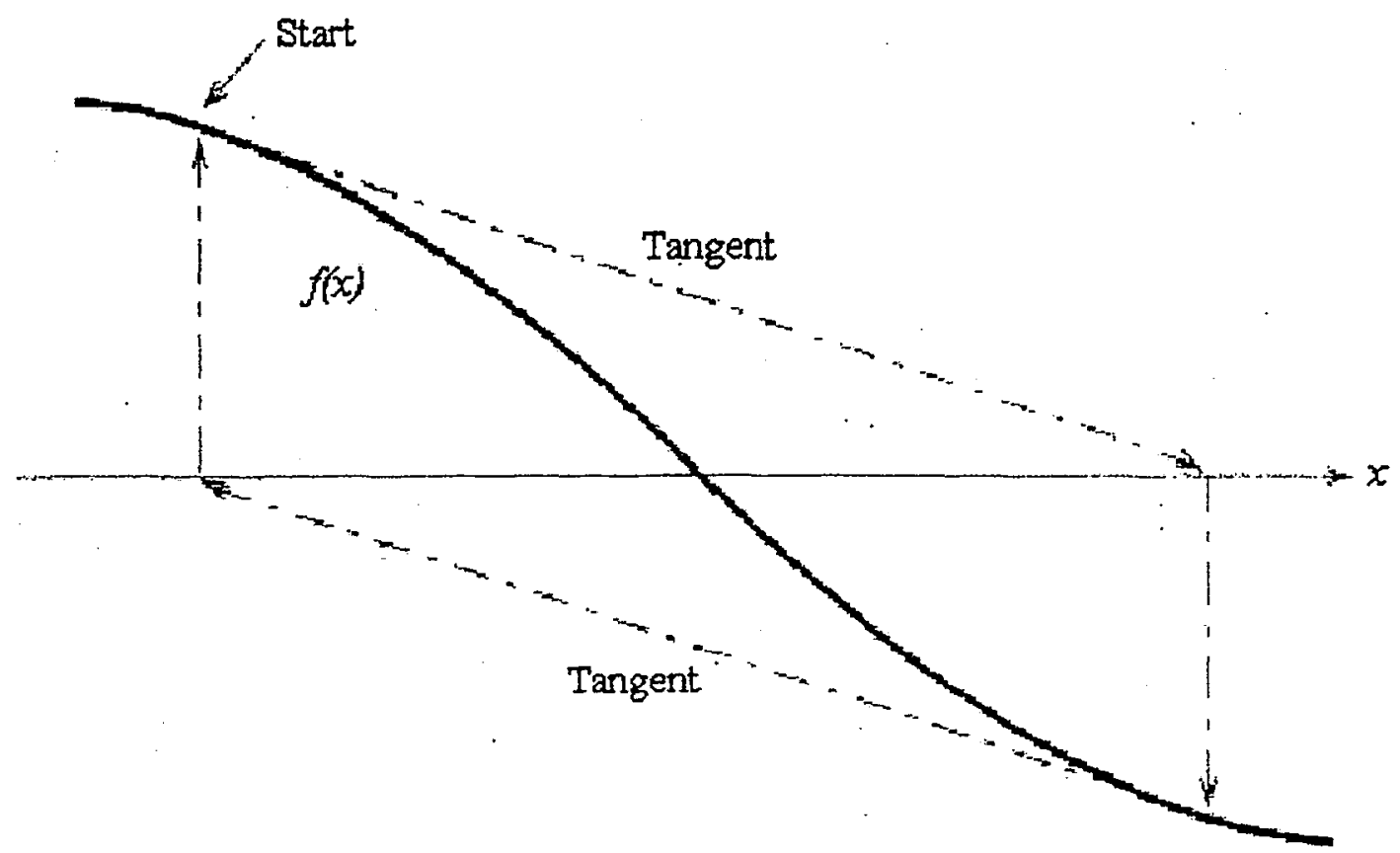

Figure D.2: Oscillations for a function with a real root (Akai, 1994). 


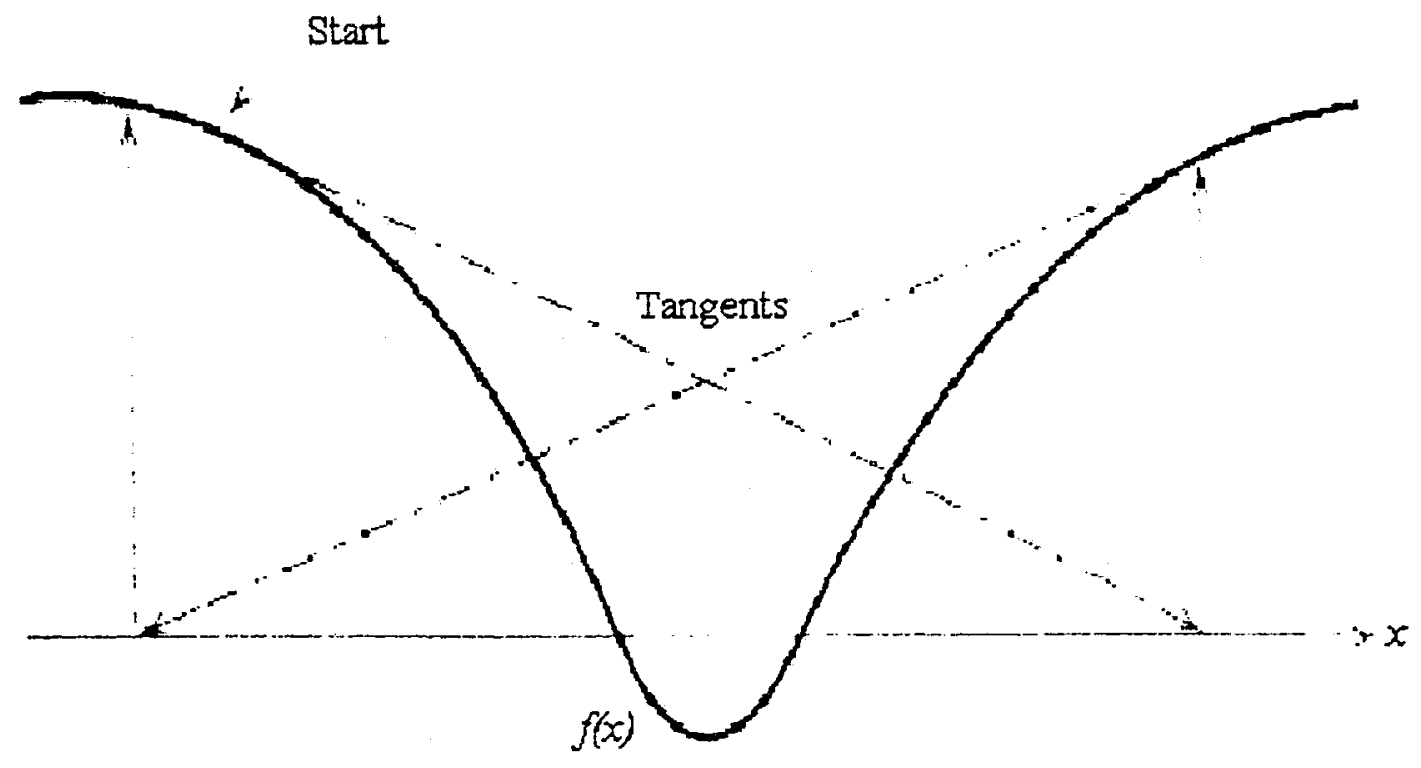

Figure D-3: Divergence for a function with two real roots (Akai, 1994). 
It is also noticed that the Newton-Raphson method will not necessarily converge to a root that is nearest to the starting point. For example, the equation

$$
\sin x=0 \quad \text { where } x \text { is in radians }
$$

has an infinite number of roots $n I I$, where $n$ is an integer. If the starting value of $x_{0}$ is 1.5 , the method converges to the root $(-4 \Pi)$. It is therefore prudent to verify that the root found by the Newton-Raphson method is the desired one (Akai, 1994).

\section{NEWTON'S METHOD FOR SOLVING SIMULTANEOUS NONLINEAR EQUATIONS}

Solving simultaneous nonlinear equations using Newton-Raphson method is derived from the above method. For systems consist of $n$ equations in $n$ variables $\left(x_{1}, x_{2}, \ldots, x_{n}\right)$ with its general form

$$
\begin{gathered}
f_{1}\left(x_{1}, x_{2}, x_{3}, \ldots, x_{n}\right)=0 \\
f_{2}\left(x_{1}, x_{2}, x_{3}, \ldots, x_{n}\right)=0 \\
f_{3}\left(x_{1}, x_{2}, x_{3}, \ldots, x_{n}\right)=0 \\
\vdots \\
f_{n}\left(x_{1}, x_{2}, x_{3}, \ldots, x_{n}\right)=0
\end{gathered}
$$

The development of the procedure for solving systems of nonlinear equations requires the concepts of matrices, vectors, norms and solutions of linear systems. First, a column vector $\mathbf{X}$ is defined as 


$$
\mathbf{X}^{\mathbf{T}}=\left[\begin{array}{lllll}
x_{1} & x_{2} & x_{3} & \ldots & x_{n}
\end{array}\right]
$$

Then, the system of equations can be rewritten in a more compactly form as

$$
f_{k}(\mathbf{X})=0 ; \quad \text { where } k=1,2, \ldots, n
$$

As in the Newton-Raphson method for solving equation with one variable, the solution process is started with an initial estimate $\mathbf{X}_{0}$ of the solution vector. The initial vector is written as

$$
\left(\mathbf{X}_{0}\right)^{\mathrm{T}}=\left[\begin{array}{llll}
\left(x_{1}\right)_{0} & \left(x_{2}\right)_{0} & \cdots & \left(x_{n}\right)_{0}
\end{array}\right]
$$

and the improved estimate is

$$
\mathbf{X}_{\text {improved }}=\mathbf{X}_{0}+\mathbf{h}
$$

where

$$
\begin{aligned}
& \left(\mathbf{X}_{\text {improved }}\right)^{\mathbf{T}}=\left[\begin{array}{llll}
\left(x_{1}\right)_{\text {improved }} & \left(x_{2}\right)_{\text {improved }} & \ldots & \left(x_{n}\right)_{\text {improved }}
\end{array}\right] \\
& \mathbf{h}^{\mathbf{T}}=\left[\begin{array}{llll}
h_{1} & h_{2} & \ldots & h_{n}
\end{array}\right] \\
& \left(x_{k}\right)_{\text {improved }}=\left(x_{k}\right)_{0}+h_{k} ; \quad \text { where } k=1,2, \ldots, n
\end{aligned}
$$

The procedure for determining $\mathbf{h}$ is based on the truncated Taylor series for a function of several variables. If the truncation takes place immediately following the first derivative terms of the series, the equation of $f_{k}\left(\mathbf{x}_{0}+\mathbf{h}\right)$ becomes

$$
\begin{gathered}
f_{k}\left(\mathbf{x}_{0}+\mathbf{h}\right)=f_{k}\left(\mathbf{x}_{0}\right)+\sum_{j=1}^{n}\left[h_{j} \partial f_{k}\left(\mathbf{x}_{0}\right) / \partial x_{j}\right] ; \\
\text { where } k=1,2, \ldots, n
\end{gathered}
$$


The matrix form of Equation [D.15] is

$$
\mathbf{J} \cdot \mathbf{h}=-\mathbf{f}
$$

in which $\mathbf{f}$ is the column vector given by

$$
\mathbf{f}^{\mathbf{T}}=\left[\begin{array}{llll}
f_{1}\left(x_{0}\right) & f_{2}\left(x_{0}\right) & \ldots & f_{n}\left(x_{0}\right)
\end{array}\right]
$$

and $\mathbf{J}$ is the partial derivative matrix known as the Jacobian and is given by

$$
\mathrm{J}=\left[\begin{array}{cccc}
\partial f_{1}\left(\mathbf{x}_{\mathbf{a}}\right) / \partial x_{1} & \partial f_{1}\left(\mathbf{x}_{\mathbf{a}}\right) / \partial x_{2} & \cdots & \partial f_{1}\left(\mathbf{x}_{\mathbf{a}}\right) / \partial x_{n} \\
\partial f_{2}\left(\mathbf{x}_{\mathbf{a}}\right) / \partial x_{1} & \partial f_{2}\left(\mathbf{x}_{\mathbf{\alpha}}\right) / \partial x_{2} & \cdots & \partial f_{2}\left(\mathbf{x}_{\mathbf{\alpha}}\right) / \partial x_{n} \\
\vdots & \vdots & & \vdots \\
\partial f_{n}\left(\mathbf{x}_{\mathbf{a}}\right) / \partial x_{1} & \partial f_{n}\left(\mathbf{x}_{\mathbf{\alpha}}\right) / \partial x_{2} & \cdots & \partial f_{n}\left(\mathbf{x}_{\mathbf{a}}\right) / \partial x_{n}
\end{array}\right]
$$

The vector $\mathbf{h}$ in Equation [D.16] may be easily found using Equation [D.11] when $n$ is small.

$$
\mathbf{h}=\mathbf{X}_{\text {improved }}-\mathbf{X}_{\mathbf{0}}
$$

The procedure for the multivariable Newton-Raphson method is as follows:

1. Choose a starting vector $\mathbf{X}_{\mathbf{0}}$.

2. Compute $f_{k}\left(\mathbf{X}_{\mathbf{0}}\right)$ for $k=1,2, \ldots, n$

3. If $\|\mathbf{f}\| \leq \varepsilon, \mathbf{X}_{\mathbf{0}}$ is the estimated solution. Otherwise, go on to step 4 .

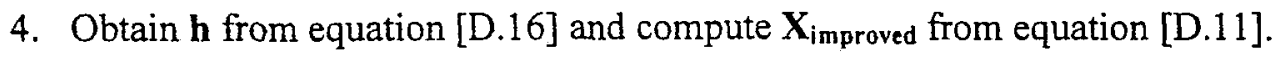

5. Set $\mathbf{X}_{\mathbf{0}}$ equal to $\mathbf{X}_{\text {improved }}$ and return to step 2 . 
The convergence criterion used in step 3 of the above procedure is similar to the one used in the previous section, except that the absolute value of a single function is now replaced by the norm of the vector whose components are the $n$ function values $f_{k}\left(\mathbf{X}_{0}\right)$. The $\infty$-norm, which is the component with the largest magnitude, provides an upper bound on the magnitudes of all components of $\mathbf{f}$. The corrective actions in the event of failure for multivariable Newton-Raphson method are the same as the single-variable version. However, the presence of several variables instead of only one may make corrective steps more difficult to accomplish (Akai, 1994). 


\section{APPENDIX E}

\section{MATLAB FUNCTION FOR SOLVING NON-LINEAR \\ EQUATIONS}


The development of the mathematical model for the oil back-up system is basically applying the MATLAB function for solving nonlinear equations using Newton's method below (Fausett, 1999).

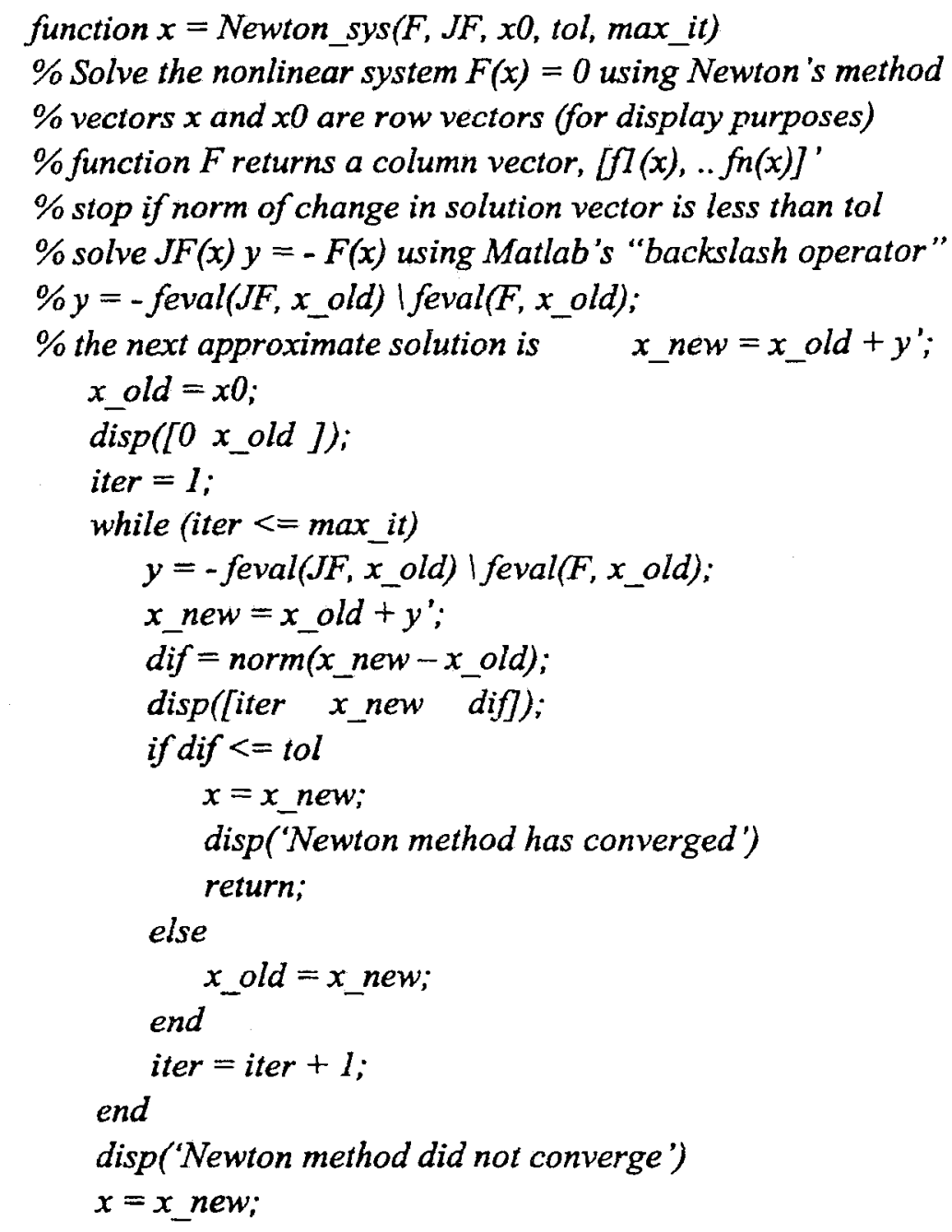

Lines 2 to 8 are explanations of the purpose of the MATLAB function. Line 9 is equivalent to step 1 of the procedure discussed on Appendix D. Line 13 is the determination of vector $h$ (Appendix D). Line 14 is same as Equation [D.11]. Line 15 
equals to step 3 of the procedure discussed on Appendix D. Variable tol at line 17 is the stopping condition, $\varepsilon$, set by the programmer (Appendix D). 


\section{APPENDIX $\mathrm{F}$}

\section{DETERMINATION OF THE FLOW RATE AT EACH DIAL}




\begin{tabular}{|c|c|c|c|c|c|c|c|c|c|c|c|c|c|c|c|c|}
\hline 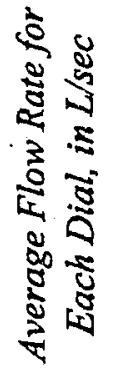 & & & & $\begin{array}{c}0 \\
0 \\
0 \\
0 \\
0 \\
0 \\
+1 \\
0 \\
0 \\
= \\
0\end{array}$ & & & & 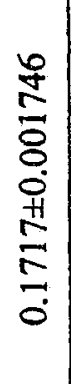 & & & & $\begin{array}{l}\frac{1}{n} \\
0 \\
8 \\
0 \\
+1 \\
\frac{1}{0} \\
\frac{n}{0}\end{array}$ & & & & 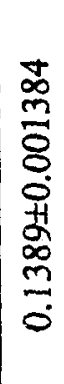 \\
\hline 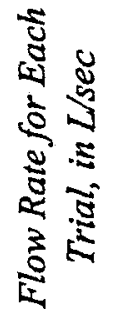 & 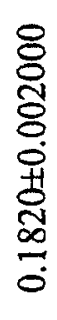 & $\begin{array}{l}\bar{\Xi} \\
\infty \\
\\
0 \\
0 \\
+ \\
\vdots \\
\vdots \\
0\end{array}$ & 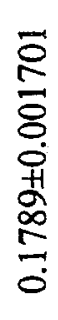 & 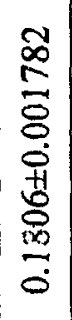 & $\begin{array}{l}0 \\
0 \\
0 \\
8 \\
0 \\
0 \\
+1 \\
0 \\
0 \\
0\end{array}$ & $\begin{array}{l}\frac{2}{2} \\
\frac{8}{0} \\
0 \\
\frac{1}{2} \\
\frac{1}{0}\end{array}$ & $\begin{array}{l}8 \\
0 \\
0 \\
0 \\
0 \\
0 \\
0 \\
\stackrel{H}{0} \\
\stackrel{0}{0} \\
\stackrel{0}{0}\end{array}$ & 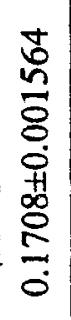 & 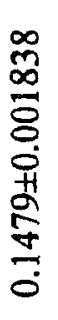 & 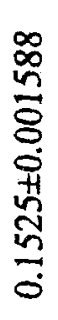 & 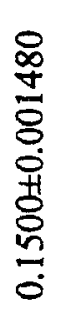 & 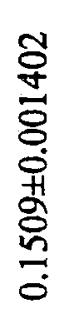 & 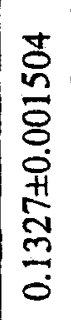 & 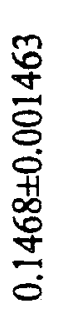 & $\begin{array}{l}\frac{a}{+} \\
\stackrel{2}{8} \\
8 \\
0 \\
0 \\
+1 \\
0 \\
\stackrel{0}{0} \\
0\end{array}$ & 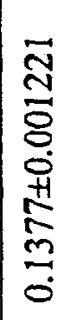 \\
\hline 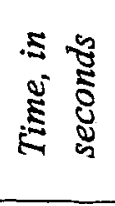 & 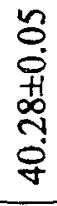 & 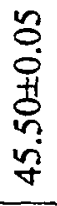 & 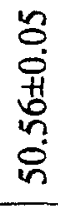 & $\begin{array}{c}2 \\
0 \\
0 \\
+ \\
+ \\
\dot{y} \\
\dot{\sigma}\end{array}$ & $\begin{array}{l}n \\
0 \\
0 \\
+ \\
+ \\
\dot{8}\end{array}$ & 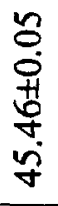 & $\begin{array}{l}2 \\
0 \\
0 \\
+1 \\
0 \\
0 \\
0\end{array}$ & $\begin{array}{l}n \\
0 \\
0 \\
+1 \\
m \\
i n \\
n\end{array}$ & \begin{tabular}{l}
2 \\
0 \\
0 \\
+1 \\
\multirow{2}{*}{} \\
$o$
\end{tabular} & $\begin{array}{l}n \\
0 \\
0 \\
0 \\
0 \\
0 \\
0 \\
0\end{array}$ & 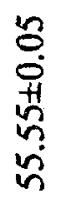 & $\begin{array}{l}2 \\
0 \\
0 \\
0 \\
0 \\
0 \\
8\end{array}$ & $\begin{array}{l}n \\
0 \\
0 \\
11 \\
0 \\
n \\
0 \\
n\end{array}$ & $\begin{array}{l}n \\
0 \\
0 \\
\text { i⿱ } \\
\text { in }\end{array}$ & $\begin{array}{l}2 \\
0 \\
0 \\
\text { H } \\
0 \\
0 \\
0\end{array}$ & $\begin{array}{l}n \\
0 \\
0 \\
+1 \\
n \\
0 \\
0\end{array}$ \\
\hline 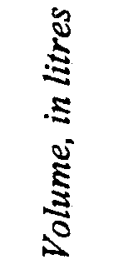 & 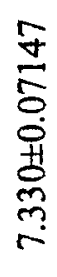 & 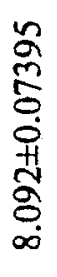 & 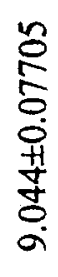 & $\begin{array}{l}n \\
n \\
0 \\
0 \\
0 \\
0 \\
0 \\
n \\
\infty\end{array}$ & 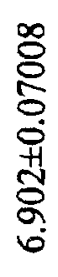 & 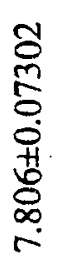 & $\begin{array}{l}0 \\
0 \\
0 \\
0 \\
0 \\
+1 \\
0 \\
\infty \\
\infty\end{array}$ & $\begin{array}{l}0 \\
0 \\
0 \\
0 \\
0 \\
+1 \\
\tilde{n} \\
a \\
0\end{array}$ & 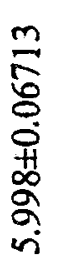 & 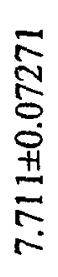 & 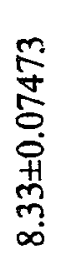 & 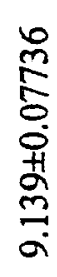 & 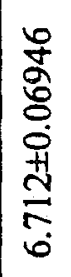 & 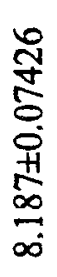 & 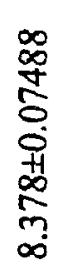 & 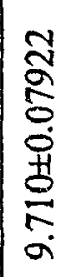 \\
\hline 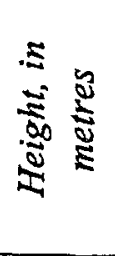 & $\begin{array}{l}n \\
8 \\
8 \\
0 \\
+1 \\
5 \\
0 \\
0\end{array}$ & 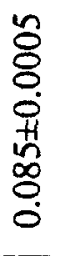 & 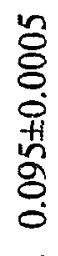 & $\begin{array}{l}2 \\
8 \\
0 \\
0 \\
0 \\
0 \\
0 \\
0 \\
0\end{array}$ & 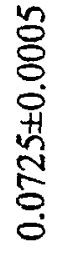 & $\begin{array}{l}n \\
8 \\
8 \\
0 \\
\dot{1} \\
0 \\
0 \\
0 \\
0\end{array}$ & $\begin{array}{l}\qquad \\
8 \\
8 \\
0 \\
+1 \\
\text { ㅇ. } \\
0\end{array}$ & \begin{tabular}{l}
$n$ \\
8 \\
8 \\
0 \\
+1 \\
\hdashline \\
0
\end{tabular} & 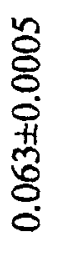 & $\begin{array}{l}\qquad \\
8 \\
\delta \\
0 \\
+1 \\
0 \\
0 \\
0\end{array}$ & $\begin{array}{l}n \\
8 \\
8 \\
0 \\
+1 \\
0 \\
\infty \\
0 \\
0\end{array}$ & 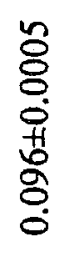 & $\begin{array}{l}0 \\
8 \\
8 \\
0 \\
\text { H } \\
\text { 竞 } \\
0 \\
0\end{array}$ & $\begin{array}{l}n \\
8 \\
8 \\
0 \\
+1 \\
0 \\
0 \\
0\end{array}$ & $\begin{array}{l}n \\
8 \\
8 \\
0 \\
+1 \\
0 \\
0 \\
0 \\
0\end{array}$ & $\begin{array}{l}2 \\
\delta \\
\delta \\
0 \\
+1 \\
0 \\
0 \\
0\end{array}$ \\
\hline 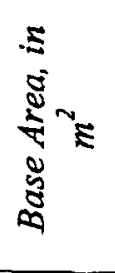 & 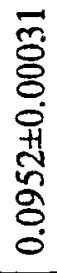 & & & & 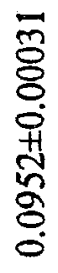 & & & & 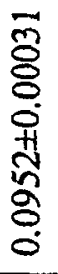 & & & & 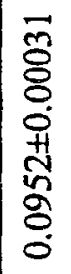 & & & \\
\hline$\overline{0}$ & - & & & & $N$ & & & & $m$ & & & & 15 & & & \\
\hline
\end{tabular}




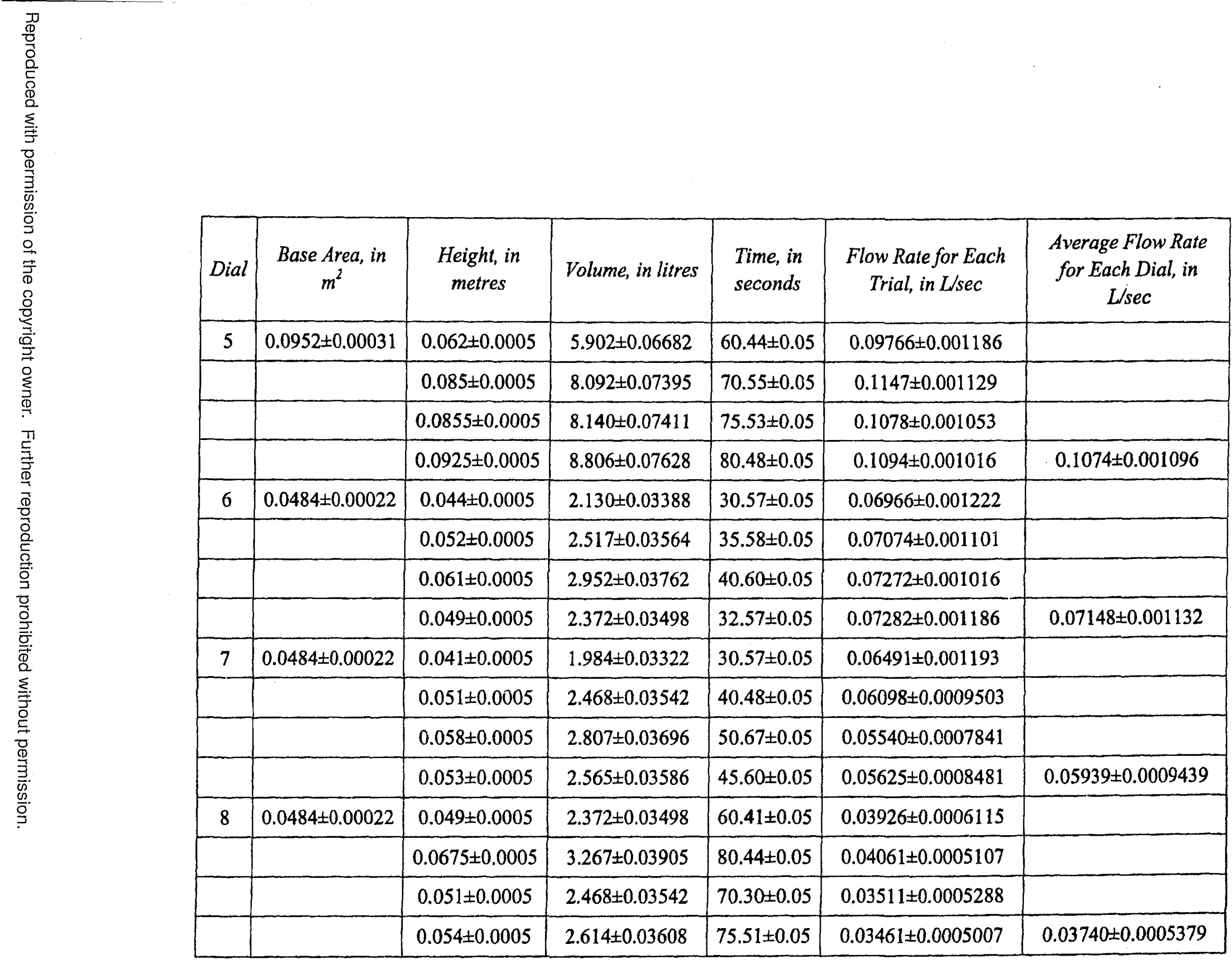




\section{APPENDIX G \\ DETERMINATION OF THE INFLOW RATE OF THE TRANSFORMER OIL}

Reproduced with permission of the copyright owner. Further reproduction prohibited without permission. 


\begin{tabular}{|c|c|c|c|c|c|}
\hline $\begin{array}{l}\text { Time, } \\
\text { in } \\
\text { seconds }\end{array}$ & $\begin{array}{c}\text { Volume of Transformer } \\
\text { Oil Goes into } \\
\text { Catchbasin for One } \\
\text { Time Step, in } \mathrm{m}^{3}\end{array}$ & $\begin{array}{c}\text { Height of Transformer } \\
\text { Oil at Concrete Pad, } \\
\text { in metres }\end{array}$ & $\begin{array}{c}\text { Total Volume of } \\
\text { Transformer Oil Remains } \\
\text { at Concrete Pad, in } \mathrm{m}^{3}\end{array}$ & $\begin{array}{c}\text { Flow Enters } \\
\text { to Catchbasin, } \\
\text { in } \mathrm{m}^{3} / \mathrm{sec}\end{array}$ & $\begin{array}{c}\text { Average Flow } \\
\text { Enters to } \\
\text { Catchbasin at Each } \\
\text { Time Step, in } \mathrm{m}^{3} / \mathrm{sec}\end{array}$ \\
\hline 0 & -..- & 0.5 & 7.5905 & 0.2147 & ---- \\
\hline 2 & 0.4293 & 0.4717 & 7.161 & 0.2085 & 0.2116 \\
\hline 4 & 0.4170 & 0.4443 & 6.744 & 0.2023 & 0.2054 \\
\hline 6 & 0.4047 & 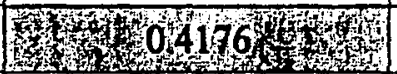 & 6.339 & 0.1962 & 0.1993 \\
\hline 8 & 0.3924 & 0.3917 & 5.947 & 0.1900 & 0.1931 \\
\hline 10 & 0.3800 & 0.3667 & 5.567 & 0.1838 & 0.1869 \\
\hline 12 & 0.3677 & 0.3425 & 5.199 & 0.1777 & 0.1808 \\
\hline 14 & 0.3553 & 0.3191 & 4.844 & 0.1715 & 0.1746 \\
\hline 16 & 0.3430 & 0.2965 & 4.501 & 0.1653 & 0.1684 \\
\hline 18 & 0.3306 & 0.2747 & 4.171 & 0.1591 & 0.1622 \\
\hline 20 & 0.3182 & 0.2538 & 3.852 & 0.1529 & 0.1560 \\
\hline 22 & 0.3059 & 0.2336 & 3.546 & 0.1467 & 0.1498 \\
\hline 24 & 0.2935 & 0.2143 & 3.253 & 0.1405 & 0.1436 \\
\hline 26 & 0.2811 & 0.1958 & 2.972 & 0.1343 & 0.1374 \\
\hline 28 & 0.2686 & 0.1781 & 2.703 & 0.1281 & 0.1312 \\
\hline 30 & 0.2562 & 0.1612 & 2.447 & 0.1219 & 0.1250 \\
\hline
\end{tabular}




\begin{tabular}{|c|c|c|c|c|c|}
\hline $\begin{array}{c}\text { Time, } \\
\text { in } \\
\text { seconds }\end{array}$ & $\begin{array}{c}\text { Volume of Transformer } \\
\text { Oil Goes into } \\
\text { Catchbasin for One } \\
\text { Time Step, in } \text { m }^{3}\end{array}$ & $\begin{array}{c}\text { Height of Transformer } \\
\text { Oil at Concrete Pad, } \\
\text { in metres }\end{array}$ & $\begin{array}{c}\text { Total Volume of } \\
\text { Transformer Oil Remains } \\
\text { at Concrete Pad, in } \text { m }^{3}\end{array}$ & $\begin{array}{c}\text { Flow Enters } \\
\text { to Catchbasin, } \\
\text { in }^{3} / \text { sec }\end{array}$ & $\begin{array}{c}\text { Average Flow } \\
\text { Enters to } \\
\text { Catchbasin at Each } \\
\text { Time Step, in } \text { m }^{3} / \text { sec }\end{array}$ \\
\hline 32 & 0.2438 & 0.1451 & 2.203 & 0.1157 & 0.1188 \\
\hline 34 & 0.2313 & 0.1299 & 1.972 & 0.1094 & 0.1125 \\
\hline 36 & 0.2188 & 0.1155 & 1.753 & 0.1032 & 0.1063 \\
\hline 38 & 0.2063 & 0.1019 & 1.547 & 0.09691 & 0.1000 \\
\hline 40 & 0.1938 & 0.08913 & 1.353 & 0.09063 & 0.09377 \\
\hline 42 & 0.1813 & 0.07719 & 1.172 & 0.08434 & 0.08749 \\
\hline 44 & 0.1687 & 0.06608 & 1.003 & 0.07804 & 0.08119 \\
\hline 46 & 0.1561 & 0.05580 & 0.8470 & 0.07171 & 0.07487 \\
\hline 48 & 0.1434 & 0.04635 & 0.7036 & 0.06536 & 0.06853 \\
\hline 50 & 0.1307 & 0.03774 & 0.5729 & 0.05897 & 0.06217 \\
\hline 52 & 0.1179 & 0.02997 & 0.4550 & 0.05255 & 0.05576 \\
\hline 54 & 0.1051 & 0.02305 & 0.3499 & 0.04609 & 0.04932 \\
\hline 56 & 0.0922 & 0.01697 & 0.2577 & 0.03955 & 0.04282 \\
\hline 58 & 0.07910 & 0.01176 & 0.1786 & 0.03293 & 0.03624 \\
\hline 60 & 0.06585 & 0.007426 & 0.1127 & 0.02616 & 0.02954 \\
\hline 62 & 0.05232 & 0.003979 & 0.06041 & 0.01915 & 0.02266 \\
\hline 64 & 0.03830 & 0.001456 & 0.02211 & 0.01159 & 0.01537 \\
\hline
\end{tabular}




\section{APPENDIX H}

\section{MATLAB PROGRAMS FOR THE MATHEMATICAL MODEL}


There are four MATLAB programs used for the mathematical model of the oil back-up system. Each program represents different stages and conditions of the time steps. The mathematical model starts with the initial.m file (Figure H.1), where boundary conditions are applied to the heights at $t=0$ (lines 27 to 31 in Figure H.1). Equations discussed in Section 4.2 are the nonlinear equations and the elements of the Jacobian matrix used in this program. In Figure H.1, lines 3 to 25 are the design dimensions of the oil back-up system assuming the initial height of spilled transformer oil at the concrete pad at $t=0$ is $0.5 \mathrm{~m}$ (Appendix G). Lines 33 to 37 are the transformation of the variabies. The numbers shown in lines 39 to 43 are the initial guesses for the Newton-Raphson method (Appendix D). Lines 44 to 65 are the preliminary setup of the variables and matrices involving in the Newton-Raphson method, where lines 56 to 59 are the function matrix of the four simultaneous nonlinear equations and lines 62 to 65 demonstrates the Jacobian matrix. MATLAB program uses space to separate the elements within a row. Thus, the yellow indications in lines 62 to 65 represent the starting point of each element in the Jacobian matrix. Lines 67 to 83 show the code from Appendix E for solving simultaneous nonlinear equations using Newton's method. Figure H.2 illustrates the commands between lines 43 to 83 of the initial.m file inside the MATLAB program. In reality, each row of the equation matrix (lines 56 to 59 in Figure H.2) and the Jacobian matrix (lines 62 to 65 in Figure H.2) in MATLAB program must be displayed within one line. This is different than the illustrations in Figure H.1 due to the lack of space. 


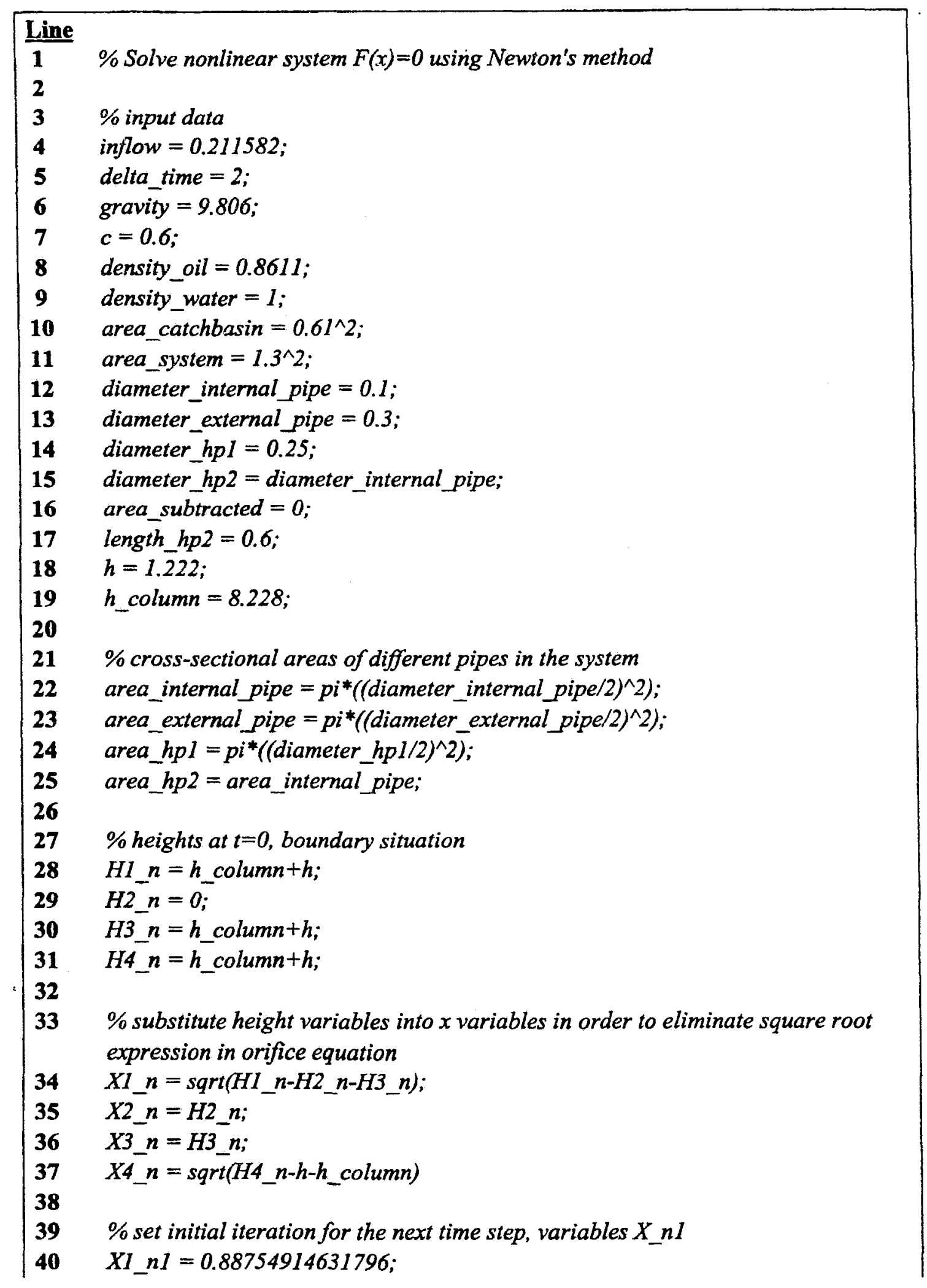




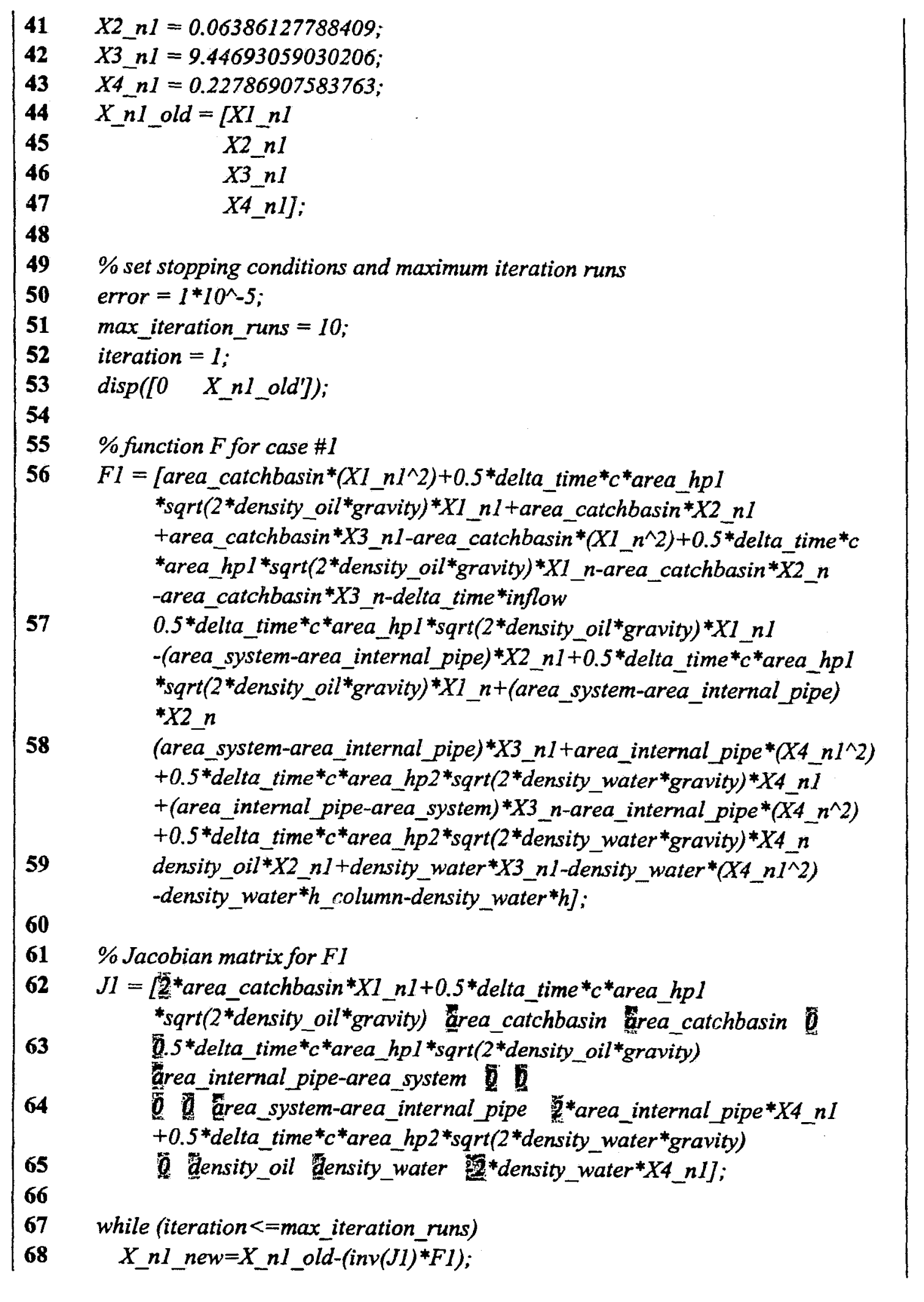




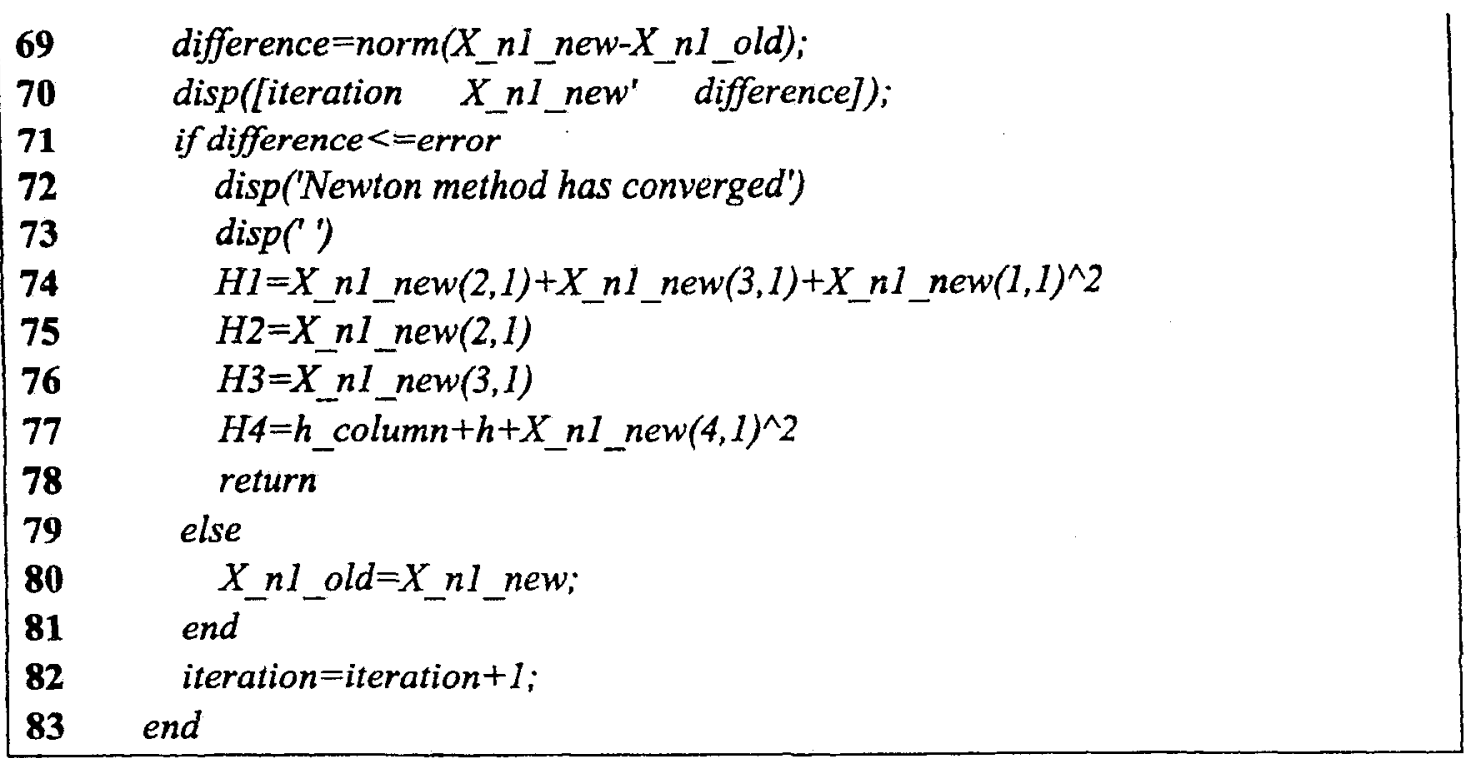

Figure H.1: Commands in initial.m file. 


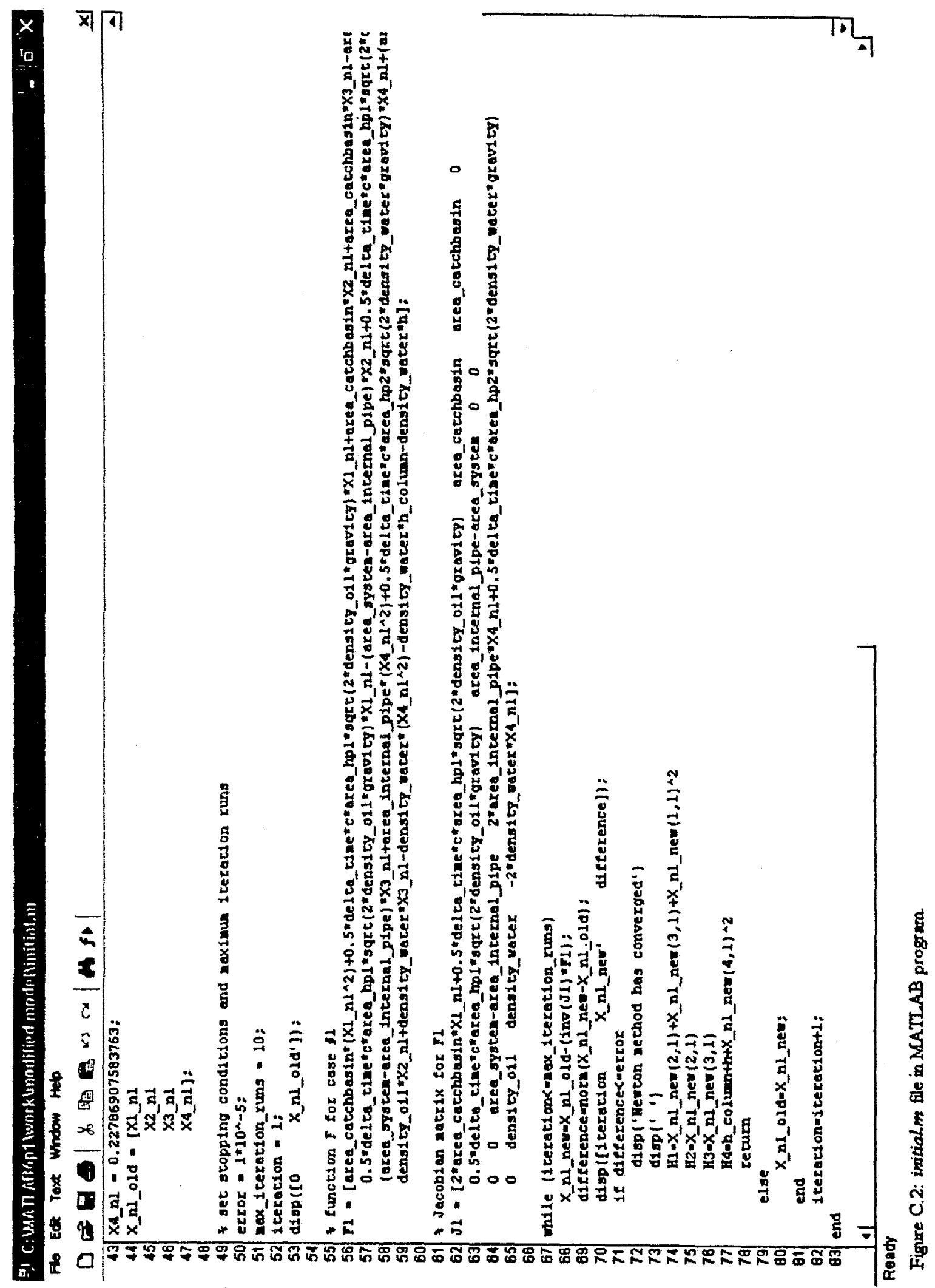


A new program in casel.m file (Figure H.3) will be applied on the mathematical model for calculating the heights at $t=4$. This program is used a similar set of commands as the initial.m file. As the name of this file has indicated, this program represents Case 1 of the mathematical model (Sections 4.1 and 4.2). Simultaneous nonlinear equations and Jacobian matrix in this program are exactly the same as the last program in the initial.m file. The reason for applying another program at $t=4$ is because boundary conditions are no longer dominate the heights. Instead, the solutions of $X 1[n+1], X 2[n+1], X 3[n+1]$, $X 4[n+1]$ found at $t=2$ (row 3 columns 2 to 4 in Appendix I) will be substituted into $X 1[n], X 2[n], X 3[n], X 4[n]$ at $t=4$ (Lines 27 to 31 in Figure H.3). The first line of the case $1 . m$ file states the restrictions of the purpose of this program. This program is only applied when

$$
\begin{aligned}
& \left(h_{\text {column }}+h\right)<(H 2[n]+H 3[n])<\left(h_{\text {column }}+h+D_{h p 2}\right) \\
& H 1[n]<\left(h_{\text {column }}+h+1.35\right) \\
& H 3[n] \geq h_{\text {column }}
\end{aligned}
$$




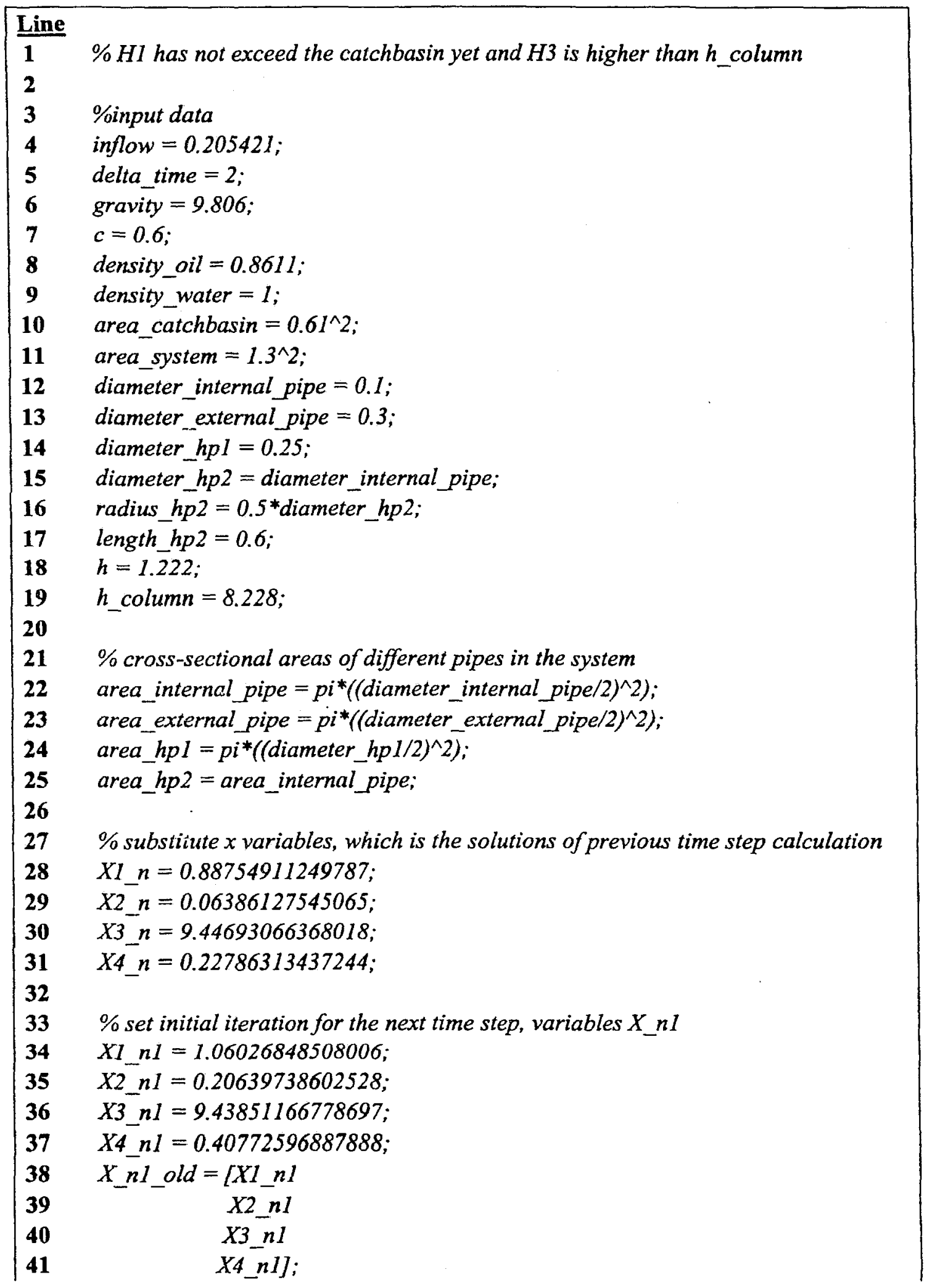


$43 \%$ set stopping conditions and maximum iteration runs

44 error $=1 * 10^{\wedge}-5$;

45 max_iteration_runs $=10$;

iteration $=1$;

48

$\operatorname{disp}\left(\left[0 \quad X \_n I \_o l d^{\prime}\right]\right)$;

$50 \quad F l=\left[\right.$ area_catchbasin $*\left(X 1 \_n 1^{\wedge} 2\right)+0.5 *$ delta_time*c*area_hpl

*sqrt $\left(2 *\right.$ density_oil $*$ gravity) ${ }^{*} X 1 \_n 1+$ area_catchbasin $* X 2$ n1+area_catchbasin ${ }^{*} X 3$ n1-area_catchbasin ${ }^{*}\left(X 1 \_n \wedge 2\right)+0.5 *$ delta_time ${ }^{*}{ }^{*}$ area_hpl

${ }^{*}$ sqrt $\left(2 *\right.$ density_oil ${ }^{*}$ gravity ${ }^{*} \bar{X} 1 \_n$-area_catchbasin ${ }^{*} X 2 \_n$-area_catchbasin *X3_n-delta_time*inflow

$510.5^{*}$ delta_time ${ }^{*} c^{*}$ area_hpl ${ }^{*}$ sqrt $\left(2{ }^{*}\right.$ density_oil ${ }^{*}$ gravity) ${ }^{*} X 1 \_n 1$-(area_system -area_internal_pipe) ${ }^{*} X 2 \_n I+0.5 *$ delta_time ${ }^{*} c^{*}$ area_hpl ${ }^{*}$ sqrt $\left(2 *\right.$ density_oil $\left.{ }^{*} g r a v i t y\right) * X I \_n+($ area_system-area_internal_pipe $) * X 2 \_n$ (area_system-area_internal_pipe) ${ }^{*} X 3 \_n I+$ area_internal_pipe*(X4_nl^2) $+0.5^{*}$ delta_time ${ }^{*} c^{*}$ area_hp $2 * \operatorname{sgrt}\left(2{ }^{*}\right.$ density_water ${ }^{*}$ gravity $) * X 4$ I $\bar{I}$ $+(\text { area_internal_pipe-area_system })^{*} X 3$ _n-area_internal_pipe* $\left(X 4 \_n^{\wedge} 2\right)$ $+0.5 *$ delta_time ${ }^{*} c^{*}$ area_hp $2 *$ sgrt $(2 *$ density_water $*$ gravity $) * X 4 \_n$ density_oil* $X 2 \_n 1+$ density_water ${ }^{*} X 3 \_n 1$-density_water ${ }^{*}\left(X 4 \_n 1^{\wedge} 2\right)$ -density_water*h_column-density_water $\left.{ }^{*} h\right]$;

$\%$ Jacobian matrix for $F I$ *sqrt(2*density_oil *gravity) ärea_catchbasin ärea_catchbasin 0 $0.5 *$ delta_time* ${ }^{*}$ area_hpl*sqrt $(2 *$ density_oil*gravity) area_internal pipe-area_system 0

$58 \quad 0$ area_system-area_internal_pipe $2 *$ area_internal_pipe* ${ }^{*} 4$ nI $+0.5 *$ delta_time ${ }^{*}{ }^{*}$ area_hp $2{ }^{*} \operatorname{sgrt}\left(2 *\right.$ density_water ${ }^{*}$ gravity)

while (iteration < =max_iteration_runs)

$$
X n 1 \_n e w=X \text { } n l \_o l d-(i n v(J 1) * F 1) \text {; }
$$




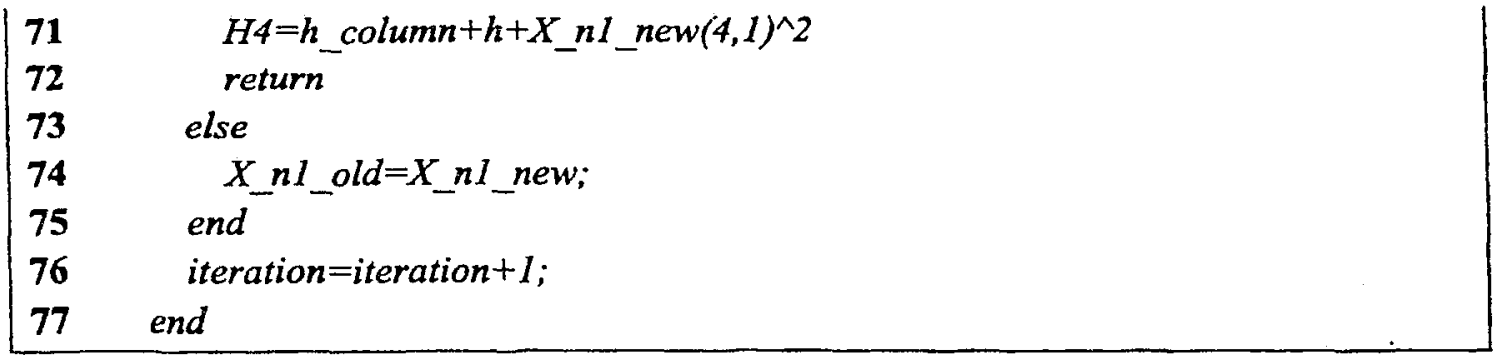

Figure H.3: Commands in casel.m file. 
Since the second statement in Equation [H.1], $H 1<\left(h_{\text {column }}+h+1.35\right)$, failed at $t=8$, the mathematical model is shifted to another program (Figure H.4) in the case1A.m file. Equations involved in this program are exactly the same as the first two programs. There are two adjustments in this program. First, variable $Q_{\text {in }}$ will be equal to zero, since the flow of transformer oil goes into the oil back-up system through horizontal pipe $h p l$ is now depending by its head. Thus, $X I[n]$ at $t=8$ (line 28 in Figure H.4) is calculated using the height of transformer oil at concrete pad at the previous time step (row 5 column 3 in Appendix G) where

$$
\begin{aligned}
(X 1[n])_{t=2} & =\sqrt{H 1[n]-H 2[n]-H 3[n]} \\
& =\sqrt{\text { (height of transformer oil at concrete paci) } t=6} \\
& =\sqrt{(0.41759[n]-H 3[n]} \\
& =1.1949555
\end{aligned}
$$

Secondly, the change of $H I$ is occurred at the concrete pad instead of the catchbasin once the second statement in equation [H.1] failed. Therefore, the parameter, $A_{\text {calchbasin }}$, in and in the first row of the Jacobian matrix (Line 51 in Figure H.4) will be replaced by $A_{\text {pad }}$. 


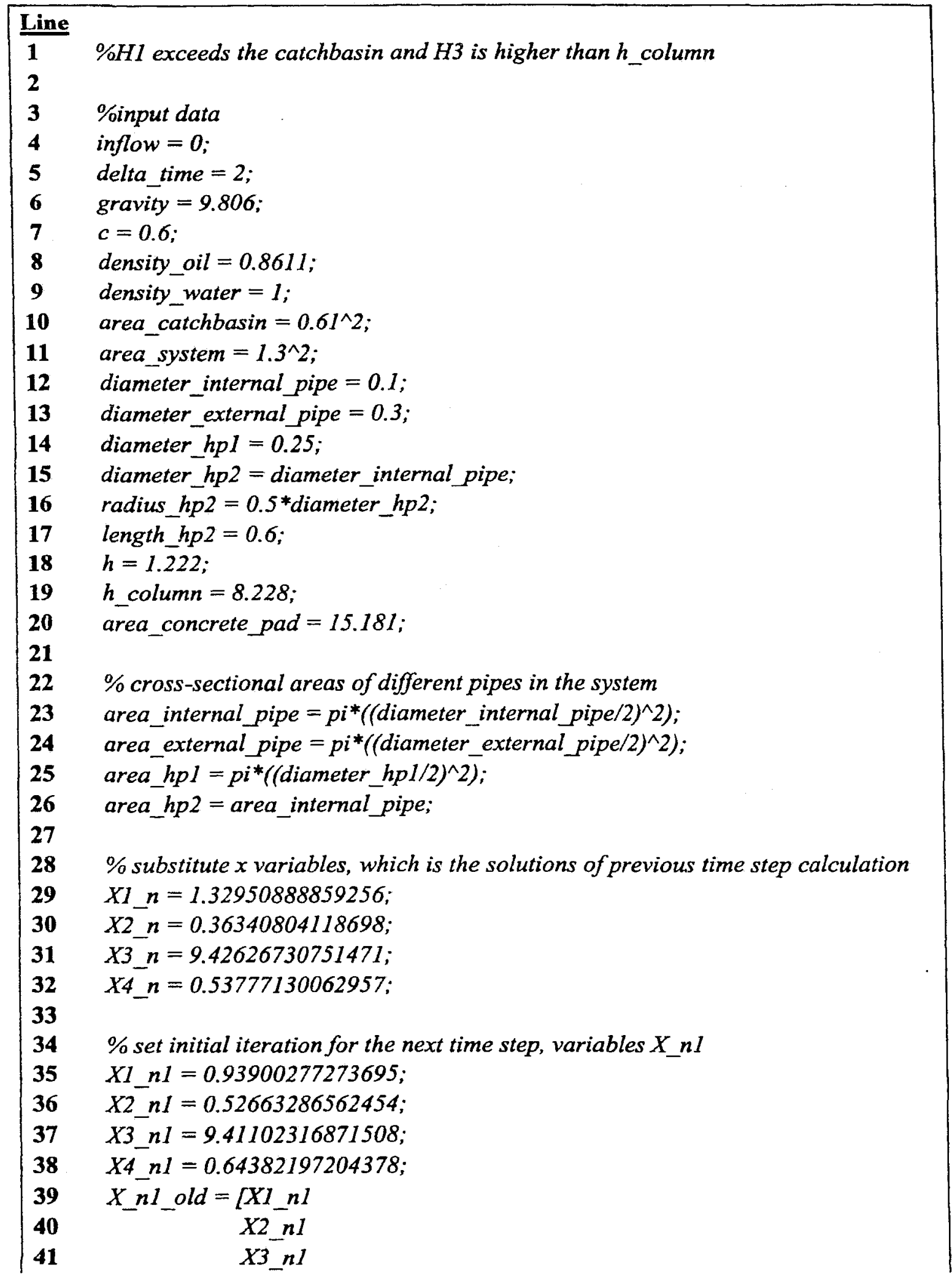




\section{X4_n1];}

$\%$ set stopping conditions and maximum iteration runs error $=1 * 10^{\wedge}-5$; max_iteration_runs $=10$; iteration $=I$; $\operatorname{disp}\left(\left[0 \quad X_{-} n l_{-}\right.\right.$old'] $)$;

$\%$ function $F$ for Case la $F I=\left[\right.$ area_concrete_pad $*\left(X I \_n 1^{\wedge} 2\right)+0.5 *$ delta_time ${ }^{*} c^{*}$ area_hpI ${ }^{*} \operatorname{sgrt}\left(2 *\right.$ density_oil ${ }^{*}$ gravity $){ }^{*} X 1 \_n 1+$ area_concrete_pad ${ }^{*} X 2 \_n 1$ + area_concrete_pad $* X 3 \_n 1$-area_concrete_pad $*\left(X 1 \_n^{\wedge} 2\right)$ $+0.5 * \overline{d e l t a \_t i m e}{ }^{*} c^{*}$ area_hpl ${ }^{*}$ sqrt $(\overline{2} *$ density_oil $*$ gravity $) * X 1 \_n$ - area_concrete_pad $* X 2 \_n$-area_concrete_pad ${ }^{*} X 3 \_n$-delta_time*inflow $0.5 *$ delta_time ${ }^{*} c * a r e a \_h p I * s q r t\left(2 *\right.$ density_oil ${ }^{*}$ gravity $) * X I \_n I$ -(area_system-area_internal_pipe) $* X 2 \_n 1+0.5 *$ delta_time ${ }^{*} c$ *area_hpl ${ }^{*}$ sqrt $\left(2 *\right.$ density_oil $\left.{ }^{*} g r a v i t y\right) * X 1 \_n+($ area_system -area_incernal_pipe)*X2_n (area_system-area_internal_pipe) ${ }^{*} X 3 \_n 1+$ area_internal_pipe $*\left(X 4 \_n 1^{\wedge} 2\right)$ $+0.5 *$ delta_time*c*area_hp $2 * \operatorname{sqrt}(2 *$ density_water $*$ gravity $) * X 4 \_n \overline{1}$ $+($ area_internal_pipe-area_system $) * X 3$ n-area_internal_pipe $*\left(\bar{X} 4 \_n \wedge 2\right)$ $+0.5 *$ delta_time*c*area_hp $2 *$ sqrt $(2 *$ density_water $*$ gravity $) * X 4$ n density_oil ${ }^{*} X 2 \_n 1+$ density_water $* X 3 \_n 1-d e n s i t y \_w a t e r *\left(X 4 \_n \bar{l}^{\wedge} 2\right)$ -density_water*h_column-density_water*h];

\section{\% Jacobian matrix for $F l$}

$J I=\left[2^{*}\right.$ area_concrete_pad ${ }^{*} X I \_n I+0.5 *$ delta_time ${ }^{*} c * a r e a \_h p I$ ${ }^{*}$ sqrt $(2 *$ density_oil*gravity) area_concrete_pad ârea_concrete_pad 0 $0.5 *$ delta_time*c*area_hpl *sqrt $(2 *$ density_oil*gravity) Trea_internal_pipe-area_system $0 \quad 0$ 0 Q 2*area_internal_pipe ${ }^{*} \bar{X} \_n 1+0.5 *$ delta_time ${ }^{*}{ }^{*}$ area_hp2 *sqrt( $2 *$ density_water*gravity) 0 density_oil density_water $2 *$ density_water $\left.* 44 \_n 1\right]$;

while (iteration $<=m a x$ iteration_runs)

$$
\left.X \_n 1 \text { new }=X \_n 1 \text { old-(inv }(J 1)^{*} F 1\right) \text {; }
$$

$$
\begin{aligned}
& \text { difference }=n o r m\left(X \_n 1 \_n e w-X \_n 1 \_ \text {old }\right) \text {; } \\
& \text { disp([iteration } \bar{X}_{-} n \bar{I}_{-} n e w^{\prime} \text { difference]); }
\end{aligned}
$$$$
\text { if difference }<=\text { error }
$$

disp('Newton method has converged') $\operatorname{disp}($ ') 


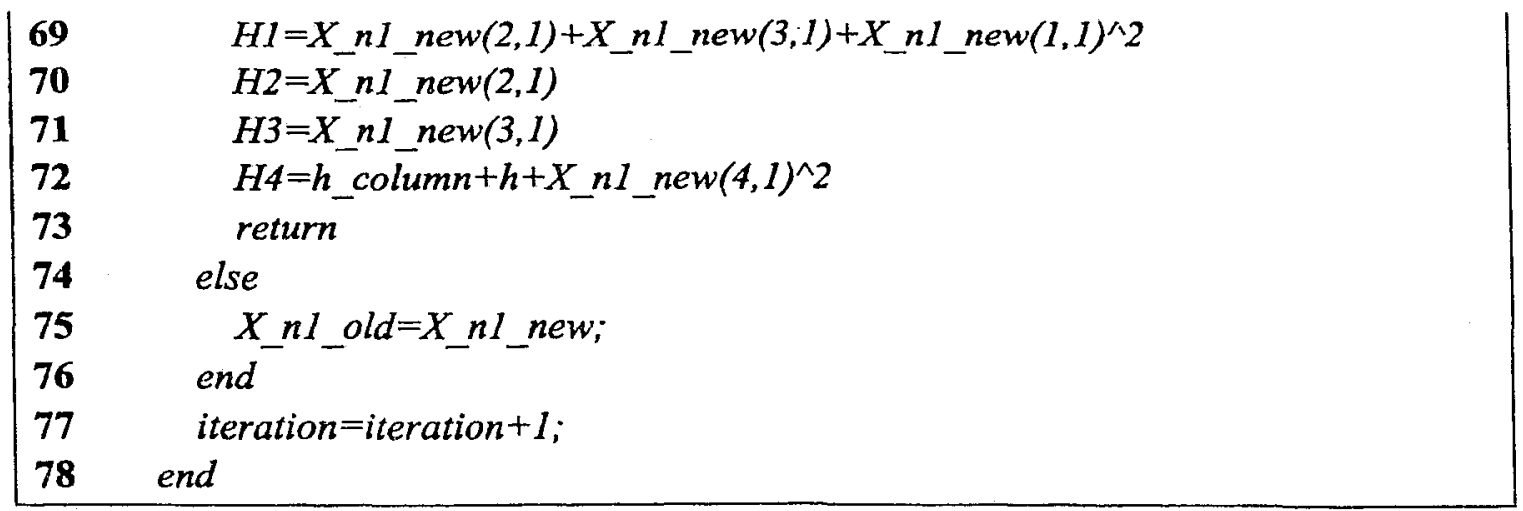

Figure H.4: Commands in caselA.m file. 
Finally, the mathematical model changes to another program in case $2 A . m$ file (Figure H.5) at $t=102$ since $H 3$ lower than $h$ at $t=100$. This means that the interface of oil and water is eventually reached the pipe column of the oil back-up system at $t=100$. Equations in Case 2 of Section 4.2 are the nonlinear equations and the elements of the Jacobian matrix involved in this program. The structure of this program is similar to the one in caselA.m file. 


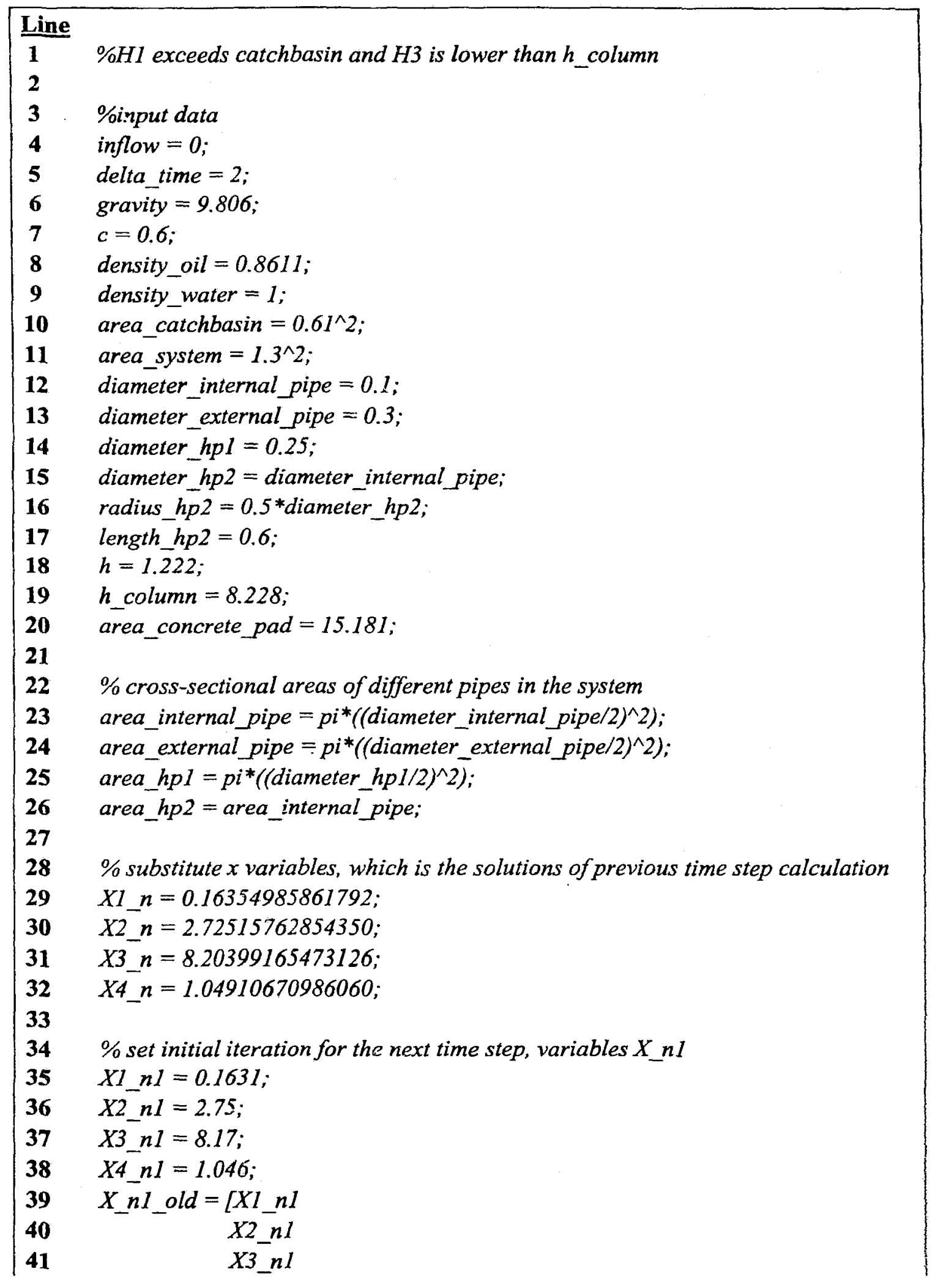


42

43

44

45

46

47

48

49

50

51

52

53

54

55

56

57

58

59

60

61

62

63

64

65

66

67

$\left.X 4 \_n 1\right]$

$\%$ set stopping conditions and maximum iteration runs error $=1 * 10^{\wedge}-5$;

max_iteration runs $=10$;

iteration $=1$;

$\left.\operatorname{disp}\left(\left[0 \quad X \_n\right] \_o l d\right]\right)$;

$\%$ function $F$ for Case $1 a$

$F I=\left[\right.$ area_concrete_pad* $\left(X I \_n I^{\wedge} 2\right)+0.5^{*}$ delta_time ${ }^{*} c^{*}$ area $h p I$ ${ }^{*}$ sqrt $\left(2 *\right.$ density_oil ${ }^{*}$ gravity) ${ }^{*} X I \_n I+$ area_concrete pa ${ }^{*} X 2 n I$ +area_concrete_pad*X3_n1-area_concrete_pad* $\left(X 1 \_n^{\wedge} 2\right)$

$+0.5 *$ delta_time ${ }^{*} c^{*}$ area_hp ${ }^{*} \operatorname{sqrt}\left(2{ }^{*}\right.$ density_oil ${ }^{*}$ gravity $) * X 1 \_n$ -area_concrete_pad ${ }^{*} X 2 \_n$-area_concrete_pad ${ }^{*} X 3$ _n-delta_time*inflow $0.5^{*}$ delta_time ${ }^{*}{ }^{*}$ area_hpl ${ }_{\text {sqrt }}\left(2 *\right.$ density_oil ${ }^{*}$ gravity $) * X I-n l$ -(area_system-area_internal_pipe) ${ }^{*} X 2 \_n 1+($ area_external_pipe -area_system $)^{*} X 3 \_n 1+0.5 *$ delta_time ${ }^{*} c^{*}$ area_hpl ${ }^{*} \operatorname{sqrt}\left(2 *\right.$ density_oil ${ }^{*}$ gravity $) * X 1 \_n+($ area_system -area_internal_pipe $)^{*} X 2 \_n+\left(\right.$ area_system-area_external pipe ${ }^{*} X 3 \_n$ (area_external_pipe-area_internal_pipe $)^{*} X 3 \_n 1+a r e a \_i n t e r n a l \_p i p e$ ${ }^{*}\left(X 4 \_n 1^{\wedge} 2\right)+0.5^{*}$ delta_time ${ }^{*} c^{*}$ area_hp $2 *$ sqrt $(2 *$ density_water $*$ gravity $) * X 4 \_n 1+($ area_internal_pipe-area_external_pipe $) * X 3 \_n$ -area_internal_pipe ${ }^{*}\left(X 4 \_n^{\wedge} 2\right)+0.5 *$ delta_time ${ }^{*} c^{*}$ area_hp2 *sqrt $(2 *$ density_water*gravity)*X4_n density_oil $* X 2 \_n 1+$ density_water $* X 3 \_n 1$-density_water $*\left(X 4 \_n 1^{\wedge} 2\right)$ -density_water ${ }^{*} h$ column-density_water $\left.{ }^{*} h\right]$;

$\%$ Jacobian matrix for $F I$

$J I=\left[2 *\right.$ area_concrete_pad*XI_nI+0.5*delta_time ${ }^{*} c^{*}$ area_hp $]$ ${ }^{*}$ sqrt $(2 *$ density_oil*gravity) area_concrete_pad area_concrete_pad 0 $0.5 *$ delta_time*c*area_hpl*sqrt $(2 *$ density_oil*gravity) area_internal_pipe-area_system area_external_pipe-area_system 0 00 area_external_pipe-area_internal pipe $2 *$ area_internal_pipe ${ }^{*} X 4$ n $1+0.5 *$ delta_time ${ }^{*} c *$ area_hp $2 *$ sqrt $\left(2 *\right.$ density_water ${ }^{*}$ gravity) 0 density_oil density_water $-2 *$ density_water $* 44$ nI];

while (iteration $<=m a x$ iteration_runs)

$X \_n I \_n e w=X$ nI_old-(inv(JI)*FI);

difference $=\operatorname{norm}\left(X \_n 1 \_n e w-X \_n 1 \_\right.$old $)$;

disp([iteration $\bar{X}_{-} n{ }_{-}{ }_{n} \boldsymbol{w}^{\prime}$ difference]);

if difference $<=$ error

disp('Newton method has converged') 


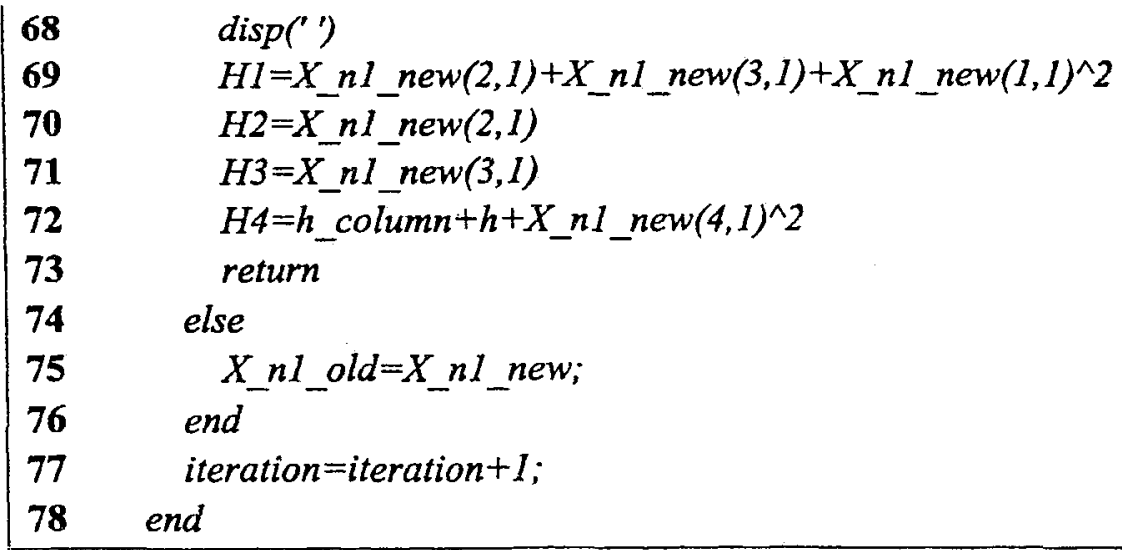

Figure H.5: Commands in case2A.m file. 


\section{APPENDIX I}

\section{NUMERICAL RESULTS OF THE MATHEMATICAL MODEL}




\begin{tabular}{|c|c|c|c|c|c|c|c|c|c|c|c|c|c|c|c|c|c|c|}
\hline 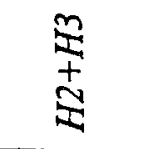 & $\begin{array}{l}n \\
+ \\
a\end{array}$ & $\begin{array}{l}= \\
\tilde{n} \\
a\end{array}$ & 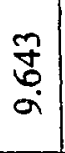 & $\begin{array}{l}0 \\
\frac{9}{a}\end{array}$ & $\begin{array}{l}\bar{\sigma} \\
\sigma \\
\sigma\end{array}$ & 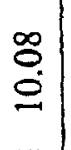 & ઼ָ. & ñ. & 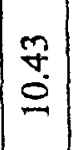 & ñ & $\begin{array}{l}\bar{b} \\
\dot{0}\end{array}$ & $\begin{array}{l}\sigma \\
0 \\
0\end{array}$ & $\begin{array}{l} \pm \\
\dot{2}\end{array}$ & $\begin{array}{l}9 \\
\dot{0} \\
0\end{array}$ & $\begin{array}{l}+ \\
\infty \\
0\end{array}$ & $\begin{array}{l}\infty \\
\infty \\
0 \\
0\end{array}$ & $\bar{a}$ & 荾 \\
\hline$\frac{\Sigma}{\Delta}$ & 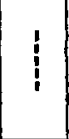 & 0 & 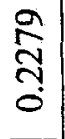 & $\begin{array}{l}\tilde{n} \\
\tilde{q} \\
\dot{\sigma}\end{array}$ & $\left|\begin{array}{l}\infty \\
n \\
n \\
0 \\
0\end{array}\right|$ & $\begin{array}{l}\overrightarrow{0} \\
\dot{0} \\
0\end{array}$ & $\frac{0}{\tilde{m}}$ & $\begin{array}{l}+ \\
8 \\
\infty \\
0\end{array}$ & $\begin{array}{c}2 \\
\infty \\
0 \\
0 \\
0\end{array}$ & 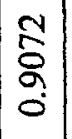 & $\begin{array}{c}\infty \\
\infty \\
\vdots \\
0 \\
0\end{array}$ & 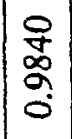 & $\frac{ \pm}{0}$ & $\begin{array}{c}0 \\
0 \\
0 \\
-1\end{array}$ & 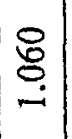 & $\underset{0}{E}$ & 吾 & $\stackrel{\Xi}{0}$ \\
\hline$\frac{E}{2}$ & 1 & $\begin{array}{l}8 \\
8 \\
\sigma\end{array}$ & 竎 & $\begin{array}{l}\stackrel{\text { m }}{+} \\
\text { aे }\end{array}$ & \begin{tabular}{l}
0 \\
\multirow{T}{*}{} \\
$\sigma$
\end{tabular} & $\begin{array}{l}\vec{z} \\
\sigma\end{array}$ & ầ & $\frac{7}{2}$ & $\begin{array}{l}\tilde{n} \\
\tilde{a} \\
\alpha\end{array}$ & $\vec{m}$ & ấ & 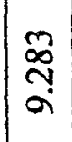 & 年 & m. & 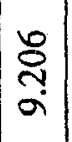 & $\frac{a}{a}$ & $\frac{\tilde{n}}{a}$ & $\frac{2}{a}$ \\
\hline$\underset{E}{E}$ & 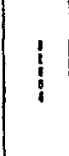 & 0 & $\begin{array}{l}0 \\
\infty \\
0 \\
0 \\
0 \\
0\end{array}$ & $\begin{array}{l}\tilde{I} \\
\stackrel{\tilde{N}}{0} \\
\dot{0}\end{array}$ & $\left|\begin{array}{c} \pm \\
\tilde{2} \\
n \\
0\end{array}\right|$ & $\begin{array}{c}\overrightarrow{0} \\
\tilde{n} \\
0\end{array}$ & $\begin{array}{l}3 \\
0 \\
0 \\
0 \\
0 \\
0\end{array}$ & 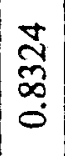 & $\mid \begin{array}{l}\mathbf{1} \\
0 \\
0 \\
0 \\
0 \\
0\end{array}$ & 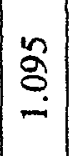 & $\bar{\beth}$ & $\frac{a}{n}$ & $\bar{F}$ & 음 & $\mid \begin{array}{c}\infty \\
\infty \\
\mathfrak{n}\end{array}$ & 音 & $\underset{\sim}{ت}$ & 要 \\
\hline$\stackrel{\Xi}{E}$ & 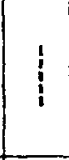 & 0 & $\mid \begin{array}{l}0 \\
0 \\
\infty \\
\infty \\
0\end{array}$ & $\ddot{6}$ & $\begin{array}{l}2 \\
2 \\
2\end{array}$ & $\stackrel{7}{3}$ & $\stackrel{0}{0}$ & $\frac{2}{2}$ & ô & $\left|\begin{array}{l}n \\
n \\
0 \\
\infty \\
0\end{array}\right|$ & 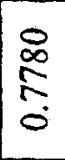 & $\frac{7}{\frac{7}{0}}$ & $\mid \begin{array}{l}\infty \\
\tilde{\pi} \\
0 \\
0 \\
0\end{array}$ & 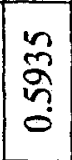 & $\left|\begin{array}{l}\infty \\
0 \\
0 \\
n \\
0 \\
0 \\
0\end{array}\right|$ & 足 & 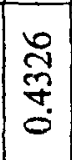 & 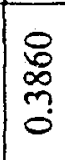 \\
\hline 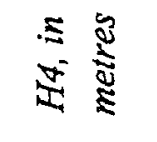 & 年 & $\begin{array}{c}\text { S } \\
\delta \\
\sigma \\
\sigma\end{array}$ & $\begin{array}{l}\frac{\nabla}{\sigma} \\
0 \\
0\end{array}$ & $\begin{array}{l}a \\
a \\
a\end{array}$ & $\begin{array}{l}0 \\
0 \\
0 \\
0\end{array} \mid$ & 声 & 8 & $\frac{9}{0}$ & $\hat{\tilde{y}}$ & $\stackrel{n}{n}$ & $\stackrel{\tilde{Y}}{\stackrel{0}{0}}$ & $\stackrel{\infty}{\stackrel{\infty}{0}}$ & 桼 & 㔯 & $\begin{array}{l}\overline{0} \\
\dot{0}\end{array}$ & 苟 & $\begin{array}{l}0 \\
0 \\
0\end{array}$ & $\mid$ \\
\hline $\begin{array}{l}\Sigma \bar{z} \\
\Sigma \\
\Sigma\end{array}$ & \begin{tabular}{l}
$n$ \\
\multirow{2}{*}{} \\
$\sigma$
\end{tabular} & 导 & के & \begin{tabular}{c}
0 \\
\multirow{c}{c}{} \\
$a$
\end{tabular} & $\begin{array}{l}\overrightarrow{7} \\
\overline{7} \\
\sigma\end{array}$ & $\begin{array}{l}m \\
\tilde{\alpha} \\
\alpha\end{array}$ & $\frac{⿱ 亠}{2}$ & $\begin{array}{l}n \\
n \\
a \\
a\end{array}$ & $\begin{array}{l}\tilde{n} \\
2 \\
a\end{array}$ & $\begin{array}{c}\hat{0} \\
\vdots \\
\vdots \\
\alpha\end{array}$ & $\begin{array}{l}n \\
\tilde{\alpha} \\
a \\
a\end{array}$ & 音 & స̃. & 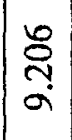 & $\frac{a}{a}$ & $\frac{\tilde{n}}{a}$ & $\stackrel{a}{\sim}$ & $\hat{\sigma}$ \\
\hline 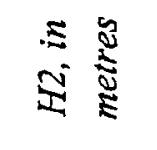 & 0 & $\begin{array}{l}0 \\
\infty \\
0 \\
0 \\
0 \\
0\end{array}$ & $\begin{array}{l}\vec{Z} \\
\tilde{y} \\
0\end{array}$ & $\begin{array}{c}\forall \\
2 \\
0 \\
m \\
0\end{array}$ & $\begin{array}{c}\overline{0} \\
\tilde{n} \\
0 \\
0\end{array}$ & $\begin{array}{l}3 \\
0 \\
0 \\
0 \\
0\end{array}$ & $\begin{array}{l}\Delta \\
\sim \\
\infty \\
0 \\
0\end{array}$ & $\mid \begin{array}{l}0 \\
0 \\
0 \\
0 \\
0\end{array}$ & $\frac{2}{2}$ & $\overline{\check{I}}$ & $\frac{a}{m}$ & $\frac{\pi}{7}$ & $\tilde{n}$ & 㐌 & $\because$ & 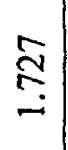 & $\stackrel{0}{\infty}$ & 疍 \\
\hline 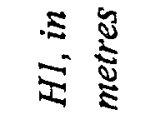 & \begin{tabular}{l}
$n$ \\
\multirow{\sigma}{*}{} \\
$\sigma$
\end{tabular} & 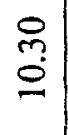 & $\frac{1}{0}$ & $\stackrel{\Xi}{\Xi}$ & $\stackrel{ }{\dddot{\Upsilon}}$ & $\begin{array}{l}\infty \\
=\end{array}$ & $\frac{1}{=}$ & $\frac{n}{=}$ & 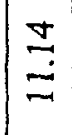 & $\begin{array}{l}Y \\
\Xi\end{array}$ & $\equiv$ & $\underline{ }$ & $\stackrel{8}{8}$ & $\mid \begin{array}{c}\infty \\
0 \\
\\
=\end{array}$ & $\underline{0}$ & $\begin{array}{l}\dot{0} \\
\dot{\Xi}\end{array}$ & $\stackrel{0}{0}$ & $\stackrel{n}{0}$ \\
\hline 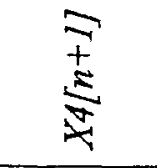 & 10 & 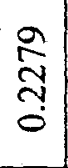 & 告 & $\mid \begin{array}{c}\infty \\
\tilde{n} \\
n \\
\vdots \\
0\end{array}$ & $\begin{array}{l}\overrightarrow{0} \\
\dot{0} \\
0 \\
0\end{array}$ & $\frac{0}{m}$ & $\begin{array}{l}4 \\
8 \\
0 \\
0 \\
0\end{array}$ & $\mid \begin{array}{l}\infty \\
\infty \\
\infty \\
\infty \\
0\end{array}$ & $\mid \begin{array}{l}0 \\
\hat{8} \\
0 \\
0\end{array}$ & $\left|\begin{array}{c}\infty \\
\infty \\
\pm \\
0 \\
0\end{array}\right|$ & $\mid \begin{array}{l}0 \\
5 \\
0 \\
0 \\
0\end{array}$ & $\underset{-}{0}$ & $\stackrel{g}{g}$ & 8 & $\begin{array}{l}2 \\
0 \\
-\end{array}$ & $\vec{g}$ & $\stackrel{\Xi}{\Xi}$ & $\stackrel{8}{=}$ \\
\hline$\frac{\vec{E}}{\stackrel{ \pm}{E}}$ & $\stackrel{n}{\sigma}$ & \begin{tabular}{l}
$f$ \\
\multirow{2}{*}{}
\end{tabular} & 官 & 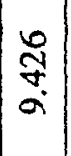 & $\overline{\bar{\nabla}}$ & $\begin{array}{l}m \\
\tilde{n} \\
\alpha\end{array}$ & $\frac{d}{2}$ & $\tilde{n}$ & 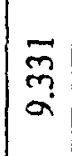 & $\mid \begin{array}{l}5 \\
0 \\
n \\
a\end{array}$ & mo & 文 & స̃. & 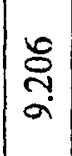 & $\frac{2}{2}$ & $\frac{\pi}{2}$ & $\frac{\approx}{a}$ & à \\
\hline$\underset{⿱ 亠 䒑}{\stackrel{F}{E}}$ & 0 & $\begin{array}{l}0 \\
\infty \\
0 \\
0 \\
0 \\
0\end{array}$ & F & $\left|\begin{array}{c} \pm \\
\tilde{0} \\
m \\
0\end{array}\right|$ & $\begin{array}{c}\overline{0} \\
\tilde{n} \\
\vdots \\
0\end{array} \mid$ & $\mid \begin{array}{l}\tilde{B} \\
0 \\
0 \\
\dot{0}\end{array}$ & 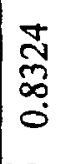 & 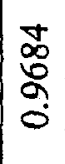 & $\stackrel{2}{8}$ & $\overline{\bar{y}}$ & $\frac{a}{m}$ & $\underset{-}{\stackrel{5}{7}}$ & 5 & 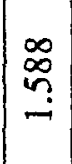 & $\bar{\sigma}$ & 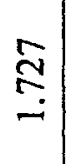 & $\stackrel{0}{\infty}$ & 孚 \\
\hline 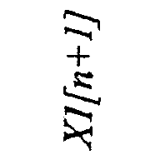 & 0 & $\begin{array}{c}0 \\
\infty \\
\infty \\
\infty \\
0\end{array} \mid$ & $\overline{8}$ & $\underline{n}$ & $\underset{\widetilde{N}}{\mathfrak{Z}}$ & $\left(\begin{array}{l}0 \\
0 \\
-1\end{array}\right.$ & $\frac{a}{2}$ & $\frac{5}{0}$ & 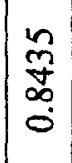 & $\left|\begin{array}{l}0 \\
\infty \\
2 \\
0 \\
0\end{array}\right|$ & $\underset{\dot{\sigma}}{\stackrel{\forall}{二}}$ & 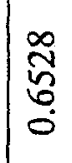 & $\begin{array}{l}n \\
2 \\
\tilde{n} \\
0\end{array}$ & $\mid \begin{array}{l}\infty \\
0 \\
0 \\
n \\
0 \\
0\end{array}$ & $\left|\begin{array}{c}0 \\
0 \\
0 \\
+ \\
0\end{array}\right|$ & $\begin{array}{c}0 \\
-1 \\
5 \\
\tilde{T} \\
0\end{array}$ & $\mid \begin{array}{c}8 \\
0 \\
2 \\
7 \\
0\end{array}$ & 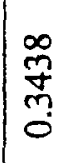 \\
\hline 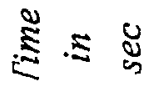 & 0 & $N$ & $\theta$ & 10 & $\infty$ & 으 & $\cong$ & \pm & 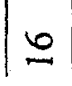 & $\infty$ & ণ্ & $\approx$ & $\stackrel{\sim}{\sim}$ & i & $\stackrel{\sim}{N}$ & $m$ & $N$ & I \\
\hline
\end{tabular}




\begin{tabular}{|c|c|c|c|c|c|c|c|c|c|c|c|c|c|c|c|c|c|c|}
\hline 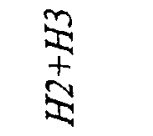 & $\begin{array}{l}0 \\
0 \\
0\end{array}$ & פ̊. & $\stackrel{\infty}{0}$ & g. & $\stackrel{g}{\circ}$ & $\begin{array}{l}\stackrel{2}{\circ} \\
\circ\end{array}$ & & $\begin{array}{l}9 \\
\vdots \\
0\end{array}$ & g. & $\begin{array}{l}g \\
0 \\
0\end{array}$ & $\begin{array}{l}\infty \\
\vdots \\
0\end{array}$ & $\begin{array}{c}\infty \\
0 \\
0\end{array}$ & $\begin{array}{l}\infty \\
0 \\
0 \\
0\end{array}$ & $\begin{array}{l}\infty \\
\vdots \\
0\end{array}$ & $\begin{array}{l}\hat{\sigma} \\
0\end{array}$ & $\begin{array}{l}5 \\
\vdots \\
0\end{array}$ & $\begin{array}{l}5 \\
0\end{array}$ & $\underline{a}$ \\
\hline$\stackrel{\Sigma}{E}$ & $\stackrel{9}{2}$ & $\begin{array}{l}\cong \\
\Xi \\
\check{Z}\end{array}$ & $\stackrel{9}{=}$ & $\stackrel{\vec{\Xi}}{\Xi}$ & $\underline{\Xi}$ & $\stackrel{\vec{\sim}}{=}$ & 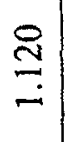 & $\begin{array}{l}\infty \\
\Xi \\
=\end{array}$ & $\underline{0}$ & $\stackrel{ \pm}{\Xi}$ & $\begin{array}{l}\Xi \\
\Xi\end{array}$ & $\begin{array}{l}9 \\
0 \\
-1\end{array}$ & $\stackrel{0}{0}$ & $\begin{array}{l} \pm \\
\Xi \\
-\end{array}$ & $\underline{\Xi}$ & $\begin{array}{l}\infty \\
8 \\
0\end{array}$ & $\begin{array}{l}0 \\
8 \\
0\end{array}$ & $\stackrel{2}{g}$ \\
\hline$\stackrel{\Xi}{\stackrel{\Xi}{2}}$ & $\left|\begin{array}{l}\hat{g} \\
\dot{0} \\
\hat{\alpha}\end{array}\right|$ & $\begin{array}{l}0 \\
\vdots \\
a\end{array}$ & $\underset{0}{\frac{\pi}{0}}$ & $\begin{array}{l} \pm \\
\square \\
\sigma\end{array}$ & $\begin{array}{l}\infty \\
\infty \\
\infty \\
\infty\end{array}$ & $\begin{array}{l}\infty \\
\infty \\
\infty \\
\infty\end{array}$ & $\begin{array}{c}\bar{m} \\
\infty\end{array}$ & $\begin{array}{l}m \\
0 \\
\infty \\
\infty\end{array}$ & $\mid \begin{array}{c}n \\
\infty \\
\infty \\
\infty\end{array}$ & $\begin{array}{c}\infty \\
+ \\
\infty \\
\infty\end{array}$ & $\begin{array}{l}8 \\
\infty \\
\infty \\
\infty\end{array}$ & $\mid \begin{array}{c}\sigma \\
\sigma \\
\infty\end{array}$ & $\begin{array}{l}n \\
2 \\
\infty\end{array}$ & $\underset{\infty}{\infty}$ & $\begin{array}{c}0 \\
\underset{1}{\infty} \\
\infty\end{array}$ & $\begin{array}{c}\infty \\
\infty \\
0 \\
\infty\end{array}$ & $\begin{array}{l}0 \\
2 \\
\infty \\
\infty\end{array}$ & త్ర్ర \\
\hline$\sum_{i}$ & $\begin{array}{l}a \\
m \\
\infty\end{array}$ & $\begin{array}{l}\infty \\
\infty \\
\infty\end{array}$ & $\tilde{\Omega}$ & $\frac{2}{2}$ & g & 0 & $\begin{array}{l}8 \\
\dot{8} \\
i\end{array}$ & $\begin{array}{c}\infty \\
\infty \\
0 \\
\sim \\
\sim\end{array}$ & $\frac{ \pm}{i}$ & $\frac{\bar{\Xi}}{i}$ & $\begin{array}{l}8 \\
8 \\
-1\end{array}$ & $\frac{\sigma}{\sigma}$ & $\stackrel{\sim}{\tilde{N}}$ & $\begin{array}{l}\tilde{J} \\
\underset{\sim}{\sim}\end{array}$ & \begin{tabular}{l}
$\tilde{y}$ \\
$y$ \\
\cline { 1 - 1 }
\end{tabular} & $\begin{array}{l}\bar{g} \\
\stackrel{y}{v}\end{array}$ & $\frac{0}{n}$ & $\vec{\nabla}$ \\
\hline$\equiv$ & $\mid \begin{array}{c}\infty \\
m \\
\tilde{y} \\
0\end{array}$ & $\begin{array}{l}\forall \\
0 \\
⿱ \\
0 \\
0\end{array}$ & 导 & $\frac{0}{2}$ & 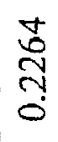 & $\frac{\sigma}{0}$ & $\frac{2}{\alpha}$ & $\mid \begin{array}{l}\Omega \\
\frac{\infty}{0} \\
0\end{array}$ & $\frac{9}{\infty}$ & $\mid \begin{array}{l}8 \\
\infty \\
\\
0\end{array}$ & $\frac{m}{2}$ & $\frac{ \pm}{2}$ & $\frac{q}{5}$ & $\stackrel{0}{\check{g}}$ & 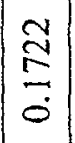 & $\frac{0}{}$ & $\frac{2}{0}$ & $\frac{n}{0}$ \\
\hline $\begin{array}{l}\Xi 5 \\
\pm \vdots \\
\pm\end{array}$ & $\begin{array}{l}0 \\
0 \\
0 \\
0\end{array}$ & $\stackrel{8}{0}$ & $\ddot{\sigma}$ & & $\overline{0}$ & $\stackrel{ }{\circ}$ & $\begin{array}{l}\stackrel{0}{0} \\
\dot{0}\end{array}$ & $\begin{array}{l}0 \\
\dot{0} \\
0\end{array}$ & $\begin{array}{l}9 \\
0 \\
0\end{array}$ & $\begin{array}{l}9 \\
0 \\
0 \\
0\end{array}$ & $\begin{array}{l}0 \\
0 \\
0 \\
0\end{array}$ & $\begin{array}{l}\sigma \\
0 \\
0\end{array}$ & $\begin{array}{l}6 \\
0 \\
0\end{array}$ & $\begin{array}{c}0 \\
0 \\
0 \\
-1\end{array}$ & $\mid \begin{array}{l}0 \\
0 \\
0 \\
0\end{array}$ & $\begin{array}{l}n \\
0 \\
0\end{array}$ & $\begin{array}{l}\nabla \\
0 \\
0 \\
0\end{array}$ & 苛 \\
\hline 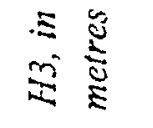 & $\left|\begin{array}{l}0 \\
0 \\
0 \\
a\end{array}\right|$ & $\begin{array}{l}\frac{1}{\Xi} \\
\sigma \\
\sigma\end{array}$ & $\begin{array}{l}\nabla \\
0 \\
0\end{array}$ & $\begin{array}{l}0 \\
\infty \\
\infty \\
\infty\end{array}$ & $\begin{array}{l}\infty \\
\infty \\
\infty \\
\infty\end{array}$ & $\bar{a}$ & $\begin{array}{l}\tilde{\hat{\sigma}} \\
\infty\end{array}$ & $\left|\begin{array}{c}n \\
\infty \\
\infty \\
\infty\end{array}\right|$ & $\mid \begin{array}{c}\infty \\
+ \\
\infty \\
\infty \\
\infty\end{array}$ & $\left|\begin{array}{c}0 \\
-1 \\
\infty \\
\infty\end{array}\right|$ & $\begin{array}{l}5 \\
2 \\
\infty\end{array}$ & $\begin{array}{l}3 \\
\infty \\
\infty\end{array}$ & $\mid \begin{array}{l}\infty \\
\sim \\
\infty \\
\infty\end{array}$ & $\frac{0}{\pi}$ & $\left|\begin{array}{c}2 \\
\infty \\
0 \\
\infty\end{array}\right|$ & $\begin{array}{c}0 \\
0 \\
0 \\
\infty\end{array}$ & $\begin{array}{l}\text { ते } \\
\sigma \\
\infty\end{array}$ & $\begin{array}{l}0 \\
\delta \\
0 \\
\infty \\
\infty\end{array}$ \\
\hline $\begin{array}{l}\Sigma \\
\vdots \\
心 \\
\Sigma\end{array}$ & $\left|\begin{array}{l}n \\
\infty \\
\infty \\
-\end{array}\right|$ & $\hat{\widehat{a}}$ & $\begin{array}{l}n \\
0 \\
0 \\
2\end{array}$ & $\frac{a}{2}$ & $\begin{array}{l}0 \\
0 \\
ن\end{array}$ & $\begin{array}{l}8 \\
0 \\
ن\end{array}$ & $\begin{array}{c}\infty \\
\infty \\
0 \\
-i\end{array}$ & $\frac{\Xi}{\vec{v}}$ & $\frac{F}{\dot{\Xi}}$ & $\frac{0}{i}$ & $\frac{\alpha}{\alpha}$ & $\frac{N}{\sim}$ & $\underset{\sim}{\stackrel{y}{J}}$ & $\begin{array}{l}\hat{S} \\
\sim \\
i\end{array} \mid$ & $\bar{g}$ & $\frac{0}{2}$ & $\begin{array}{l}\bar{J} \\
\sim \\
\sim\end{array}$ & $\begin{array}{l}n \\
\tilde{n} \\
\sim \\
\sim\end{array}$ \\
\hline 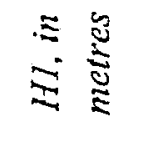 & $\begin{array}{l}n \\
0 \\
=\end{array}$ & $\stackrel{\Xi}{\Xi}$ & $\begin{array}{l}\dot{O} \\
= \\
=\end{array}$ & $\begin{array}{l} \pm \\
\stackrel{ \pm}{二}\end{array}$ & $\stackrel{3}{0}$ & $\stackrel{8}{=}$ & $\stackrel{\Xi}{\varrho}$ & $\begin{array}{l}\tilde{0} \\
\dot{z}\end{array}$ & $\stackrel{\tilde{O}}{\mathrm{O}}$ & $\begin{array}{l}0 \\
- \\
=\end{array}$ & $\stackrel{O}{O}$ & $\begin{array}{l}\dot{0} \\
\dot{Z}\end{array}$ & $\stackrel{0}{=}$ & $\underline{0}$ & $\stackrel{8}{\Xi}$ & 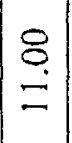 & $\underline{8}$ & $\stackrel{8}{\stackrel{8}{\Xi}}$ \\
\hline$\underset{E}{ \pm}$ & 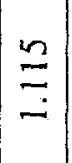 & $\stackrel{\Xi}{\Xi}$ & $\stackrel{\check{I}}{\check{\sim}}$ & $\stackrel{\Xi}{\beth}$ & $\stackrel{\bar{\Xi}}{\longleftarrow}$ & $\stackrel{尺}{\stackrel{ }{2}}$ & $\stackrel{\infty}{=}$ & $\cong$ & \pm & $\stackrel{v}{=}$ & $\stackrel{8}{=}$ & $\stackrel{8}{\Xi}$ & \begin{tabular}{l}
0 \\
0 \\
\hdashline
\end{tabular} & $\underset{\Xi}{\Xi}$ & $\mid \begin{array}{l}\infty \\
8 \\
0 \\
-1\end{array}$ & $\mid \begin{array}{l}0 \\
8 \\
8 \\
-1\end{array}$ & $\ddot{g}$ & 8 \\
\hline$\underset{ \pm}{ \pm}$ & $\left|\begin{array}{c}0 \\
\delta \\
0 \\
a\end{array}\right|$ & $\begin{array}{l}\tilde{Z} \\
\tilde{Q} \\
\sigma\end{array}$ & $\frac{\nabla}{0}$ & $\begin{array}{l}0 \\
\infty \\
0 \\
\infty\end{array}$ & $\begin{array}{l}\infty \\
\stackrel{2}{\Omega} \\
\infty\end{array}$ & $\bar{\alpha}$ & $\begin{array}{l}3 \\
\infty \\
\infty\end{array}$ & $\left|\begin{array}{l}n \\
\infty \\
\infty \\
\infty\end{array}\right|$ & $\mid$\begin{tabular}{c}
$\infty$ \\
\multirow{1}{*}{} \\
$\infty$ \\
$\infty$ \\
$\infty$
\end{tabular} & $\left|\begin{array}{c}\mathbb{8} \\
\infty \\
\infty\end{array}\right|$ & $\begin{array}{l}\Omega \\
\alpha \\
\infty\end{array}$ & $\frac{2}{2}$ & $\underset{\infty}{\infty}$ & $\frac{0}{\infty}$ & $\left|\begin{array}{c}0 \\
\infty \\
0 \\
\infty\end{array}\right|$ & $\left|\begin{array}{l}0 \\
n \\
\infty \\
\infty\end{array}\right|$ & 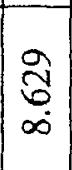 & $\underset{\infty}{\mathscr{\delta}}$ \\
\hline 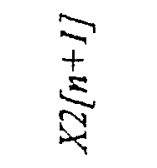 & $\left|\begin{array}{c}2 \\
\infty \\
\infty \\
-1\end{array}\right|$ & $\widehat{\widehat{~}}$ & $\begin{array}{l}n \\
0 \\
2 \\
-1\end{array}$ & $\stackrel{g}{\alpha}$ & 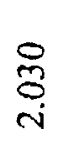 & $\mid \begin{array}{l}8 \\
8 \\
ن \\
ن\end{array}$ & $\begin{array}{l}\infty \\
\infty \\
0 \\
ن\end{array}$ & $\frac{ \pm}{d}$ & $\frac{\vec{\nabla}}{\vec{v}}$ & $\frac{0}{i}$ & $\frac{\alpha}{\alpha}$ & $\frac{\pi}{\tilde{c}}$ & 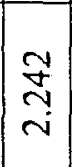 & $\begin{array}{l}\hat{\sigma} \\
\tilde{y} \\
i\end{array} \mid$ & $\begin{array}{l}\bar{g} \\
\tilde{y} \\
\tilde{v}\end{array} \mid$ & $\frac{0}{2}$ & $\bar{J}$ & $\begin{array}{l}n \\
n \\
i\end{array}$ \\
\hline$\sum_{D}^{ \pm}$ & $\begin{array}{c}\text { 苛 } \\
0 \\
0 \\
0\end{array}$ & 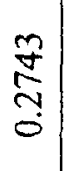 & $\frac{0}{\stackrel{5}{J}}$ & $\begin{array}{l}\mathbb{J} \\
\stackrel{J}{ } \\
ٍ\end{array}$ & $\frac{\mathcal{O}}{\tilde{y}}$ & $\frac{a}{\infty}$ & $\frac{2}{2}$ & $\left|\begin{array}{c}0 \\
0 \\
0 \\
0\end{array}\right|$ & $\mid \begin{array}{l}8 \\
\infty \\
0\end{array}$ & $\begin{array}{l}0 \\
5 \\
0\end{array}$ & $\frac{\nabla}{5}$ & $\frac{q}{ \pm}$ & $\mid \begin{array}{c}0 \\
\stackrel{2}{=} \\
0\end{array}$ & $\frac{\tilde{\Xi}}{\tilde{D}}$ & $\frac{0}{2}$ & $\frac{0}{2}$ & $\frac{n}{2}$ & $\frac{8}{9}$ \\
\hline$\Xi \Xi U$ & 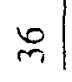 & $\stackrel{\infty}{m}$ & 움 & J & 寸 & I & $\stackrel{\infty}{\forall}$ & $\left|\theta_{1}\right|$ & $N$ & 吉 & $n \mid$ & $|n|$ & 18 & 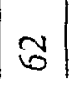 & J & 8 & 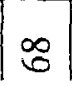 & 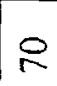 \\
\hline
\end{tabular}




\begin{tabular}{|c|c|c|c|c|c|c|c|c|c|c|c|c|c|c|}
\hline 新 & 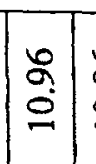 & $\begin{array}{l}\stackrel{\circ}{\circ} \stackrel{\circ}{\circ} \\
\stackrel{\circ}{0}\end{array}$ & & 恣 & & & 过 & & & & & & & $\mid \begin{array}{l}0 \\
0 \\
0\end{array}$ \\
\hline 芠 & 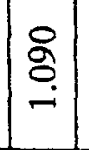 & & 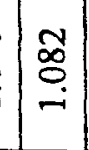 & 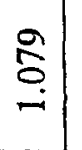 & $b_{5}^{\circ}$ & & ?at & & : & & 施 & & & $\hat{0}$ \\
\hline 跑 & \begin{tabular}{|c}
0 \\
$\infty$ \\
$\infty$
\end{tabular} & 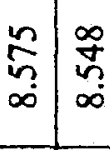 & $\overrightarrow{\widetilde{\sigma}}$ & $\mid$ & \begin{tabular}{l}
0 \\
$⿱ 亠 䒑$ \\
\hdashline
\end{tabular} & $\left.\right|_{\infty} ^{+}$ & 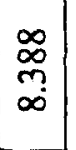 & & D & & 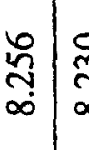 & & & 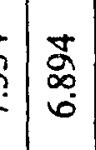 \\
\hline$\stackrel{\Xi}{\tilde{x}}$ & 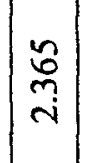 & & & & & $\mid i x$ & 总 & $\begin{array}{l}0 \\
\substack{3\\
}\end{array}$ & तु & & . & & & $\begin{array}{l}\tilde{m} \\
\tilde{q} \\
\dot{q}\end{array}$ \\
\hline$\Xi$ & $\mid \begin{array}{l}0 \\
0 \\
0 \\
0\end{array}$ & \begin{tabular}{l|l} 
\\
\end{tabular} & $\begin{array}{l}\tilde{a} \\
\stackrel{\alpha}{0} \\
0\end{array}$ & $\begin{array}{l}0 \\
: \\
0 \\
0 \\
0\end{array}$ & 8 & 18 & $\begin{array}{l}n \\
0 \\
0 \\
0\end{array}$ & 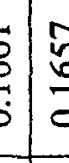 & 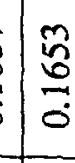 & & $\begin{array}{l}f_{0} \\
0\end{array}$ & 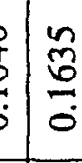 & & $\begin{array}{c}0 \\
0 \\
0 \\
0 \\
0\end{array}$ \\
\hline 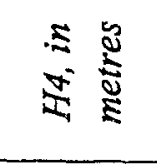 & 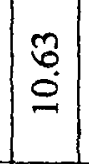 & 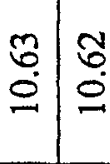 & $\stackrel{\sigma}{\circ}$ & : & & & ồ & 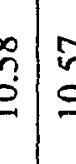 & 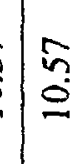 & & 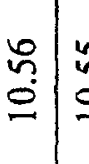 & & & $\stackrel{\infty}{\Xi}$ \\
\hline 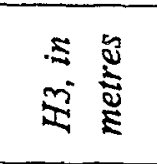 & $\left|\begin{array}{c}n \\
\vdots \\
0 \\
\infty\end{array}\right|$ & 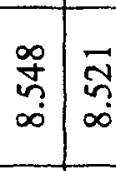 & \pm & | $\left.\begin{array}{c}0 \\
\infty \\
\infty\end{array}\right]$ & & & $\left|\begin{array}{|c|}\overrightarrow{0} \\
\vdots \\
\infty\end{array}\right|$ & & & & & & & bे \\
\hline 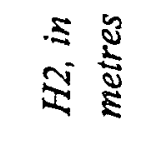 & $\left|\begin{array}{l}0 \\
0 \\
i \\
i\end{array}\right|$ & 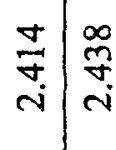 & 10 & $\left|\begin{array}{c}\hat{o} \\
\hat{v} \\
\mathrm{i}\end{array}\right|$ & & & $\left|\begin{array}{l}\infty \\
\vdots \\
i \\
c\end{array}\right|$ & & & & : & & & $\vec{\forall}$ \\
\hline 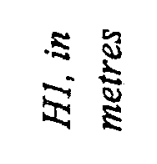 & $\mid \begin{array}{l}0 \\
0 \\
0\end{array}$ & $\begin{array}{l}\dot{2} \\
:\end{array}$ & & $\begin{array}{l}\infty \\
: \\
:\end{array}$ & & & $|a|$ & & 910 & & 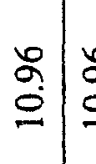 & & & $\begin{array}{l}0 \\
0 \\
0\end{array}$ \\
\hline 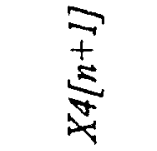 & $\left|\begin{array}{c}\infty \\
0 \\
\hdashline\end{array}\right|$ & : & 1 & $\mid$ & & & 18 & & & ֶֶ. & $\pi$ & & & ã \\
\hline $\overrightarrow{\bar{z}}$ & $\left|\begin{array}{l}n \\
0 \\
\infty \\
\infty\end{array}\right|$ & $\left.\right|^{\infty}$ & $\infty$ & $\infty$ & & & $\infty$ & & & & & & & 离 \\
\hline$\underset{\bar{z}}{\bar{\pi}}$ & $\mathrm{A}$ & $\pi$ & & i) & & & & & & & & $\mathrm{G}$ & & $\underset{\forall}{\vec{\sigma}}$ \\
\hline $\begin{array}{l}\overline{\vec{z}} \\
\overline{\vec{z}}\end{array}$ & $\left|\begin{array}{l}0 \\
0 \\
0 \\
0\end{array}\right|$ & & 10 & 01 & & & 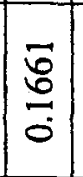 & & & & fo & \begin{tabular}{l}
0 \\
\hdashline
\end{tabular} & $\left|\begin{array}{l}0 \\
0 \\
0 \\
0\end{array}\right|$ & $\mid \begin{array}{l}0 \\
\frac{0}{2} \\
0\end{array}$ \\
\hline$\Xi$ & 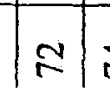 & 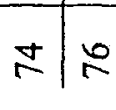 & & & & & & & & & & & & \\
\hline
\end{tabular}




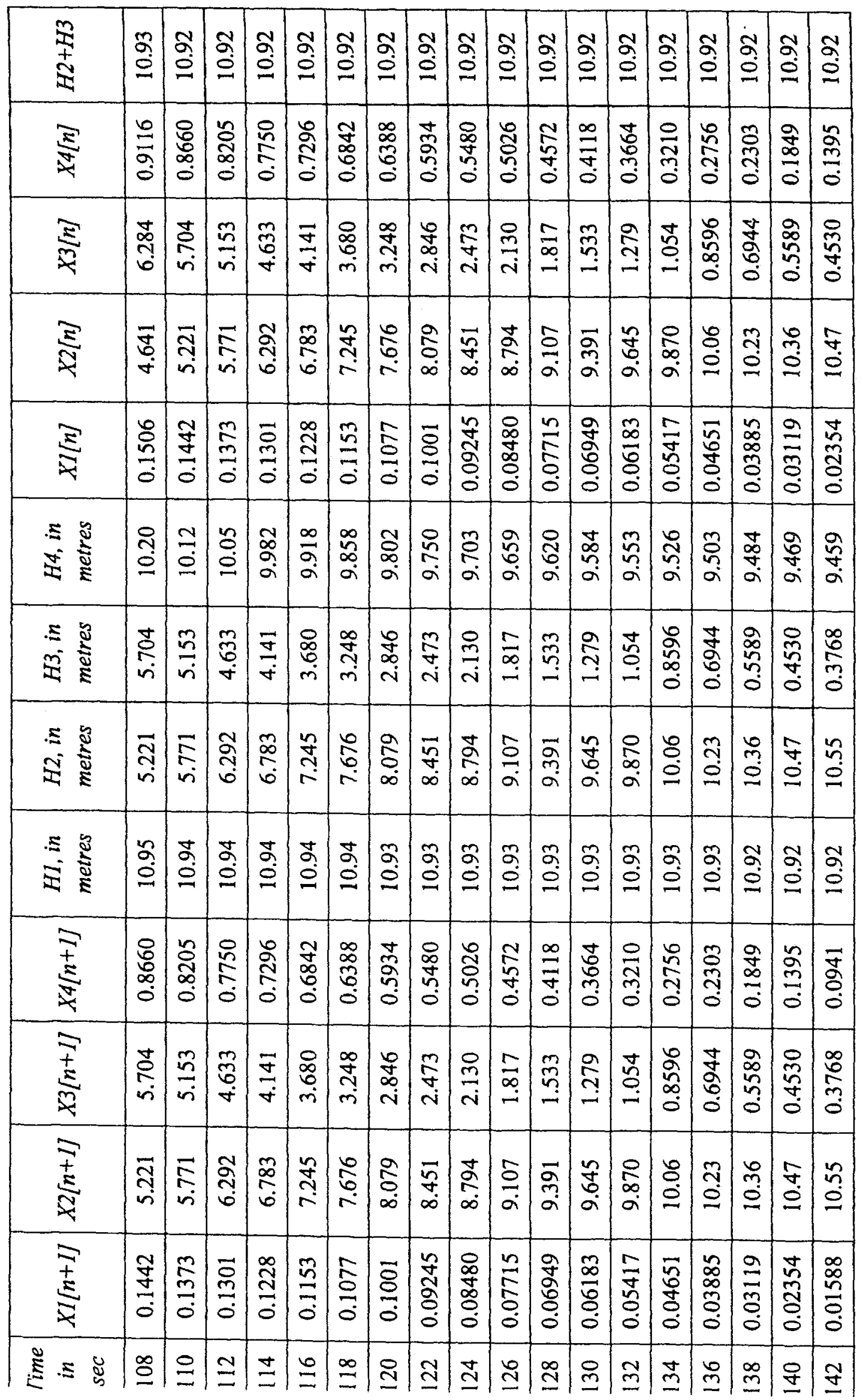




\begin{tabular}{|c|c|c|c|}
\hline$\underset{\mathbb{Z}}{\stackrel{N}{+}}$ & જ̊ & જ̊ & \\
\hline 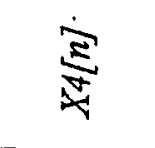 & \begin{tabular}{l}
$\infty$ \\
\multirow{8}{+}{} \\
$\stackrel{0}{0}$ \\
0 \\
0
\end{tabular} & $\begin{array}{l}0 \\
8 \\
\infty \\
0 \\
0 \\
0\end{array}$ & 吕 \\
\hline$\frac{E}{m}$ & $\frac{\infty}{\stackrel{\infty}{n}}$ & 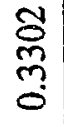 & $\frac{\tilde{n}}{m}$ \\
\hline$\frac{E}{N}$ & $\stackrel{n}{n}$ & ஜุ & $\begin{array}{l}\vec{b} \\
\dot{0}\end{array}$ \\
\hline$\underset{E}{E}$ & $\begin{array}{l}\infty \\
\stackrel{\infty}{\infty} \\
\stackrel{0}{0} \\
0\end{array}$ & $\begin{array}{l}\widetilde{1} \\
\infty \\
\delta \\
0 \\
0\end{array}$ & $\begin{array}{l}0 \\
8 \\
\delta \\
0\end{array}$ \\
\hline 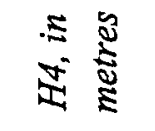 & ๙̃ & $\begin{array}{l}\text { 음 } \\
\text { å }\end{array}$ & \\
\hline 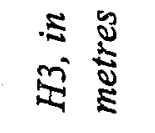 & 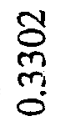 & $\frac{\tilde{m}}{m}$ & \\
\hline 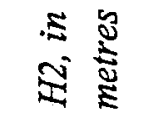 & ڤึ. & $\begin{array}{l}\bar{\sigma} \\
\dot{0}\end{array}$ & \\
\hline 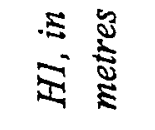 & $\tilde{g}$ & $\tilde{\alpha}$ & \\
\hline$\underset{⿱ 乛}{ \pm}$ & $\begin{array}{l}0 \\
0 \\
0 \\
0 \\
0 \\
0\end{array}$ & 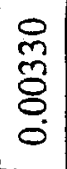 & \\
\hline 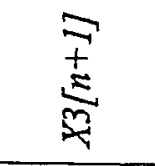 & 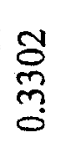 & $\frac{\tilde{m}}{m}$ & $\mid \begin{array}{c}0 \\
\tilde{n} \\
\tilde{n} \\
0\end{array}$ \\
\hline$\underset{\underset{y}{ \pm}}{\stackrel{+}{+}}$ & กุ & $\begin{array}{l}\overrightarrow{6} \\
\dot{0}\end{array}$ & $\begin{array}{c}\ddot{0} \\
\dot{0}\end{array}$ \\
\hline$\underset{E}{ \pm}$ & $\begin{array}{l}\text { స్ } \\
\text { Oे } \\
0 \\
0\end{array}$ & $\begin{array}{l}0 \\
2 \\
8 \\
8 \\
0\end{array}$ & \\
\hline 芯 & \pm & $\stackrel{0}{ \pm}$ & $\stackrel{\infty}{ \pm}^{\infty}$ \\
\hline
\end{tabular}




\section{APPENDIX $J$}

\section{CHARACTERISTICS OF TRANSFORMER OIL}


Transformer oils are obtained by processing petroleum. Petroleum differs in chemical composition according to its source. This also applies to its products, especially to transformer oils. The hydrocarbon compounds, which constitute the major part of the oil, can be divided into three main groups: paraffins, naphthenes and aromatic compounds.

Paraffins are saturated hydrocarbons with a straight chain (normal paraffins) or a branched chain (isoparaffins) without any cyclic structures (Figure J.1). Cycloparaffins or alicyclic compounds (popularly called naphthenes) are saturated hydrocarbons containing one or more five- or six-membered rings. Each of these rings may have one or several straight or branched bicyclic, tricyclic (Figure J.2). Aromatic hydrocarbons contain one or several aromatic rings which may be combined with alicyclic rings. The rings may or may not have alkyl chains and/or paraffin side chains. The aromatic nuclei may be condensed as in naphthalene and phenanthrene or isolated (Figure J.3). A mixed alicyclic-aromatic hydrocarbon is also shown in Figure J.3.

Generally, the solubility of water in transformer oil is negligible. From the point of view of the molecular theory, the very low solubility of water in petroleum products is explained by the great differences in sizes between the hydrocarbon and water molecules. The overall field of the intramolecular forces prevents mixing of the liquids. 


$$
\mathrm{H}_{3} \mathrm{C}-\left(\mathrm{CH}_{2}\right)_{\mathrm{n}}-\mathrm{CH}_{3}
$$<smiles>CCCC(C)(C)CC(C)(C)C(C)C</smiles>

normal paraffins

isoparaffins

Figure J.1: Paraffins group of hydrocarbon compounds.<smiles>CCCC1CCC1</smiles><smiles>CCCC1CCC2CCCCC2C1</smiles>

Figure J.2: Naphthenes group of hydrocarbon compounds. 


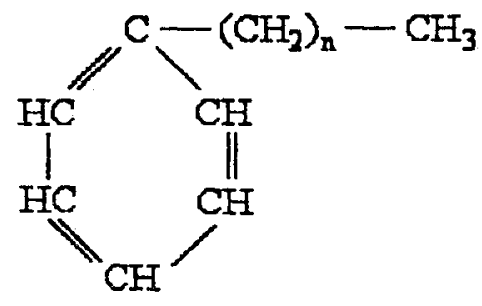

aromatic hydrocarbon with one aromatic ring<smiles>CCCC1=CC2C=CC=CC2C=C1</smiles>

aromatic nuclei condensed as phenanthrene

aromatic nuclei are isolated

mixed alicyclic-aromatic hydrocarbon<smiles>CCCC12C=CC3=C(CC4CCCC4C3)CC1C2</smiles>

Figure J.3: Aromatic group of hydrocarbon compounds. 


\section{REFERENCE}

Akai, Terrence J. 1994. Applied Numerical Methods for Engineers. pp.124-143. Canada: John Wiley \& Sons, Inc.

American Petroleum Institute. $1^{\text {st }}$ Edition: February 1990. Design and Operation of Oil-Water Separators. Monographs on Refinery Environmental Control-Management of Water Discharges.

Chui, Jenny, King-Lai. 2002. Control of Oil Spills in Urban Areas. Canada: Ryerson University.

Cross, R.H. and Hoult, D.P. May 1971. "Collection of Oil Slicks". Jourral of the Waterways, Harbors, and Coastal Engineering Division, ASCE. Vol. 97, No. WW2, Proc. Paper 8122, pp. 313-322.

Etter, Delores M. 1997. Engineering Problem Solving with MATLAB. $2^{\text {nd }}$ Edition. New Jersey: Prentice Hall, Inc.

Fausett, Laurene V. 1999. Applied Numerical Analysis Using MATLAB. U.S.A.: Prentice-Hall, Inc.

Golub, Gene H. \& Van Loari, Charles F. Matrix Computations. pp.256-259. $2^{\text {nd }}$ Edition. London: The Johns Hopkins University Press.

Hanselman, D. and Littlefield, B. 2001. Mastering MATLAB 6, A Comprehensive Tutorial and Reference. U.S.A.: Prentice Hall, Inc.

Hunt, Brian R. and Lipsman, Ronald L. 2001. A Guide to MATLAB for Beginners and Experienced Users. U.S.A.: Cambridge University Press.

Jones, W.T. December, 1972. "Instability at an Interface Between Oil and Flowing Water". Trans. ASME. Vol. 94, pp. 874-878.

Kline, S.J. 1965. Similitude and Approximation Theory. New York: McGraw-Hill.

Lewis, Gary L. and Viessman Jr., Warren. 1996. Introduction to Hydrology. $4^{\text {th }}$ Euition. U.S.: HarperCollins College Publishers. 
Mays, Larry W. 2001. Water Resources Engineering. U.S.A.: John Wiley \& Sons, Inc.

Moir, J. and Lau, Y.L. May, 1975. A Review of the Dynamics of Contained Oil Slicks in Flowing Water. Canada EPS 3/EE 74-3.

Moir, J. and Lau, Y.L. November, 19"75. Experiments on Containment and Diversion of oil by a Vertical Barrier. Canada Centre for Inland Waters. Hydraulics Research Division.

Pankhurst, R.C. 1964. Dimensional Analysis and Scale Factors. London: Chapmazs and Hall, Inc.

Sharp, J.J. 1981. Hydraulic Modelling. U.S.A.: Butterworth (Publishers) Inc.

Sit, Michael B. 1999. Characterization of Oil Spills in Urban Regions of the Greater Toronto Area. Canada: Ryerson University.

Truong, Patrick. 2002. Hydraulic Oil Control System. Canada: Ryerson University,

U.S. Department of Agriculture Soil Conservation Service, June 1986. "Urbor: Hydrology of Small Watersheds". Tech. Release No. 55, Washington, DC.

Weslake, Inc. October, 2002. Hydro One Spill Study.

Wicks, M. III. December, 1969. "Fluid Dynamics of Floating Oil Containment s"y Mechanical Barriers in the Presence of Water Currents". Proceedings APIFWPC Joint Conference on Prevention and Control of Oil Spills. Vol. 15-17, pp.55-106. Krss York.

Wilkinson, D.L. June, 1972. "Dynamics of Contained Oil Slicks". Journal of Hydraulics Division, ASCE. Vol. 98, No. HY^, Proc. Paper 8950, pp. 1013-1030.

Wilkinson, D.L. May, 1973. "Limitations to Length of Contained Oil Slicks". Joumizis: of the Hydraulics Division, ASCE. Vol. 99, No. HY5, Proc. Paper 9711, pp. $701-712$

Zhen, Qiaohua. 1998. Evaluation of Oil Water Separators in Removing Hydrocartase Contaminants in Stormwater. Canada: Ryerson University. 